\title{
Dispute Resolution Mechanisms and Trademark Cybersquatting
}

\author{
In ccTLD, Old Style gTLD and New Style gTLD Systems \\ COMPARATIVE ANALYSIS OF THE US, EU AND INTERNATIONAL APPROACHES
}

By

Waddah Al-rawashdedh

University of Szeged

Faculty of Law and Political Sciences

Graduate School

Hungary

2017 Spring 


\section{Table of Contents}

DEDICATION

ACKNOWLEDGMENTS

LIST OF ABBREVIATIONS 10

ABSTRACT 12

INTRODUCTION

\section{CHAPTER 1}

DOMAIN NAMES AND TRADEMARKS ............................................. 22

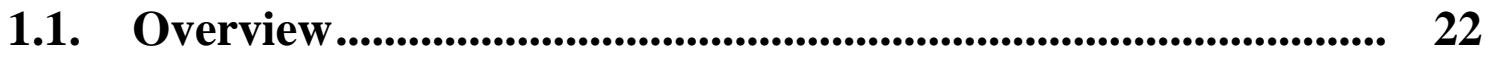

1.2. Meaning of Domain Names and Domain Name System (DNS)

1.3. The Need and Importance of Domain Names............................ 25

1.4. Types of Domain Names ................................................................. 26

1.4.1. "Country-code" TLDs.......................................................................... 26

1.4.2. "generic" TLDs ................................................................................... 27

1.5. Who Runs gTLDs and ceTLDs? .............................................. 30

1.6. What are New gTLDs?........................................................................... 34

1.7. The Contractual Nature of Domain Name Registration Processes ..................................................................................... 37

1.7.1. The Contractual Relationship under ICANN's Registrar Accreditation Agreement (RAA)

1.7.2. The Contractual Relationship between the Registrar and the Registrant under the Umbrella of Registrar Accreditation Agreement (RAA)

1.8. The Correlation between Trademarks and Domain Names .. 44

1.9. Comparing Distinctions and Similarities between Trademarks and Domain Names 


\section{CHAPTER 2}

CYBERSQUATTING AS A GLOBAL PROBLEM AND ICANN AS

A GLOBAL SOLUTION ..................................................................52

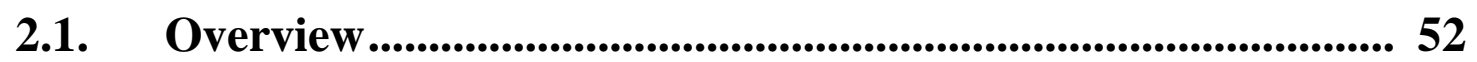

2.2. Basic Understanding of Cybersquatting ................................... 54

2.2.1. Registering a Domain Name Completely Identical with a Registered Trademark (Domain Name Piracy) (Cybersquatting).............................. 57

2.2.2. Registering a Domain Name Largely Similar to a Registered Trademark (Typosquatting)

2.2.3. Registering a Trademark as a Domain Name to Express the Dissatisfaction with a Product or Service Provided by a Certain Corporation (Cybersmearing) (Derogatory Domain Names)

2.2.4. The Attempt to Deprive a Properly Registered Domain Name Holder from the Domain Name that he Registered (Reverse Domain Name Hijacking)

2.2.5. Inadvertent Failing to Renew Registration of Domain Name

2.2.6. Registering a Trademark of a Competitor as a Domain Name (Competing Use) or Registering a Trademark of Non-Competitor as a Domain Name (Non-Competing Use)

\subsection{ICANN's UDRP as a Model for Trademark Cybersquatting}

Disputes Settlement

\subsubsection{The Dispute Resolution Mechanism for Cybersquatting under ICANN's UDRP.......................................................69}

2.3.1.1. Identical or Confusingly Similar.................................................. 71

2.3.1.2. Rights or Legitimate Interests ................................................... 73 
2.3.1.3. Bad Faith Registration and Use

2.3.2. Remedies of ICANN's UDRP 78

2.3.3. ICANN's WHOIS Service ............................................................. 79

2.3.4. Jurisdiction of ICANN's UDRP........................ 82

2.3.5. Pros and Cons of ICANN's UDRP ........................................... 86

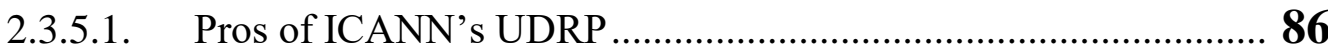

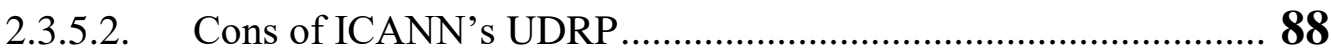

2.4. Cybersquatting and ICANN's New gTLD ................................ 89

2.4.1. New Pre- and Post-Delegation Dispute Resolution

Procedures under ICANN ........................................................... 89

2.4.1.1. Pre-Delegation Dispute Resolution Cybersquatting under ICANN's DRSP ................................................................... 90

2.4.1.2. Post-Delegation Dispute Resolution Procedure under ICANN's

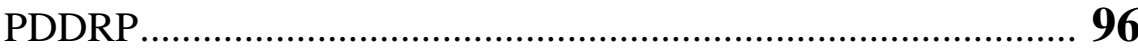

2.4.2. Extra Protection Mechanisms in the New gTLD Space.... 101

2.4.2.1. ICANN's URS as an Extra Protection Mechanisms in the New

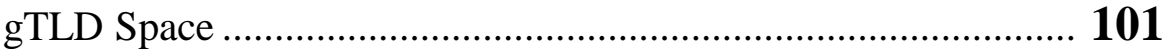

2.4.2.2. ICANN's Trademark Clearinghouse Model.................................. 105 


\section{CHAPTER 3}

CYBERSQUATTING UNDER US AND EU APPROACHES

3.1. Overview

3.2. Cybersquatting in the United States...................................... 110

3.2.1. Roots and Development of the Legal Framework of Anticybersquatting statute in USA

3.2.2. U.S. Courts Treated Domain Names before 2014 as Property and in 2014 ICANN told U.S. Courts that ccTLDs are not Property......... 113

3.2.3. The Mechanism of the Anticybersquatting Consumer Protection Act (ACPA) ............................................................................................................ 116

3.2.3.1. "Identity or Confusing Similarity" Standard ................................ 117

3.2.3.2. The "Bad Faith" Requirement ………………………………….... 119

3.2.3.3. The Defense in Cybersquatting Claim............................................. 121

3.2.3.4. Remedies under the ACPA .......................................................... 123

3.2.3.5. In Rem Jurisdiction and the ACPA ................................................ 125

3.2.4. Registrar's Liability and the ACPA ................................... 128

3.2.5. National Registration of Domain Names under ccTLD (.us)

3.2.5.1. usTLD Nexus Dispute Policy (usNDP) ........................................ 131

3.2.5.2. usTLD Dispute Resolution Policy (usDRP) .................................. 132 
3.3. Cybersquatting in the European Union

\subsubsection{Overview of Anticybersquatting Claims in EU Member}

States

3.3.1.1. Austria ............................................................................... 137

3.3.1.1.1. Anticybersquatting Claims under Austrian Trade Mark Act ........... 137

3.3.1.1.2. Anticybersquatting Claims under Austrian Unfair Amendment Competition Act .......................................................................... 138

3.3.1.1.3. National Registration of Domain Names under ccTLD (.at) ............ 140

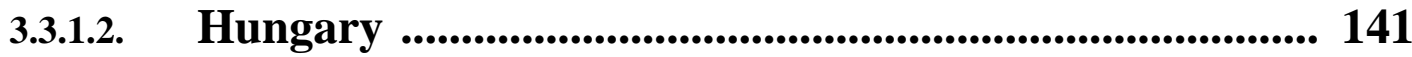

3.3.1.2.1. Anticybersquatting Claims under Hungarian Act on Trademarks .... 142

3.3.1.2.2. Anticybersquatting Claims under Hungarian Unfair Market

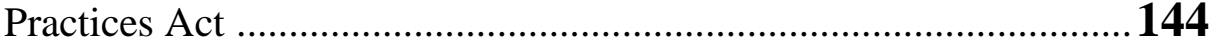

3.3.1.2.3. Anticybersquatting Crime under Hungarian Criminal Code .............. 146

3.3.1.2.4. National Registration of Domain Names under ccTLD (.hu) ............ 147

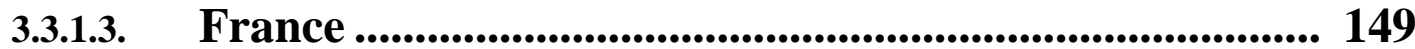

3.3.1.3.1. Anticybersquatting Claims under French Intellectual Property Code. 150

3.3.1.3.2. Anticybersquatting Claims under French Civil Code ........................ 154

3.3.1.3.3. National Registration of Domain Names under ccTLD (.fr) .............. 156

3.3.1.4. Germany ................................................................... 159

3.3.1.4.1. Anticybersquatting Claim under German Trademark Law ................ 160

3.3.1.4.2. Anticybersquatting Claim under German Unfair Competition Law . 162

3.3.1.4.3. National Registration of Domain Names under ccTLD (.de) ........... 164

3.3.1.5. United Kingdom ...................................................................... 165

3.3.1.5.1. Anticybersquatting Claim under UK Trade Marks Act ..................... 166

3.3.1.5.2. National Registration of Domain Names under ccTLD (.uk) ....... 169

3.3.2. Registration of Domain Names under ccTLD (.eu) ........... 170 


\section{CHAPTER 4}

ANTICYBERSQUATTING LEGAL SYSTEM FROM THE MIDDLE EASTERN COUNTRIES, JORDAN AS A CASE STUDY.

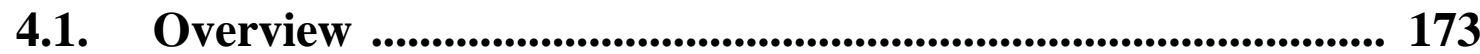

4.2. Roots and Developments of the Legal Framework of Cyberspace in Jordan

4.3. The Mechanism of Cybersquatting Claim

4.3.1. The Mechanism of Cybersquatting Claim under the Jordanian Trademark Law

4.3.1.1. Infringement Claim under Trademarks Law 178

4.3.1.2. Civil Remedies under the Trademarks Law 178

4.3.1.3. Criminal Sanctions under the Trademarks Law

4.3.2. The Mechanism of Cybersquatting Claim under the Unfair Competition and Trade Secrets Law

4.3.2.1. Infringement Claim under the Unfair Competition Law 183

4.3.2.2. Civil Remedies under the Unfair Competition Law 184

4.3.3. Jordanian Jurisdiction over Cybersquatting Claims 186

Conclusion 194

Bibliography 199 


\section{DEDICATION}

This thesis is dedicated to my parents, especially my mother who has been a sublime source of motivation, encouragement and inspiration from the commencing of my studies. This thesis is also dedicated to all of those who gave me the possibility to complete it especially to my country because without their untiring support I could not have achieved it. 


\section{ACKNOWLEDGMENTS}

I wish to thank God first for giving me the chance to study my Ph.D in Hungary and to knowledge this amazing country.

I would like to express my special appreciation to the following:

My supervisor Dr. Péter Mezei for his inspiring support and guidance throughout the research and writing period. I am also indebted to him for his encouragement in difficult times during my research, for his patience in reading the earlier draft of this work, and for his valuable comments thereon, despite all his educational and administrative responsibilities as Deputy Head of the Institute of Comparative Law.

I feel deeply grateful to the doctors of Laws in the University of Szeged, especially Chair of Department of Roman Law Prof. Éva Jakab, Prof. Dr. Karsai Krisztina, Dr. Zsuzsanna Fejes, and Dr. Varga Norbert, for their guidance, friendship, help, support, and kind treatment during my study for this degree. 


\section{LIST OF ABBREVIATIONS}

AAA- American Arbitration Association

ACDR- Arab Center for Domain Name Dispute Resolution

ACPA- Anti-cybersquatting Consumer Protection Act

ADNDRC- Asian Domain Name Dispute Resolution Center

ADR- Alternative Dispute Resolution

AFNIC-Association for French Network Information Centre

ADR - Country Code Names Supporting Organization

ccTLD - Country-code Top Level Domain

CISP - Council of Internet Service Providers

DNS - Domain Name System

DRSPs- Dispute Resolution Service Providers

ECJ- European Court of Justice

EU- European Union

EURid-European Registry for Internet Domains

FTDA- Federal Trademark Dilution Act

GNSO-Generic Names Supporting Organization

gTLD - generic Top Level Domain

IAHC- International Ad Hoc Committee

IANA - Internet Assigned Numbers Authority

ICANN - Internet Corporation for Assigned Names and Numbers

ICC-International Chamber of Commerce

IDNs-Internationalized Domain Names

IP - Internet Protocol

ISI- Information Sciences Institute

ISPs-Internet Service Providers

NAF - National Arbitration Forum

New gTLD- new generic Top Level Domain

NITC - National Information Technology Center

NSF - National Science Foundation 
NTIA - National Telecommunication and Information Administration

RAA- Registrar Accreditation Agreements

RAS-Registry Agreements

SLD - Second Level Domain

SOs- Supporting Organizations

TCP - Transmission Control Protocol

TLD - Top Level Domain

TMCH- Trademark Clearinghouse

TRIPs - Trade-Related aspects of Intellectual Property Rights

UDRP - Uniform Domain Name Dispute Resolution Policy

URS-Uniform Rapid Suspension System

USA- United States of America

USC- University of Southern California

usDRP- usTLD Dispute Resolution Policy

usNDP - usTLD Nexus Dispute Policy

WIPO - World Intellectual Property Organization 


\section{Dispute Resolution Mechanisms and Trademark Cybersquatting}

In ccTLD, Old Style gTLD and New Style gTLD Systems

Comparative Analysis of, US, EU and International Approaches

\section{By}

\section{Waddah Al Rwashdeh}

University of Szeged

Faculty of Law and Political Sciences, Institute of Comparative Law

E-mail: rwashdeh@lawyer.com

\section{Supervisor}

\section{Dr. Péter Mezei}

\section{Abstract}

The legal protection of trademark has met modern challenges with the incredible growth of Cyberspace. Since the 1990s, the trademarks on the Cyberspace are necessary for doing business fame in the modern commercial world. Thus, trademarks can be used on the Cyberspace with or without reference to products and services in domain names. Such double function of domain name, as Internet address and distinctive trademark, has created Cybersquatting activities. For instance; when a Cyber-squatter register trademarked names, especially famous undertakings names, as Internet domain names, in order to resell them at a profit. Thus, countries have been moved towards evolving a comprehensive domain name dispute resolution mechanisms before the national courts and/or out-court dispute resolution. Such kinds of dispute resolution mechanisms have been well-served by the American Anti-cybersquatting Consumer Protection Act (ACPA) of 1999 and the Uniform Domain Name Dispute Resolution Policy (UDRP).

On the one hand, the goal of this thesis is to determine the dishonest or abusive use and/or registration of trademarks as an Internet domain name whether in ccTLD, old style gTLD and new style gTLD systems by giving more attention for the trademark cybersquatting in new gTLD system particularly after Internet Corporation for Assigned Names and Number (ICANN) expansion in new gTLD program in 2011. New gTLD program was the greatest expansion of digital area since the Internet had begun. The New gTLD Program allowed for the registration of trademarks under TLDs, which created another arena for trademark Cybersquatting, requiring trademark owners 
to monitor applications for new TLDs to ensure that their rights are not infringed via cyberspace. Thus, ICANN presented new protection mechanisms to the trademark owners in the pre-delegation phase "Pre-delegation Dispute Resolution" by Dispute Resolution Service Providers "DRSPs", as a new way for settlement the disputes in new gTLD space, whereas other mechanisms will be applied after the delegation of the gTLD "post-delegation dispute resolution" which are called the Trademark Post-delegation Dispute Resolution Procedure (Trademark PDDRP).

This study focuses specifically on cybersquatting phenomenon within the frame of legislations, polices and dispute resolution mechanisms wither before the court or out-court dispute resolution on regional levels in US, EU and international approaches. As it is quite often the case that the trademark-based domain-name disputes, thus this thesis outlines the scope of trademark protection in US, EU and international approaches as background for trademark cybersquatting phenomenon.

It explains correlation between domain name and trademark, registration domain name by ICANN, national registration domain name in several European Member States, cybersquatting as a global problem and ICANN as a global solution, ICANN'S UDRP, and new pre- and postdelegation dispute resolution procedures for ICANN's new gTLD system.

This thesis also proposes to explore the several approaches taken by the US, and EU evolving cybersquatting frame of legislations and dispute resolution mechanisms wither before the court or out-court dispute resolution. In addition, it holds cybersquatting legal system in the Middle Eastern countries, Jordan as a case study.

This study ends in concluding that a harmonization of the legislation governing domain names disputes is needed on the global stage. It needs more efforts to obligate all the countries to admit a uniform anticybersquatting legal system. While there is no commonly agreed detailed treaty governing domain names disputes, trademark owner might take advantage of dispute resolution mechanisms wither before the national court and/or out-court dispute resolution. 


\section{Introduction}

The Cyberspace has changed enormously from the radical means invented by the US Department of Defense for connection with nations all over the world in an urgency matter. ${ }^{1}$ The "information superhighway" or Cyberspace has evolved into an online market for commerce, appealing Internet consumer. ${ }^{2}$ Since the 1990 s, e-commerce demand greater attention to guarantee that individuals do not violate or infringe intellectual property rights in the Cyberspace such as trademark. ${ }^{3}$

Trademarks are vital tools of commerce. The trademark owners have an exclusive rights which entitle them to compete in the marketplace by distinguishing their products or services from those of their competitors, and assists consumers to identify the source of a products or services. ${ }^{4}$ Several marks have also become famous and broadly known all over the world, for instance, the soft drink Coca-Cola, Burger King for fast food, and Levi's jeans. The concept of famous trademark has obtained a dynamic extends beyond the value of the goods and services with which they are mainly related as they might maintain secondary meanings in the mind of the customer, "loyalty between products, services and categories over time and to separate it from tangible production". ${ }^{5}$

Some commercial companies are seeking to evolve some modern ways of coping with their trademarks by making use of the reputation they obtained in the offline world and transfer such goodwill to the online world. ${ }^{6}$ On the other hand, one of the active elements in commerce through the Cyberspace is domain name. A domain name is basically that guides computers to the website that links to the IP address through the Cyberspace. Thus, instead of typing the IP address 192.0.34.65, Internet user can type (www.icann.org), ${ }^{7}$ this system, which ensures that there is a unique matching of IP addresses and domain names, is the Domain Name System "DNS".

\footnotetext{
${ }^{1}$ Anahid Chalikian, Cybersquatting, Journal of Legal Advocacy and Practice San Fernando Valley College of Law, Vol.3, 2001, p 106.

${ }^{2}$ Ibid.

${ }^{3}$ Jacqueline Lipton, Beyond Cybersquatting: Taking Domain Name Disputes Past Trademark Policy, Wake Forest Law Review, V. 40, 2005, p 1361.

${ }^{4}$ USA Congressional Record, Proceedings and Debates of the 106th Congress, First Session, V. 145, Pt. 21, 1999, p 31015.

${ }^{5}$ David Haigh, Brand Valuation - Understanding, Exploiting and Communicating Brand Values, London, Financial Times Retail \& Consumer Publishing, 1998, p29.

${ }^{6}$ Lipton, Beyond Cybersquatting: Taking Domain Name Disputes Past Trademark Policy, p 1361.

${ }^{7}$ ICANN, Glossary of Who is Terms, <https://whois.icann.org/en/glossary-whois-terms > accessed 27 November 2016.

${ }^{8}$ Ibid.
} 
Until the date of issuing New gTLD Program, ${ }^{9}$ Top-level domains, were divided into two categories; the top-level domain was a generic top-level domain "gTLD", and a country code top-level domain "ccTLD". Each of the "ccTLDs" bears a two letters (such as .de, .mx, and .jp) country code, ${ }^{10}$ for example; (.hu) for Hungary, (.us) for United State, (.jp) for Japan, (.jo) for Jordan. While "gTLDs" is abbreviation to the "generic" TLDs. Each of the "gTLDs" bears a three or more letters (such as .com, .net, and .org). ${ }^{11}$

Domain name database is administered by Internet Corporation for Assigned Names and Number (ICANN), which has an exclusive direct strategy control over the gTLDs registration process as policy maker and coordinator regarding gTLDs ${ }^{12}$ and assignment of Internet Protocol (IP) addresses to Internet Service Providers (ISPs) through its IANA, ${ }^{13}$ which also makes decisions on matters such as delegation of ccTLDs. ${ }^{14}$

However, the trust in trademarks by consumers and, the use of trademarks by companies may become more significant when a trademarked name is registered and used as a company's domain name in ccTLDs, or gTLDs via Cyberspace, consumers identify where to go online to buy product or service from that company. ${ }^{15}$

\footnotetext{
${ }^{9}$ In June 2011, ICANN approved and authorized the launch of the new gTLD program. The program's aims for enhancing competition and consumer choice, and supporting the benefits of innovation by introduction of new gTLDs. ICANN, About the Program, <https://newgtlds.icann.org/en/about/program > accessed 10 December 2016.

${ }^{10}$ Country code derived from standard 3166 of the International Organization for Standardization (ISO 3166 which is the International Standard for country codes and codes for their subdivisions. ICANN, ICANN and the International Organization for Standardization (ISO), < https://www.icann.org/resources/pages/icann-iso-3166-2012-05-09-en > accessed 29 November 2016.

${ }^{11}$ ICANN, Glossary, <https://www.icann.org/resources/pages/glossary-2014-02-03-en > accessed 2 December 2016.

${ }^{12}$ Francis Medeiros, Is 'com' International? The .com gTLD: an Analysis of Its Global Nature Through the Prism of Jurisdiction, International Journal of Law and Information Technology, Vol. 21, No. 3, 2013, p 276.

${ }^{13}$ The IANA is a department of ICANN, a nonprofit private American corporation that oversees global IP address allocation, autonomous system number allocation, root zone management in the DNS.

Prabir Purkayastha, and Bailey Rishab, U.S. Control of the Internet Problems Facing the Movement to International Governance, < monthlyreview.org/2014/07/01/u-s-control-of-the-internet/> accessed 6 December 2016.

${ }^{14}$ International Telecommunication Union, Administering the Root: Delegations and Redelegations - Every Country is Unique, 2003, < https://archive.icann.org/en/cctlds/administering-the-root-25feb03.pdf > accessed 7 December 2016.

${ }^{15}$ USA Congressional Record, Proceedings and Debates of the 106th Congress, 331015.
} 
Conversely, the rapid growth of the cyberspace and electronic commerce has imparted about an unprecedented variety of challenges to the classical concept of trademarks statute, ${ }^{16}$ the most important of these challenges is domain names and their relation to trademarks.

The challenge comes to the light when infringers register domain names of a trademark, specifically well known undertakings names, with the purpose to resell. This activity is called "cybersquatting". Such double function of domain name, as Internet address and distinctive trademark, has created cybersquatting activities.

Cybersquatters have been described as "individuals who attempt to profit from the Internet by reserving and later reselling or licensing domain names back to the companies that spent millions of dollars developing the goodwill of the trademark." ${ }^{17}$ For instance, since the birthdate of the cyberspace in the US, this activity has been really become a quandary for the trademark owners as a victims of cybersquatting. ${ }^{18}$ "In some cases, the prices that cybersquatters demand for selling domain names are very high. For example, (AltaVista.com) was sold for \$ 3.3 million and (HeraldSun.com) was sold for \$2.5 million." ${ }^{\prime 19}$ In addition, there are different subcategories of one category "cybersquatting". ${ }^{20}$ Cybersquatting phenomenon may include "Typosquatting" 21 , "Cybersmearing", ${ }^{22}$ and many other subcategories.

However, since the 1990s, law reviews and court recorders were crowded with debates and arguments about how the statute and legislation should arrange the Cybersquatting phenomenon and domain names disputes, specifically in terms of their correlation with trademark law. ${ }^{23}$ Simply because the majority of the countries do not have anticybersquatting statute which enables trademark owners to protect their trademarks against such illegal use. Thus, countries have been moved towards evolving a comprehensive domain name dispute resolution mechanisms to address

\footnotetext{
${ }^{16}$ Lipton, Beyond Cybersquatting, p 1363.

${ }^{17}$ Chalikian, Cybersquatting, p 106.

${ }^{18}$ A CMS IP Group Publication, Protection of Trade Marks: Online Use and Anticybersquatting, A European Perspective, 2007 <docplayer.net/10942010-Protection-of-trade-marks-online-use-and-anticybersquatting.html> accessed 20 September 2015.

${ }^{19}$ Ibid.

${ }^{20}$ Ibid.

${ }^{21}$ When a Cybersquatter registers a name largely similar to a registered trademark.

${ }^{22}$ When a Cybersquatter registers a trademarked name as a domain name to express the dissatisfaction with a product or service provided by a certain corporation.

${ }^{23}$ Lipton, Beyond Cybersquatting, p 1362.
} 
the disputed domain name, in the context of cybersquatting phenomenon, before the national courts and/or out-court dispute resolution.

The courts have addressed the problem of cybersquatting by applying traditional trademark infringement and dilution legislations to claims brought by the trademark owner. ${ }^{24}$ Filing anticybersquatting claim under traditional trademark law before the national courts has become much more sophisticated, when the cybersquatters register and/or use trademarked names on the cyberspace without any indication to the products or services. As the trademark legislation provides the legal protection of trademarks with reference to the products and services in the course of trade, but it does not provide any protection against such unauthorized use. ${ }^{25}$

Accordingly, there is a various approaches applied by the countries. Some countries enacted special domain name legislations, such as France and United State. ${ }^{26}$ While some other European countries provide the legal protection against cybersquatting phenomenon based on traditional trademark infringement and unfair competition legislations such, Hungary, Austria, and Germany. ${ }^{27}$

On the other hand, ICANN well addressed the problem of cybersquatting by out-court dispute resolution mechanism. In August 1999, the ICANN adopted a Uniform Disputes Resolution Policy (UDRP). ${ }^{28}$ According to the UDRP; the trademark owner must prove that the domain name registered is identical or confusingly similar to a trademark in which the trademark owner has rights, the registrant has no rights or legitimate interests in respect of domain name registered, and the domain name has been registered and is being used in bad faith. ${ }^{29}$

The ICANN's UDRP applies to resolve and settle the domain name disputes wither in gTLDs, or ccTLDs. ${ }^{30}$ Currently, ICANN's UDRP settles the domain name disputes in gTLDs while in the

\footnotetext{
${ }^{24}$ Chalikian, Cybersquatting, p 106.

${ }^{25}$ The Cybersquatting phenomenon also generates a tension when it comes to private international law and specifically to jurisdiction and applicable law.

${ }^{26}$ American Anti-cybersquatting Consumer Protection Act (ACPA) of 1999, and the French Postal and Electronic Communication Code of 2007.

${ }^{27}$ Chapter three of this thesis will show in details the anticybersquatting legal system for these countries.

${ }^{28}$ Daniel Tunkel, and Stephen York, E-commerce: A Guide to the Law of Electronic Business, second edition, Butterworths, 2000, p 186.

${ }^{29}$ Paragraph 4 (a) of the UDRP Policy.

${ }^{30}$ WIPO, Domain Name Dispute Resolution Service for country code top level domains (ccTLDs), <http://www.wipo.int/amc/en/domains/gtld/udrp/> accessed 11 March 2016.
} 
context of trademark cybersquatting in ccTLDs, some ccTLD registry operators have completely adopted the UDRP such Namibia (.nu), Tuvalu (.tv), Samoa (.ws). ${ }^{31}$ Some others have evolved their own alternative dispute resolution mechanism that are unrelated to the UDRP such as USA adopted usTLD Dispute Resolution Policy (usDRP). ${ }^{32}$ While some other did not adopt any alternative dispute resolution mechanism such as Austria then legal action could be filed before Austrian court as a last resolution. ${ }^{33}$

Under European Union, the EU Regulation 874/2004 of 28 April 2004, ${ }^{34}$ which deals only trademark cybersquatting in (.eu) ccTLDs. Similar to the ICANN's UDRP Policy, ${ }^{35}$ the Regulation pursues the tactic of ICANN's UDRP Policy, ${ }^{36}$ as any disputes regarding (.eu) ccTLDs are subject to the (.eu) Alternative Dispute Resolution Rules (the "ADR Rules"). ${ }^{37}$

In June 2011, ICANN approved and authorized the launch of the "New gTLD Program". ${ }^{38}$ New gTLD program is the greatest expansion of digital area since the Internet began. ${ }^{39}$ The program's aims for enhancing competition and consumer choice, and supporting the benefits of innovation by introduction of new gTLDs besides the old style of gTLDs, such as; .com, .net, or .org. According to the new gTLDs Program, an applicant for a domain name can register a domain name not only within the few generic gTLDs, but may also apply to register an entirely new TLD for ICANN. For instance, if Apple Company is looking to have subdomains for its products or services under the .apple TLD, such as (ipad.apple) or (itunes.apple), which may serve to strengthen its

31 ICANN, Non-Lawyers' Guide to the May 2009 Registrar Accreditation Agreement, <https://www.icann.org/resources/pages/non-lawyers-guide-2010-02-15-en> accessed 12 December 2016.

${ }^{32}$ Jenny Ng, the Domain Name Registration System: Liberalization, Consumer Protection and Growth, Routledge, $2012, \mathrm{p} 42$.

${ }^{33}$ Nic.at, Legal Issues, < https://www.nic.at/en/faq/legal-issues/> accessed 25 April 2016.

${ }^{34}$ Commission Regulation (EC) No 874/2004 of 28 April 2004 laying down Public Policy Rules Concerning the Implementation and Functions of The .eu Top Level Domain and the Principles Governing Registration [2004] OJ L $162 / 40$.

${ }^{35}$ David Taylor, Alternative Dispute Resolution: It's Application to Protect Intellectual Property Rights under .EU: The First Pan-Regional Top Level Domain Tribune, International Business Law Journal (Revue De Droit Des Affaires) No. 1, 2007, p 235.

${ }^{36}$ For instance, the wording in article 21 of the .eu Regulation is very similar the paragraph 4 (a) of the UDRP.

${ }^{37}$ EURid, (.eu)- Alternative Dispute Resolution, <https://eurid.eu/media/filer_public/a0/69/a0694eb7-5a9c-4ff7a510-a7bae3787c71/adr_rules_en.pdf> accessed 22 February 2016.

${ }^{38}$ ICANN, About the Program, <https://newgtlds.icann.org/en/about/program > accessed 10 December 2016.

39 ICANN, Applicant Guidebook, 2011, <http://www.icann.org/en/topics/new-gtlds/rfp-clean-30may11-en.pdf > accessed 11 December 2016. 
brand and maintain its businesses. ${ }^{40}$ Nevertheless, where third parties may apply for domain names within the applied-for TLD, the new TLD will be an open registry.

"Given the fact that the new gTLD Program allowed for the registration of trademarks as TLDs, it was inherent to the nature of the gTLD regime that the prospect of coincidence of brand names will exist." ${ }^{41}$

The new gTLD program has released unforeseen and sophisticated a legal troubles. It allowed for the registration of trademarks under TLDs, which created another arena for trademark Cybersquatting, requiring trademark owners to monitor applications for new TLDs to ensure that their rights are not infringed. Thus, ICANN sets up newly advanced out-court dispute resolution mechanisms and several right protection methods to assist trademark owners in preventing third parties or infringers from register their trademarks under a new gTLD.

The new protection mechanisms are now available to the trademark owners in the pre-delegation phase "Pre-delegation dispute resolution" by Dispute Resolution Service Providers "DRSPs", as a new way for settlement the disputes in new gTLD space, whereas other mechanisms apply after the delegation of the gTLD "post-delegation dispute resolution" ${ }^{42}$ which is called the Trademark Post-delegation Dispute Resolution Procedure (Trademark PDDRP).

This thesis proposes to explore the cybersquatting phenomenon within the frame of legislations, policies and dispute resolution mechanisms wither before the court or out-court dispute resolution mechanisms on regional levels in US, EU and international approaches. Broadly speaking, the current activities of cybersquatting in Middle East area is still fresh and not commonly widespread as the situations in the U.S. or EU. For this reason, there has been limited research on comprehensive study of Anti-cybersquatting Acts in Middle East area, which purports to examine the importance of dealing with legal protection of trademark against registered in bad faith a domain name. Indeed, despite having varying geographical descriptions of Middle East area within

40 Sadulla Karjiker, the New gTLDs and the Resolution of Trade Mark Disputes, 2014, <blogs.sun.ac.za/iplaw/files/2016/04/The-new-gTLDs-and-the-resolution-of-trade-mark-disputes.pdf > accessed 10 December 2016.

${ }^{41}$ Ibid.

42 Allen and Overy, the new gTLDs: What do trademark owners need to know? , 2012, <www.allenovery.com/SiteCollectionDocuments/The\%20new\%20gtlds.pdf > accessed 13 December 2016. 
different academic circles, ${ }^{43}$ Jordan is located in heart of the Middle East area ${ }^{44}$ under all different academic circles. Select Jordan as an example to show the anticybersquatting legal system from the Middle Eastern countries, "Jordan as a case study".

This thesis is divided into five chapters as a following frame:

The first chapter aims to provide a framework for better understanding of the role of domain name via cyberspace, meaning of domain names, how does it work, types of domain names (ccTLD, gTLD and New gTLD space), the need and importance of the domain names, and who runs domain names system? In addition, this chapter studies the contractual nature of domain name registration processes, correlations between trademarks and domain names, and what are the differences between domain name and trademark?

The second chapter shows cybersquatting as a global problem and ICANN as a global solution. The first section of this chapter examines the phenomenon of Cybersquatting, other types of the domain name disputes, and the mechanism of the domain names disputes settlements under the ICANN's UDRP as a Model for domain names disputes settlement. The second section of this chapter examines the challenge of new gTLDs disputes and provides the reader with a roadmap to the controlling legal tools that may apply, to new gTLDs disputes under ICANN's DRSPs and Trademark PDDRP, by focusing only on the protection of trademarks in the New gTLD Program, the pre and post-delegation of dispute resolution and will be considered as it is the most important legal approaches for trademark owner. Additionally, the second section of this chapter studies the ICANN's WHOIS service as well as the ICANN's jurisdiction.

The third chapter analyzes the cybersquatting phenomenon within the frame of legislations and dispute resolution mechanisms wither before the court or out-court dispute resolution mechanisms on regional levels in US, and EU approaches. The first section of this chapter will shed some light upon roots and development of the legal framework of anticybersquatting in USA, legal nature of domain names as property right, and then it will discuss how the U.S. Courts had applied the legal

\footnotetext{
${ }^{43}$ Jesse Brown, Middle East, Mid East, Near East, North Africa, <http://peprimer.com/middle-east.html> accessed 28 April, 2016.

${ }^{44}$ Jordan is located in the heart of the Middle East, Northwest of Saudi Arabia, south of Syria, Southwest of Iraq, and east of Israel and the Occupied West Bank.

The Embassy of the Hashemite Kingdom of Jordan-Washington, D.C., Quick Facts, 2016, <http://www.jordanembassyus.org/page/quick-facts> accessed 28 April, 2016.
} 
provisions to cybersquatting acts, namely, provisions of the Anti-cybersquatting Consumer Protection Act for the year 1999. Then, it tackles legal issues as sets forth in the ACPA such as in rem jurisdiction under the ACPA, registrar liability and national registration of domain names under ".us" ccTLD. The second section of this chapter highlights the methods of protecting trademarks from cybersquatting activities in European Union, and how the trademark owners can affirm their rights in the trademark. This section provides a quick views of the legal framework on the relevant laws in a number of EU Member States with respect to anticybersquatting claims, as well as national registry operators for ccTLD in the escort of out-court dispute resolution mechanisms if it is available. In addition, the second section presents the registration of domain names under (.eu) domain names and the alternative dispute resolution for cybersquatting in (.eu) ccTLDs as a solution for trademark cybersquatting in (.eu) ccTLDs.

The fourth chapter shows the anticybersquatting legal system in Jordan as a case study from the Middle Eastern countries. This section discusses the roots and developments of the legal framework of cyberspace in Jordan and then inspects whether it is possible to apply the Unfair Competition Law and Jordanian Trademarks Law to cybersquatting acts, as well as the last section of this chapter analyses the capacity of the NITC and its role in curbing cybersquatting activities.

Finally, the conclusion of this thesis fastens together the various subjects explored in the chapters and states a certain recommendations for improving the anticybersquatting legal system. 


\section{Chapter 1}

\section{Domain Names and Trademarks}

\subsection{Overview}

This thesis mainly focuses trademarks cybersquatting thus it is necessary to explain domain names and trademarks in general. This chapter aims to provide a framework for better understanding of the role of domain names via cyberspace. Namely of domain names, how does it work, types of domain names (ccTLD, gTLD and New gTLD space), the need and importance of domain names, and who runs domain names system? In addition, this chapter studies the contractual nature of domain name registration processes, correlations between trademarks and domain names, and the differences between domain names and trademarks?

\subsection{Meaning of Domain Names and Domain Name System (DNS)}

It is well known that the roots of the internet lie in the United States where the academic and military research establishment developed an experimental system of connected computers in the 1950s. ${ }^{45}$ The network also proved to be of great value for American universities, which used it to connect themselves and enhance the exchange of information between their different research facilities. In the 1980s, a US Government agency (the "National Science Foundation", NSF) created a new High-Speed-Network, which was capable of integrating many existing networks. ${ }^{46}$ Networks in other countries were eventually integrated into the NSF-Network and gradually the Internet, as we know, was created. ${ }^{47}$

It is important to note that the Internet is not a tangible object. What does exist is a developing group of national and international, private and public computer Networks which can connect with each other, and these networks, when taken together, form the thing which people often refer to

\footnotetext{
${ }^{45}$ The Secretariat of the WIPO, Multilingual Domain Names: Joint ITU/WIPO Symposium, Geneva, 2001, p 4.

${ }^{46}$ U.S. Congress Office of Technology Assessment, Making Government Work: Electronic Delivery of Federal Services, 1993, < https://www.princeton.edu/ ota/disk1/1993/9333/9333.PDF> accessed 26 November 2016.

${ }^{47}$ Ibid.
} 
commonly as the 'Internet'. There is, therefore, no single entity, which owns or controls the Internet. ${ }^{48}$

The use of Internet expanded at an amazing pace in the last decade. For instance, "from 1990 to 1997, the estimated number of Internet users grew from around one million to around 70 million". ${ }^{49}$ Recently, the International Telecommunication Union remarks that "the number of Internet users has increased from 738 million in 2000 to 3.2 billion in $2015 " .{ }^{50}$ However, one of the keys to the great success of the Internet is the DNS. ${ }^{51}$ Every computer on the Internet has a distinctive or unique address just like a telephone number, which is a rather complicated series of numbers. It is called "IP address" (IP stands for "Internet Protocol"). ${ }^{52}$ Domain name is a name that identifies one or more (IP) addresses. Before explaining DNS, it is very important to know what (IP) is.

A web-site is a group of electronic messages preserved on a type of computer known as a webserver. This web-server is controlled by the owner of the web-site who will provide web-hosting services. The Internet user may access the information maintained on the web-site by identifying the Internet address of the relevant web-site via an IP address. IP addresses work as an identifier for a computer or device on Transmission Control Protocol / Internet Protocol a (TCP/IP network), the collection of communications protocols used to connect hosts on the Internet. The format of an IP address is a 32-bit numeric address written as four numbers separated by periods. Each number can be zero to 255 . For example, 1.160.10.240 could be an IP address. Within an isolated network, you can assign IP addresses at random as long as each one is unique. The four numbers in an IP address are used in different ways to identify a particular network and a host on that network. However, connecting a private network to the Internet requires using registered IP addresses to avoid duplicates. ${ }^{53}$ IP addresses are in a simple words Internet language used by

\footnotetext{
${ }^{48}$ Davis Lars, Law and Internet, Oxford, Hart publishing, 1997, p100.

${ }^{49}$ WIPO, the Management of Internet Names and Addresses: Intellectual Property Issues, Interim Report of the WIPO Internet Domain Name Process, 1998, <http://www.wipo.int/amc/en/processes/process1/rfc/3/interim2_ch1.html> accessed 26 November 2016.

50 Jacob Davidson, Here's How Many Internet Users There Are, 2015, <http://time.com/money/3896219/internetusers-worldwide/> accessed 26 November 2016.

${ }^{51}$ Internet Society Organization, DNS Transition to the Private Sector, < http://www.internetsociety.org/dns > accessed 26 November 2016.

${ }^{52}$ Ibid.

${ }^{53}$ Vangie Beal, IP Address - Internet Protocol (IP) Address, <http://www.webopedia.com/TERM/I/IP_address.html> accessed 26 November 2016.
} 
computers, which are not user friendly, and that is why the DNS was introduced so computers on the Internet recognize each other by IP addresses.

Domain names are the human-friendly forms of Internet addresses and are commonly used to find web sites. For example, the domain name wipo.int is used to locate the WIPO web site at http://www.wipo.int. DNS is an abbreviation to the Domain Name System. DNS helps users to find their way around the Internet. It is hard to remember everyone's IP address. The DNS makes finding IP address easier by allowing a familiar string of letters the domain name to be used instead of the hidden IP address, thus, instead of typing 192.0.34.65, user can type www.icann.org. ${ }^{54}$

The DNS is essentially a global addressing system and an Internet service that translates domain names into IP addresses. For example, when the user types into a browser, www.wipo.int, the browser sends a request to look up a database table in its local DNS name server receiving the corresponding IP address either from the local server or through a series of queries to locate authoritative names server, and uses that IP address to contact the target internet computer. The process of finding out the IP address that corresponds to a domain name is known as resolving the domain name. ${ }^{55}$ Therefore, if someone is looking for www.wipo.int, he or she will automatically be transferred to the IP address relating to that site which will be identified by the computer and he will reach to the requested site.

In other words, every computer connected to the World Wide Web has an address, which is a set of numbers. Those addresses are of great importance in identifying the computer that is dealing with the international web. Web services can identify those numbers or the IP address through the domain names system, which is a huge database, distributed in the computer root servers. ${ }^{56}$

Actually, there are three main features for domain names:

- A way to identify computers. Every computer on the Internet has a unique address, which is called IP address. This address is very important for identifying the computer, which is

\footnotetext{
${ }^{54}$ ICANN, Glossary of Who is Terms, <https://whois.icann.org/en/glossary-whois-terms > accessed 27 November 2016.

${ }_{55}^{5}$ Graham Smith, Internet Law and Regulation, third edition, London, Sweet \& Maxwell, 2002, p 78.

${ }^{56}$ Ibid, p 79.
} 
dealing on the Internet, by identifying the IP address through the domain names system, which is a huge database, distributed in the computer root servers.

- Unique. Every domain name on the Internet translates to a distinctive or unique address just like a telephone number, to avoid duplicates between two domain names.

- A corresponding IP address. Every domain name on the Internet translates to a distinctive or unique address, which is a rather complicated series of numbers. It is called its "IP address", thus, if user of the Internet is looking for one domain name, he will automatically be transferred to the IP address relating to that site which will be identified by the computer and he or she will reach to the requested site.

\subsection{The Need and Importance of Domain Names}

Domain names are the human-friendly forms of Internet addresses and are commonly used to find web sites. As noted above, the domain name makes accessing on IP address easier by allowing a familiar string of letters instead of the hidden IP address. Thus, instead of typing 192.0.34.65, the user can type: http://www.wipo.int. As a result, the domain name makes addresses easier to remember. Also, the Internet gives people all over the world comparably cheap access to a huge source of information of different kinds. ${ }^{57}$ It universally accelerate the flow of information in the business world. Customers are able to quickly gather information about suppliers in different regions and countries. The revolutionary property of this huge network is its almost unrestricted use and availability.

In addition, the Internet represents a combination of shop windows by creating a whole new marketplace. Thus, every website includes information provided by the designer of that website. When a commercial entity wants to market its goods or services through the Internet, it usually does so by designing a web site and posting information concerning goods or services to that site. Therefore, domain names are means, which are used to introduce activities and commercial services presented through the web to users of the Internet. For example: a merchant, a company, or a service provider can choose a domain name and register it at the competent authorities offering

\footnotetext{
${ }^{57}$ WIPO, the Management of Internet Names and Addresses: Intellectual Property Issues, Interim Report of the WIPO Internet Domain Name Process, <http://www.wipo.int/amc/en/processes/process1/rfc/3/interim2_ch1.html> accessed 28 November 2016.
} 
through it the goods or services he or she provides. ${ }^{58}$ In the traditional sense, one shall visit the company place of business to buy products or obtain services, which bears a trading name. In the cyberspace, the domain name will be more than sufficient to provide for such need. Moreover, most companies with valuable trademark will have proper usage of a handbook to refer to use of their marks on the website. ${ }^{59}$

\subsection{Types of Domain Names}

Domain names are usually given by a non-governmental organization ${ }^{60}$ in order to provide a global electronic address which ensures that the corresponding online address is accessible online from anywhere. As a result of the global nature of domain names, there is a need to regulate the assignment or designation of domain names to an international organization.

Each domain name is invented of a series of character strings (called "labels") separated by dots. Most labels in a domain name are referred to as its "top-level domain" (TLD). The responsibility for operating each TLD is delegated to a particular organization. These organizations are referred to as "registry operators". ${ }^{61}$ Top-level domains, which are usually divided into two categories: "Country-code" TLDs and "generic" TLDs.

\subsection{1. "Country-code" TLDs}

This type of domain names is assigned to each country. "Country-code" TLDs (ccTLDs) are administered independently by nationally designated registration authorities. For example the domain name www.ju.edu.jo, the suffix (jo) is the country code top-level domain name that indicates that this site is located in Jordan and as such registered with a registration body located in Jordan and authorized to make such registration.

\footnotetext{
58 Taking into consideration that he can ask to register any domain name, provided that it has not been previously registered. Noteworthy is that registering a domain name similar to a trademark is one of the important issues that will be discussed later in this thesis.

${ }^{59}$ Sections of such a proper use handbook can be put on the company's web page in order to state if that trademark prepared to license others to use its marks in certain circumstances. Smith, Internet law and Regulation, p 75.

${ }^{60}$ It is very important to note that ICANN is responsible for the administration and registration of the gTLDs and IANA is responsible for the administration of the ccTLDs.

61 Domain Name Business, What is a Top-Level Domain? < http://domainbiz.org/topdomain.asp > accessed 28 November 2016.
} 
Each of the "ccTLDs" bears two letters (such as .de, .mx or .jp) country code derived from standard 3166 of the International Organization for Standardization (ISO 3166) (which is the International Standard for country codes and codes for their subdivisions). ${ }^{62}$ "The ISO Standard 3166 defines Codes for the representation of names of countries and their subdivisions. ISO 3166 consists of the following 3 parts:

- Part 1: Country codes

- Part 2: Country subdivision code

- Part 3: Code for formerly used names of countries". ${ }^{63}$

Actually, "part 1: country codes (ISO 3166-1), is used to define the country-code Top-Level Domains (ccTLDs), e.g., “.fr”, “.za”, “.au”, “.br”, or “.jp” in the Internet domain name system”. ${ }^{64}$

There are currently 252 countries and external territories and are referred to as "ccTLDs". ${ }^{65}$ A number of these domain names are open in the sense that there are no restrictions on the persons or entities who may register in them. Others are restricted, in that only persons or entities satisfying certain criteria, for example, domicile within the territory may register names in them. ${ }^{66}$ For instances, of ccTLDs: (uk) for United Kingdom, (mx) for Mexico, (us) for United States.

\subsection{2. "generic" TLDs}

"gTLDs" is abbreviation to the "generic" TLDs. Each of the "gTLDs" includes three or more letters (such as .com, .net, and .org). They can be subdivided into two types, "restricted" or "sponsored" TLDs (sTLDs) and "not restricted or open", that is, "unsponsored TLDs" (uTLDs). Each of the "generic" TLDs was created for a general category of organizations. In the 1980s, seven gTLDs (.com, .edu, .gov, .int, .mil, .net, and org) were created. Domain names may be

62 ICANN, ICANN and the International Organization for Standardization (ISO), < https://www.icann.org/resources/pages/icann-iso-3166-2012-05-09-en > accessed 29 November 2016.

63 Ibid.

64 Ibid.

${ }^{65}$ WIPO, ccTLD Database, <http://www.wipo.int/amc/en/domains/cctld_db/index.html > accessed 29 November 2016.

${ }^{66}$ WIPO, the Management of Internet Names and Addresses: Intellectual Property Issues, Interim Report of the WIPO Internet Domain Name Process, <http://www.wipo.int/amc/en/processes/process1/rfc/3/interim2_ch1.html> accessed 29 November 2016. 
registered in three of these (.com, .net, and .org) without restriction; the other four have limited purposes. ${ }^{67}$

Various negotiations occurred concerning additional gTLDs leading to new gTLDs, which were introduced in 2001 and 2002. Four of the new TLDs (.biz, .info, .name, .pro) are unsponsored "not restricted or open". The other three new TLDs (.aero, .coop, .museum) are sponsored "restricted". A sponsor is an institution or organization to which is delegated some defined ongoing policyformulation authority concerning the method in which a particular sponsored TLD is operated. The sponsored TLD has a charter, which defines the purpose for which the sponsored TLD has been created and will be operated. ${ }^{68}$

The sponsor is responsible for developing policies on the delegated topics so that the TLD is operated for the benefit of a defined group of stakeholders, known as the sponsored TLD community. The scope to which policy formulation responsibilities are suitably delegated to a sponsor depends upon the characteristics of the institution that may make such delegation appropriate. These characteristics may include the mechanisms of the organization uses to formulate policies, its mission, its guarantees of independence from the registry operator and registrars, who will be permitted to contribute to the sponsor's policy - development efforts and in what way, and the sponsor's degree and types of accountability to the sponsored TLD Community. ${ }^{69}$ The following is the table of the gTLDs: ${ }^{70}$

\footnotetext{
${ }^{67}$ ICANN, Glossary, <https://www.icann.org/resources/pages/glossary-2014-02-03-en > accessed 2 December 2016.

${ }^{68}$ An unsponsored TLD operates under strategies established by the international internet community directly through the ICANN process, sponsored TLD is a specialized TLD that has a sponsor representing the narrower community that is most affected by the TLD. The sponsor thus carries out delegated policy-formulating responsibilities ever many matters concerning the TLD. ICANN, Glossary, <https://www.icann.org/resources/pages/glossary-2014-02-03-en > accessed 2 December 2016. California Licensed Real Estate Brokerage, Worldwide Domain Name Registration and Renewal, <http://www.domainsnext.com/top-leveldomains.htm> accessed 2 December 2016.

${ }^{69}$ It is very important to recognize that most of the conflicts between domain names and trademarks are under the unsponsored "not restricted or open" TLDs, because it's open TLDs and not restricted. Thus, any person can register domain name under unsponsored "not restricted or open" TLDs. ICANN, Glossary, <https://www.icann.org/resources/pages/glossary-2014-02-03-en > accessed 2 December 2016.

${ }^{70}$ Michael Katz, Gregory Rosston, and Theresa Sullivan, an Economic Framework for the Analysis of the Expansion of Generic Top-Level Domain Names, 2010, <https://archive.icann.org/en/topics/new-gtlds/economic-analysis-ofnew-gtlds-16jun10-en.pdf> accessed 3 December 2016.
} 


\begin{tabular}{|c|c|c|c|}
\hline TLD & Introduced & $\begin{array}{l}\text { Sponsored/Unsponsored } \\
\text { Current Registry Operator }\end{array}$ & Purpose \\
\hline .arpa & 1985 & $\begin{array}{l}\text { Sponsored / Internet architecture IANA (Internet } \\
\text { Architecture Board) }\end{array}$ & Internet architecture \\
\hline .com & 1985 & $\begin{array}{l}\text { Unsponsored / Unrestricted } \\
\text { VeriSign, Inc. }\end{array}$ & $\begin{array}{l}\text { intended for commercial registrant } \\
\text { and Businesses }\end{array}$ \\
\hline .edu & 1985 & Sponsored / EDUCAUSE/VeriSign, Inc. & $\begin{array}{ll}\text { United States educational } \\
\text { institutions. }\end{array}$ \\
\hline .gov & 1985 & $\begin{array}{l}\text { Sponsored/ ZoneEdit (US General Services } \\
\text { Administration) }\end{array}$ & United States government \\
\hline .mil & 1985 & $\begin{array}{l}\text { Sponsored/ Defense Information Systems Agency } \\
\text { (US DOD Network Information Center) }\end{array}$ & United States military \\
\hline .net & 1985 & $\begin{array}{l}\text { Unsponsored/ Unrestricted } \\
\text { VeriSign, Inc. }\end{array}$ & $\begin{array}{l}\text { Intended for network providers, } \\
\text { etc. }\end{array}$ \\
\hline .org & 1985 & $\begin{array}{l}\text { Unsponsored/ Unrestricted } \\
\text { Public Interest Registry, Afilias }\end{array}$ & $\begin{array}{l}\text { Intended for organizations that do } \\
\text { not fit elsewhere. }\end{array}$ \\
\hline int & 1988 & $\begin{array}{l}\text { Unsponsored /Unrestricted } \\
\text { ICANN (IANA) }\end{array}$ & $\begin{array}{l}\text { Organizations } \\
\text { international treaties between } \\
\text { governments }\end{array}$ \\
\hline .aero & 2001 & $\begin{array}{l}\text { Sponsored } \\
\text { SITA (SITA) }\end{array}$ & Air-transport industry \\
\hline .biz & 2001 & $\begin{array}{l}\text { Sponsored } \\
\text { NeuStar }\end{array}$ & Businesses \\
\hline .coop & 2001 & $\begin{array}{l}\text { Sponsored } \\
\text { DotCooperation, LLC (NCBA) }\end{array}$ & Cooperatives \\
\hline info & 2001 & $\begin{array}{l}\text { Unsponsored/ Unrestricted } \\
\text { Afilias Limited }\end{array}$ & Unrestricted use \\
\hline .museum & 2001 & $\begin{array}{l}\text { Sponsored } \\
\text { Museum Domain Management Association }\end{array}$ & Museums \\
\hline .name & 2001 & $\begin{array}{l}\text { Sponsored } \\
\text { VeriSign Information Services, Inc. }\end{array}$ & For registration by individuals \\
\hline .pro & 2002 & $\begin{array}{l}\text { Sponsored } \\
\text { RegistryPro (RegistryPro) }\end{array}$ & All professionals \\
\hline .cat & 2005 & $\begin{array}{l}\text { Sponsored } \\
\text { Catalan linguistic \& cultural community }\end{array}$ & $\begin{array}{l}\text { Associació puntCAT (Fundació } \\
\text { puntCAT) }\end{array}$ \\
\hline .jobs & 2005 & $\begin{array}{l}\text { Sponsored } \\
\text { Employ Media LLC/Verisign (Society for Human } \\
\text { Resource Management) }\end{array}$ & $\begin{array}{l}\text { The international human resource } \\
\text { management community }\end{array}$ \\
\hline .mobi, & 2005 & $\begin{array}{l}\text { Sponsored } \\
\text { Microsoft, Afilias }\end{array}$ & $\begin{array}{l}\text { Mobile content providers and } \\
\text { users community dotMobi (Nokia, } \\
\text { Vodafone) }\end{array}$ \\
\hline .travel & 2005 & $\begin{array}{l}\text { Sponsored } \\
\text { Tralliance Registry Management Company, LLC. } \\
\text { (The Travel Partnership Corporation) }\end{array}$ & Travel and tourism community \\
\hline .tel & 2006 & $\begin{array}{l}\text { Sponsored } \\
\text { Telnic Ltd. (Telnic Ltd.) }\end{array}$ & $\begin{array}{l}\text { For individuals and businesses to } \\
\text { store and manage their contact } \\
\text { information in the DNS }\end{array}$ \\
\hline .asia & 2007 & $\begin{array}{l}\text { Sponsored } \\
\text { (dotAsia Organisation) }\end{array}$ & From Asia/For Asia Afilias \\
\hline
\end{tabular}


Currently, there is a huge expansion in the number of gTLDs in order to encourage more competition and to serve users better. ${ }^{71}$

\subsection{Who Runs gTLDs and ccTLDs?}

It is very important to note that registration of a domain name in ccTLD provides exactly the same connectivity as a domain name registered in a gTLDs. ${ }^{72}$ The registration, of gTLD or a ccTLD spaces, was considered as a global electronic address which guaranteed that the corresponding online address to be easily reached from anyplace. ${ }^{73}$ Thus, there was an urgent need to regulate the registration of domain names through international organizations. These organizations had been inspired by an ambition to institutionalize the functions associated with the management of the DNS in a manner which will allow the system to hold the developing volume of traffic flow on the cyberspace. ${ }^{74}$

More than 30 years ago, the cyberspace developed from a network infrastructure generated by the U.S. Department of Defense. ${ }^{75}$ Thus, prior to widespread use of the cyberspace, the U.S. Government undoubtedly possessed and managed, this network infrastructure through private contractors, ${ }^{76}$ one of these contractors was mainly IANA. ${ }^{77}$ Internet Assigned Numbers Authority managed the assignment of domain names system at that time within the research and academic communities, ${ }^{78}$ which was administrated mainly by Dr. Jon Postel at the Information Sciences Institute (ISI), of the University of Southern California (USC). ${ }^{79}$

\footnotetext{
71 Ibid.

IANA, Root Zone Database, <www.iana.org/domains/root/db> accessed 3 December 2016.

72 WIPO, the Management of Internet Names and Addresses: Intellectual Property Issues, Interim Report of the WIPO Internet Domain Name Process, <http://www.wipo.int/amc/en/processes/process1/rfc/3/interim2_ch1.html> accessed 29 November 2016.

73 Ibid.

74 Ibid.

75 The Secretariat of the WIPO, Multilingual Domain Names, p 4.

${ }^{76}$ Such as the USC, SRI International, and Network Solutions Inc.

Lennard Kruger, Internet Domain Names: Background and Policy Issues, 2015, < https://fas.org/sgp/crs/misc/97868.pdf > accessed 4 December 2016.

${ }^{77}$ As of 1 October 2016, the IANA functions are being provided by Public Technical Identifiers, a new affiliate of ICANN. IANA, IANA, < http://www.iana.org/> accessed 4 December 2016.

78 U.S. Department of Commerce, Management of Internet Names and Addresses, <https://www.icann.org/resources/unthemed-pages/white-paper-2012-02-25-en> accessed 4 December 2016.

79 Ibid.
} 
In the 1990s, as the cyberspace developed to a global service. There was an intense pressure to increase the number of "gTLDs", and "ccTLDs". ${ }^{80}$ However, a severe argument within the cyberspace operational community did not find a resolution for this problem. As a result, the International Ad Hoc Committee (IAHC) was formed by a variety of cyberspace and international sponsoring organizations to create a proposal for the improvement. ${ }^{81}$

In 1997, the final report of IAHC contained recommendations for the management of gTLDs. These recommendations were aimed at enhancing the operation of the gTLDs and balancing concerns for stale operations, continued growth, business opportunities and legal restrictions. ${ }^{82}$

In 1998, after the National Telecommunication and Information Administration (NTIA), an agency of the U.S. Department of Commerce, issued a statement of strategy on the management of internet names and addresses, a process occurred which resulted to create Internet Corporation for Assigned Names and Numbers (ICANN). ${ }^{83}$ After the birth of the ICANN, the U.S. Department of Commerce signed a Memorandum of Understanding (MoU) with $\mathrm{ICANN}^{84}$ in which authorized ICANN to establish laws and identify a conventional legal source of authority over and responsibility for the DNS. ${ }^{85}$ Since that time, IANA remained to run global IP address allocation, autonomous system number allocation, and root zone management in the DNS. ${ }^{86}$

\footnotetext{
${ }^{80}$ Digital Production Group, Domain Name Information, < www.dpgnc.com/information-about-domains.html> accessed 4 December 2016.

81 U.S. Department of Commerce, Management of Internet Names and Addresses, <https://www.icann.org/resources/unthemed-pages/white-paper-2012-02-25-en> accessed 4 December 2016.

${ }^{82}$ WIPO, the Management of Internet Names and Addresses: Intellectual Property Issues, Final Report of the WIPO Internet Domain Name Process, 1999,

< http://www.wipo.int/amc/en/processes/process1/report/finalreport.html > accessed 5 December 2016.

${ }^{83}$ Ibid.

841 October 2016, the contract between the ICANN and the United States Department of Commerce National Telecommunications and Information Administration (NTIA), to perform the IANA functions, has officially expired. This historic moment marks the transition of the coordination and management of the Internet's unique identifiers to the private-sector, a process that has been committed to and underway since 1998. Stewardship of ICANN, IANA Functions Transitions to Global Internet Community as Contract with U.S. Government Ends, 2016, <https://www.icann.org/news/announcement-2016-10-01-en > accessed 5 December 2016.

85 Before establishing ICANN these issues (identifying a conventional legal source of authority over, and responsibility for the domain name system...etc) were unclear quest. WIPO, the Management of Internet Names and Addresses: Intellectual Property Issues, Interim Report of the WIPO Internet Domain Name Process, <http://www.wipo.int/amc/en/processes/process1/rfc/3/interim2_ch1.html> accessed 26 November 2016.

${ }^{86}$ IANA, Number Resources, < https://www.iana.org/numbers > accessed 3 December 2016.
} 
On the other hand, ICANN is a not-for-profit organization incorporated in California as the body to take responsibility for future strategy for the technical operation of the Internet. ${ }^{87}$ ICANN has an exclusive direct strategy control over the gTLDs, registration process as policy maker and coordinator regarding gTLDs ${ }^{88}$ and the assignment of IP addresses to ISPs through its IANA. ${ }^{89}$

Meanwhile, IANA had become a department of ICANN, and continues to make decisions on matters such as delegation of ccTLDs. ${ }^{90}$ ICANN also creates plans to develop the IANA service over the ccTLD community, and to focus on improving the engagement with the community to provide an efficient and responded service. ${ }^{91}$

However, the registration of domain names through ICANN and its related assignees was built at the beginning on the basis of a hierarchy of names, ${ }^{92}$ with the top layer taken by gTLDs and ccTLDs. ${ }^{93}$

Currently, ICANN has Supporting Organizations (SOs), ${ }^{94}$ which assist as the specialized consultative bodies for the ICANN Board of Directors, with the main responsibility of improving

\footnotetext{
${ }^{87}$ Smith, Internet Law and Regulation, p 80.

${ }^{88}$ While ICANN is primarily a policy-maker and a coordinator of the Internet name space, the registry and registrar have functions that are more technical in nature. Medeiros, Is '.com' International? The .com gTLD: an Analysis of Its Global Nature Through the Prism of Jurisdiction, p 276.

${ }^{89}$ The IANA is a department of ICANN, a nonprofit private American corporation that oversees global IP address allocation, autonomous system number allocation, root zone management in the DNS.

Purkayastha, and Rishab, U.S. Control of the Internet Problems Facing the Movement to International Governance, < monthlyreview.org/2014/07/01/u-s-control-of-the-internet/> accessed 6 December 2016.

${ }^{90}$ Although ICANN does not implement operational control over the ccTLDs, it does pursue contractual arrangements with the operators of ccTLDs. However, the IANA has delegated responsibility to state or private organizations within each country for the management of country code domains.

International Telecommunication Union, Administering the Root: Delegations and Redelegations - Every Country is Unique, < https://archive.icann.org/en/cctlds/administering-the-root-25feb03.pdf > accessed 7 December 2016.

${ }^{91}$ Organization for Economic Co-operation and Development, Evolution in the Management of Country Code TopLevel Domain Names (ccTLDs), 2006, <https://www.oecd.org/sti/ieconomy/37730629.pdf> accessed 8 December 2016.

${ }^{2}$ WIPO, the Management of Internet Names and Addresses: Intellectual Property Issues, Final Report of the WIPO Internet Domain Name Process, 1999

< http://www.wipo.int/amc/en/processes/process1/report/finalreport.html > accessed 5 December 2016.

${ }^{93}$ It is vital to recognize that the registration of a domain name can be made after the payment of a fee through an Internet Service Provider (ISP) agent. However, the registration of a domain name does not mean that the owner of the domain name is protected from threating of cancellation of its domain name, as it will be discussed on the next chapters.

${ }^{94}$ In addition to these SOs, ICANN also relies on advice from advisory committees regarding the interests of their stakeholders who are not part of any of the SOs. Glenn McKnight, North American Regional At-Large Organization (NARALO) Tribal Ambassadors Pilot for ICANN 57, 2016, <https://community.icann.org/display/NARALO/ NARALO+Tribal+Ambassadors+Pilot+for+ICANN+57> accessed 9 December 2016.
} 
and recommending essential policies and strategies regarding those matters falling within DNS. ${ }^{95}$ The main two ICANN's SOs are the Generic Names Supporting Organization (GNSO) ${ }^{96}$ and Country Code Names Supporting Organization (CCNSO). ${ }^{97}$

GNSO improves strategies policies regarding those matters falling within gTLD space. For instances: GNSO spends efforts to operate in a fair manner internationally beside their role to support innovation and competition. GNSO deals with matters falling within the registration of a gTLD, such as the services and facilities which must be provided by a registrar, as well as; the matter which is related to the renewal of a domain name registration. ${ }^{98}$

In 2003, CCNSO was created mainly for ccTLD managers. ${ }^{99}$ CCNSO is a forum for ccTLD managers to meet and discuss several matters of interest, beside their role to encourage technical assistance between ccTLD managers. ${ }^{100}$

As Jenny $\mathrm{Ng}$ remarks that "each country may regulate its ccTLD in accordance with its own specific circumstances. This also takes into account the needs of the registrants in the country and the public interest generally". ${ }^{101}$ As prior noted, that some ccTLDs are open in the sense; thus there are no restrictions on the persons or entities who may register in them. Others are restricted, in that only persons or entities satisfying certain criteria, for example, domicile within the territory may register names in them. ${ }^{102}$

Indeed, the vital dissimilarity between the ccTLDs and gTLDs is the general recognition that control over the running of ccTLDs falls within the sovereign and dominant competence of the countries which they indicate. ${ }^{103}$

\footnotetext{
95 Ibid.

${ }^{96}$ GNSO, About the (GNSO), 2014, < https://gnso.icann.org/en/about > accessed 9 December 2016.

${ }^{97}$ ccNSO, About, <https://ccnso.icann.org/about> accessed 9 December 2016.

${ }^{98}$ GNSO, About the (GNSO), < https://gnso.icann.org/en/about > accessed 9 December 2016.

99 ccNSO, About, <https://ccnso.icann.org/about> accessed 9 December 2016.

100 Ibid.

${ }^{101} \mathrm{Ng}$, the Domain Name Registration System: Liberalization, Consumer Protection and Growth, p 14.

${ }^{102}$ WIPO, the Management of Internet Names and Addresses: Intellectual Property Issues, Interim Report of the WIPO Internet Domain Name Process, <http://www.wipo.int/amc/en/processes/process 1/rfc/3/interim2_ch1.html> accessed 27 November 2016.

103 Ibid.
} 
Conversely, it is also important to note that each gTLD, such as (.com), (.gov), "is administered by Registry Operator, which keeps the "registry," i.e. the master database of all domain names registered in the TLD. However, internet users who wish to register a SLD name do not generally enter into contact with the registry operator. They have to negotiate a registration agreement with (one of) the registrar(s) accredited by ICANN and authorized by the registry operator to sell SLDs under the specific gTLD." 104

ICANN's relations with registry operators and registrars have a contractual nature and are regulated, respectively, by Registry Agreements (RAS) and Registrar Accreditation Agreements (RAA) based on a standard form. As has been observed earlier, "the power of ICANN to impose the contracts is based on its control over the root that is on its prominent, authority-like position: so, operators are compelled to sign them if they want to start with their activity". ${ }^{105}$ Thus, ICANN can carry out its own rules, which attain a legally compulsory nature by way of integration in contractual provisions.

To sum up, ICANN has an exclusive direct strategy control over the gTLDs, registration process and the assignment of IP addresses to ISPs ${ }^{106}$ through its IANA. ${ }^{107}$ While IANA, as department of ICANN, has an exclusive direct strategy control over the delegation of ccTLDs. ${ }^{108}$

\subsection{What are New gTLDs?}

In June 2011, ICANN approved and authorized the launch of the new gTLD program. The program aims for enhancing competition and consumer choice, and supporting the benefits of innovation by introduction of new gTLDs. ${ }^{109}$

On 12 January 2012, the application window has been started to receive many applications for registering a new gTLDs. On 22 March 2013, ICANN released the first set of Initial Evaluation

\footnotetext{
${ }^{104}$ Simone Vezzani, ICANN's New Generic Top-Level Domain Names Dispute Resolution Procedure Viewed Against the Protection of the Public Interest of the Internet Community: Litigation Regarding Health-Related Strings, the Law $\&$ Practice of International Courts and Tribunals: A Practitioners' Journal, Volume 13, Issue 3, 2014, p 310-311. ${ }^{105}$ Ibid.

${ }^{106}$ Internet Service Providers (ISPs)

${ }^{107}$ Purkayastha, and Rishab, U.S. Control of the Internet Problems Facing the Movement to International Governance, < monthlyreview.org/2014/07/01/u-s-control-of-the-internet/> accessed 6 December 2016.

${ }^{108}$ International Telecommunication Union, Administering the Root: Delegations and Redelegations - Every Country is Unique, < https://archive.icann.org/en/cctlds/administering-the-root-25feb03.pdf > accessed 7 December 2016

${ }^{109}$ ICANN, About the Program, <https://newgtlds.icann.org/en/about/program > accessed 10 December 2016.
} 
results to applicants and the public. ${ }^{110}$ In 2014, new gTLDs had become available for entrepreneurs, which are called operators, to enable them creating their own TLDs that they can control on their own. ${ }^{111}$ At present, there are basically an unending amount of TLDs. Business owners could pay to have their site end with things like .xyz, .toys, .soy, .wed, and more. ${ }^{12}$ The following are the top ten new gTLDs until the date 1st. of December 2016": ${ }^{113}$

\section{TLD}

\section{Domains until the date} 1st. of December 2016

$1 \quad$.xyz

2 .top

3 .win

$4 \quad$.wang (net)

$5 \quad$.club

6 .bid

7 .loan

8 .site

9 .online

10 .vip
$6,232,133$

$4,498,841$

$1,176,297$

961,770

818,564

579,761

541,600

531,392

495,704

475,123

"With the introduction of vast numbers of new gTLDs, equally significant changes to the global DNS landscape have been occurring through ICANN's approval in early 2010 of a phased

\footnotetext{
110 Ibid.

${ }^{111}$ Peter Roesler, Will New Top Level Domains Matter in 2015? Will New URL Endings Change Web Design and Marketing in 2015? , 2015, < http://www.inc.com/peter-roesler/will-new-top-level-domains-matter-in-2015.html > accessed 10 December 2016.

112 Ibid.

${ }^{113}$ Namestats, gTLD Stats, Metrics and Analysis, < http://www.inc.com/peter-roesler/will-new-top-level-domainsmatter-in-2015.html > accessed 1st. of December 2016.
} 
introduction of Internationalized Domain Names (IDNs), i.e., domain names in local language characters such as Arabic (العربية), Chinese (中文), or Cyrillic (Цыриллиц).”114

As Ashley Roberts noted "there are certain terms which are barred from the first application round for political reasons: ICANN has a list of approximately 30 terms which are reserved at the top level for stability issues, including .ICANN and .WHOIS, and country or territory names cannot be applied for, following governmental input into policy development. Furthermore, relevant government or public authority approval is required in order to apply for terms considered geographic names: capital city names, sub-national place names (for example, counties or provinces), a city name where the applicant intends to use the gTLD for purposes associated with the city name, and UNESCO regions or terms appearing in the UN Composition of macro geographical (continental) regions, geographical sub-regions, and selected economic and other groupings list." 115

In other words, the new gTLD program ${ }^{116}$ is the greatest expansion of digital area since the Internet began. As Roesler remarks "the opportunities to engage customers, drive revenue, and promote brands online are practically unlimited. It can help to success and safeguard the brands in this transformed online world". ${ }^{117}$

However, the real challenge now for the new gTLDs is that "though people can use them to quickly understand the purpose of a site, consumers don't inherently trust sites with unusual TLDs more than ones with more traditional endings". ${ }^{118}$ For this reason, the sites with older alternative TLDs that have been serving customers for years such as; .com, .biz or .org, never really took off. ${ }^{119}$

In short, an applicant for a domain name can register a domain name not only within the few generic gTLDs, but also may apply to register an entirely new TLD for ICANN. For instance, an

114 WIPO, WIPO Observations on New gTLD Dispute Resolution Mechanisms, < www.wipo.int/amc/en/domains/newgtld/ > accessed 11 December 2016.

115 Ashley Roberts, an Overview of the New gTLD Programme, 2011, <https://valideus.com/sites/default/files/documents/new-gTLD-white-paper-final.pdf > accessed 11 December 2016. 116 A full list of the questions can be found in the Applicant Guide Book. ICANN, Applicant Guidebook, <http://www.icann.org/en/topics/new-gtlds/rfp-clean-30may11-en.pdf > accessed 11 December 2016.

117 Roesler, Will New Top Level Domains Matter in 2015? Will New URL Endings Change Web Design and Marketing in 2015? < http://www.inc.com/peter-roesler/will-new-top-level-domains-matter-in-2015.html > accessed 10 December 2016.

${ }^{118}$ Ibid.

${ }^{119}$ Ibid. 
applicant could seek to register for a geographic area, or, a general category such as .capetown or .music as a TLD, with the aim of launching a domain registry business offering others second level domain names ${ }^{120}$ to register within such TLD. Another example, a trademark, such as (.dunlop), with the purpose that only related commerce or trade may register second level domain names in that TLD. ${ }^{121}$

\subsection{The Contractual Nature of Domain Name Registration Processes}

In reality, a domain name registrant is anybody, it might be a person or organization, who has registered the domain name. ${ }^{122}$ However, the domain name registrant applies normally online to register a domain name through the registrar or one of their resellers. ${ }^{123}$

Accordingly, the registrant is obligated by the online terms and conditions of the registrar with which it registers its domain name, "for instances; obligating to a certain code of conduct or indemnifying the registrar and registry against any legal or civil action taken as a result of use of the domain name." 124

Domain name registrants have definite obligations that are integrated into these online terms and conditions such as "payment of registration fees and submission and timely update of accurate data." 125 The registrants can retain using the domain names as long as the renewal fees are paid to the registrars by them. ${ }^{126}$

In order to have that domain name reachable and online via cyberspace, the registrants need, after registering their domain names, to have their domain names programmed on name servers. ${ }^{127}$

\footnotetext{
120 The second-level domain is generally located on the left of the top-level domain. For example, in the domain www.yahoo.com, "yahoo" is the second-level domain. Quackit, Second-Level Domain Names, <www.quackit.com/domain-names/second-level_domain_names.cfm > accessed 10 December 2016.

${ }^{121}$ Karjiker, the new gTLDs and the resolution of trade mark disputes, <blogs.sun.ac.za/iplaw/files/2016/04/Thenew-gTLDs-and-the-resolution-of-trade-mark-disputes.pdf > accessed 10 December 2016.

122 ICANN, Domain Name Registration Process, <https://whois.icann.org/en/domain-name-registration-process > accessed 10 December 2016.

123 Ibid.

124 Ibid.

${ }^{125}$ Ibid.

126 Claudio Caruana, the Legal Nature of Domain Names, <www.elsa.org.mt/wp-content/uploads/2015/02/5.Caruana-Claudio-The-Legal-Nature-of-Domain-Names.pdf > accessed 11 December 2016.

127 Ibid.
} 
In general, a registrant is also responsible for buying or hosting his own name server, however; not all the registrars offer this service but some of them offer this service when the registrants are buying the domain name. ${ }^{128}$

The registration of a domain name is for a limited term. The shortest registration period of a domain name is one year, and registration period can also be done for up to ten years. After a registration term expires, the domain name holder may renew the registration. If a domain name holder does not renew the registration, the domain name should ultimately be deleted by the Registrar and then the domain name holder will not have the right to the domain name any more. As a result, the domain name will be available again for another online consumer to register it as a new registrant. $^{129}$

Briefly, a registrant must register domain name with one of ICANN's accredited registrars. The registrar will usually check if the domain name is still available. If it is still available the registrar will register it on behalf of the registrant after paying the required fees. The registrants need to have their domain names programmed on name servers. Basically, registrants can retain using the domain names as long as the renewal fees is paid to the registrars by them. ${ }^{130}$

In the light of the foregoing, it should be mentioned that domain name registration processes are governed with two main contractual relationships. The first one between ICANN and the registrar, which is known as Registrar Accreditation Agreement "RAA" and the second one between the registrar and the registrant. In the following, these two contractual relationships will be introduced:

\footnotetext{
128 Ibid.

129 ICANN, Non-Lawyers' Guide to the May 2009 Registrar Accreditation Agreement, <https://www.icann.org/resources/pages/non-lawyers-guide-2010-02-15-en> accessed 12 December 2016.

130 Caruana, the Legal Nature of Domain Names, <www.elsa.org.mt/wp-content/uploads/2015/02/5.-CaruanaClaudio-The-Legal-Nature-of-Domain-Names.pdf > accessed 11 December 2016.
} 


\subsubsection{The Contractual Relationship under ICANN's Registrar Accreditation Agreement (RAA)}

In order to register a domain name, a registrant has to acquire the services for registration by one of ICANN's accredited registrars. In order to become an ICANN's accredited registrar, the registrar must enter into an agreement with ICANN, known as the RAA. ${ }^{131}$

The RAA is a binding legal contract between ICANN as a first party and each of its accredited registrars as a second party. The RAA role is mainly to state the registrar's tasks in the DNS and also how does the registrar manage their registrants. ${ }^{132}$

The fact that every domain name registrar of a gTLD or new gTLD at anyplace in the world has a RAA in force with ICANN. Accordingly, ICANN has administrative authority over and organizes the registration operation of the entire DNS (for gTLD and new gTLD) all over the world. ${ }^{133}$ Taking into consideration that the RAA does not apply or cover for ccTLDs registrations as accreditation of registrars for ccTLDs is a subject of choice for the ccTLD Registry Operators. ${ }^{134}$

Under RAA legal terminology, in order to help domain name registrants to understand better the rights and responsibilities that come along with the domain name registration process,

131 ICANN, Non-Lawyers' Guide to the May 2009 Registrar Accreditation Agreement, <https://www.icann.org/resources/pages/non-lawyers-guide-2010-02-15-en> accessed 12 December 2016.

${ }^{132}$ Ibid.

${ }^{133}$ Peter Michaelson, Emergency Arbitration: Fast, Effective and Economical (March 18, 2016), Just Resolutions, American Bar Association Dispute Resolution Section, 2016, < https://ssrn.com/abstract=2762715> accessed 13 December 2016.

134 ICANN, Non-Lawyers' Guide to the May 2009 Registrar Accreditation Agreement, <https://www.icann.org/resources/pages/non-lawyers-guide-2010-02-15-en> accessed 12 December 2016. 
the RAA provides several rights and responsibilities for registrants. These are expressed in separate ICANN policies and specifications, ${ }^{135}$ which the registrars agree to follow in advance. ${ }^{136}$

Simply, there is a "flow-through" prerequisite under RAA legal terminology. Accordingly, registrars must include a similar provision in their agreements to all registrants (end-users) with whom they sell the domain names, obligating the registrants to be adhered with ICANN policies and specifications. ${ }^{137}$

The RAA is divided into five sections: definitions, ICANN obligations, registrar obligations, procedures for establishment or revision of specifications and policies, and miscellaneous provisions. ${ }^{138}$

Generally, the definition section defines specific terms that are used in the RAA, while ICANN obligations section states that ICANN is obligated "to act in an open and transparent manner, apply standards equitably among Registrars". ${ }^{139}$ Under the same section, the registrar is accredited and granted a license to act on behalf of ICANN. On the other hand, the registrar obligations section contains many provisions detailing registrars' obligations in relation to dealings with "Registered Name Holders". For example, registrars are obliged "to follow ICANN policies

${ }^{135}$ For example, WHOIS Accuracy Program Specification, which will be examined in details in the next chapter. In addition, the following are some samples of ICANN policies and specifications:

- Uniform Domain Name Dispute Resolution Policy (adopted by ICANN Board 26 August 1999; form of implementation documents approved 24 October 1999).

- Whois Data Reminder Policy (adopted by ICANN Board 27 March 2003; implementation documents issued 16 June 2003).

- Inter-Registrar Transfer Policy (effective 1 June 2012).

- Whois Marketing Restriction Policy (effective on 12 November 2004, adopted by ICANN Board 27 March 2003; implementation documents issued 12 August 2004).

- $\quad$ Restored Names Accuracy Policy (effective on 12 November 2004, adopted by ICANN Board 27 March 2003; implementation documents issued 12 August 2004).

- $\quad$ Expired Domain Deletion Policy (effective on 21 December 2004, adopted by ICANN Board 31 October 2003; implementation documents issued 21 September 2004).

ICANN, Consensus Policies, <https://www.icann.org/resources/pages/registrars/consensus-policies-en > accessed 11 December 2016.

136 Some ICANN-accredited Registrars may offer registration services for (ccTLDs) such as (.DE), (.UK), and (.ME). ICANN does not accredit registrars for ccTLDs, and the requirements of the RAA do not apply for registrations within those ccTLDs. Accreditation of registrars for ccTLDs is a matter of choice for the ccTLD Registry Operators - ccTLDs do not have to accredit registrars, and if they choose to accredit, ccTLDs may set their own standards and obligations for accreditation.

ICANN, Registrant Rights and Responsibilities Under the 2009 Registrar Accreditation Agreement,

$<$ https://www.icann.org/resources/pages/responsibilities-2014-03-14-en> accessed 12 December 2016.

${ }^{137}$ Ibid.

${ }^{138}$ Ibid.

${ }^{139}$ Ibid. 
and consensus policies, and to operate in accordance with the law." ${ }^{140}$ The RAA obliges briefly registrar to: ${ }^{141}$

- post fees ${ }^{142}$ charged for recovery of registered domain names (as the registrars may not activate a domain name until they receive assurance that the registration fee will be paid);

- $\quad$ abide by the Uniform Domain Name Dispute Resolution Policy (UDRP) ${ }^{143}$ and court orders;

- maintain records of all communications with registrants;

- maintain a database of all registrants;

- provide each new registrant with notice of the registrar's auto-renewal policies;

- enter into electronic or paper registration agreements with all registrants, by including a provisions to be adhered with ICANN policies in their agreements;

- verify the contact data supplied by the registrants when the domain is first registered; and,

- $\quad$ pay to ICANN annual fees plus variable fees according to the terms of payment of fees under RAA.

Lastly, section 5 of the RAA sets forth a several provisions that primarily concentrate on the "resolution of disputes under the RAA, the termination of the RAA, and the type of relief that ICANN or the Registrar may seek through a lawsuit or arbitration that is initiated under the RAA." 144 The term of the RAA is five years, and if a registrar is looking to renew its RAA at the end of this period, ICANN will permit a renewal, in case if the registrar is in well compliance with its obligations and commitments under the RAA. On the one hand, the registrar may terminate the RAA at any time previous to the termination of the RAA by giving ICANN thirty days written notification. On the other hand, ICANN may only terminate the RAA under the

140 "The RAA also specifically requires Registrars to abide by the Uniform Domain Name Dispute Resolution Policy, commonly referred to as the UDRP. Registrars also have specific items on which they must provide notice to Registered Name Holders, including notifications of the end of a registration term, use of Registered Name Holder's Personal Data, and in some cases notices regarding escrowing of data for domain names registered through privacy or proxy registration services" ICANN, Registrant Rights and Responsibilities Under the 2009 Registrar Accreditation Agreement, <https://www.icann.org/resources/pages/responsibilities-2014-03-14-en> accessed 12 December 2016.

${ }^{141}$ Ibid.

142 The RAA does not impose limitations on the fees that Registrars may charge to Registered Name Holders for registration services. Ibid.

${ }_{143}$ ICANN, Uniform Domain Name Dispute Resolution Policy, <https://www.icann.org/resources/pages/help/dndr/udrp-en > accessed 12 December 2016.

144 ICANN, Registrant Rights and Responsibilities Under the 2009 Registrar Accreditation Agreement, < https://www.icann.org/resources/pages/responsibilities-2014-03-14-en> accessed 12 December 2016. 
certain conditions set out under section 5 of RAA. Such a condition is that a registrar: "makes material misrepresentations in its application for accreditation; faces a conviction or legal judgment related to fraud or similar offenses; is subject to governmental discipline for the misuse of the funds of others; and fails to cure a breach of the RAA that was identified in a notice of breach from ICANN. ICANN also may terminate a Registrar's accreditation when the Registrar becomes bankrupt or insolvent, or when the Registrar is engaging in action that ICANN determines to endanger the operational stability of the Internet." ${ }^{145}$ Disputes arising under RAA, shall be resolved in a court of competent jurisdiction or, at the election of either party, by an arbitration conducted by International Arbitration Rules of the American Arbitration Association ("AAA"). ${ }^{146}$ However, in a case where litigation has been launched instead of arbitration or for the purpose to enforce an arbitration award, the RAA states that the exclusive jurisdiction for such litigation shall be in a court located in Los Angeles, California, USA, as well as, the RAA gives the two parties the right to enforce a judgment of such a court in any competent jurisdiction court. ${ }^{147}$

\subsubsection{The Contractual Relationship between the Registrar and the Registrant under the Umbrella of Registrar Accreditation Agreement (RAA)}

As stated above, the registrars are obliged under RAA by ICANN to enter into electronic or paper registration agreements with all their registrants, by including a provisions to be adhered with ICANN policies in their agreements. ${ }^{148}$ There is a "flow-through" prerequisite under RAA legal terminology; that is, registrars must include a similar provision in their agreements with all registrants (end-users) with whom they sold the domain names, obligating the registrants to be adhered with ICANN policies. ${ }^{149}$ The main role of the registrar, under this contractual relationship with the registrant, is to ensure that the registered domain name is available and if it will match IP

\footnotetext{
${ }^{145} \mathrm{Ibid}$

${ }^{146}$ ICANN, Registrar Accreditation Agreement, <https://www.icann.org/resources/pages/ra-agreement-2009-05-21en\#3.7.5.1> accessed 13 December 2016.

147 Ibid.

148 ICANN, Non-Lawyers' Guide to the May 2009 Registrar Accreditation Agreement, <https://www.icann.org/resources/pages/non-lawyers-guide-2010-02-15-en> accessed 12 December 2016.

149 ICANN, Registrant Rights and Responsibilities Under the 2009 Registrar Accreditation Agreement, < https://www.icann.org/resources/pages/responsibilities-2014-03-14-en> accessed 12 December 2016.
} 
address with the domain name. ${ }^{150}$ On the other hand, the registrant, under this contractual relationship, has the capability to keep using the registered domain name provided that the renewal fee is paid to the registrar and no any infringements of the intellectual property rights of others occur as a result of such registration of the domain name. ${ }^{151}$

Many authors maintain that the domain name registrant has the conditional contractual right to the exclusive association of the registered domain name with the IP address for the period of the registration. ${ }^{152}$

However, this contractual relationship between the registrar and the registrant mainly obliges the registrant to provide an accurate contact information and must quickly update them during the registration term. ${ }^{153}$ Thus, if the registrant provides inaccurate information, or fails to update the information, or fails to reply over fifteen (15) days to registrar request for correctness contact information, the registrant will be in breach of his contractual relationship with the registrar and as a result the registration may be cancelled. ${ }^{154}$ Conversely, the registrar must provide notification of: how it aims to use this data (which is provided by the registrant and who will also receive the registrant's data) and also provide notice of how the registrants may access and update data and information. ${ }^{155}$ Additionally, the registrar has to guarantee that all precautions are taken to protect the registrant's information and data from "loss, misuse, unauthorized access or disclosure, alteration, or destruction."156

According to sections 3 of the RAA, the agreement between the registrar and registrant must mainly include registrants' rights and responsibilities. In short, the following are the main rights of registrants under the agreement between the registrar and registrant: ${ }^{157}$

- the registrar has to guarantee that all precautions are taken to protect the registrant's information and data;

150 Caruana, the Legal Nature of Domain Names, <www.elsa.org.mt/wp-content/uploads/2015/02/5.-CaruanaClaudio-The-Legal-Nature-of-Domain-Names.pdf > accessed 11 December 2016.

151 Ibid.

152 Ibid.

${ }^{153}$ ICANN, Registrant Rights and Responsibilities Under the 2009 Registrar Accreditation Agreement, < https://www.icann.org/resources/pages/responsibilities-2014-03-14-en> accessed 12 December 2016.

${ }^{154}$ Ibid.

155 Ibid.

156 Ibid.

157 Ibid. 
- display of registration information;

- fair treatment from ICANN, registrars and registries;

- communications through registries or registrars;

- renewal domain name registrations;

- clear pricing of domain name; and

- demonstration of any changes to the registrar contract according to ICANN policy.

Registrants have also the following responsibilities under the agreement between the registrar and registrant: ${ }^{158}$

- to be contactable, if not responding then the registrar has the right to suspend its registration; and

- not to violate the legal rights of others, and if that occurred the registrant should accept dispute settlement procedures adopted by ICANN.

\subsection{The Correlation between Trademarks and Domain Names}

Trademarks are one of the most significant branches of industrial property. Giving their role as commercial identifiers, and distinguishing one's goods or services from those of competitors, trademarks play the role in organizing the marketplace, and encourage honest commercial competition between competitors using different trademarks. Trademarks may be one or a combination of words, letters, and numerals. They may consist of drawings, symbols, threedimensional signs such as the shape and packaging of goods, audible signs such as music or vocal sounds, smells (fragrances), or colors used as distinguishing features. ${ }^{159}$ At the present, trademarks are valuable properties for the owners of commercial establishments to distinguish their goods or services from that of others, thus, protection of trademark and well-known trademark has great importance to ensure the source from which a given products or service originates. For instance, a trademark gives an incentive for commercial establishments to maintain the quality of their

\footnotetext{
158 Ibid.

${ }^{159}$ WIPO, what is a trademark? 2015 <http://www.wipo.int/trademarks/en/> accessed15 October 2015.
} 
products or services such as COCA-COLA, Google, BMW and DELL. The customer will observe the trademark, indicating that certain products or services as a guarantee of quality. ${ }^{160}$

The concept of famous trademark has obtained a dynamic extends beyond the value of the goods and services with which they are mainly related as they might maintain secondary meanings in the mind of the customer, "loyalty between products, services and categories over time and to separate it from tangible production". ${ }^{161}$ As a result of widespread of the license and franchise brands, famous trademarks have been widely become as the most important assets engaged by modern companies.

It is obviously noticeable that commercial entities are trying to develop some new methods of dealing to exploit the facilities offered by such a medium as the Internet. Moreover, commercial entities are trying to develop some new means of dealing with their trademarks by making use of the goodwill they acquired in the real world and transfer that such goodwill to the Internet.

One of the active elements in commerce and promotion through the internet is the domain name, as mentioned above, when a trademarked name is used as a commercial firm's domain name through the Internet, ${ }^{162}$ consumer identify where to go online to conduct business with that firm. Therefore, domain names are means, which were used to introduce users of the Internet to activities and commercial services presented through the web.

The main objective of which shall be to introduce the works they do, and services they provide with their clients and customers wherever they might be. Such commercial firms were not satisfied by making their websites as a facade for their commercial stores, exhibiting various goods and commodities, they also imparted to them a positive and interactive characteristic which enables the client to perform his contracts and lodge his own purchasing applications immediately through filing a form or contract already fixed in the website without taking the trouble of the direct contact with such firms.

\footnotetext{
${ }^{160}$ WIPO, Standing Committee on the Law of Trademarks, Industrial Designs and Geographical Indications, 2016, <http://www.wipo.int/edocs/mdocs/sct/en/sct_16/sct_16_9.pdf> accessed 24 November 2015.

${ }^{161}$ Haigh, Brand Valuation - Understanding, Exploiting and Communicating Brand Values, London, p29.

162 Some commercial firms want to market its goods or services via the cyberspace, thus it usually does so by creating a "web-site" and "posting" information concerning goods or services to that site.
} 
As a preliminary step towards establishing such websites, it was predictable to reserve and register a domain name that is easy to remember, which suits the name of such firms or their trademarks' name. Such firms might be surprised when they resort to the competent authorities entitled with the registration of gTLDs like (.com) used for commercial domains or (.biz) used for business domains and others, as well as ccTLDs like (.us) for United States, (.eu) for European Union and (.jo) for Jordan, and find out that their trademarks have been registered as domain names by persons who have no relation with such names. Every domain name is a unique one, and no two identical domain names might be registered in cyberspace. Contrary, trademark legal system permits the registration of similar, or even identical, trademarks to distinguish different products and goods. ${ }^{163}$

Such firms incorporate in their well-designed and attractive websites what make clients and users constantly come one after the other to peruse the products and services they offer. The websites of such firms include their trademarks, which distinguish their goods and products from others, owned and relating to other firms.

It would be interesting to note that under new gTLD is quite often the case that trademark proprietor seeks to register a trademark as a TLD and restricts registration of second level domain names to approved and maintain the businesses, for example, a "dotbrand" TLD, and is a closed TLD registry, while the trademark Apple is an example, if Apple Company is looking to have subdomains for its goods or services under the .apple TLD, such as (ipad.apple) or (itunes.apple), which may serve to strengthen its brand and maintain its businesses. ${ }^{164}$ On the other hand, where third parties may apply for domain names within the applied-for TLD, the new TLD will be an open registry. "Given the fact that the New gTLD Program allowed for the registration of trademarks as TLDs, it was inherent to the nature of the gTLD regime that the prospect of coincidence of brand names will exist.”165

However, the relation between trademark and domain name is a modern issue and there is no clear international system that is put to clarify the interaction between trademarks and domain names.

\footnotetext{
163 The legal system that governs famous trademarks, which does not permit the registration of similar, or even identical, trademarks to distinguish different products and goods. Article 16 of TRIPs Agreement.

${ }^{164}$ Karjiker, the New gTLDs and the Resolution of Trade Mark Disputes, <blogs.sun.ac.za/iplaw/files/2016/04/Thenew-gTLDs-and-the-resolution-of-trade-mark-disputes.pdf > accessed 10 December 2016.

${ }^{165}$ Ibid.
} 


\subsection{Comparing Distinctions and Similarities between Trademarks and Domain Names}

There is no doubt that domain names and trademarks ${ }^{166}$ are similar in nature, however, they differ in their functions. Trademarks are used to distinguish goods or services of a trader. On the other hand, domain names serve as a new method to provide an address that identifies a specific location on the internet. ${ }^{167}$ Trademarks have to be registered in relation to certain goods and services. Domain names are not linked to any goods and services but it used to identify businesses on the Internet. It remains registered as long as the domain name registration is valid and renewed while the scope of protection of a trademark is determined by those goods and services for which a trademark is registered and it can be revoked if they are not used for these goods and services for which they are registered. ${ }^{168}$ Further, the registration system of trademarks is administered by a governmental authority on a territorial basis (either domestic, regional or international), while the domain names registration system is usually administered by a non-governmental organization without any functional limitation. ${ }^{169}$ It is very important to recognize the main differences between domain names and trademarks through the following table: ${ }^{170}$

\begin{tabular}{|l|l|}
\hline \multicolumn{1}{|c|}{ Trademark } & \multicolumn{1}{c|}{ Domain name } \\
\hline Trademark registrations are national or regional. & Domain names have no geographical limitations. \\
\hline $\begin{array}{l}\text { Trademark registration protects use of the mark in the } \\
\text { course of trade. }\end{array}$ & $\begin{array}{l}\text { The purpose of the domain name registrant may be } \\
\text { commercial or not. }\end{array}$ \\
\hline $\begin{array}{l}\text { Trademark is registered for specified types of good or } \\
\text { services. }\end{array}$ & $\begin{array}{l}\text { The registration of a domain name (in the open TLDs) } \\
\text { is not linked to any specific class of goods or services. }\end{array}$ \\
\hline $\begin{array}{l}\text { The same trademarks can be registered for different } \\
\text { goods or services by numerous different applicants. }\end{array}$ & Only one instance of a domain name can be registered. \\
\hline
\end{tabular}

\footnotetext{
166 This study does not cover the Tradenames or personal names in the context trademark cybersquatting, as the main target is to focus on the dispute resolution mechanisms and trademark cybersquatting in gTLDs old style, ccTLD style and gTLD new style.

167 Tomas Korman, the Relationship between Domain Names and Trademarks, LL.M. thesis, Legal Studies Department, Central European University, 2013, p1.

${ }^{168}$ Marinkovic Anaracki, On Domain names and Trademarks, Vol. 15 Issue 12, Journal of Internet Law, 2012, p 3031.

169 WIPO, WIPO Internet Domain Name Process, 2015, <http://www.wipo.int/amc/en/processes/process1/ > Accessed 9 Jan 2015.

${ }^{170}$ Graham, Internet Law and Regulation, p 84.
} 
As mentioned above, there are some interactions between trademarks and domain names, however, the following are clarifications on these differences which have been sustained most of the confusion in this area:

- Identical trademarks can be used for different classes of goods, while domain names are restricted to just one. Domain names are not classified, as trade mark classes, for goods and services. ${ }^{171}$

- Trademark rights are national by nature so the similar products with the same trademark can be sold by different companies in different countries, while domain name have no geographical limitations. ${ }^{172}$

- Trademark rights arise from registering the mark with a governmental entity. In other words, trademark rights are administered by governmental entities, e.g. the Trademarks Registration Office in the UK is a governmental body. The Intellectual Property Office (IPO) is the official government body responsible for intellectual property rights in the United Kingdom. The IPO will receive and process trademark applications and where an application is successful, will register the sign as a trademark. ${ }^{173}$ In the event of a dispute over the rights over trademark, there are procedures to oppose registration and to settle such disputes. However, domain names are not administered by the state but are granted by private companies. ${ }^{174}$ These companies will naturally intend to increase commercial profit margins through selling and registering more domain names for customers all over the world.

- $\quad$ To register a specific trademark is not enough for the purpose of possession of the rights; it must be in use to sustain the rights of registration and avoid cancellation of the trademark. ${ }^{175}$

${ }^{171}$ Queensland, What Are the Differences between Trademarks, Business Names, Company Names and Domain Names, Australia, 2015, <https://www.business.qld.gov.au/business/support-tools-grants/tools/intellectual-propertyinfo-kit/browse/names/differences> Accessed 15 November, 2015.

172 WIPO, WIPO-WTO Colloquium Papers: Research Papers from the WIPO-WTO Colloquium for Teachers of Intellectual Property, 2010, <http://www.wipo.int/export/sites/www/academy/en/courses/academic _institutions/pdf/wipo_wto_colloquium_2010.pdf > Accessed 15 October, 2015.

${ }^{173}$ Taylor Alasdair, How to register a UK trade mark without a lawyer, 2011, <http://www.seqlegal.com/blog/howregister-uk-trade-mark-without-lawyer> Accessed 17 October 2015.

${ }^{174}$ Exception of the ccTLD domain names, these domain names are granted by governmental bodies in many countries. 175 Article 19 of TRIPS Agreement. 
Likewise, mere registration of a domain name could be held endlessly with no effect for nonuse, so it might be registered but without any use.

Moreover, it is very important to note here that international protection for famous trademarks can give expression in respect of domain names; there are three areas of conceptual difficulty that need to be borne in mind:

1. It is clearly noticeable that the provisions of the Paris Conventions and the Trade-Related aspects of Intellectual Property Rights "TRIPs Agreement" are intended for protection of famous marks against the registration or use of other infringing marks. Domain names are also used as a means of identifying goods and services with the producer or seller of those goods and services but the purpose of the domain name registrant may be commercial or not.

2. The protection of famous trademarks under the Paris Convention and the TRIPs Agreement extends to those countries where the competent authority considers that the trademarks is famous. ${ }^{176}$ While there is an international obligation to accord protection to famous trademarks, but there is not an established treaty definition of what constitutes a trademarks famous. It is left to the appreciation of the competent authority in the country where protection is asserted ${ }^{177}$ and to the Joint Recommendation Concerning Provisions on the

\footnotetext{
${ }^{176}$ For instance, no definition of well-known trademark or famous trademark under United States law. Further, the United States Law stipulated the term of "famous trademark" but not "well-known trademark" through its provisions. Actually, section 3 of the Federal Trademarks Dilution Act in 1995 states that "the owner of a famous mark shall be entitled, subject to the principles of equity and upon such terms as the court deems reasonable, to an injunction against another person's commercial use of a mark or trade name, if such use begins after the mark has become famous and causes dilution of the distinctive quality of the mark, and to obtain such other relief as is provided in this subsection". In European Union legislation, both the Trademark Directive and the Trademark Regulation did not adopt the terms "famous trademark" or "well-known trademark" in their English versions. The alternative concept formally used is the "mark having a reputation". However, a question that has not yet been clarified in the European context is the exact definition of "marks having a reputation". Actually, the "reputation" of a trademark means its exclusive attraction which can also be described as its "advertising value". In very simple words, the concept of "famous trademark" or "well-known trademark" are used differently from state to state with varies levels of purpose. Despite of such differences, the "famous trademark" or "well-known trademark" can be defined as "a trademark which is widely known by many people within the relevant territory or is considered and recognized by the authorities of the countries regardless of where it is used or registered or not". Heath Christopher, and Chung Liu Kung, the Protection of Well-known Marks in Asia, Max Planck Series on Asian Intellectual Property Law, 2000, p 12.

177 As prior mentioned, article 16.2 of the TRIPs Agreement states some guidance as to the criteria that such a competent authority must take into account in forming its appreciation. In addition, such criteria have been developed in national case law and regulatory practices and decisions around the world.
} 
protection of Intellectual Property and General Assembly of the WIPO. ${ }^{178}$ The criteria for determining whether a trademark is well-known trademarks is still a grey area internationally. It needs more efforts to obligate all the countries to admit a uniform criteria for determining whether a trademark is well-known trademarks

3. While the protection of famous marks has increasingly been implemented at the national level by laws directed at prohibiting any use of famous marks by third parties that dilutes the integrity and reputation of such marks, the protection of well-known marks exists often only in respect of the registration or use of a confusingly similar mark in relation to the same goods or services as those for which the well-known mark is registered or used. Because of the special attention that fame attracts, famous and well-known marks have for a long time been considered in intellectual property laws to warrant special protection.

Currently, the gTLDs are largely undifferentiated. There is no enforcement mechanism to ensure that those who have registered domain names in open gTLDs confine their use of the domain name to the broad purposes of the gTLDs. Therefore, one can have a domain name registered in (.com) without undertaking any commercial activity, or a domain name registered in (.net) while undertaking commercial activity that is completely unrelated to the provision of Internet or network services. ${ }^{179}$

In addition, it is important to mention that the mechanism, under ICANN, generally should be introduced whereby the proprietor of a famous trademarks can obtain exclusion in some or all

\footnotetext{
${ }^{178}$ In short, it should be mentioned that while there is no commonly agreed detailed definition of what constitutes a "well-known" mark; countries might take advantage of criteria for determining whether a Mark is Well-known under the WIPO Joint Recommendations on the Protection of Well-Known Marks. Article 2 of the same sets the following factors to be taken into consideration when determining whether a mark falls in to the "well-known" category:

- The degree of knowledge of the mark.

- The duration and extent of any publicity associated with it.

- The number of registrations of it worldwide.

-The diligence with which its owner can prove that he has defended it against copiers.

- The value of the mark.

WIPO, Joint Recommendation Concerning Provisions on the Protection of Well-known Marks, 1999, <http://www.wipo.int/edocs/pubdocs/en/marks/833/pub833.pdf> accessed 15 April 2016.

179 There is a lack of connection between the foundations of differentiation in the registration and use of famous trademarks and differentiation in the registration and use of domain names, since differentiation is intended to serve a different purpose in each case.

WIPO, the Management of Internet Names and Addresses: Intellectual Property Issues, Interim Report of the WIPO Internet Domain Name Process, <http://www.wipo.int/amc/en/processes/process1/rfc/3/interim2_ch1.html> accessed 26 November 2016.
} 
gTLDs for the name of the trademark if his or her trademark is famous on a widespread geographical basis and across different classes of goods or services. The effect of the exclusion would be to prohibit any person other than the owner of the famous trademarks from registering the trademarks as a domain name. ${ }^{180}$

It should be mentioned here that the relation between trademark and domain name is a modern issue and there is no clear international legal system to clarify the interaction or differences between trademarks and domain names via cyberspace.

${ }^{180}$ Ibid. 


\section{Chapter 2}

\section{Cybersquatting as a Global Problem and ICANN as a Global Solution}

\subsection{Overview}

The most obvious manner in which a conflict may arise between a trademark ${ }^{181}$ and a domain name is when the latter is identical or confusingly similar to another's trademark, which confuses Internet browsers and users, between the owner of the visited website and trademark known by the audience to distinguish a specific good or product. Additionally, it is vital to note that commercial firms are trying to develop some new means of dealing with their trademarks by making use of the goodwill they acquired in the real word and transfer that such goodwill to the Internet by registering their famous trademark as a domain name. One might register a trademark, which belongs to a well-known world firm, as a domain name and tries to extort such firm through asking it to pay large amounts of money in order to assign the registered domain name or transfer it to the firm. ${ }^{182}$

Broadly speaking, the possibility of such conflicts result from the shortage of connection between the system for registering domain names and the system for registering trademarks. ${ }^{183}$ The trademarks registration system is administered by a governmental authority on a territorial basis,

\footnotetext{
${ }^{181}$ It should be noted that the exclusion mechanism gives expression in cyberspace to the special protection that is established for famous trademarks in the Paris Convention for the Protection of Industrial Property and the TRIPS Agreement. However, an exclusion would cover only the exact name of the famous mark, and as experience shows that cybersquatters register many close variations of famous marks, an exclusion, once granted, should give rise to an evidentiary presumption in the administrative procedure. The effect of the evidentiary presumption would to place the burden of proving justification for the use of a domain name on holder the domain name where the domain name is identical or misleadingly similar to the famous or well-known mark and the domain name is being used in a way that is likely to damage the interests of the owner of the mark. WIPO, the Management of Internet Names and Addresses: Intellectual Property Issues, Interim Report of the WIPO Internet Domain Name Process, <http://www.wipo.int/amc/en/processes/process1/rfc/3/interim2_ch1.html> accessed 26 November 2016.

${ }^{182}$ Registering a domain name completely identical with a registered famous trademark is called (Domain Name Piracy) or (Cybersquatting). For more information see: Michael Chissick and Alistair Kelman, Electronic Commerce: law and practice, third edition, London, Sweet \& Maxwell, 2002, p24.

${ }^{183}$ WIPO, the Management of Internet Names and Addresses: Intellectual Property Issues, Interim Report of the WIPO Internet Domain Name Process, <http://www.wipo.int/amc/en/processes/process1/rfc/3/interim2_ch1.html> accessed 26 November 2016.
} 
while the domain names registration system is usually administered by a non-governmental organization without any functional limitation. ${ }^{184}$

Actually, there is no doubt that the double function of domain names, such as internet address and distinctive trademark created several forms of the conflicts between domain names and trademarks via cyberspace. One of these disputes called "cybersquatting", for instance, the abusive registration of trademarks for the purpose of reaping money from the trademark owner. ${ }^{185}$ Other different types of the domain names disputes are also arisen these days via the cyberspace, such as, Typosquatting ${ }^{186}$ and Cybersmearing. ${ }^{187}$ Thus, on 24 August 1999, ICANN introduced the Uniform Dispute Resolution Policy (UDRP), as a model alternative dispute resolution process for settling disputes relating to bad faith domain name registrations in the existing domain names. ${ }^{188}$ In addition, the new gTLD Program allowed for the registration of trademarks as TLDs, however, ICANN set up several right protection mechanisms to assist trademark owners in preventing third parties to register their trademarks under a new gTLD. "Some of these right protection mechanisms will be available to trademark owners in the pre-delegation phase, whereas other mechanisms will apply after the delegation of the gTLD". ${ }^{189}$ Indeed, the pre-delegation phase is by presenting formal objections on the applications to register a new gTLD, which will be resolved through a using independent dispute resolution services, by Dispute Resolution Service Providers (DRSPs), ${ }^{190}$ while the post delegation phase is by presenting a complaint, which will also be resolved through using an independent dispute resolution procedure, which is called Trademark Post-delegation Dispute Resolution Procedure (Trademark PDDRP). ${ }^{191}$

\footnotetext{
184 Ibid.

${ }^{185}$ Ida Madieha Azmi, Domain Names and Cyberspace: the Application of Old Norms to New Problems, International Journal of Law and Information Technology, Vol.8, no.2, 2000, p 194.

${ }^{186}$ Aaron Schwabach, Internet and the Law: Technology, Society, and Compromises, ABC-CLIO, California/USA, 2014 , p 59.

187 Jonathan Armstrong, Mark Rhys-Jones, and Daniel Dresner, Managing Risk: Technology and Communications: Managing Risk Series, Taylor \& Francis, 2004, p 69.

${ }^{188}$ ICANN, Uniform Domain Name Dispute Resolution Policy, August 26, 1999, <https://www.icann.org/resources/pages/policy-2012-02-25-en > accessed 12 December 2016.

${ }^{189}$ Allen and Overy, the new gTLDs: What do trademark owners need to know? , <www.allenovery.com/SiteCollectionDocuments/The\%20new\%20gtlds.pdf > accessed 13 December 2016.

${ }^{190}$ Karjiker, the New gTLDs and the Resolution of Trade Mark Disputes, <blogs.sun.ac.za/iplaw/files/2016/04/Thenew-gTLDs-and-the-resolution-of-trade-mark-disputes.pdf > accessed 10 December 2016.

191 ICANN, Understanding Post-Delegation Dispute Resolution Procedures, < https: //newgtlds.icann.org/en/program-status/pddrp > accessed 13 December 2016.
} 
The first section of this chapter examines the phenomenon of Cybersquatting, other types of domain name disputes, and the mechanism of the domain names disputes settlements under the ICANN's UDRP as a model for domain names disputes settlement. The second section of this chapter shows the challenge of new gTLD disputes and provides the reader with a roadmap to the controlling legal tools that may apply to new gTLDs disputes under ICANN's DRSPs and Trademark PDDRP, by focusing only on the protection of trademarks in the New gTLD Program, the pre-delegation and post-delegation of dispute resolution and will be considered as it is the most important legal approach for trademark owner. In addition, the second section of this chapter also studies the ICANN's WHOIS service as well as the ICANN's jurisdiction.

\subsection{Basic Understanding of Cybersquatting}

The term "cybersquatting" consists of two main words cyber and squat. Cyber means "relating to or characteristic of the culture of computers, information technology, and virtual reality", ${ }^{192}$ while the squat is "to live in a building or on land without the owner's permission and without paying." 193 In the same way, cybersquatting is "the registration of a commercially valuable Internet domain name, as a trademark, with the intention of selling it or profiting from its use." ${ }^{194}$

Prof. Vandana remarks that "Cyber-squatting occurs when domain names bearing a resemblance to famous trademarks are registered by persons, those hopes to sell the registration to a corresponding trademark holder. Typically, in such cases, persons who have absolutely nothing to do with the name, virtually pirate the name by obtaining a SLD, (like word 'Google' from 'google.com') registration with the '.com' top level domain name, TLD of a well-known company or brand." ${ }^{195}$

\footnotetext{
192 Oxford Living Dictionaries, Cyber, < https://en.oxforddictionaries.com/definition/cyber> accessed 15 December 2016.

193 Merriam-webster, Definition of Squat, < https://www.merriam-webster.com/dictionary/squat> accessed 15 December 2016.

${ }^{194}$ Dictionary.com, Cybersquatting, < www.dictionary.com/browse/cybersquatting?s=t > accessed 16 December 2016.

195 Vandana Kadam, Analytical Study of Domain Name System, its Disputes and Legal Issues, 2013, <www.bvimsr.com/documents/publication/NCIT2013/23.pdf > accessed 16 December 2016.
} 
Cybersquatting has been also defined with broad meaning as "the deliberate, bad-faith, and abusive registration of Internet domain names in violation of the rights of trademark owners" ${ }^{196}$ Generally, the cybersquatter "intends to profit from the sale of rights in the domain name at an inflated price". ${ }^{197}$ A variation on this practice is typosquatting, "when a party registers a domain name that is very close to another's trademark or name for the purpose of capitalizing on an Internet user's typographical errors when entering a web address." 198 "This variation falls into the larger category of cybersquatting for the purpose of traffic diversion, in which the cybersquatter registers a misspelling, pluralization, or other obvious derivation of another's mark in order to divert traffic to some web site other than the one sought by the consumer." 199

Under this variation, which falls into the larger category of cybersquatting, there are a number of practical types of cybersquatting that deserve attention. These variations include "typosquatting", "classic cybersquatting", "cyberpiracy", and "pseudo cybersquatting". The "classical cybersquatting" is the simple registration of a domain name established on a trademark with the faith to sell it to the real owner of the trademark to get a payoff. ${ }^{200}$ "Cyberpiracy" is considered by integration of trademarks in domain names with the intention of attracting more traffic to the collection of related web pages ascertained with a common domain name. ${ }^{201}$ While the "pseudo cybersquatting", is considered by registering a domain name without even using it or connecting it with any online webpages or active website. These are called also "blocking registrations", the target of such registrations is to prohibit the legitimate right proprietors from using the domain names. ${ }^{202}$

All the above acts are considered as different subcategories of "cybersquatting". ${ }^{203}$ In other words, the misappropriation of trademarks via cyberspace is a mounting dilemma for trademark proprietors.

\footnotetext{
${ }^{196}$ Brian Holland, Tempest in a Teapot or Tidal Wave? CyberSquatting Remedies Run Amok, Journal of Technology Law and Policy Vol. 10, 2005, p 307.

197 Ibid.

198 Ibid.

199 Ibid.

${ }^{200}$ Pantov Ventsislav, the Prevention of Cybersquatting in Europe: Diverging Approaches and Prospects for Harmonization, Munich Intellectual Property Law Center (MIPLC) Master thesis, 2012, p6.

${ }^{201}$ Ibid p7.

${ }^{202}$ Ibid.

${ }^{203}$ Ibid.
} 
In 1999 s, this activity became a significant dilemma in the USA. ${ }^{204}$ "In some cases, the prices that cybersquatters demand for selling domain names are very high. For example, (AltaVista.com) was sold for \$ 3.3 million and (HeraldSun.com) was sold for \$ 2.5 million.”205

Companies were struggling to put themselves on the cyberspace, which launched a pipeline for cybersquatters. ${ }^{206}$ To the extent that it is seen as a dilemma, and can be addressed in three main scenarios:

In the first scenario, the trademark proprietor could simply try to buy the domain name from the alleged cybersquatter. On the other hand, it hardly seems as a suitable solution for most trademark proprietors who consider they must protect their trademarks and should not give in to the demands of cybersquatters.

In the second scenario, the trademark proprietor could raise a lawsuit based on violating rules of the national legislations of trademarks, unfair competition and other related legislation. ${ }^{207}$

In the third scenario, the trademark proprietor could refer to the international cyber arbitration regime put in place by ICANN. ICANN introduced the Uniform Dispute Resolution Policy (UDRP), as a model ADR process for settling disputes relating to bad faith domain name registrations in the existing domain names. ${ }^{208}$

The ICANN adapted in August 1999 a Uniform Disputes Resolution Policy. ${ }^{209}$ UDRP states that any person or entity with rights in a trademark may initiate an administrative dispute resolution

\footnotetext{
${ }^{204}$ A CMS IP Group Publication, Protection of Trade Marks: Online Use and Anticybersquatting, A European Perspective, <docplayer.net/10942010-Protection-of-trade-marks-online-use-and-anticybersquatting.html> accessed 20 September 2015.

205 Ibid.

${ }^{206}$ Wayne Overbeck, and Genelle Belmas, Major Principles of Media Law, Cengage Learning, 2011, p 305.

${ }^{207}$ Such as the ACPA in the U.S.

${ }^{208}$ ICANN, List of Approved Dispute Resolution Service Providers, < http://www.icann.org/udrp/approvedproviders.htm > accessed 16 December 2016.

${ }^{209}$ The UDRP is based on recommendations made by WIPO Internet in the report. On the first WIPO Internet Domain Name Process caused by the conflict between domain name and trademark. Also a number of further issues identified in that report that were considered to be outside the second WIPO Internet Domain Name Process. Tunkel, and York, E-commerce: A Guide to the Law of Electronic Business, p186.
} 
proceeding by submitting a complaint to one of the seven ICANN approved dispute resolution service providers: ${ }^{210}$

1. Asian Domain Name Dispute Resolution Center (ADNDRC);

2. The World Intellectual Property Organization (WIPO);

3. The National Arbitration Forum (NAF);

4. E-Resolution;

5. The CPR Institute for Dispute Resolution;

6. Arab Center for Domain Name Dispute Resolution (ACDR);

7. The Czech Arbitration Court Arbitration Center for Internet Disputes.

However, the following are common samples of cybersquatting phenomenon which settled by ICANN's UDRP through WIPO.

\subsubsection{Registering a Domain Name Completely Identical with a Registered Trademark (Domain Name Piracy) (Cybersquatting)}

In such form of domain name dispute, one might register a trademark, which belongs to a famous international firm as a domain name, and tries to obtain by threatening such firm through asking it to pay large amounts of money in order to assign the registered domain name or transfer it to the firm. ${ }^{211}$ For example: registering the domain name of www.toyota.com, www.adidas.com and Www.burgerking.com. ${ }^{212}$

In the Philip Morris Incorporated v. r9.net, WIPO Case, the Marlboro marks are the most widely recognized trademarks in the United States. Complainant (Philip Morris USA) developed

\footnotetext{
${ }^{210}$ ICANN), List of Approved Dispute Resolution Service Providers, < http://www.icann.org/udrp/approvedproviders.htm > accessed 16 December 2016.

211 Chissick, and Kelman, Electronic Commerce: Law and Practice, p24.

212 One in a Million, United Kingdom Case, was in the 1998, in this case the Court of Appeal held that the practice of registering the names and trademarks of well-known companies as domain names, and then attempting to sell them to the companies or anyone else prepared to pay a handsome fee, constituted a threat of trademark infringement and passing off. One in a Million and Global Media Communications were therefore ordered to assign the domain names over to the relevant companies.

It is imperative to note here that in the One in a Million Case the motive for the registrations was to extract money from the owners of the goodwill in the registered names by threatening to exploit the goodwill, either by trading under the names or selling the names to another to use. This case is the first in United Kingdom, see British Telecommunications PLC \& Ors v One In A Million \& Ors Court of Appeal 23.7.98. Tunkel, and York, E-commerce: A Guide to the Law of Electronic Business, p189.
} 
significant goodwill in these marks. On March 6, 2000, respondent registered <marlboro.com> through ICANN. The complainant alleged that respondent had misappropriated complainant's famous Marlboro Marks, and that the domain name was confusingly similar to the Marlboro marks because the disputed domain name completely included the MARLBORO® mark. Furthermore, the complainant alleged that respondent had no rights or legitimate interests in the disputed domain, and used the domain in bad faith. On other side, the respondent did not reply to the complainant's contentions. In this case, the panelist decided to transfer the domain name (www.marlboro.com) to the complainant company (Philip Morris Company). ${ }^{213}$ As the panelist recognized in its decision that the respondent registered a domain name (www.marlboro.com) completely identical with a complainant's famous Marlboro marks, the purpose of the respondent from that was to exploit the goodwill of Marlboro marks, either by trading under the famous Marlboro mark or selling the famous Marlboro mark to another to use it.

\subsubsection{Registering a Domain Name Largely Similar to a Registered Trademark (Typosquatting)}

Amber Bennett notes that typosquatting occurs "when someone buys a domain name that is similar to another domain name with small typos that people commonly make. This type of cybersquatting relies on common typos made by users." ${ }^{214}$ The typosquatter uses a trick or deception in registering a domain name largely similar or close to the famous trademark, ${ }^{215}$ with a slight modification or small typos on some letters of the trademark, that typosquatter commonly make.

213 WIPO Case No. D2003-0004. The Complainant is Philip Morris Incorporated ("Philip Morris"), Barry M. Krivisky, Esq., 800 Westchester Avenue, Rye Brook, NY 10573-1301, USA, represented by Arnold \& Porter of USA. The Respondent is r9.net of Dallas, Texas, USA. Philip Morris manufactures, markets and sells cigarettes, including cigarettes under its MARLBORO® trademark. MARLBORO® cigarettes have been made and sold by Philip Morris (and various predecessor entities) since 1883. For many decades, Philip Morris USA has used the MARLBORO ${ }^{\circledR}$ mark in connection with its tobacco and smoking related products. Philip Morris USA also sells cigarettes under variations of this MARLBORO® mark including, without limitation, MARLBORO LIGHTS ${ }^{\circledR}$ and MARLBORO® LIGHTS MENTHOL cigarettes. The MARLBORO® mark and these and other numerous variations of the mark are referred to herein as the "Marlboro Marks." WIPO Case No. D2000-1106. WIPO, Search WIPO Cases and WIPO Panel Decisions/ WIPO Case No. D2003-0004, 2003,<http://www.wipo.int/amc/en/domains/decisions/ html/2003/d2003-0004.html> accessed 20 September 2015.

${ }^{214}$ Amber Bennett, Cybersquatting, 2015, <http://campus.murraystate.edu/academic/faculty/wlyle/540/2015/ BennettPaper.docx $>$ accessed 20 September 2015.

${ }^{215}$ It is very important to note that this registration of domain names is not identical as in the first type mentioned above. Schwabach, Internet and the Law: Technology, Society, and Compromises, p 59. 
In other words, typosquatting is an activity of registering domain names involving misspelt trademarks. ${ }^{216}$ Individuals registered unlawfully these domain names to attract cyberspace users. ${ }^{217}$ As cyberspace users normally make spelling typos, for example, typing a domain name (amazone.com) instead of (amazon.com). ${ }^{218}$

It is very important to note that the registrants "typosquatters" can also gain money "from selling the rights to use a given domain name to a trademark owner, who will buy it in order to regain control over customers." ${ }^{219}$ The following are some examples in respect of typosquatting activity;

- Registering a domain name www.microosoft.com, adding other (o) to the wellknown trademark Microsoft.

- Registering a domain name www.wwwhotmail.com, adding another (www) to the well-known trademark hotmail.

- Registering a domain name yafoo.com, placing of the letter (f) instead of (h).

In Shell International Petroleum Company Limited, Shell Trademark Management B.V. v. Domains - Best Domain, WIPO Case, the respondent registered the domain name <wwwshell.com> through ICANN. The respondent has linked the domain name to the "abortionismurder.org" website. The complainant states that the domain name is confusingly similar to the "SHELL" trademark. The complainant also challenges that respondent is an ordinary cybersquatter who has continually linked domain names that are confusingly similar to wellknown trademarks to the "abortionismurder.org" website. Furthermore, the complainant argue that respondents have no right or legitimate interest in using the domain name and submit that the respondent registered and used the domain name in bad faith as evidenced by the fact that respondent offered to sell the domain name for $\$ 549.000$ after complainants sent a cease letter to

${ }^{216}$ A CMS IP Group Publication, Protection of Trade Marks: Online Use and Anticybersquatting, A European Perspective <docplayer.net/10942010-Protection-of-trade-marks-online-use-and-anticybersquatting.html> accessed 20 September 2015.

${ }^{217}$ Ibid.

${ }^{218}$ Ibid.

${ }^{219}$ Ibid. 
respondent. The respondent also did not reply to the complainant's contentions. In this case, the panelist decided to transfer the domain name (www.wwwshell.com) to the complainants. ${ }^{220}$

Indeed, it is clear that registered a domain name (www.wwwshell.com) largely similar with a complainant's famous trademark, and used a trick or deception in registering a domain name by adding another (www) to the complainant's famous trademark "SHELL", the motive of the respondent from that was to avoid cancellation of his domain name if he registered it identical to a trademarked name complainant. ${ }^{221}$

\subsubsection{Registering a Trademark as a Domain Name to Express the Dissatisfaction with a Product or Service Provided by a Certain Corporation (Cybersmearing) (Derogatory Domain Names) ${ }^{222}$}

Broadly speaking, cybersmearing is the smearing the commercial firms online (via cyberspace) and it can take various forms including, domain name, website, and email. ${ }^{223}$ Cybersmearing is "when domain names are registered which contain trademarks joined to other words with negative connotations." 224 Individuals who want to present a trademark in a negative appearance may use this practice. ${ }^{225}$

\footnotetext{
${ }^{220}$ WIPO Case No. D2003-0066. The Complainants are Shell International Petroleum Company Limited, Shell Center, London, SE1 7NA, United Kingdom of Great Britain and Northern Ireland; and Shell Trademark Management B.V., Carel van Bylandtlaan 30, 2596 HR, The Hague, Netherlands. The Complainants are represented by Kimbley L. Muller of Shell Oil Company, USA. The Respondent is Domains - Best Domain, of the Bronx, NY 10471, of the USA. The complainants are affiliated companies operating within the world-wide Royal Dutch Shell group of companies. The complainants are the proprietors of over 4,027 registered trademarks throughout the world which comprise the word SHELL and 3,221 additional registrations of which the word SHELL is the dominant feature. SHELL trademarks have been used since at least as early as 1904 on a variety of goods and services including, but not limited to, petroleum goods and services, gasoline, motor oil, chemicals, credit card services, gasoline stations and convenience stores, foodstuffs, apparel, Internet services and Information Technology services. SHELL is one of the most popular gasoline brands in the world with over 45,000 sites world-wide serving approximately twenty million customers per day.

WIPO, Search WIPO Cases and WIPO Panel Decisions/ WIPO Case D2003-0066, 2003, <http://www.wipo.int/amc/en/domains/decisions/html/2003/d2003-0066.html> accessed 20 September 2015.

${ }^{221}$ Ibid.

222 WIPO, Search WIPO Cases and WIPO Panel Decisions/ WIPO Case D2003-0596, 2003, <http://www.wipo.int/amc/en/domains/decisions/html/2003/d2003-0596.html> accessed 20 September 2015.

${ }^{223}$ Armstrong, Rhys-Jones, and Dresner, Managing Risk: Technology and Communications: Managing risk series, p69.

${ }^{224}$ A CMS IP Group Publication, Protection of Trade Marks: Online Use and Anticybersquatting, A European Perspective <docplayer.net/10942010-Protection-of-trade-marks-online-use-and-anticybersquatting.html> accessed 20 September 2015.

${ }^{225}$ Ibid.
} 
Commonly, worker who has been dismissed from his or her job or a consumer who is dissatisfied with the quality and feature of the goods or services of the firm, might register the most wellknown trademark of the certain firm as domain name and add the suck suffix to it and he will register a complete website for that target. ${ }^{226}$

In very simple words, cybersmearing occurs when one of the previous consumers of a firm, wants to state his annoyance and anger regarding some of the goods or services produced by that firm, however; the purpose from that is simply to make the consumers not dealing with goods or services bearing that trademark of the firm by insulting or damages the reputation of such trademark. The following are some examples in respect of cybersmearing activity: ${ }^{227}$

- $\quad$ www.ihatetoyotta.com to negatively affect the reputation of the trademark Toyota.

- $\quad$ www.boycott.cocola.com to negatively affect the reputation of the trademark Coca-Cola.

- $\quad$ www.toyottasuck.com to insult the reputation of the trademark Toyota.

One might register a trademark owned by the firm as a domain name with addition of a short syllable before the name Toyota (www.ihatetoyota.com) or after the name Coca-Cola (www. boycott.cocola.com). Such these suffixes are intending to strictly harm the firm, it is also possible for anyone in the website, he established, to claim false allegations which negatively affect the reputation of the firm..$^{228}$

However, a number of cases have been filed in front of the WIPO center by adding "suck" suffix websites.

In Koninklijke Philips Electronics N.V. v. In Seo Kim, WIPO Case, ${ }^{229}$ the complainant has registered "Philips" as a famous trademark in numerous countries. On January 8, 2000, the respondent registered the domain name together with 14 other domain names ending in

\footnotetext{
${ }^{226}$ Rami Olwan, the Case of Suck Domain Names and Cyber-smearing Examination of Suck Cases with the WIPO Arbitration and Mediation Center, < docshare01.docshare.tips/files/390/3901550.pdf > accessed 20 September 2016. ${ }^{227}$ Ibid.

${ }^{228}$ Ibid.

${ }^{229}$ WIPO Case No. D2001-1195.The parties are Koninklijke Philips Electronics N.V. of Groenenwoudseweg 1, 5621 BA Eindhoven, The Netherlands "Complainant" and In Seo Kim of 213-4501 North Road Burnaby, B.C. V3N 4R7 Canada "Respondent".The Complainant is a very well-known manufacturer and supplier of electrical and electronic goods. Its primary branding is its name "Philips" and a logo incorporating this name. WIPO, Search WIPO Cases and WIPO Panel Decisions/ WIPO Case D2001-1195, 2001, <http://www.wipo.int/amc/en/domains/decisions/html/2001/d2001-1195.html> accessed 20 September 2015.
} 
<sucks.com>. The complainant challenge that the domain name <philipssucks.com> is confusingly similar to its registered trademark "Philips", and the respondent has no rights or legitimate interest in using it, and that the respondent registered and is using the domain name in bad faith in order to disrupt the complainant's business. The complainant refers in particular to the respondent's registration of a series of domain names comprising a well-known brand followed by $<$ sucks.com>." In this case the panel decided that the domain name <philipssucks.com> should be transferred to the complainant. ${ }^{230}$

Some authors might argue that establishing derogatory domain name, such as <philipssucks.com> is incorporated under the framework of freedom of speech, however; the registrant aims to affect negatively over the reputation of the complainant's company. The panelist states the respondent registered a famous trademark "Philips", which owned by the complainant company, as a domain name <philipssucks.com> with addition obscene word after the name Philips <philipssucks.com>, (notice addition of the word (suck) to the domain name <philips.com>), the motive from that was to harm the complainant company and express the dissatisfaction with a products or services provided by a complainant company which harmfully affect the renown of the complainant's company. ${ }^{231}$

\footnotetext{
${ }^{230}$ Ibid.
}

${ }^{231}$ Ibid. 


\subsubsection{The Attempt to Deprive a Properly Registered Domain Name Holder from the Domain Name that he registered (Reverse Domain Name Hijacking) $)^{232}$}

Michael Rustad remarks that "Reverse Domain name Hijacking can occur when a trademark owner attempts to secure a domain name by making false cybersquatting claims against a domain names rightful owner using a trademark registration as leverage."233

The proprietor of a registered trademark brings a complaint before one of the domain name dispute resolution arbitration panels ${ }^{234}$ demanding to deprive the owner of the properly registered domain name from his domain name. The claimant or plaintiff does not depend on acceptable justification, which authorizes the acceptance of his demand (except for his trademark registered as a domain name; this might not be sufficient to get back the registered domain name). The claimant knows that the registrant of the domain name has the full right in his registration and that he did not infringe upon the registered trademark.

Nevertheless, the claimant insists on raising the complaint. When the mala fide of this person has been confirmed by the arbitration panel to which the claim has been raised, such panel shall judge that the action of such person constitutes an infringement on the dispute resolution procedures and his application shall be rejected. ${ }^{235}$

In Goldline International Inc and Gold Line, WIPO Case ${ }^{236}$ the required "bad faith" registration and use of the domain name "goldline.com" was claimed by the complainant primarily because of a claimed likelihood of confusion with the complainant's name, even though the two businesses

\footnotetext{
${ }^{232}$ Reverse Domain Name Hijacking is defined under the UDRP Rules as "using the UDRP in bad faith to attempt to deprive a registered domain-name holder of a domain name." WIPO, Search WIPO Cases and WIPO Panel Decisions/ WIPO Case D2016-1975, 2016, <http://www.wipo.int/amc/en/domains/decisions/text/2016/d2016-1975.html> accessed 28 December 2016.

${ }^{233}$ Michael Rustad, Global Internet Law, West Academic, 2013, p 746-747.

${ }^{234}$ Approved by ICANN.

${ }^{235}$ Gregory Battersby, and Charles Grimes, Trademark \& Copyright Disputes: Litigation Forms and Analysis, Aspen Publishers Online, 2003, p 205.

${ }^{236}$ WIPO Case No. (D2000-1151). The complainant, Goldline International, was a business dealing in goods and services relating to coins and precious metals. The respondent, Gold Line Internet, was the business name for an individual who ran a consulting business specializing in intellectual property, including intellectual property arising from the use of vanity domain names and 800 telephone numbers.

WIPO, Search WIPO Cases and WIPO Panel Decisions/ WIPO Case D2000-1151, 2000, <http://www.wipo.int/amc/en/domains/decisions/html/2000/d2000-1151.html> accessed 25 January 2016.
} 
had nothing to do with each other and were unlikely to be confused with each other in reality. Moreover, the panel found that the respondent had brought this and other facts undermining the case, to the complainant's attention before the case was commenced. The panel held that the complainant's actions in this case constitute bad faith. Prior to filing its complaint, complainant had to know that complainant's mark was limited to a narrow field, and that respondent's registration and use of the domain name could not, under any fair interpretation of the facts, constitute bad faith. Moreover, the respondent put the complainant on express notice of these facts and that any further attempt to prosecute this matter would be abusive and would constitute reverse domain name "hijacking". Accordingly, the panel finds that complainant has engaged in reverse domain name hijacking. ${ }^{237}$

In short, "Reverse Domain Name Hijacking" is a method used by a complainant in bad faith to attempt to deprive a registered domain name holder of a domain name. This bad faith can arise under many circumstances, including when confusion is unlikely, when the complainant fails to disclose certain facts and when a domain name registrant has not used a domain name. Such panel shall judge that the action of such complainant constitutes an abuse of the administrative proceeding and his application shall be rejected.

\subsubsection{Inadvertent Failing to Renew Registration of Domain Name}

Generally speaking, when a certain firm registers a domain name, such firm does not own the name of the registered domain, and it has to renew its registration and pay the due yearly fees according to the contractual relationship between the registrar and registrant complete, ${ }^{238}$ as prior mentioned. Thus, if the firm fails to renew its domain name registration, ${ }^{239}$ one might try to take advantage of the non-renewal of the domain name and register the trademark belonging to the firm in his or her name as a domain name and then will suggest assigning the domain name in return of large

\footnotetext{
${ }^{237}$ Ibid.

${ }^{238}$ Domain Name Registration Agreement.

${ }^{239}$ If the firm fails to pay the registration fees in order to renew its domain name registration, the registrar , after sending an e- mail to the registrant to inform him that he must renew his registration, shall confer upon the domain name to any other person capable of paying the registration fees. Gerald Levine, Right of Trademark Owner to Recapture Domain Name after Inadvertent Lapse of Registration, 2008, <https://www.lexisnexis.com/legalnewsroom/ intellectual-property/b/copyright-trademark-law-blog/archive/2008/06/09/right-of-trademark-owner-to-recapturedomain-name-after-inadvertent-lapse-of-registration.aspx?Redirected=true\#sthash.GAzR78Ry.dpuf> accessed 25 January 2016.
} 
amounts of money. ${ }^{240}$ For instances, Philip Morris company was unintentionally failing to renew the registration of its trademark (Marlboro) as a domain name for one reason or another. A cybersquatter took advantage of this, and then registered the trademark in his or her name as a domain name. The cybersquatter will absolutely resell the domain name in return of large amounts of money.

However, in many cases such cybersquatting activity occurs with owners of weak trademarks. It happens, because these trademarks are not famous and their owners are also not in the full sense of the term. While the proprietors of strong trademarks have an advanced degree of attention from inadvertent failing to renew registration of a domain name. ${ }^{241}$

Gerald Levine observed that according to the general rule, if a domain name has expired and has not been renewed, thus that does not give the right for the cybersquatter to use a famous trademark as domain name simply, because such use could confuse the customers and harm to the trademark holder. Likewise, the trademark owner who is claiming unregistered rights on domain name shall carry a heavier burden in front of the panel. ${ }^{242}$

In Donna Karan Studio v. Raymond Donn, WIPO Case, ${ }^{243}$ the domain name registration of (dknyjeans.com) has expired and the trademark owner was inadvertently failing to renew registration of domain name, and then the respondent (cybersquatter) has registered it. The panel held that "that the domain name with the same trademark had expired does not mean that the Respondent has any right to use a well-known trademark as its domain name when such use could cause confusion to consumers and damage to the owner of the trademark." 244 Accordingly, the panel decided that the domain name must be transferred to the complainant. ${ }^{245}$

\footnotetext{
${ }^{240}$ Ibid.

241 Gerald Levine, Failing to Renew Registration: Difficulty of Recapturing Lapsed Domain Names, 2012, <https://www.iplegalcorner.com/failing-to-renew-registration-difficulty-of-recapturing-lapsed-domain-names/> accessed 25 January 2016.

242 Levine, Right of Trademark Owner to Recapture Domain Name after Inadvertent Lapse of Registration, <https://www.lexisnexis.com/legalnewsroom/intellectual-property/b/copyright-trademark-lawblog/archive/2008/06/09/right-of-trademark-owner-to-recapture-domain-name-after-inadvertent-lapse-ofregistration.aspx?Redirected=true\#sthash.GAzR78Ry.dpuf $>$ accessed 25 January 2016.

${ }^{243}$ D2001-0587 (WIPO June 27, 2001)

WIPO, Search WIPO Cases and WIPO Panel Decisions/ WIPO Case D2001-0587, 2001, < http://www. wipo.int/amc/en/domains/decisions/html/2001/d2001-0587.html> accessed 28 January 2016.

244 Ibid.

245 Ibid.
} 


\subsubsection{Registering a Trademark of a Competitor as a Domain Name (Competing Use) or Registering a Trademark of Non-Competitor as a Domain Name (Non-Competing Use)}

Actually, another cybersquatting activity is happened when one competitive company registers a competitor trademark as a domain name (competing use). Both firms are direct competitors, in the same field or providing the same goods and products, and one of them registers the trademark that belongs to the other company as a domain name in order to deprive it from registering its own trademark as a domain name ${ }^{246}$ For example, if (Pepsi's) company registered the domain name (www.cococal.com). Under this example, it is clear that both companies provide a soft drink, but Pepsi's has registered the domain name that belongs to the other competitive company "Cococal" in order to deprive Cococal Company from registering its own trademark as a domain name. ${ }^{247}$

On the other hand, there is another type of the cybersquatting activity, such as registration a noncompetitor trademark as a domain name (non-competing use), where one company, of two noncompetitive companies (in different fields or they serve different products and services), register the trademark that belongs to the other non-competitive company as a domain name in order to deprive it from registering its own trademark as a domain name "such as an offer to sell or an intent to block the trademark holder from using the name." ${ }^{248}$ For example, if (Kodak) company for film registered a domain name, such as (Burgerking.com), which belongs to another trademark, owned by a non-competitive company (Burgerking), and serves different products.

In SAFE Credit Union v. Mike Morgan, WIPO Case, ${ }^{249}$ both firms were competitors in the payper-click website. Further, respondent used the domain name for a pay-per-click website advertising links to competing and non-competing products and services at the same time. As a result, the panel ordered that the domain name <safecreditunion.org> must be transferred to

\footnotetext{
${ }^{246}$ Cyber Harvard, Domain Name Case Law, <https://cyber.harvard.edu/property00/domain/CaseLaw.html> accessed 29 January 2016.

${ }^{247}$ Another example, registering the domain name (channel.com) by the (Yves Laint Laurent) company. It is clearly noticeable that both companies' manufacture and produce perfumes, and that the company of (Yves Saint Laurent) had registered the trademark registered and owned by the company of (Channel) as a domain name. Ibid. 248 Ibid.

249 WIPO, Search WIPO Cases and WIPO Panel Decisions/ WIPO Case D2006-0588, 2006, <http://www.wipo.int/amc/en/domains/decisions/html/2006/d2006-0588.html> accessed 25 September 2015.
} 
complainant. ${ }^{250}$ In the light of the foregoing, it is important to note that the panel have decided against such behavior as the two activities existed in the same case.

In short, these two activities are very similar but the difference between them relies on the fact that both companies are non-competitive in the same field or competitive in the same field.

\subsection{ICANN's UDRP as a Model for Trademark Cybersquatting Disputes Settlement}

International dispute settlement between domain names and trademarks are the outcome of the effort of several bodies concerned with finding out-court solutions for the cybersquatting disputes and as such to satisfy some of the trademark owners concerns.

One of these bodies was ICANN, which is responsible for the administration of the "gTLDs" and "new gTLD". In August 1999, the ICANN adopted a UDRP. ${ }^{251}$ "As a way of preventing cybersquatters from purposefully registering someone else's trademark or service mark as a domain name, and then using bad faith tactics to sell that domain name registration to the trademark owner or its competition at a vastly inflated price, the UDRP has compelled those who register their domain name to also incorporate by reference into the registration agreement specific terms and conditions by which disputes can be appropriately resolved between the entity registering the domain name, and any party who believes they will be injured by such registration. Proceedings are governed by the rules for uniform domain name dispute resolution which are available on the ICANN website." 252 UDRP states that any person or entity with rights in a trademark may initiate an administrative dispute resolution proceeding by submitting a complaint to one of the seven ICANN approved dispute resolution service providers: ${ }^{253}$

1. Asian Domain Name Dispute Resolution Center (ADNDRC);

2. The World Intellectual Property Organization (WIPO);

\footnotetext{
${ }^{250}$ Ibid.

${ }^{251}$ The UDRP is based on recommendations made by WIPO Internet in the report. On the first WIPO Internet Domain Name Process caused by the conflict between domain name and trademark. Also a number of further issues identified in that report that were considered to be outside the second WIPO Internet Domain Name Process.

Tunkel, and York, E-commerce: A Guide to the Law of Electronic Business, p 186.

${ }^{252}$ Howard Rockman, Intellectual Property Law for Engineers and Scientists, John Wiley \& Sons, 2004, p 463.

${ }^{253}$ ICANN, List of Approved Dispute Resolution Service Providers, < http://www.icann.org/udrp/approvedproviders.htm > accessed 16 December 2016.
} 
3. The National Arbitration Forum (NAF);

4. E-Resolution;

5. The CPR Institute for Dispute Resolution;

6. Arab Center for Domain Name Dispute Resolution (ACDR);

7. The Czech Arbitration Court Arbitration Center for Internet Disputes.

"Unlike registration in the gTLDs, there is no obligation on part of the ccTLD administrators or registries to adopt the UDRP. On the contrary, it is left to them to decide whether to accept the UDRP, and if so to make it part of their registration agreement with the domain name registrant. The UDRP provides a mandatory administrative proceeding for the trademark owners to challenge domain names registered by others. The UDRP is meant to enable trademark owners to resolve domain name disputes without having to go to court. Questions of trademark invalidity are not within the preview of any UDRP proceedings. Certain ccTLDs has not yet developed a domain name dispute policy on their own, but rather has adopted the UDRP entirely as it is, and referred any case related to their ccTLDs to the WIPO's Arbitration and Mediation Center. The UDRP has been adopted by certain managers of ccTLDs in the following countries Namibia (.nu), Tuvalu (.tv), Samoa (.ws) and many other more." ${ }^{254}$

The majority of the ccTLDs ${ }^{255}$ have adopted ADR procedures that are dissimilar from UDRP and are designed to national needs, for instances, include CIRA's (.ca) dispute resolution process or Nominet's (.uk) Dispute Resolution Service. ${ }^{256}$ While some ccTLDs, such as the ccTLD registry for the United Arab Emirates (.ue) have implemented the UDRP, through WIPO's Arbitration and Mediation Center manages dispute procedures for these ccTLD registry. ${ }^{257}$

254 Olwan, the Case of Suck Domain Names and Cyber-smearing Examination of Suck Cases with the WIPO Arbitration and Mediation Center, <docshare01.docshare.tips/files/390/3901550.pdf > accessed 20 September 2016.

255 The WIPO Arbitration and Mediation Center was requested by its Member States to develop, for the assistance of the administrators of ccTLDs, voluntary guidelines for the development of practices and policies to curb abusive and bad faith registration of protected names, and to resolve related disputes. This request was endorsed by the WIPO General Assembly, and subsequently led to the publication of the WIPO ccTLD Best Practices for the Prevention and Resolution of Intellectual Property Disputes. The Secretariat of the WIPO, Multilingual Domain Names, p 30.

256 Nominet, Policies and Rules, <http://www.nominet.uk/resources/policy/policies-rules/\#drspolicy> accessed 27 September 2016.

${ }^{257}$ ICANN, Uniform Domain Name Dispute Resolution Policy,

<https://www.icann.org/resources/pages/help/dndr/udrp-en > accessed 12 December 2016. 
To sum up, the UDRP Policy sets out the legal framework for the resolution of disputes between a domain name registrant and a third party, over the abusive registration and use of an Internet domain name in the gTLD or new gTLDs, and some ccTLDs that have adopted the UDRP Policy on a voluntary basis. ${ }^{258}$ In addition, the ICANN's UDRP is also applicable to all New gTLDs (e.g, (.xyz), (.top), (.win), etc). ${ }^{259}$

\subsubsection{The Dispute Resolution Mechanism for Cybersquatting under ICANN's UDRP}

In general, each cybersquatting dispute under the UDRP should normally be resolved within 60 days of the date the WIPO Center receives the complaint. ${ }^{260}$ However, the applicability of the UDRP stems from the registrant's consent. When a registrant of domain name is keen to register a trademark as a domain name under ICANN policy, that person is asked to enter into a contract incorporating the terms of the dispute policy. ${ }^{261}$

The registration of a domain name does not mean that the registrant or holder of the domain name is protected from threat of cancellation or transfer of its domain name. Such registered domain name can be identical or confusingly similar to a famous trade or service mark. Most of conflicts between domain names and trademarks "cybersquatting" via cyberspace are represented in registering identical or similar domain names with them. As a result, the owner of the famous trademark may consider that as a violation of his right and constitution conflicting between his trademark and registrant's domain name. In this case, the owner of the famous trademark may initiate a proceeding under the UDRP.

Essentially, the trademark owner must prove, ${ }^{262}$ that the domain name registered is identical or confusingly similar to a trade or service mark in which the trademark owner has rights; the registrant has no rights or legitimate interests in respect of domain name registered; and the domain name has been registered and is being used in bad faith. ${ }^{263}$ Conversely, ICANN's UDRP panels

\footnotetext{
258 WIPO, Domain Name Dispute Resolution Service for Generic Top-Level Domains, <www.wipo.int/amc/en/domains/gtld/> accessed 12 March 2016.

${ }^{259}$ Ibid.

260 WIPO, WIPO Guide to the Uniform Domain Name Dispute Resolution Policy (UDRP), <www.wipo.int/amc/en/domains/guide/> accessed 12 March 2016.

${ }^{261}$ Smith, Internet Law and Regulation, p153.

${ }^{262}$ According to the ICANN's UDRP.

${ }^{263}$ Paragraph 4 (a) of the UDRP.
} 
can only decide to transfer or cancel the domain name or deny the complaint. Consequently, ICANN's UDRP is not the proper way for claiming damages or monetary remedies, simply because the powers granted to a panel applying the policy are merely reflecting the contractual provision embodied in the phase of registering the domain name. The UDRP stipulates that the domain name proceedings shall be conducted in the language of the Registration Agreement. Paragraph 11 of the UDRP (Language of Proceedings) provides:

“(a) Unless otherwise agreed by the Parties, or specified otherwise in the Registration Agreement, the language of the administrative proceeding shall be the language of the Registration Agreement, subject to the authority of the Panel to determine otherwise, having regard to the circumstances of the administrative proceeding.

(b) The Panel may order that any documents submitted in languages other than the language of the administrative proceeding be accompanied by a translation in whole or in part into the language of the administrative proceeding." 264

However, according to the paragraph 4 (a) of the UDRP, a trade mark's owner has the right to apply for one of the seven ICANN approved dispute resolution service providers by asking it to cancel or transfer of the registration of a domain name if three elements are met. These elements are: 265

1. the registered domain name is identical or confusingly similar to a trade or service mark in which the complainant has rights;

2. the registrant has no rights or legitimate interests in respect of domain name registered;

3. the domain name has been registered and is being used in bad faith.

In administrative proceedings, the claimant must "prove that each of these three elements are present in order to succeed his case to cancel or transfer a registered domain name". ${ }^{266}$

\footnotetext{
${ }^{264}$ Paragraph 11 of the UDRP.

265 Ibid.

${ }^{266}$ Remedies available under the UDRP, paragraph 3 are the transfer or cancellation, or otherwise making changes of the domain name. A UDRP panel decision to transfer or cancel a domain name will be implemented by the domain name registrar unless within ten business days, the domain name registrant files with the registrar official documentation evidencing the commencement of legal proceedings against the complainant in one of the jurisdiction to which the complainant has submitted under the UDRP rules of procedure.
} 


\subsubsection{Identical or Confusingly Similar}

According to this element, the complainant must prove that the domain name is identical or confusingly similar to his trade or service mark in order to succeed his case to cancel or transfer a registered domain name. ${ }^{267}$ However, the complainant has to satisfy the panelist that he has the rights of trade or service mark in his mark. These rights can be as a result of registration of that mark as well as rights that come even without formal registration. Moreover, it is significant to understand here that the panelist, before issuing the decision, must give attention to a number of factors, including:

1. the distinctive character of the name and the requirement that the domain name must be "identical or confusingly similar" to it;

2. the relationship between this distinctive character and use of the name in connection with goods or services in commerce; and

3. the location of the parties and the bearing that this may have on the acquisition of unregistered trademark rights. ${ }^{268}$

It is important to note that the location of the parties can be relevant for the determination whether the complainant has trademark rights. Paragraph 15(a) of the UDRP provides that the panel shall decide a complaint on the basis, inter alia, of "(...) any rules and principles of law that it deems applicable." The applicable law will depend on the facts of the case, including the location of the parties. This rule has allowed panels the flexibility to deal with disputes between parties with different nationalities concerning activity on a global medium. It is also a feature that has enabled complainants to seek protection for their names under trademark law, although they have not registered their names as a trademark or service mark in every country of the world. ${ }^{269}$

\footnotetext{
${ }^{267}$ Paragraph 4 of UDRP.

${ }^{268}$ The protection of personal names under the UDRP is discussed in the Report of the Second WIPO Internet Domain Name Process, dated September 3, 2001, under paragraphs 181-184. It is pointed out these relevant factors.

WIPO, Second WIPO Internet Domain Name Process: the Recognition of Rights and the Use of Names in the Internet Domain Name System, <www.wipo.int/amc/en/processes/process2/report/html/report.html >, accessed 10 September, 2015.

${ }^{269}$ Ibid.
} 
Moreover, the complainants are in most cases easily able to prove this element. For example, in Philip Morris Incorporated v. r9.net, ${ }^{270}$ the complainant claimed that the respondent had misappropriated complainant's famous Marlboro marks, and that the respondent's domain name "marlboro.com" was confusingly similar to the Marlboro marks because the disputed domain name completely incorporated the MARLBORO® mark. Furthermore, the complainant alleged that the respondent had no rights in the disputed domain. The evidence demonstrated that the complainant clearly had rights in a family of registered marks incorporating the MARLBORO ${ }^{\circledR}$ mark. In fact, the MARLBORO® mark was first registered 95 years ago in the United States, and apparently is among the most widely recognized trademarks in the USA. The panel found that the disputed domain name was identical or confusingly similar to complainant's registered marks. The complainant satisfied the panelist that he had the rights in his trademarks. These rights can be as a result of registration of that mark. Moreover, the panelist, before issuing the decision "to cancel or transfer a registered domain name", gave attention to the requirement that the domain name must be "identical or confusingly similar" to trademark in which the complainant has rights by studying the distinctive character of the mark "MARLBORO" and the relationship between this distinctive character and use of the mark in connection with goods or services in commerce. ${ }^{271}$

This topic was also discussed in Shell International Petroleum Company Limited, Shell Trademark Management B.V. v. Domains - Best Domain. In this case the complainant stated that the respondent's domain name is identical or confusingly similar to his trademark "SHELL". The evidence demonstrated that the respondent's domain name (wwwshell.com) is identical to complainant's trademark except for the addition of the letters "www" before the mark. Incorporating complainants' famous trademark with the letters "www" is likely to appear to Internet users as the domain name is identical to complainants' trademark, because most domain names include "www" followed by a dot before the SLD, and Internet users would most likely not

${ }^{270}$ WIPO Case No. D2003-0004. WIPO, Search WIPO Cases and WIPO Panel Decisions/ WIPO Case No. D20030004, 2015, <http://www.wipo.int/amc/en/domains/decisions/html/2003/d2003-0004 >, accessed 10 September, 2015.

${ }^{271}$ Ibid. 
notice the omission of the dot. Accordingly, the panel found that the domain name is confusingly similar to complainants' trademark "SHELL". 272

It is important to recognize that the complainant, also in this case, satisfied the panelist that he has the rights in his trademark "SHELL". These rights can be as a result of registration of that mark. Moreover, the panelist gave attention to the requirement that the domain name must be "identical or confusingly similar" to trademark in which the complainant has rights by studying the distinctive character of the mark and the relationship between this distinctive character and use of the mark in connection with goods or services in commerce.

Additionally, in John Swire \& Sons Limited v. David Huang, WIPO Case, the disputed domain name was "swiregroup.com". The complainant claims that respondent has registered the domain name which similar to complainant's trademarks "Swire", and that respondent has no rights in respect of the domain name. Consequently, the complainant requires the transfer of the domain name registration to the complainant. The panel therefore found the domain name is confusingly similar to trademarks in which complainant has rights ${ }^{273}$

It is vital to note that the complainant also proved that domain name is confusingly similar to his trademark by satisfying the panelist that he has the rights in his trademark and these rights can be as a result of registration of that mark in many countries of the world. ${ }^{274}$

\subsubsection{Rights or Legitimate Interests}

This element states that the complainant must prove that the registrant does not have rights or legitimate interests in respect of the domain name. Therefore, the complainant must show a prima facie case of paragraph 4 (a) (2) of the UDRP, that he has rights or legitimate interests. The burden then shifts to the respondent to deny the showing by proving evidence that it has rights to or

\footnotetext{
${ }^{272}$ WIPO Case No. D2003-0066. WIPO, Search WIPO Cases and WIPO Panel Decisions/ WIPO Case No. D20030066, 2015, <http://www.wipo.int/amc/en/domains/decisions/html/2003/d2003-0066.html / >, accessed 18 September, 2015.

${ }^{273}$ The complainant is John Swire \& Sons Limited of Swire House, 59 Buckingham Gate, London SW1E 6AJ, England. Complainant is represented by: Johnson Stokes \& Master, 10th Floor, Prince's Building, 10 Charter Road, Central Hong Kong. The respondent is; David Huang, of 4F, 256 Nanking East Road, Sec.5, Taipei City, Taiwan 105. The Respondent is not represented. WIPO Case No. D2000-1106. WIPO, Search WIPO Cases and WIPO Panel Decisions/ WIPO Case No. D2000-1106, 2015, <http://www.wipo.int/amc/en/domains/decisions/html/2000/d2000-1106.html / >, accessed 19 September, 2015.

${ }^{274}$ Ibid
} 
legitimate interests in the domain name. ${ }^{275}$ The concept of burden shifting is derived from paragraph 4(c) of the UDRP, entitled "how to demonstrate your rights to and legitimate interests in the domain name in responding to a complaint".

Paragraph 4(c) discusses the different kinds of evidences a respondent should evidence that it has rights or legitimate interests in the domain name. Paragraph 4(c) of the UDRP sets out a number of circumstances, in order to demonstrate that the respondent has legal interests or rights. These circumstances are:

1. the registrant used or demonstrably prepared to use the domain name or a corresponding name in connection with a bona fide offering of goods or services prior to notice of the dispute;

2. the registrant (as an individual, business, or other organization) has been commonly known by the domain name, even if it has not acquired trademark rights; or

3. the registrant is making a legitimate non-commercial or fair use of the domain name, without intent for commercial gain to misleadingly divert consumers or to tarnish the complainant's trade or service mark. ${ }^{276}$

In John Swire \& Sons Limited v. David Huang, ${ }^{277}$ WIPO Case, the WIPO panel shifted the burden of proof to the respondent due to the fame of the complainant. The panel stated that the renown of complainant's group of companies and the wide-spread trade mark registrations which it holds renders it almost impossible for respondent to claim any such right or interest. Whilst the burden of proof lies on complainant, that burden has shifted to the respondent and the latter has done nothing to deny complainant's prima facie showing used or prepared to use the domain name or a corresponding name in connection with a bona fide offering of goods or services prior to notice of the dispute.

\footnotetext{
${ }^{275}$ Paragraph 4 (c) of the UDRP.

ICANN, Uniform Domain-Name Dispute-Resolution Policy, 1999, <http://www.icann.org/udrp/udrp-policy24oct99.htm >, accessed 19 September, 2015.

${ }^{276}$ Paragraph 4 (c) of the Uniform Domain Name Dispute Resolution Policy (UDRP). ICANN, Uniform Domain-Name Dispute-Resolution Policy, <https://www.icann.org/resources/pages/policy-2012-02-25-en\#4aii>, accessed 10 October 2015.

${ }^{277}$ WIPO Case No. D2000-1106. WIPO, Search WIPO Cases and WIPO Panel Decisions/ WIPO Case No. D20001106, <http://www.wipo.int/amc/en/domains/decisions/html/2000/d2000-1106.html >, accessed 20 September, 2015.
} 
Moreover, in INTOCAST AG v. Lee Daeyoon, WIPO Case, it was very hard for the complainant to prove that the respondent did not have rights or legitimate interests in respect of the domain name. The burden thus shifted to the respondent to deny the evidence of complainant by proving evidence that it has rights to or legitimate interests in the domain name. ${ }^{278}$

It should be noted that the respondent of this case presented the evidence to the panel that it has rights to or legitimate interests in the domain name by using the domain name in connection with a bona fide offering of goods or services prior to notice of the dispute. Consequently, the panel is convinced that the domain name has been registered and is being used in bona fide by the respondent.

Also, in Shell International Petroleum Company Limited, Shell Trademark Management B.V. v. Domains - Best Domain, WIPO Case, the respondent has not provided any evidence of rights or legitimate interest in the domain name as well as has not presented evidence that

- $\quad$ it used or made preparations to use the domain name in connection with a bona fide offering of goods or services, or,

- it is commonly known by the domain name, or,

- $\quad$ it is making a noncommercial or fair use of the domain name.

In this case, the panel found that respondent does not have any right or legitimate interest in the domain name. 279

\footnotetext{
${ }^{278}$ WIPO Case No. D2000-1467. Complainant is INTOCAST AG, Kaiserswerther 86-88, 40880 Ratingen, Germany. Respondent is Lee Daeyoon, Hangyureh 3rd floor, 116-25 Gongduk, Mapo, Seoul, 121-020, Republik of Korea. Complainant contends that respondent has registered the domain name which is identical to complainant's "INTOCAST" mark, that respondent has no rights or legitimate interests in respect of the domain name, and that the domain name has been registered and is being used in bad faith. Consequently, complainant requires the transfer of the domain name registration to the Complainant. Respondent has not contested the allegations of the complaint and is in default. Since the panel found that not all of the elements under paragraph 4(a) are fulfilled, the complaint is dismissed. WIPO, Search WIPO Cases and WIPO Panel Decisions/ WIPO Case No. D2000-1467, 2015, <http://www.wipo.int/amc/en/domains/decisions/html/2000/d2000-1467.html>, accessed 20 September, 2015.

${ }^{279}$ WIPO Case No. D2003-0066.

WIPO, Search WIPO Cases and WIPO Panel Decisions/ WIPO Case No. D2003-0066, 2015, <http://www.wipo.int/amc/en/domains/decisions/html/2003/d2003-0066.html >, accessed 10 September, 2015.
} 


\subsubsection{Bad Faith Registration and Use}

Bad faith registration and use is the last element required by the UDRP in order to cancel or transfer a registered domain name. This element states that the complainant must prove that the domain name has been registered and is being used in bad faith.

The establishment of a proof of bad faith is the core matter with regard to the UDRP, as it originally aims at protecting the rights of a legitimate owner of a trademark against those who registered and used it in bad faith. The UDRP demonstrates the following factors which indicate bad faith:

1. circumstances indicating registration of domain name primarily for the purpose of selling, renting, or otherwise transferring that registration to the complainant who is the owner of the trademark or service mark or to a competitor of that complainant, for valuable consideration in excess of your documented out-of-pocket costs directly related to the domain name;

2. the domain name was registered to prevent the owner of the trademark or service mark from reflecting the mark in a corresponding domain name;

3. the domain name was registered primarily for the purpose of disrupting the business of a competitor;

4. the domain name was registered to intentionally attempt to attract, for commercial gain, Internet users to the web-site (or other on-line location) by creating a likelihood of confusion with the complainant's trade or service mark as to the source, sponsorship, affiliation, or endorsement of the web-site or a product or service on the web-site. ${ }^{280}$

In most, if not all cases where there is a finding of bad faith registration and use, the other elements are also met under paragraph 4 of UDRP, and the decision is in favor of the complainant. The complainant must show that both the registration and the use are in bad faith.

In Philip Morris Incorporated v. r9.net the respondent had legal, notice of complainant's marks prior to registering the disputed domain name. Certainly, the MARLBORO ${ }^{\circledR}$ mark has been registered for 95 years, and it is one of the most famous trademarks in the USA. It is inconceivable that respondent was not aware of the MARLBORO® mark when it registered the disputed domain name. The panel therefore found that the disputed domain name was registered in bad faith.

\footnotetext{
${ }^{280}$ Under Article 4(b) of the UDRP these circumstances are non-exclusive, but serve only for examples.
} 
Moreover, it appears that this respondent has engaged in a pattern of bad faith conduct by registering many 100 other domain names containing well-known marks, and using them to direct traffic to other sites for commercial gain. ${ }^{281}$ It has been found that these other registered domain names included famous trademarks owned by third parties. All these facts led the panel to the result that the respondent had registered and used the domain name in bad faith. ${ }^{282}$

In Shell International Petroleum Company Limited, Shell Trademark Management B.V. v. Domains - Best Domain, WIPO Case, the complainant has presented evidence that respondent offered to sell the domain name for $\$ 549.00$, which indicates that respondent acquired the domain name primarily for the purpose of selling, renting, or otherwise transferring the domain name registration to complainants. Also, in this case, the panel found that respondent has registered and used the domain name in bad faith. ${ }^{283}$ Paragraph 4(b) (1) of the UDRP is directly applicable in this situation. This article includes use of the domain name intentionally to sell, rent, or transfer that registration to the complainant who is the owner of the trademark. It should be noted that the complainant presented evidence that respondent offered to sell the domain name for $\$ 549.00$ to the complainant or to a competitor of that complainant, for valuable consideration in excess of your documented out-of-pocket costs directly related to the domain name. ${ }^{284}$

The topic was also discussed in, Ingram Micro, Inc. v. Ingredients Among Modern Microwaves, WIPO Case. Under this case, there is no evidence of bad faith use and no effort has been made to sell the domain names to the mark owner or a competitor and no attempt was made to attract users to the site for commercial gain. In this case, the panel found the complainant has failed to establish bad faith use. ${ }^{285}$

However, it should be mentioned here that instead of some non-exclusive circumstances which are clarified by paragraph 4(b) of the UDRP there is a great need for international community to agree in a formal way to offer resolution of the conflict between domain names and trademarks policy

\footnotetext{
${ }^{281}$ WIPO Case No. D2003-0004.

${ }^{282}$ Ibid.

${ }^{283}$ WIPO Case No. D2003-0066.

${ }^{284}$ Ibid.

${ }^{285}$ WIPO Case No. D2002-0301.
} 
by including more clear standard to decide whether certain registration or use of domain name is made in bad faith or not. ${ }^{286}$

\subsubsection{Remedies of ICANN's UDRP}

Generally, the complainant shall file the UDPR complaint with either the WIPO or other providers. The respondent has twenty (20) calendar days to respond the complaint. ${ }^{287}$ Commonly, the respondent does not respond, then the complainant generally prevails and wins by default. The majority of UDRP cases are succeed as the respondent basically did not or fails to respond to the complainant. If the respondent responds, then the complainant has five days to present any extra appropriate materials. ${ }^{288}$ The complainant and respondent shall further select three-member panels, each selecting and eliminating panelists, as both have the right to say in who is and is not on the panel. ${ }^{289}$ A final decision by the panel should be issued within fourteen (14) days of the last submission, by the respondent. ${ }^{290}$ The only remedy available to the complainant is either the cancellation of the domain name or the transfer of the disputed domain name to the complainant. ${ }^{291}$

However, ICANN's UDRP is not the proper way for claiming damages or monetary remedies, simply because the powers granted to a panel applying the policy are merely reflecting the contractual provision embodied in the phase of registering the domain name. ${ }^{292}$

Simply, it is not possible for the UDRP panel to make any monetary judgments, the ICANN's UDRP panels can only decide to transfer or cancel the domain name or deny the complaint. As a result, there is also an urgent need, in the nearest future, for international community to agree in a formal way to offer new rules under ICANN's UDRP to justify claims for damages and lost profit in front of the panel, beside of the panel power to transfer or cancel the domain name, or deny the complaint. However, drafting and issuing such new rules will not be an easy task; it will take a long period of time, and need of widespread awareness of the importance

\footnotetext{
286 Ibid.

${ }^{287}$ Paragraph 5 (a) of the UDRP.

${ }^{288}$ Paragraph 4 (d) of the UDRP.

${ }^{289}$ Ibid, Paragraph 6.

${ }^{290}$ Ibid, Paragraph 15 (b).

${ }^{291}$ Ibid, Paragraph 3 (b) (xii).

292 Terrence Fernbach, "What is in a name?" A Comparative Look at the ICANN Uniform Domain Name Dispute Resolution Policy and the United States Anti-Cybersquatting Consumer Protection Act, Munich Intellectual Property Law Center (MIPLC) Master thesis, 2011, p 14.
} 
and value of domain names in order to offer new rules under ICANN's UDRP to give the power for the panel to make any monetary judgments.

"One of the most important features of the UDRP is that its decisions are not final, and the losing party in the UDRP proceedings can bring an action against the winning party in a court of a competent jurisdiction within ten days of the issuance of the decision and its implementation." 293 In addition, "the UDRP does not cover all kind of abuses that relate to trademark infringements in cyberspace, but only cases of deliberate bad faith registration of domain names and all other issues related to trademark validity are not within the scope of the UDRP. The only relief that the UDRP offers to the trademark owner is to transfer or cancel the disputed domain name. In order to enable the trademark owner to recover any remedies, he or she must file his suit in front of the competent court." 294

\subsubsection{ICANN's WHOIS Service}

In 1998, WHOIS database was established by ICANN. ${ }^{295}$ The "WHOIS data" service is managed by the registry operators or registrars who are responsible for confirming and maintaining the registry for domain names which is sold by the registrars. ${ }^{296}$ The main task for the registry operator or registrars is approving the registration requests by maintaining a database of the essential registration data and providing name servers to be published for the public domain via cyberspace. For instances; an information about the location of a domain name should be published for the public domain via cyberspace. ${ }^{297}$

As prior noted, each registrant "must provide identifying and contact information which may include: name, address, email, phone number, and administrative and technical contacts. This information is often referred to as WHOIS data. But the WHOIS data or service is not a single, centrally-operated database. Instead, the data is managed by independent entities known as

293 Olwan, the Case of Suck Domain Names and Cyber-smearing Examination of Suck Cases with the WIPO Arbitration and Mediation Center, <docshare01.docshare.tips/files/390/3901550.pdf > accessed 20 September 2016. ${ }^{294}$ Ibid.

${ }^{295}$ WHOIS refers to 1982, when the Internet Engineering Task Force published a protocol for a directory service for ARPANET users. Initially, the directory simply listed the contact information that was requested of anyone transmitting data across the ARPANET. ICANN, About WHOIS, <https://whois.icann.org/en/about-whois>, accessed 10 September, 2015.

${ }^{296}$ ICANN, Domain Name Registration Process, <https://whois.icann.org/en/domain-name-registration-process > accessed 10 December 2016.

${ }^{297}$ Ibid. 
(registrars) and/or (registries). Any entity that wants to become a registrar must earn ICANN accreditation. Similarly, registries are under contract with ICANN to operate a gTLDs, such as .COM, .ORG", ${ }^{298}$ or even with the new gTLDs. ${ }^{299}$ According to the RAA between ICANN and the registrar, ICANN can even force registrars to suspend registrant domain names or even cancelled, if there is inaccurate data listed in the registry. ${ }^{300}$ In addition, ICANN states that "registrars are organizations accredited by ICANN and qualified by the registry operators to sell domains. They are bound by the Registrar Accreditation Agreement (RAA) with ICANN - and by their agreements with the registry operators. The RAA sets out responsibilities for the registrar including maintenance of WHOIS data, submission of data to domain registries, facilitating public WHOIS queries, ensuring registrants details are escrowed, and complying with RAA conditions relating to the conclusion of the registration period." ${ }^{301}$ ICANN added that "Registrars are required to have an interactive web page and port 43 WHOIS service that is available to the public to query free of charge." 302 The RAA stipulates certain data that should be provided in response to a query: the registered name, names of the primary and secondary name servers for the domain name, registrar Identity which might usually be presented through Registrar's website, the original registration date, the registration expiration date, the name and postal address of the domain name holder, the name, postal address, e-mail address, voice telephone number, of the technical contact for the domain name, and the name, postal address, e-mail address, voice telephone number, of the administrative contact for the domain name. ${ }^{303}$

As a useful benefit, WHOIS data offers free services for many stakeholders "such as registrants, law enforcement agents, intellectual property and trademark owners, businesses and individual users." 304 ICANN states that "WHOIS is used for many legitimate purposes. Under ICANN's

\footnotetext{
${ }^{298}$ ICANN, About WHOIS, <https://whois.icann.org/en/about-whois>, accessed 10 September, 2015.

${ }^{299}$ Ibid.

300 ICANN, Registrant Rights and Responsibilities Under the 2009 Registrar Accreditation Agreement, < https://www.icann.org/resources/pages/responsibilities-2014-03-14-en> accessed 1 December 2016.

301 "Some registrants may opt to register through a reseller. These are affiliated or under contract with registrars, and usually offer other services such as web hosting, email mailboxes etc. Resellers are bound by their agreements with the registrar(s) whose services they sell; they are not accredited by ICANN. However, the registrar for whom they are re-selling will still be the sponsor for the domain name registration and accountable for the domains sold by the reseller." ICANN, Domain Name Registration Process, <https://whois.icann.org/en/domain-name-registrationprocess $>$ accessed 10 December 2016.

302 ICANN, Registrant Rights and Responsibilities Under the 2009 Registrar Accreditation Agreement, <https://www.icann.org/resources/pages/responsibilities-2014-03-14-en〉, accessed 10 July, 2016.

${ }^{303}$ Ibid

${ }^{304}$ ICANN, About WHOIS, <https://whois.icann.org/en/about-whois>, accessed 10 September, 2015.
} 
agreements, WHOIS may be used for any lawful purposes except to enable marketing or spam, or to enable high volume, automated processes to query a registrar or registry's systems, except to manage domain names. In addition to identifying domain name holders, WHOIS data also allows network administrators and others to find and fix system problems and to maintain Internet stability. With it, they can determine the availability of domain names, combat spam or fraud, identify trademark infringement and enhance accountability of domain name registrants. WHOIS data is sometimes used to track down and identify registrants who may be posting illegal content or engaging in phishing scams. These are just a few examples of how WHOIS helps maintain a healthy Internet ecosystem." 305

Briefly, some registration data can be obtained for domain names registered in the gTLDs by launching a "WHOIS" search, in particular at (https://whois.icann.org/en) $)^{306}$ while WHOIS service for ccTLDs, it may be accessed via the concerned registrar's website. ${ }^{307}$ Even the registration data for new gTLD are now available for domain names registered in the new gTLDs by launching a "WHOIS" search. ICANN provides the list of new gTLD strings, each string in the new gTLD should have a website "WHOIS" search, for examples; the string ".aaa" is managed by registrar "American Automobile Association, Inc", provides the following website for "WHOIS" data: (http://WHOIS.nic.aaa/). ${ }^{308}$ The reason for that ICANN enforced the American Automobile Association, Inc, pursuant to the Registrar Accreditation Agreement (RAA), to launch "WHOIS" search in order to be reachable for public internet users.

ICANN's WHOIS data is "a publicly searchable tool that searches the databases of registries and registrars to detail the domain owner contact information across all contracted gTLDs," 309 Therefore, WHOIS data helps the trademark holder to ascertain in easy and quick way the true address and identity of the cybersquatters (domain name infringers) and their registrars via cyberspace.

\footnotetext{
${ }^{305}$ ICANN, Basics of WHOIS, <https://whois.icann.org/en/basics-whois >, accessed 10 September, 2015.

${ }^{306}$ ICANN, Who Registered That? < https://whois.icann.org/en >, accessed 10 September, 2015.

307 WIPO, WIPO Guide to the Uniform Domain Name Dispute Resolution Policy (UDRP), <www.wipo.int/amc/en/domains/guide/> accessed 12 March 2016.

308 ICANN, Registry Listing, <https://www.icann.org/resources/pages/listing-2012-02-25-en> accessed 10 September, 2015.

${ }^{309}$ ICANN, Using WHOIS, < https://whois.icann.org/en/using-whois >, accessed 10 June, 2016.
} 


\subsubsection{Jurisdiction of ICANN's UDRP}

As previously mentioned, every domain name registrar of gTLD or new gTLD has a RAA in force with ICANN. Accordingly, ICANN has administrative authority over and organizes the registration operation of the entire DNS (for gTLD and new gTLD) all over the world. ${ }^{310}$ As a result, the registrars are obligated under RAA by ICANN to enter into an electronic or hard paper registration agreements (contractual relationship) with all their registrants, by including provisions to be adhered with ICANN policies in their agreements. ${ }^{311}$

Under the contractual relationship between the registrant and registrar, the registrant must undertake that: "to the best of the Registered Name Holder's knowledge and belief, neither the registration of the Registered Name nor the manner in which it is directly or indirectly used infringes the legal rights of any third party." 312 Thus, the registrant must undertake to the registrar that the domain name is not being registered for direct or indirect use in a way that would infringe or violate the legal rights of others. For instance, the "infringement" could be a registration of a domain name that violates a trademark held by someone that is not the registrant.

However, if any dispute arising as a result of the infringement or violation of the legal rights of others, then the registrant should accept in the contract concluded with the registrar that the dispute resolution mechanism should be ICANN's UDRP. ${ }^{313}$

As Holger Hestermeyer remarks that "the first and most obvious place to challenge the panel's jurisdiction would be within the UDRP proceeding itself." 314

In Quixtar Investments, Inc. v. Scott A. Smithberger and QUIXTAR-IBO, ${ }^{315}$ WIPO Case, the complainant is Quixtar Investments, Inc. initiated the UDRP proceeding by filing a complaint

\footnotetext{
${ }^{310}$ Michaelson, Emergency Arbitration: Fast, Effective and Economical (March 18, 2016), Just Resolutions, American Bar Association Dispute Resolution Section, < https://ssrn.com/abstract=2762715> accessed 13 December 2016.

311 ICANN, Non-Lawyers' Guide to the May 2009 Registrar Accreditation Agreement, <https://www.icann.org/resources/pages/non-lawyers-guide-2010-02-15-en> accessed 12 December 2016.

312 ICANN, Registrant Rights and Responsibilities Under the 2009 Registrar Accreditation Agreement, <https://www.icann.org/resources/pages/responsibilities-2014-03-14-en>, accessed 10 July, 2016.

${ }^{313}$ Ibid.

${ }^{314}$ Holger Hestermeyer, the Invalidity of ICANN's UDRP under National Law, Intellectual Property Revew, 2002, p 29.

315 WIPO, Search WIPO Cases and WIPO Panel Decisions/ WIPO Case No. D2000-0138, 2000, < http:// www.wipo.int/amc/en/domains/decisions/html/2000/d2000-0138.html> accessed 20 September 2015.
} 
against both respondents Scott A. Smithberger and QUIXTAR-IBO. However, the panel held that it could not adjudicate over the respondent "Scott A. Smithberger" who have not agreed to the UDRP but it adjudicated over QUIXTAR-IBO who have agreed, according to its contractual relationship with the registrar, that dispute resolution mechanism should be ICANN's UDRP. ${ }^{316}$

It is clear that the panel had to look at whether the cybersquatter agreed, according to its contractual relationship terms with the registrar, that dispute resolution mechanism should be ICANN's UDRP. Therefore, if such terms are invalid, then the cybersquatter should be deemed not to have agreed to such terms. ${ }^{317}$

In addition to the ICANN's UDRP, if any dispute arising as a result of infringement or violation of the legal rights of others, then the registrant should also accept in the contractual relationship with registrar that the jurisdiction of the courts as follows:

1. where the registrar is located which often mentioned on the website or in the Agreement between the registrar and registrant, and/or;

2. the registrant's domicile. "Domicile" will typically be the venue of the registrant provides to the registrar in the required personal information. ${ }^{318}$

Equally, even when UDRP policy are stipulated in the contractual relationship, between the registrant and registrar, to be an dispute resolution procedures if any dispute arising such as cybersquatting, the use of local courts is also possible in parallel to the dispute resolution mechanisms offered.

In summary, the trademark owner can easily search for all the details in WHOIS data, which provides publicity online accurate details for each registration in gTLDs or new gTLDs, including the information for the location of the registrar and the cybersquatter's domicile location (registrant's domicile). Approving to jurisdiction means that the registrant agrees that the courts in those two venues have the authority to review and decide these types of cases. ${ }^{319}$

\footnotetext{
316 Ibid.

317 Ibid.

${ }^{318}$ ICANN, Registrant Rights and Responsibilities Under the 2009 Registrar Accreditation Agreement, <https://www.icann.org/resources/pages/responsibilities-2014-03-14-en>, accessed 10 July, 2016.

319 Ibid.
} 
It would be interesting to cite provision of domain registration agreement as an example for determining the jurisdiction if any dispute arise, as follow: "For the adjudication of disputes concerning or arising from use of the Registered Name, the Registered Name Holder shall submit, without prejudice to other potentially applicable jurisdictions, to the jurisdiction of the courts (1) of the Registered Name Holder's domicile and (2) where Registrar is located." 320

It is important to note that these are non-exclusive selections, as there is also the provision regarding "other potentially applicable jurisdictions". ${ }^{321}$ Francis Medeiros noted that "it has a symbolic value, as a third party who is not bound by a contract that he has not signed is not subject to these jurisdiction agreements." 322

It is vital to remind as prior mentioned, that the RAA does not apply or cover for ccTLDs registrations as accreditation of registrars for ccTLDs is a subject of choice for the ccTLD registry operators. ${ }^{323}$ Accordingly, each ccTLD registry is subject to the legal jurisdiction in which the registry manager is based. Thus, within that jurisdiction the ultimate authority is a domestic court. $^{324}$

The registrant of gTLDs has to agree that its registration is subject to "suspension, cancellation, or transfer" 325 according to his agreement with registrar. The reason for that if an ICANN adopted policy or arrangement requires or involves it or if a registry or registrar procedure requires it "to correct mistakes by Registrar or the Registry Operator in registering the name or for the resolution of disputes concerning the Registered Name." ${ }^{326}$ For example, the UDRP policy that stipulates that an administrative panel hearing a domain name dispute could order that a domain name registration

320 Strato, Particular terms of contract for the Registration, <http://www.stratohosting.co.uk/_assets_uk/pdf/terms_and_conditions/particular_terms.pdf >, accessed 10 July, 2016.

321 Medeiros, Is 'com' International? The .com gTLD: an Analysis of Its Global Nature through the Prism of Jurisdiction, p 278.

322 Ibid.

323 ICANN, Non-Lawyers' Guide to the May 2009 Registrar Accreditation Agreement, <https://www.icann.org/resources/pages/non-lawyers-guide-2010-02-15-en> accessed 12 December 2016.

${ }^{324}$ Kim Arx, and Gregory Hagan, Sovereign Domains: A Declaration of Independence of ccTLDs from Foreign Control, 2002, <http://scholarship.richmond.edu/jolt/vo19/iss1/6> accessed 12 December 2016.

${ }^{325}$ ICANN, Registrant Rights and Responsibilities Under the 2009 Registrar Accreditation Agreement, <https://www.icann.org/resources/pages/responsibilities-2014-03-14-en>, accessed 10 July, 2016.

326 Ibid. 
be suspended, transferred or cancelled, and the registrant has no any chance to disagree or challenge in this regard. ${ }^{327}$

However, by comparing "the number of cases that has been brought in front of courts challenging the decisions to the number of UDRP complaints, it will be clear that in very minor cases the UDRP decisions has been challenged. This is due to several reasons. Among that domain name registrant are usually poor and do not afford paying court fees, which are always more expensive than UDRP, and secondly many domain name registrants do not know that the UDRP decisions can be challenged or simply they are not interested to defend their position anymore."”28

Basically, it should also be noted, as prior stated, that no mention regarding "choice of law" or "applicable laws" was made concerning gTLDs under RAA or even the contractual relationship between the registrant and registrar. ${ }^{329}$ The contractual relationship between the registrant and registrar is silent regarding which law shall govern gTLDs disputes, ${ }^{330}$ while in the ccTLD delegation there is a clear acknowledgement that the laws of national jurisdictions should form the administration of this type of ccTLD space. ${ }^{331}$

In short, the use of local courts is also possible to sue the cybersquatters, in parallel to UDRP policy offered. "The court of competent jurisdiction in general is either the location of Registrar's principal office or the registrant's address as shown in WHOIS database" ${ }^{332}$ thus if the registered domain name in gTLDs abuse a famous trademark, then the trademark owners can directly adjudicate the cybersquatter under ICANN's UDRP or they can easily determine the court of competent jurisdiction by searching in WHOIS data, for the location of the registrar or the

\footnotetext{
${ }^{327}$ The registrant shall also "indemnify and hold harmless the Registry Operator and its directors, officers, employees, and agents from and against any and all claims, damages, liabilities, costs, and expenses (including reasonable legal fees and expenses) arising out of or related to the Registered Name Holder's domain name registration." This means that if the registry operator or any one behalf it for the registered domain name is sued because of the registrant's domain name registration, the registrant will pay the Registry Operator for all fees and expenses in defending against the suit as well as pay for any judgments or liabilities awarded. This "indemnification" is not solely limited to court cases. Ibid.

${ }^{328}$ Olwan, the Case of Suck Domain Names and Cyber-smearing Examination of Suck Cases with the WIPO Arbitration and Mediation Center, <docshare01.docshare.tips/files/390/3901550.pdf > accessed 20 September 2016. ${ }^{329}$ Ibid, p 276.

${ }^{330}$ The gTLD provision is silent regarding such matters. As a result, the Jordanian Private International Law principles should apply. Ibid.

${ }^{331}$ Thus it is interesting to note that under IANA contract "the contractor shall also take into account the relevant national frameworks and applicable laws of the jurisdiction that the TLD registry serves." Ibid.
}

${ }^{332}$ Ibid. 
cybersquatter's domicile location (registrant's domicile), in order to file a lawsuit against the cybersquatters. The elimination of a jurisdiction clause does not help to determine which jurisdiction would be the most suitable for hearing disputes involving international domain names. $^{333}$

\subsubsection{Pros and Cons of ICANN's UDRP}

It is an undisputed fact that UDRP attends an imperative function to settle domain name disputes that can be effected on an international stage, in an out of court proceeding. ${ }^{334}$

Due to the varied pros and cons of that are inherently in the ICANN's UDRP, one has to think before deciding to use ICANN's UDRP instead of filing a suit in front of the competent court.

Indeed, there are quite a few pros and cons of ICANN's UDRP to filing a domain name dispute with one the ICANN approved providers. The following are the main pros and cons of ICANN's UDRP:

\subsubsection{Pros of ICANN's UDRP}

First, the process is relatively fast. As mentioned above, each conflict between domain name and trademark filed under the UDRP will be resolved normally within 60 days of the date on which the provider receives the complaint. ${ }^{335}$

Second, the proceedings under the ICANN's UDRP are significantly cheaper than a contested case in litigation. Even though the filing fees vary between the different organizations, they are smaller than the costs of proceedings in front of courts such as a United States Federal Court. ${ }^{336}$ According to the WIPO Guide to the UDRP, "the main advantage of the UDRP Administrative Procedure is

\footnotetext{
${ }^{333}$ Medeiros, Is 'com' International? The .com gTLD: an Analysis of Its Global Nature through the Prism of Jurisdiction, p 278.

${ }^{334}$ Sourabh Ghosh, Domain Name Disputes and Evaluation of The ICANN's Uniform Domain Name Dispute Resolution Policy, September 2004, <www.niscair.res.in/ScienceCommunication/ResearchJournals/rejour/jipr/

Fulltextsearch/2004/September\%202004/JIPR-vol\%209-September\%202004-pp\%20424-439.htm> accessed 12 March 2016.

335 WIPO, WIPO Guide to the Uniform Domain Name Dispute Resolution Policy (UDRP), <www.wipo.int/amc/en/domains/guide/> accessed 12 March 2016.

${ }^{336}$ Ibid.
} 
that it typically provides a faster and cheaper way to resolve a dispute regarding the registration and use of an Internet domain name than going to court." 337

Third, the trademark owner is able to exclude several jurisdictional issues by applying ICANN's UDRP. The ICANN's UDRP can also apply to registrants who have used a foreign registrar that have adopted the ICANN Policy. ${ }^{338}$ As prior mentioned, UDRP Policy sets out the legal framework for the resolution of disputes between a domain name registrant and a third party, over the abusive registration and use of an Internet domain name in the gTLDs (e.g., .biz, .com, .info,.. etc), and some ccTLDs that have adopted the ICANN's UDRP Policy on a voluntary basis. ${ }^{339}$ In addition, the ICANN's UDRP is also applicable to all new gTLDs. ${ }^{340}$

Fourth, arbitrators selected to sit on panels of UDRP procedures are typically experts in trademark law. This guarantees that an ICANN's UDRP proceeding will be settled by expert who has specified knowledge in the zone of trademark law. This can be one of the significant pros over courts, where the judge assigned the case may not have much knowledge in trademark issues. ${ }^{341}$ According to the WIPO Guide to the UDRP, "the procedures are considerably more informal than litigation and the decision-makers are experts in such areas as international trademark law, domain name issues, electronic commerce, the Internet and dispute resolution." 342

\subsubsection{Cons of ICANN's UDRP}

First, the main drawback with the ICANN's UDRP is that it is not possible for the UDRP panel to make any monetary judgments. As prior mentioned, the only remedy available to the complainant is either the cancellation of the domain name or the transfer of the disputed domain name to the complainant, ${ }^{343}$ simply because the powers granted to a panel applying the policy are merely reflecting the contractual provision embodied in the phase of registering the domain name. ${ }^{344}$

\footnotetext{
337 Ibid.

338 Ibid.

339 WIPO, Domain Name Dispute Resolution Service for Generic Top-Level Domains, <www.wipo.int/amc/en/domains/gtld/> accessed 12 March 2016.

340 Ibid.

341 Ibid

342 Ibid

${ }^{343}$ Fernbach, "What is in a name?” A Comparative Look at the ICANN Uniform Domain Name Dispute Resolution Policy and the United States Anti-Cybersquatting Consumer Protection Act, p 14.

344 Ibid.
} 
As a result, there is also an urgent need, in the nearest future, for international community to agree in a formal way to offer new rules under ICANN's UDRP to justify claims for damages and lost profit in front of the panel, beside of the panel power to transfer or cancel the domain name, or deny the complaint. However, drafting and issuing such new rules will not be an easy task; it will take long time, and need to widespread awareness of the importance and value of domain names in order to offer new rules under ICANN's UDRP to give the power for the panel to make any monetary judgments.

Second, the UDRP panel's decisions are non-binding in the sense that it does not preclude a following or concurrent court proceeding. ${ }^{345}$ Moreover, it is not expectable what weight courts will give to an arbitration panel decision. ${ }^{346}$

Another potential drawback with the UDRP procedures is that no appeal process exists to correct erroneous decisions. ${ }^{347}$ Further, if the UDRP panel does not request any additional information the parties shall not present anything further. For instances, in a situation where a party wishes to present new evidence that was not prior available after the ending of the party's initial submission.

Fourth, nothings guarantees that the UDRP panel's decision is the final adjudication of the cybersquatting since parties can file a lawsuit under the national courts as well. ${ }^{348}$

Notwithstanding the above, it is undoubted that UDRP attends an imperative purpose to settle domain name disputes that can be effected on a worldwide stage, in an out of court dispute resolution mechanism.

\footnotetext{
345 Ibid.

${ }^{346}$ In one case in particular, Weber-Stephen Products v. Armitage Hardware, the federal court for the Northern District of Illinois held that it was not bound by the outcome of UDRP proceedings and also declined to state that standard it would use to review UDRP arbitration panel decisions. Weber-Stephen Prods. Co. v. Armitage Hardware \& Bldg. Supply, 54 U.S.P.Q.2d1766 (2000).

${ }^{347}$ John Buche, Cybersquatting - What it is and How to Stop it, 2014 <www.pacificpatentlawyers.com/cybersquattingwhat-it-is-and-how-to-stop-it/\#sdfootnote10sym>, accessed 10 September, 2015.

348 Ibid.
} 


\subsection{Cybersquatting and ICANN's New gTLD}

At the present time, it is quite often that all trade mark proprietors seek to register a trademark as a new gTLD and/or restricts registration of SLDs to approved and maintain the businesses, for example, a trademark Apple is an example for a closed TLD registry, if Apple Company is looking to have subdomains for its products or services under the apple TLD, such as (ipad.apple) or (itunes.apple), which may serve to strengthen its brand and maintain its businesses. ${ }^{349}$ Nevertheless, where third parties may apply for domain names within the applied-for TLD, the new TLD will be an open registry. "Given the fact that the new gTLD Program allowed for the registration of trademarks as TLDs, it was inherent to the nature of the gTLD regime that the prospect of coincidence of brand names will exist." ${ }^{350}$ Thus, the new gTLD Program allowed for the registration of trade marks under TLDs, ICANN set up several right protection mechanisms to assist trademark owners in preventing third parties to register their trademarks under a new gTLD. In fact, the ICANN's new gTLDs Program has shown pros and cons. On the one hand, it has created another cadre for trade mark disputes, requiring trade mark proprietors to monitor and observe the abusive new gTLD to ensure that their rights are not infringed. On the other hand, some authors argue that the new gTLD process is, complex, expensive and time consuming, and might be considered nothing more than an unwanted problem by some trademark holders. ${ }^{351}$ However, the following sections addresses a dispute resolution mechanism for cybersquatting under ICANN's new gTLD, with a focus on trademark-related provisions.

\subsubsection{New Pre- and Post-Delegation Dispute Resolution Procedures under ICANN}

The protection mechanisms are now available to the trademark owners in the pre-delegation phase "Pre-delegation dispute resolution" by Dispute Resolution Service Providers (DRSPs), as a new way for settlement the disputes in new gTLD space, whereas other mechanisms will apply after

\footnotetext{
${ }^{349}$ Karjiker, the New gTLDs and the Resolution of Trade Mark Disputes, <blogs.sun.ac.za/iplaw/files/2016/04/Thenew-gTLDs-and-the-resolution-of-trade-mark-disputes.pdf > accessed 10 December 2016.

${ }^{350}$ Ibid.

${ }^{351}$ Roberts, an Overview of the New gTLD Programme, <https://valideus.com/sites/default/files/documents/newgTLD-white-paper-final.pdf > accessed 11 December 2016.
} 
the delegation of the gTLD "post-delegation dispute resolution", 352 which is called the Trademark Post-delegation Dispute Resolution Procedure (Trademark PDDRP). This section addresses an outline to the new pre and post-delegation dispute resolution procedures and the trademark clearinghouse, with a focus on trademark-related provisions.

\subsubsection{Pre-Delegation Dispute Resolution Cybersquatting under ICANN's DRSP}

The applicants under the new gTLD program, shall fulfill the conditions, which are established in the Applicant Guidebook, ${ }^{353}$ to have their proposed New gTLD to be approved, issued by ICANN in June 2011. ${ }^{354}$

"The new gTLD program includes a dispute resolution procedure, pursuant to which disputes between a person or entity who applies for a new gTLD and a person or entity who objects to that gTLD are resolved in accordance with this New gTLD Dispute Resolution Procedure," 355 which shall be administered by a Dispute Resolution Service Provider (“DRSP”). 356

After filing an application and before a new gTLD is approved, a public observation period permits for comments to be posted by cyberspace users via ICANN's website. Article 7 (a) of the procedures states that a person may file an objection to a new gTLD for which an application has been submitted, however, this objection must be applied before the published deadline of the Objection Filing period.

Article 7 (a) of the procedures provides that: “(a) A person wishing to object to a new gTLD for which an application has been submitted may file an objection (“Objection”). Any Objection to a

352 Allen and Overy, the new gTLDs: What do trademark owners need to know? , <www.allenovery.com/SiteCollectionDocuments/The\%20new\%20gtlds.pdf > accessed 13 December 2016.

${ }^{353}$ Contention sets are groups of applications containing identical or confusingly similar applied for gTLD strings. Contention sets must be resolved prior to the execution of a Registry Agreement for an applied-for gTLD string. An ICANN facilitated auction is a last resort for resolving string contention sets, as described in the Applicant Guidebook (AGB) section 4.3.

ICANN, gTLD Applicant Guidebook, 2012,

< https://newgtlds.icann.org/en/applicants/agb/guidebook-full-04jun12-en.pdf>, accessed 10 July, 2016.

${ }^{354}$ It was ultimately revised in June 2012.

355 Article 1 (b) of the New gTLD Dispute Resolution Procedure.

ICANN, New gTLD Dispute Resolution Procedure, 2012, < https://newgtlds.icann.org/en/applicants/agb/disputeresolution-procedure-04jun12-en.pdf>, accessed 15 July, 2016.

${ }^{356}$ Article 1 (c) of the New gTLD Dispute Resolution Procedure. 
proposed new gTLD must be filed before the published closing date for the Objection Filing period." $" 357$

In addition, the applicant is obliged to pay ICANN an evaluation fee of $\$ 185,000$ in order to serve as Registry Operator for the string. ${ }^{358}$ By filing an application for a new gTLDs, the applicant agrees for the applicability of the New gTLDs Dispute Resolution Procedure, which are established by the Applicant Guidebook.

Indeed, the new gTLD dispute resolution procedure states that definite disputes that may appear before a new gTLD is approved, one of these disputes is trademark confusion. While not mainly a trademark issue, the problem of how competing applications for confusingly similar or identical new gTLDs will be settled is of general interest. ${ }^{359}$ "ICANN has a string similarity review process that is intended to prevent a new gTLD from being too similar to existing TLDs, reserved names and other applied-for TLD strings." ${ }^{360}$ In addition, if the objection is successful, the application will be rejected. ${ }^{361}$ Actually, the objections stand on the grounds of:

1. String confusion: the existing TLD operators or other gTLD applicants have the right to stand on this ground as "The applied-for gTLD string is confusingly similar to an existing TLD or to another applied for gTLD string in the same round of applications." ${ }^{362}$ This ground is administrated by the International Centre for Dispute Resolution as Dispute Resolution Service Provider. ${ }^{363}$

2. Limited public interest: anyone has the right to stand on this ground of objection as "the applied-for gTLD string is contrary to generally accepted legal norms of morality and public order that are recognized under principles of international law." 364 This ground is

\footnotetext{
357 Article 7 (a) of the New gTLD Dispute Resolution Procedure.

358 As described in the Applicant Guidebook (AGB) section 1.5.1.

359 Jeffrey Kaufman and Kyoko Imai, Ready to object? Protecting your Trademark in the New gTLD Regime, 2012, $<$ http://www.worldtrademarkreview.com/Magazine/Issue/38/Features/Ready-to-object-Protecting-your-trademarkin-the-new-gTLD-regime>, accessed 10 July, 2016.

${ }^{360}$ Ibid.

${ }^{361}$ Ibid.

362 Applicant Guidebook (AGB) section 3.2.1.

363 Articles 2 (e) (i) and 3 (a) of the New gTLD Dispute Resolution Procedure.

${ }^{364}$ Applicant Guidebook (AGB) section 3.5.3.
} 
administrated by the International Chamber of Commerce (ICC) Expertise Dispute Resolution Services as Dispute Resolution Service Provider. ${ }^{365}$

3. Community opposition: the established institutions associated with clearly delineated communities have the right to stand on this ground of objection as "there is substantial opposition to the gTLD application from a significant portion of the community to which the gTLD string may be explicitly or implicitly targeted." 366 This ground is also administrated by the ICC Expertise Dispute Resolution Services as Dispute Resolution Service Provider. ${ }^{367}$

4. Legal rights: ${ }^{368}$ every rights holder has the right to stand on this ground of objection as "the string comprising the potential new gTLD infringes the existing legal rights of others that are recognized or enforceable under generally accepted and internationally recognized principles of law." ${ }^{369}$ This ground is also administrated by the Arbitration and Mediation Center of the WIPO as Dispute Resolution Service Provider. ${ }^{370}$

As prior mentioned, this section addresses a dispute resolution procedures with a focus on trademark related provisions, thus, the last ground which is administered by WIPO Arbitration and Mediation Center shall be further discussed under this part.

Before new gTLDs are approved, the trademark owners have the right to object to applications for gTLDs that are confusingly similar or identical to their trademarks. The disputes will be addressed by WIPO and appointed by panels of one or three panelists as "Single-Expert Panel or ThreeExpert Panel". ${ }^{371}$ The procedure obliges each party (each gTLD applicant and the objector) to pay $\$ 2,000$ as a minimum filing fee. Furthermore, "each DRSP shall determine the costs for the proceedings that it administers under this Procedure in accordance with the applicable DRSP Rules. Such costs shall cover the fees and expenses of the members of the Panel, as well as the administrative fees of the DRSP (the "Costs")."

\footnotetext{
365 Articles, 2 (e) (iii) and 3 (c) of the New gTLD Dispute Resolution Procedure.

${ }^{366}$ Ibid, article 2 (e) (iv).

${ }^{367}$ Ibid, article $3(\mathrm{~d})$.

368 WIPO, WIPO Arbitration and Mediation Center: End Report on Legal Rights Objection Procedure, 2013, < www.wipo.int/export/sites/www/amc/en/docs/lroreport.pdf > accessed 12 March 2016.

${ }^{369}$ Article 2 (e) (ii) of the New gTLD Dispute Resolution Procedure.

${ }^{370}$ Ibid, article 3 (b).

${ }^{371}$ Ibid, article 13.

372 Ibid, article 14 (a).
} 
Section 3.3 of the guidebook states that the parties must pay the full cost, which is $\$ 8,000$ for "Single-Expert Panel", the cost is actually higher if three expert panel are involved. ${ }^{373}$ However, the previous sum will be refunded to the prevailing party once the dispute has been settled. ${ }^{374}$ Article 14 (e) of the procedure states that: "(e) Upon the termination of the proceedings, after the Panel has rendered its Expert Determination, the DRSP shall refund to the prevailing party, as determined by the Panel, its advance payment(s) of Costs." ${ }^{\prime 375}$

Despite the fact that the new procedure did not contain any guidelines or factors for the panel to decide legal rights for objections, Module 3 of ICANN's guidebook states several factors. Thus, under article 20 (b) of the procedure, "(b) ..., the Panel may refer to and base its findings upon the statements and documents submitted and any rules or principles that it determines to be applicable." ${ }^{" 376}$ Section 3.5.2 of the guidebook states that "the following nonexclusive factors" 377 will be reviewed and considered:

"1. Whether the applied-for gTLD is identical or similar, including in appearance, phonetic sound, or meaning, to the objector's existing mark.

2. Whether the objector's acquisition and use of rights in the mark has been bona fide.

3. Whether and to what extent there is recognition in the relevant sector of the public of the sign corresponding to the gTLD, as the mark of the objector, of the applicant or of a third party.

4. Applicant's intent in applying for the gTLD, including whether the applicant, at the time of application for the gTLD, had knowledge of the objector's mark, or could not have reasonably been unaware of that mark, and including whether the applicant engaged in a pattern of conduct whereby it applied for or operates TLDs or registrations in TLDs which are identical or confusingly similar to the marks of others.

5. Whether and to what extent the applicant has used, or has made demonstrable preparations to use, the sign corresponding to the gTLD in connection with a bona fide offering of goods or

\footnotetext{
373 WIPO, WIPO Arbitration and Mediation Center: End Report on Legal Rights Objection Procedure, < www.wipo.int/export/sites/www/amc/en/docs/lroreport.pdf > accessed 12 March 2016.

${ }^{374}$ Ibid.

${ }^{375}$ Article 14 (e) of the New gTLD Dispute Resolution Procedure.

${ }^{376}$ Ibid, article 20 (b).

377 Applicant Guidebook (AGB) section 3.5.2.
} 
services or a bona fide provision of information in a way that does not interfere with the legitimate exercise by the objector of its mark rights.

6. Whether the applicant has marks or other intellectual property rights in the sign corresponding to the gTLD, and, if so, whether any acquisition of such a right in the sign, and use of the sign, has been bona fide, and whether the purported or likely use of the gTLD by the applicant is consistent with such acquisition or use.

7. Whether and to what extent the applicant has been commonly known by the sign corresponding to the gTLD, and if so, whether any purported or likely use of the gTLD by the applicant is consistent therewith and bona fide.

8. Whether the applicant's intended use of the gTLD would create a likelihood of confusion with the objector's mark as to the source, sponsorship, affiliation, or endorsement of the gTLD." ${ }^{378}$

Further, article 20 (c) of the procedure states that "the Objector bears the burden of proving that its Objection should be sustained in accordance with the applicable standards." ${ }^{379}$

Article 16 (a) of the procedure provides that the parties have the option to negotiate and/or mediate for accomplishing a dispute settlement. Article 16 (a) of the procedure states: "The parties are encouraged, but not required, to participate in negotiations and/or mediation at any time throughout the dispute resolution process aimed at settling their dispute amicably." ${ }^{380}$ Further, the parties may request a suspension of proceedings for up to 30 days generally as article 16 (d) of the procedure states: “(d) the conduct of negotiations or mediation shall not, ipso facto, be the basis for a suspension of the dispute resolution proceedings or the extension of any deadline under this Procedure. Upon the joint request of the parties, the DRSP or (after it has been constituted) the Panel may grant the extension of a deadline or the suspension of the proceedings. Absent exceptional circumstances, such extension or suspension shall not exceed thirty (30) days and shall not delay the administration of any other Objection." ${ }^{381}$

\footnotetext{
${ }^{378}$ Ibid.

${ }^{379}$ Article 20 (c) of the New gTLD Dispute Resolution Procedure.

${ }^{380}$ Ibid, article 16 (a).

${ }^{381} \mathrm{Ibid}$, article 16 (d).
} 
If the parties agree on a settlement of the matter during negotiations and/or mediation, then they shall inform the DRSP, which shall terminate the proceedings, subject to the parties' payment obligation. Article 16 (e) of the procedure states:

"e. If, during negotiations and/or mediation, the parties agree on a settlement of the matter referred to the DRSP under this Procedure, the parties shall inform the DRSP, which shall terminate the proceedings, subject to the parties' payment obligation under this Procedure having been satisfied, and inform ICANN and the parties accordingly." 382

It should be noted that ICANN has attained a deep knowledge in settling disputes of "cybersquatting" between domain name holders as "cybersquatters" and trademark owners. As previously mentioned, ICANN's UDRP, is the model to settle the disputes related to the registration and mala fide use of domain names "cybersquatting". Similar to the UDRP Policy, the Procedure is only internal to ICANN. Therefore, the jurisdiction of domestic courts, relating to disputes of "cybersquatting" is still available and associated with the operation of a domain name. Furthermore, domestic courts are not obliged by the decision of a panel. ${ }^{383}$ Thus, the objector may launch a civil action (claiming for instance that the domain name is identical or similar to his or her trademark), and the domestic courts may rule in his or her favor. ${ }^{384}$

On 12 January 2012, the ICANN opened application window for receiving applications new gTLD. On 13 March 2013, ICANN closed application window and received 1,930 applications for new gTLDs. ${ }^{385}$ The objection period began on 13 June 2012 until March $132013 .{ }^{386}$ The objectors filed more than 270 objections across all of the DRSPs. ${ }^{387}$ It would be interesting to cite the objection on gTLD string 〈.merck〉, in Merck \& Co, Inc. v. Merck KGaA Case, 388 "the Panel finds that the potential use of the Disputed gTLD String by Applicant does not: (i) take unfair advantage of the distinctive character or the reputation of Objector's registered or unregistered trademark or service mark, or (ii) unjustifiably impair the distinctive character or the reputation of Objector's

\footnotetext{
${ }^{382}$ Ibid, article 16 (e).

383 Vezzani, ICANN's New Generic Top-Level Domain Names Dispute Resolution Procedure Viewed Against the Protection of the Public Interest of the Internet Community: Litigation Regarding Health-Related Strings, p 313.

384 Ibid.

${ }^{385}$ ICANN, Program History, 2012, <https://newgtlds.icann.org/en/about/program >, accessed 15 July, 2016.

${ }^{386}$ Ibid.

${ }^{387}$ Ibid.

388 WIPO, Merck \& Co, Inc. v. Merck KGaA, Case No. LRO2013-0069, 2013, < http://www.wipo.int/export/sites/www/amc/en/domains/lro/docs/lro2013-0069.pdf> accessed 25 September 2015.
} 
mark, or (iii) otherwise create an impermissible likelihood of confusion between the Disputed gTLD String and Objector's mark." ${ }^{389}$ The Panel decided to reject the objection. ${ }^{390}$ On the contrary in the DirecTV Group Inc. v. Dish DBS Corporation Case, ${ }^{391}$ the objection was upheld. Even though, the applicant did not have any rights in the trademark DIRECT, but decided to apply with ICANN for <.direct>, which was one trademark of the complainant's collection trademarks. It was clear in this case that the two parties were competitors for market portion via cyberspace brand presence. Panelists concluded that the applicant had actual intention to initiate confusion for the purpose of improving their own market status and upset their competitor. ${ }^{392}$

As a final point, the head of ICANN's global domains division has indicated that it might be 2020 as the earliest accurate timetable for the next round of new gTLD applications. Nonetheless, it is still unknown whether it will be a permanent window or a round. ${ }^{393}$

\subsubsection{Post-Delegation Dispute Resolution Procedure under ICANN's PDDRP}

After approval for new gTLDs application, trademark proprietors will also have a chance to raise a complain. The burden for pursue the dispute at this stage will be in advanced level. Section 6.1 of the Trademark Post-delegation Dispute Resolution Procedure (Trademark PDDRP) states:

"2.1 This procedure is intended to cover Trademark post-delegation dispute resolution proceedings generally. To the extent more than one Trademark PDDRP provider ("Provider") is selected to implement the Trademark PDDRP, each Provider may have additional rules that must be followed when filing a Complaint. The following are general procedures to be followed by all Providers." ${ }^{394}$ ICANN also states that "Post-Delegation Dispute Resolution Procedures have been developed to

\footnotetext{
${ }^{389}$ Ibid.

390 Ibid.

391 WIPO, DirecTV Group Inc. v. Dish DBS Corporation, Case No. LRO2013-0005, 2013, $<$ https://newgtlds.icann.org/sites/default/files/drsp/25sep13/determination-1-1-2007-43424-en.pdf > accessed 25 September 2015.

392 Ibid.

393 Trevor Little, ICANN Eyes 2020 as Realistic Timeframe for Next Round of New gTLDs, 2016, <www.worldtrademarkreview.com/blog/detail.aspx?g=530DC4AD-6BD7-4969-8A41-EC538340C852> accessed 25 September 2016.

${ }^{394}$ Section 6.1 of the PDDRP.

ICANN, Trademark Post-delegation Dispute Resolution Procedure (Trademark PDDRP), 2012, <https://newgtlds.icann.org/en/applicants/agb/pddrp-04jun12-en.pdf>, accessed 15 July, 2016.
} 
provide those harmed by a new gTLD Registry Operator's conduct an alternative avenue to complain about that conduct. All such dispute resolution procedures will be handled by providers external to ICANN and require that complainants take specific steps to address their issues before filing a formal complaint. An Expert Panel will determine whether a Registry Operator is at fault and recommend remedies to ICANN." ${ }^{395}$ However, ICANN has appointed the following providers to support Trademark Post-Delegation Dispute Resolutions Procedures: ${ }^{396}$

- $\quad$ The Asian Domain Name Dispute Resolution Centre (ADNDRC)

- $\quad$ The National Arbitration Forum (NAF)

- The World Intellectual Property Organization (WIPO Center)

It is important to note that a complaint is not against a single second-level domain, but also an entire TLD or TLD registry's practice. Thus, section 6.1 of the Trademark PDDRP states that the parties to the dispute will be the trademark holder and the gTLD registry operator while ICANN is not considered any more as a party.

For instances, the trademark proprietors may bring a PDDRP complaint founded on a registry operator's use of a gTLD string. Section 6.1 of the Trademark PDDRP provides that the complaint might be against gTLD strings as a following: "A complainant must assert and prove, by clear and convincing evidence, that the registry operator's affirmative conduct in its operation or use of its gTLD string that is identical or confusingly similar to the complainant's mark, causes or materially contributes to the gTLD doing one of the following:

${ }^{395}$ Currently, there are three Post-Delegation Dispute Resolution Procedures:

1. Trademark Post-Delegation Dispute Resolution Procedure (Trademark PDDRP) - completed The Trademark PDDRP generally addresses a Registry Operator's complicity in trademark infringement on the first or second level of a New gTLD. At least 30 days prior to filing a formal complaint, a rights holder must notify the Registry of the alleged infringing conduct and express a willingness to meet to resolve the issue

2. Registration Restriction Dispute Resolution Procedure (RRDRP) - completed The RRDRP is intended to address circumstances in which a community-based New gTLD Registry Operator deviates from the registration restrictions outlined in its Registry Agreement. An RRDRP complaint may only be filed by an established institution. Prior to filing a formal RRDRP proceeding, a complainant will be required to utilize an online complaint system (in development) similar to the current Whois Data Problem Report System.

3. Public Interest Commitments Dispute Resolution Procedure (PICDRP) - completed The PICDRP addresses complaints that a Registry may not be complying with the Public Interest Commitment(s) in Specification 11 of their Registry Agreement. Prior to filing a formal PICDRP proceeding, the procedure envisions that a complainant will be required to utilize an online complaint system (in development) similar to the current Whois Data Problem Report System.

ICANN, Post-Delegation Dispute Resolution Procedures (PDDRP), 2012, < https://newgtlds.icann.org/en/programstatus/pddrp>, accessed 27 July, 2016.

${ }^{396}$ Ibid. 
(a) taking unfair advantage of the distinctive character or the reputation of the complainant's mark; or

(b) impairing the distinctive character or the reputation of the complainant's mark; or

(c) creating a likelihood of confusion with the complainant's mark. An example of infringement at the top-level is where a TLD string is identical to a trademark and then the registry operator holds itself out as the beneficiary of the mark." 397

In the same way, the trademark proprietor may also bring a complaint based on the second-level domain registrations allowed by a registry operator. Section 6.2 (b) of the Trademark PDDRP also states that complaints to a registry operator's pattern or practice of selling second-level domains in a manner to get income or profit from the sale of trademark infringing domain names. Section 6.2 of the Trademark PDDRP that: "Complainants are required to prove, by clear and convincing evidence that, through the registry operator's affirmative conduct:....

b) the registry operator's bad faith intent to profit from the systematic registration of domain names within the gTLD that are identical or confusingly similar to the complainant's mark, which: (i) takes unfair advantage of the distinctive character or the reputation of the complainant's mark;or (ii) impairs the distinctive character or the reputation of the complainant's mark, or

(iii) creates a likelihood of confusion with the complainant's mark."398

This provision is intended to address affirmative bad-faith practices, but it is not recommended to address unintended registrations or even individual registrations of infringing second-level domain names. ${ }^{399}$ In other words, "the registry operator is not liable under the Trademark PDDRP solely because infringing names are in its registry, or the registry operator knows that infringing names are in its registry, or the registry operator did not monitor the registrations within its registry."400

Section 9.7 of the Trademark PDDRP, states that if the panel determines that the complaint does not satisfy the conditions, the WIPO Center "will dismiss the proceedings on the grounds that the Complainant lacks standing and declare that the registry operator is the prevailing party." 401 The

\footnotetext{
${ }^{397}$ Section 6.1 of the Trademark PDDRP.

${ }^{398}$ Ibid, section 6.2.

${ }^{399}$ Ibid.

400 WIPO, Trademark Post-Delegation Dispute Resolution Procedure Q\&A, <www.wipo.int/amc/en/domains/tmpddrp/guide/> accessed 25 September 2016.

${ }^{401}$ Section 9.7 of the Trademark PDDRP.
} 
post-delegation procedure allows the chance for discovery and a hearing. ${ }^{402}$ It also demands that the complainant must submit a previous notice to the registry and show willingness to resolve the dispute. ${ }^{403}$ If the panel results was that the registry operator is responsible and liable, then it may recommend a variety of remedies, which may not include monetary damages. It should be considered that the registrants are not a party to the dispute, remedies may generally not contain the deletion, transfer or suspension of registrations. The Trademark PDDRP provides that:

"Since registrants are not a party to the action, a recommended remedy cannot take the form of deleting, transferring or suspending registrations (except to the extent registrants have been shown to be officers, directors, agents, employees, or entities under common control with a registry operator).

Recommended remedies will not include monetary damages or sanctions to be paid to any party other than fees awarded pursuant to section." ${ }^{{ }^{404}}$

The remedies that could be recommended by a panel stipulated under section 18.3 of the Trademark PDDRP as a following: "The Expert Panel may recommend a variety of graduated enforcement tools against the registry operator if it the Expert Panel determines that the registry operator is liable under this Trademark PDDRP, including:

18.3.1 Remedial measures for the registry to employ to ensure against allowing future infringing registrations, ...

18.3.2 Suspension of accepting new domain name registrations in the gTLD until such time as the violation(s) identified in the Determination is(are) cured or a set period of time; OR,

18.3.3 In extraordinary circumstances where the registry operator acted with malice, providing for the termination of a Registry Agreement." ${ }^{\star 405}$

The panel might recommend the following remedies:

- demanding the registry to employ standards protecting against future infringing registrations;

- prohibiting and suspension registration of new domain name registrations in the gTLD until violations addressed by the panel are cured; or

\footnotetext{
${ }^{402}$ Ibid, sections 7.1 and 7.2.3.d.

${ }^{403}$ Ibid, sections 15 and 16.

${ }^{404}$ Ibid, sections 18.1 and 18.2.

${ }^{405}$ Ibid, section 18.3.
} 
- in extraordinary circumstances where the registry operator acted with malice, terminating the Registry Agreement.

In the light of this wording, it should be mentioned that the PDDRP provides famous trademark owners an important settlement dispute resolution against new gTLD operators integrating in, or enhancing, harmful and illicit conduct as "cybersquatting". 406

Unlike the gTLD Objection Procedure or UDRP Policy, the PDDRP permits for a de novo appeal of any expert determination. A three-member appeal panel should be appointed by the provider in order to review the appeal, which may not involve of member of the Appeal Panel shall also have been an Expert Panel member. Further, the fees for an appeal in the first instance shall be paid by the appellant. However, an award of costs of appeal will be refunded to the prevailing party once the appeal decision has been issued. Generally, an Appeals Panel might hear additional testimony and evidence, whether or not such evidence pre-dates the filing of the complaint. The providers should determine the specific rules and procedures for appeals. ${ }^{407}$

Similar to the gTLD Objection Procedure or UDRP Policy, the procedure is only internal to ICANN. It is clear that ICANN states that the PDDRP does not prevent complainants from seeking compensation in courts at the same time with or subsequent to a PDDRP proceeding. ${ }^{408}$ Further, ICANN states that PDDRP Expert Determinations may be reviewed by a court. ${ }^{409}$ Therefore, the jurisdiction of domestic courts, relating to disputes of "cybersquatting" is still available and associated to the operation of a domain name. Furthermore, domestic courts are not obliged by the decision of a panel. ${ }^{410}$ Thus, the complainant may launch a civil action, and the domestic courts may rule in his or her favor. ${ }^{411}$

\footnotetext{
${ }^{406}$ It would be important to remark that until of the date writing this part on 7. 12. 2016, there was not any case available by ICANN's providers.

${ }^{407}$ Section 20 of the Trademark PDDRP.

${ }^{408}$ David Einhorn and Alan Pate, Challenging Delegated Top-level Domains: ICANN's Trademark Post Delegation Dispute Resolution Procedure, 2014, <www.lexology.com/library/detail.aspx?g=9e339387-e627-4d19-a8a55dddd79732c4> accessed 25 September 2015.

${ }^{409}$ Ibid.

410 Vezzani, ICANN's New Generic Top-Level Domain Names Dispute Resolution Procedure Viewed against the Protection of the Public Interest of the Internet Community: Litigation Regarding Health-Related Strings, p 313. ${ }^{411}$ Ibid.
} 


\subsubsection{Extra Protection Mechanisms in the New gTLD Space}

Currently, there are also extra protection mechanisms in the new gTLD space besides ICANN's UDRP, and pre-and post-delegation Dispute Resolution Procedure. These are:

1. ICANN's URS: Uniform Rapid Suspension System (URS), and;412

2. ICANN's Trademark Clearinghouse Model. ${ }^{413}$

\subsubsection{ICANN's URS as an Extra Protection Mechanisms in the New gTLD Space}

In addition to the Trademark PDDRP, trademark owners have another options for out-of-court dispute resolution procedures to settle abusive registration of domain names in new gTLDs:

1. Uniform Rapid Suspension System (URS).

2. UDRP Policy as prior mentioned. ${ }^{414}$

Most importantly the URS enables the trademark owners to settle abusive registration of domain names in new gTLDs. URS is included in ICANN's guidebook. ${ }^{415}$ The URS is a quicker alternative to the UDRP. ${ }^{416}$ The procedure is also very similarly to the UDRP policy, but the URS requires an advanced burden of evidence such as, convincing and clear proofs. ${ }^{417}$

412 ICANN, Uniform Rapid Suspension System (URS), < https://newgtlds.icann.org/en/applicants/urs>, accessed 27 July 2016.

413 ICANN, Trademark Clearinghouse (TMCH), < https://newgtlds.icann.org/en/about/trademark-clearinghouse >, accessed 28 July 2016.

414 ICANN, Uniform Rapid Suspension System (URS), < https://newgtlds.icann.org/en/applicants/urs>, accessed 27 July 2016.

415 Specification 7, Minimum Requirements for Rights Protection Mechanisms as described in ICANN's guidebook. ICANN, gTLD Applicant Guidebook, < https://newgtlds.icann.org/en/applicants/agb/guidebook-full-04jun12en.pdf>, accessed 10 July, 2016.

416 The UDRP Procedure normally should be completed within 60 days of the date the WIPO Center receives the Complaint. While the Forum's timeline shows that URS determinations should be issued within 21 days after a complaint has been filed. And, many determinations have been issued much more quickly, with the average time to a default determination being only 18 days.

Doug Isenberg, When to File a URS Complaint Instead of or in Addition to a UDRP Complaint, 2015 <http://www.gigalaw.com/2015/07/06/when-to-file-a-urs-complaint-instead-of-or-in-addition-to-a-udrpcomplaint/>, accessed 10 August, 2016.

417 Ibid. 
A rights holder (complainant) can submit a complaint with one of the URS providers, which are MFSD, ADNDRC (The Asian Domain Name Dispute Resolution Centre), or NAF. ${ }^{418}$ The purpose of the complaint is against the registrant who register an abusive domain names in new gTLDs. ${ }^{419}$ This can be done if all of the following three pre-conditions ${ }^{420}$ are met:

- the registered domain is identical or confusingly similar to the trademark.

- the registrant has no legitimate right or interest to the domain name.

- the domain name was registered and is used in bad faith (cybersquatting).

Section 1.2.6.3 of the URS for the year 2013, points out non-exclusive cybersquatting circumstances which are demonstrating bad-faith registration and use as following:

" a. Registrant has registered or acquired the domain name primarily for the purpose of selling, renting or otherwise transferring the domain name registration to the complainant who is the owner of the trademark or service mark or to a competitor of that complainant, for valuable consideration in excess of documented out-of pocket costs directly related to the domain name; or

b. Registrant has registered the domain name in order to prevent the trademark holder or service mark from reflecting the mark in a corresponding domain name, provided that Registrant has engaged in a pattern of such conduct; or

c. Registrant registered the domain name primarily for the purpose of disrupting the business of a competitor; or

d. By using the domain name Registrant has intentionally attempted to attract for commercial gain, Internet users to Registrant's web site or other on-line location, by creating a likelihood of

${ }^{418}$ URS dispute providers: -

1. the National Arbitration Forum ("NAF") and

2. the recently approved Asian Domain Name Dispute Resolution Centre ("ADNDRC")

3. MFSD, ICANN today announced that it has signed a Memorandum of Understanding (MoU) with MFSD Srl (MFSD) establishing MFSD as a new URS provider. MFSD, headquartered in Italy, is the first European URS provider. MFSD has a proven track record of handling domain name disputes for the IT ccTLD since 2001. MFSD has also administered cases for the Intellectual Property Mediation Center and Academy authorized by the Italian Ministry of Justice since 2012. Additional URS providers are located in Asia and North America.

Ibid.

ICANN, ICANNAppoints MFSD as First European Uniform Rapid Suspension System Provider, <https://www.icann.org/news/announcement-2-2015-12-16-en>, accessed 10 July, 2016.

${ }^{419}$ Section 1 of the URS Rules.

ICANN, Uniform Rapid Suspension System (URS) Rules, < https://newgtlds.icann.org/en/applicants/urs/rules04mar13-en.pdf >, accessed 10 July, 2016.

${ }^{420}$ Section 1.2.6 of the URS Rules. 
confusion with the complainant's mark as to the source, sponsorship, affiliation, or endorsement of Registrant's web site or location or of a product or service on that web site or location."

Normally, the complaints are reviewed by the URS provider within two days. Further; a "lock" is put on the domain name within 24 hours. ${ }^{421}$ The "lock" prohibits the registrant from making any changes to registration data. This means that no delete or transfer can be done anymore for registration data. ${ }^{422}$ The registrant has 14 days to submit a response. ${ }^{423} \mathrm{~A}$ decision must be issued by the examiner, ${ }^{424}$ no later than 5 business days after the response is submitted. ${ }^{425}$ The only available remedy is the suspension of the domain name in new gTLDs for the rest of the registration period. No deletion, modification or transfer of the domain name in new gTLDs is allowed during the life of the registration. ${ }^{426}$ If the Examiner's decision is in favor of the registrant, then the domain is unlocked and returned to full control of the registrant without any restrictions on registration data. However, if the Examiner's decision is in favor of the complainant, then the domain is redirected to an informational web page of the URS provider and remains locked by the registry. ${ }^{427}$

The registrant has 6 months to file an extra response and ask for another examination. ${ }^{428}$ Unlike the UDRP, the URS also allows for an appeal. ${ }^{429}$ However, the main difference between the URS, PDDRP and the UDRP is that URS stipulates for the penalties for abusive complaints. For example, if a complainant filed two "abusive complaints" and then one complaint involves a "deliberate material falsehood", then the complainant will be prevented from using the URS for one year. Indeed, if a complainant filed two complaints involving a deliberate material falsehood, then the complainant might be permanently barred. ${ }^{430}$

\footnotetext{
421 Section 4.1 of the URS. ICANN, Uniform Rapid Suspension System (URS), <https://newgtlds.icann.org/en/applicants/urs/procedure-01mar13-en.pdf >, accessed 1 July, 2016.

${ }^{422}$ Ibid.

${ }^{423}$ Ibid, Section 5.1.

${ }^{424}$ Section 1 of the URS Rules states that "Examiner" means an individual appointed by a Provider to make a determination.

${ }^{425}$ Section 9.6 of the URS.

${ }^{426}$ Ibid, Section 10.2 .

${ }^{427}$ Ibid, Section 10.

${ }^{428}$ Ibid, Section 6.4.

${ }^{429}$ Ibid, Section 12.

${ }^{430}$ Ibid, Section 11.3.
} 
It would be interesting to cite the first URS Claim in 2013, Facebook Inc. v. Radoslav Claim, ${ }^{431}$ which was a victory for Facebook at the NAF for the following domain name: (<facebok.pw〉). Panelist Darryl Wilson reviewed the above-mentioned three pre-conditions as a following:

- Identical or confusingly similar: the examiner found that "the only difference between the Domain Name, <facebok.pw>, and the Complainant's FACEBOOK mark is the absence of one letter ("o") in the Domain Name...The examiner finds that the Domain Name is confusingly similar to Complainant's FACEBOOK mark." ${ }^{332}$

- Rights or legitimate interests: the examiner also found that the respondent does not have any rights or legitimate interests in the domain name, as Facebook had not licensed or authorized the use of its mark. ${ }^{433}$

- Bad faith registration and use: the examiner found that the domain name was registered and is being used in bad faith for several convincing evidences, such as the landing page contained "sponsored links" and the respondent also had a "pattern of illegal domain name registrations" including others' trademarks. ${ }^{434}$ It would not be exaggerating to say that the respondent was engaged in pattern of "Typosquatting" registration. However, the Panelist Darryl Wilson, ordered to suspend the domain name <facebok.pw> for the duration of the registration. ${ }^{435}$

In summary, the trademark owner during the period of objections, can file an objection against abusive new gTLD application on the basis of the legal rights ground set out as pre-delegation dispute resolution procedure under ICANN's DRSP. The trademark owner might, however, move after the end of the objection period, through the post-delegation dispute resolution procedure under ICANN's PDDRP dispute resolution process within the competent DRSPs. In addition, trademark owners, after the end of the objection period, have another options for out-of-court dispute resolution procedures to settle abusive registration of domain names in new gTLDs, such as, URS and UDRP Policy.

\footnotetext{
${ }^{431}$ National Arbitration Forum, Facebook Inc. v. Radoslav, Claim No. FA1308001515825, Sep. 27, 2013, <http://www.adrforum.com/domaindecisions/1515825D.htm>, accessed 23 July, 2016.

${ }^{432}$ Ibid.

${ }^{433}$ Ibid.

${ }^{434}$ Ibid.

${ }^{435}$ Ibid.
} 


\subsubsection{ICANN's Trademark Clearinghouse Model}

ICANN has also adopted a trademark clearinghouse model, ${ }^{436}$ as the guidebook stipulates a clear provision for the Trademark Clearinghouse (TMCH). ${ }^{437}$ The TMCH was established by ICANN with cooperation with WIPO. ${ }^{438}$ In 2013, the TMCH became operational and now is serving trademark confirmation services to support trademark protection mechanisms in the new gTLDs space. ${ }^{439}$ Currently, TMCH is one of the more recent procedures to address trademark concerns in the new gTLD space. The main role of service providers ${ }^{440}$ are registering and authenticating information connecting to existing trademarks on the "Trademark Clearinghouse" database. ${ }^{441}$ The TMCH is open to:

“- Nationally or regionally registered word marks from all jurisdictions;

- Any word mark that has been validated through a court of law or other judicial proceeding; and - Other marks that constitute intellectual property." ${ }^{\prime 42}$

In addition, "the trademark owner has an affirmative obligation to notify the clearinghouse if a mark is abandoned, cancelled or assigned. Registrations with the clearinghouse will be for a limited period, with a renewal option." ${ }^{433}$

In other words, the clearinghouse database are used to confirm and maintain trademark information from rights holders of trademarks all over the world in centralized database and at the same time, notifies new gTLD registries and registrars, during TLD startup processes, of possible conflict with registered trademarks that are covered by the clearinghouse system. The database might be used as part of the dispute resolution procedure such as ICANN's URS. ${ }^{444}$

\footnotetext{
436 Amer Raja, ICANN's New Generic Top-Level Domain Program and Appication Results, 2012, < www.ipbrief.net/wp-content/uploads/2013/02/IPB_Raja.pdf >, accessed 15 July, 2016.

437 The guidebook includes provisions for the Trademark Clearinghouse - a central repository across new gTLDs for validated data on trademarks. As described in the Applicant Guidebook (AGB) section 5.4.1.

438 Raja, ICANN's New Generic Top-Level Domain Program and Appication Results, <www.ipbrief.net/wpcontent/uploads/2013/02/IPB_Raja.pdf >, accessed 15 July, 2016.

439 ICANN, Trademark Clearinghouse (TMCH), < https://newgtlds.icann.org/en/about/trademark-clearinghouse >, accessed 14 July 2016.

440 ICANN, Trademark Clearinghouse, 2012, < https://newgtlds.icann.org/en/applicants/agb/trademarkclearinghouse-11jan12-en.pdf>, accessed 16 July 2016.

${ }^{441}$ Ibid.

${ }^{442}$ Ibid.

${ }^{443}$ Ibid.

${ }^{444}$ Section 1.2.6.1 of the URS provides that use can be shown by demonstrating that evidence of use - which can be a declaration and one specimen of current use in commerce - was submitted to, and validated by, the TMCH.
} 
Accordingly, during the pre-launch and early-launch periods of new gTLDs, ${ }^{445}$ the TMCH serves trademark proprietors with two main benefits: the sunrise service and the trademark claim notification service. ${ }^{446}$

- $\quad$ Sunrise service. ICANN states that "every new gTLD is required to organize a Sunrise Period of at least 30 days before domain names are offered to the general public." ${ }^{447}$ During this sunrise period, trademark holders that registered their trademark in the TMCH shall have the first right and early opportunity to register a domain name corresponding to their trademark under the new gTLD. ${ }^{448}$

- The "Trademark Claims services" follow the sunrise service. It is a notification service directed by ICANN, during the trademark claims period, ${ }^{449}$ to notify both domain name registrants in new gTLD space as well as trademark owners of potential infringements or conflict with registered trademark within the $\mathrm{TMCH}$ system. ${ }^{450}$ If the domain name registrant registered the domain name, then the trademark owners who has been received a notification of the domain name registration, can take any appropriate action if they are looking for protecting their trademark from any infringement. ${ }^{451}$

ICANN states that "subscription in the TMCH is based on annual fees which cover access to all Sunrise Periods active in that period and all Notifications triggered in that period." ${ }^{452}$ ICANN added that "no extra fees for opting in or out of sunrise services or Trademark Claims notifications" $" 453$

445 Kaufman and Imai, Ready to object? Protecting your Trademark in the New gTLD Regime, <http://www.worldtrademarkreview.com/Magazine/Issue/38/Features/Ready-to-object-Protecting-your-trademarkin-the-new-gTLD-regime>, accessed 9 July, 2016.

$446 \mathrm{TMCH}$, Reasons to Record your Marks in the Trademark Clearinghouse, < http://trademarkclearinghouse.com/content/reasons-record-your-marks-trademark-clearinghouse >, accessed 9 July, 2016.

${ }^{447}$ TMCH, Sunrise Services, <http://trademark-clearinghouse.com/content/sunrise-services〉, accessed 9 July, 2016.

448 Ibid.

${ }^{449}$ Which was maximum 90 days from the date the domain opens to the public.

TMCH, Reasons to Record your Marks in the Trademark Clearinghouse, < http://trademarkclearinghouse.com/content/reasons-record-your-marks-trademark-clearinghouse >, accessed 9 July, 2016.

${ }^{450} \mathrm{TMCH}$, Trademark Claims Services, < http://trademark-clearinghouse.com/content/trademark-claims-services >, accessed 9 July, 2016.

${ }^{451}$ Ibid.

452 TMCH, Reasons to Record your Marks in the Trademark Clearinghouse, < http://trademarkclearinghouse.com/content/reasons-record-your-marks-trademark-clearinghouse >, accessed 9 July, 2016.

453 TMCH, Trademark Agent, < http://trademark-clearinghouse.com/content/trademark-agent >, accessed 9 July, 2016. 
Although recording trademarks with the clearinghouse is not obligatory, the benefits may be worth the expense, not only for key marks in a portfolio, but also for less well-known marks.

In short, the clearinghouse is open for registered trademarks from national or regional jurisdictions; or any trademark that has been validated through a judicial proceeding; and other trademarks that establish intellectual property rights. ${ }^{454}$

454 ICANN, Trademark Clearinghouse, 2012, <https://newgtlds.icann.org/en/applicants/agb/trademarkclearinghouse-11jan12-en.pdf>, accessed 16 July 2016. 


\section{Chapter 3}

\section{Cybersquatting under US and EU Approaches}

\subsection{Overview}

In 1999, cybersquatting has really become a dilemma. Companies were struggling to exist themselves on the cyberspace, which launched a pipeline for cybersquatters. ${ }^{455}$ This dilemma might be addressed in three main scenarios.

First, the trademark proprietor could simply try to buy the domain name from the alleged cybersquatter. On the other hand, it hardly seems as a suitable solution for most trademark proprietors who consider they must protect their trademarks and should not give in to the demands of cybersquatters.

Second, the trademark proprietor could refer to the international cyber arbitration regime put in place by ICANN. UDRP serves as a model ADR process for settling disputes relating to bad faith domain name registrations in some ccTLDs space, and covers all the gTLDs and new gTLDs space. In addition, ICANN introduced the new protection mechanisms in new gTLTD space, including ICANN's pre- and post-delegation Dispute Resolution Procedure, URS, and TMCH Model. ${ }^{456}$

Third, the trademark proprietor could raise a lawsuit based on violating rules of the national legislations. The courts have addressed the problem of cybersquatting by applying traditional trademark infringement and dilution legislations to claims brought by the trademark owner. ${ }^{457}$ Filing anticybersquatting claim under traditional trademark law before the national courts has become much more sophisticated, when the cybersquatters register and/or use trademarked names on the cyberspace without any indication to the products or services. As the trademark legislations provide the legal protection of trademarks with reference to the products and services in the course of trade, but it does not provide any protection against such unauthorized use. Another reason,

\footnotetext{
455 Overbeck, and Belmas, Major Principles of Media Law, p 305.

${ }^{456}$ ICANN, List of Approved Dispute Resolution Service Providers, < https://newgtlds.icann.org/en/ > accessed 16 December 2016.

${ }^{457}$ Chalikian, Cybersquatting, p 106.
} 
some countries provide legal protection only for registered trademark. ${ }^{458}$ As a result, the trademark proprietor could raise a lawsuit based on the violation on the national legislations of trademarks, unfair competition and other related legislation. ${ }^{459}$

However, countries vary in their approaches to cybersquatting. Some countries enacted specific statutes that deal directly with cybersquatting such as U.S. Anti-cybersquatting Consumer Protection Act of 1999. ${ }^{460}$ Others have amended trademark or unfair competition laws to extend and cover an act of unfair competition on the cyberspace. Such an example is the Japanese amendment of Unfair Competition Prevention Act 1993 to protect the owners of the registered and unregistered trademarks by providing that no one may acquire, preserve or use in bad faith a domain name that is identical or similar to a trademark owned by other party. ${ }^{461}$

Other countries such as the U.K did neither enact new anti-cybersquatting laws nor did they amended their unfair competition or trademark laws, but they hinged on the judgements of their courts which treated cybersquatting as an act of trademark infringement. ${ }^{462}$

However, this chapter covers the trademark cybersquatting in ccTLDs and old style of gTLDs as the trademark cybersquatting in new gTLDs space is still a fresh dispute and there are not any precedents in US or EU courts regarding trademark cybersquatting in new gTLDs until the date of writing this thesis.

This chapter examines the domestic rules on anticybersquatting in the U.S. and the EU legal systems, especially those related to the cybersquatting activity. However, this chapter analyzes cybersquatting phenomenon within the frame of legislations and dispute resolution mechanisms whether before the court or out-court dispute resolution mechanisms on regional levels in US, and EU approaches.

\footnotetext{
458 The Cybersquatting phenomenon also generates a tension when it comes to private international law and specifically to jurisdiction and applicable law.

${ }^{459}$ Such as the Anticybersquatting Consumer Protection Act in the U.S.

${ }^{460}$ Govtrack, U.S. Anti-Cybersquatting Consumer Protection Act 1999, <https://www.govtrack.us/congress/bills/106/s1255/text> accessed 30 December 2016.

${ }^{461}$ Hitomi Iwase, Tamao Shinbo and Shinichiro Hara, Japan: Legal Framework, <www.worldtrademarkreview.com/Intelligence/Yearbook/2016/Country-chapters/Japan> accessed 1 January 2017.

462 Talal Abu-Ghazaleh Organization, Laws and Cybersquatting, 2003, <www.agip.com/news.aspx?id=71\&lang=en> accessed 1 January 2016.
} 


\subsection{Cybersquatting in the United States}

The U.S. is considered to be the first country in the world to enact and legislate anti cybersquatters. ${ }^{463}$ As Anahid Chalikian remarks that "the courts have addressed the problem of cybersquatting by applying traditional trademark infringement and dilution laws to claims brought by victims of cybersquatting. However, as trademark law proved to be inadequate in the Internet arena for providing a remedy for trademark owners, Congress passed the Anticybersquatting Consumers Protection Act (ACPA) in November of 1999." 464 In other words, before the ACPA was approved by Congress, the most acceptable remedies to the trademark owners as victims of cybersquatting, were settled by federal trademark law, such as the Lanham Act and the Federal Trademark Dilution Act "FTDA". ${ }^{655}$ Thus, the cybersquatting phenomenon can be resolved also under the U.S. legal system in a multitude of ways, which are covered by trademark laws, including the Lanham Act and the FTDA. The following sections address the legal provisions to deal with cybersquatting acts under "ACPA" 466

This chapter will shed some light upon roots and development of the legal framework of anticybersquatting in USA, legal nature of domain names as property right, and then it will discuss how the U.S. courts had applied the legal provisions to cybersquatting acts, namely, provisions of the ACPA since 1999. Then, it tackles legal issues as sets forth in the ACPA such as in rem jurisdiction under the ACPA, registrar liability and national registration of domain names under “.us" ccTLD.

\footnotetext{
${ }^{463}$ Azmi, Domain Names and Cyberspace: The Application of Old Norms to New Problems, p 195.

${ }^{464}$ Chalikian, Cybersquatting, p 106.

${ }^{465}$ Ibid, p 107.

${ }^{466}$ United States Patent and Trademark Office (USPTO), Report to Congress: The Anticybersquatting Consumer Protection Act Of 1999, <https://www.uspto.gov/web/offices/dcom/olia/tmcybpiracy/repcongress.pdf> accessed 5 December 2016.
} 


\subsubsection{Roots and Development of the Legal Framework of Anti- cybersquatting statute in USA}

The first legislation to fight cybersquatting was heard in Washington. The American legislators were realized that cybersquatting registrations created a dangerous trend to American commerce, consumers, and e-business in general. They had also realized that a new method was needed to combat this a dangerous trend. ${ }^{467}$

On the other hand, the White House opposed, through the legislative process, the proposed new bill to stop cybersquatting via cyberspace. ${ }^{468}$ After the anti-cybersquatting bill was approved in the House of Representatives, White House spokesman Joe Lockhart said, "We believe that fundamentally we'd be walking down the wrong road if we legislated a cybersquatting law and then the 200 or so Internet countries around the world started legislating their own rules and laws." $" 469$

However, the U.S. Senate decided that the uncertainty as to the application of trademark law including the Lanham Act and the ACPA, unpredictable judicial judgements, and expensive legal cost required to stop cybersquatters needed to be treated. ${ }^{470}$ For instances, the FTDA, was considered as a dominant tool for trademark holders to fight cybersquatters. ${ }^{471}$ In simple words, previous to enactment of anticybersquatting statutes in the US, the way to resolve a domain name dispute was by the litigation only through filing a trademark dilution action or a trademark infringement. ${ }^{472}$ The FTDA provides the holder of a famous mark "shall be entitled to an injunction against another person's commercial use in commerce of a mark or trade name, if such use begins after the mark has become famous and causes dilution of the distinctive quality of the famous mark." 473

\footnotetext{
${ }^{467}$ Zohar Efroni, the Anticybersquatting Consumer Protection Act and the Uniform Dispute Resolution Policy: New Opportunities for International Forum Shopping? , Columbia Journal of Law \& the Arts, Vol. 26, 2003, p381.

468 Ibid.

${ }^{469}$ Ibid.

${ }^{470}$ Chalikian, Cybersquatting, p 110.

${ }^{471}$ Fernbach, "What is in a name?" A Comparative Look at the ICANN Uniform Domain Name Dispute Resolution Policy and the United States Anti-Cybersquatting Consumer Protection Act, p 17.

472 Ibid.

${ }^{473}$ Lanham Act, 15 U.S.C. § 1025 (c).
} 
Conversely, the FTDA contained a few gaps and problems that made it difficult to effectively sue and launch action against cybersquatters. According to $§ 1125(\mathrm{c})(1)$ of the FTDA indicates that the suspected cybersquatter's use of the trademark domain name must be commercial nature. This means that any infringer who commits cybersquatting without any commercial purpose shall be exempted from the liability. This gap in the FTDA prohibited the legal action against cybersquatters who had just registered the domain name and did not use in commercial or did not do anything with it, in other words; holding the domain name until trademark holder made an offer to buy that domain name. ${ }^{474}$

Another gap appeared in the wording of the FTDA. The statute provided protection for the proprietor of a famous trademark, but some courts suggested that the trademark had to be distinctive and well-known. For example the Court of Appeals for the Second Circuit has decided that highly distinctiveness is obligatory under the FTDA, as the anti-dilution protection must only cover the highly distinctive famous marks. In Nabisco Inc. v. PF Brands Case $^{475}$ the court provided that "it seems unlikely that the statute contemplates allowing the holders of such common, albeit famous, marks to exclude all new entrants. That is why the statute grants the privilege only to holders of distinctive marks." ${ }^{\prime 46}$ This opinion has effectively prevented a lot of trademark owners to get a relief against cybersquatters under the FTDA. For these reasons, the American legislators had realized an urgent need for a more successful and effective legislation to tackle cybersquatting in the cyberspace.

In Sporty's Farm LLC v. Sportsman's Market, Inc. Case, ${ }^{477}$ the Court of Appeals for the Second Circuit, discussed the gaps and limitations of the FTDA and then the Congress' had responded as follows: “...cybersquatters have become increasingly sophisticated as the case law has developed and now take the necessary precautions to insulate themselves from liability (under the FTDA)." ${ }^{\prime 78}$

\footnotetext{
${ }^{474}$ Fernbach, "What is in a name?" A Comparative Look at the ICANN Uniform Domain Name Dispute Resolution Policy and the United States Anti-Cybersquatting Consumer Protection Act, p 17

${ }^{475}$ Nabisco Inc. v. PF Brands Inc., 191 F.3d 208, 216 (2d Cir. 1999).

476 Ibid.

477 Sporty's Farm LLC v. Sportsman's Market, Inc., 202 F.3d 489, (2000).

${ }^{478}$ Konstantinos Komaitis, the Current State of Domain Name Regulation: Domain Names as Second Class Citizens in a Mark-Dominated World, Routledge, 2010, p 223.
} 
As a result, President Clinton signed into statute the Anti-cybersquatting Consumer Protection Act (ACPA) on 29 November 1999. ${ }^{479}$ The ACPA amended the Lanham Act by adding Section 43(d), which mainly forbids the act of registering, trafficking in or using a domain name that is identical or confusingly similar to a mark or dilutive of a famous mark provided that the act should be with bad faith intent to profit. ${ }^{480}$ The elements of this new federal tort are: (i) the existence of a protected mark (registered or not, including a personal name), (ii) which, without regard to goods and services a corresponding domain name was registered, trafficked or used, (iii) with a bad faith intent to profit from that activity. ${ }^{481}$ For instance, in Sporty's Farm Case, the court decided that the ACPA "was passed to remedy the perceived shortcomings of applying the FTDA in cybersquatting cases" 482 the court added that the ACPA remedies shall effect in cases where the domain name proprietor had not explicitly held out the domain name for the purpose of sale. ${ }^{483}$

Consequently, the trademark principles in US are expanded and amended by issuing the ACPA, in order to apply to a specific dilemmas via cyberspace.

\subsubsection{U.S. Courts Treated Domain Names before 2014 as Property and in 2014 ICANN told U.S. Courts that ccTLDs are not Property}

It has been approved that under the ACPA a domain name is a form of "property" since the ACPA explicitly allows in rem lawsuits, that is, lawsuits against the domain name itself rather than against the domain name owner. ${ }^{484}$

However, the U.S courts adopted various approaches in this regard. For example, in Porsche Cars North America, Inc v. Porsche.net, ${ }^{485}$ Court of Appeals for the Fourth Circuit refused an argument by numerous domain name defendants in an ACPA in rem case that "domain names are not property - only an address." 486 The court indicated that "Congress plainly treated domain names

\footnotetext{
${ }^{479}$ United States Patent and Trademark Office (USPTO), Report to Congress: The Anticybersquatting Consumer Protection Act Of 1999, <https://www.uspto.gov/web/offices/dcom/olia/tmcybpiracy/repcongress.pdf> accessed 5 December 2016.

${ }^{480}$ ACPA, 15 U.S.C. $\$ 1125(\mathrm{~d})(1)(\mathrm{A})$.

481 Ibid.

482 Sporty's Farm LLC v. Sportsman's Market, Inc., 202 F.3d 489, (2000).

${ }^{483}$ Ibid.

${ }^{484}$ ACPA, 15 U.S.C. $\$ 1125(d)$ (1) (A)., 15 U.S.C. $\$ 1125$ (d) (2) (a).

${ }^{485}$ North America, Inc v. Porsche.net, 302 F. 3d 240 (2002).

486 Ibid.
} 
as property in the ACPA. ${ }^{487}$ Indeed, it is clear that a domain name serves as a trademark, and it can be approved as a form of "property". On the other hand, the nature of that "property right", "as one's rights in a trademark have no legal existence independent of the goods or services for which the mark serves as a source identifier." 488 In addition, "in a bankruptcy, the estate of the debtor is composed of all interests in property. Therefore in the ambit of State law collection remedies, a domain name can only form part of the estate of the bankrupt debtor if it is considered to constitute property." 489

As Jacqueline Lipton remarked that "people operating via cyberspace have taken to treating domain names as a species of asset that can be efficiently traded, even if they are not allowed the strict legal status of property; there is nothing wrong with buying and selling domain names. As long as buyers and sellers are willing to form a market, domain names can be traded just like any other commodity." 490 She added that "clearly, possessory securities such as liens and pledges will not be available in this context. Additionally, charges and mortgages are unadvisable until the proprietary status of domain names is clarified. A purported mortgage or charge over a domain name will be worthless while such names are not legally considered to be property capable of giving rise to legal and equitable proprietary interests for the purposes of such arrangements. It is necessary for lenders seeking to take some form of security over an Internet domain name to consider alternatives."491

In the light of the above, there is no doubt that prior to 2014 the U.S courts approved a domain name as form of "property" despite of the reservations in this regards. Nonetheless, a chain of lawsuits were filed by victims of terrorism against North Korea, Iran, and Syria ${ }^{492}$ trying to seize their ccTLDs for damages. ICANN has told the US federal court in 2014 that ccTLDs are not

\footnotetext{
487 Ibid.

488 Robert Badgley, Domain Name Disputes, Aspen Publishers Online, 2002, p15.

489 Caruana, the Legal Nature of Domain Names, <www.elsa.org.mt/wp-content/uploads/2015/02/5.-CaruanaClaudio-The-Legal-Nature-of-Domain-Names.pdf $>$ accessed 11 December 2016.

490 Jaqueline Lipton, What's in a Domain Name? , 1999,

<https://www2.warwick.ac.uk/fac/soc/law/elj/jilt/1999_2/lipton/> accessed 11 May 2016.

491 Ibid.

492 ICANN's arguments were put forth when the victims of terrorism who had successfully won lawsuits against Iran, Syria and North Korea, sought to collect on those civil judgments. In their attempt to recover assets from these countries, the plaintiffs served ICANN with "writs of attachment" and subpoenas seeking information to help them seize the ccTLDs of those nations.
} 
property and cannot be seized and has filed a clue to dismiss the request. ${ }^{493}$ The victims of terrorism and their families filed lawsuits to recover compensations what they hold to be state sponsorship of terrorism. ${ }^{494}$

John Jeffrey, ICANN's General Counsel and Secretary, said "we filed a Motion to Quash in the US federal court today, to ensure that the court has the essential information about how the Internet's domain name system (DNS) works. While we sympathize with what plaintiffs may have endured, ICANN's role in the domain name system has nothing to do with any property of the countries involved", 495 Jeffrey added "we explained in our Motion to Quash, that country code Top-Level Domains (ccTLD) are part of a single, global interoperable Internet which ICANN serves to help maintain." ${ }^{, 96} \mathrm{He}$ further clarified that "ccTLD's are not property, and are not 'owned' or 'possessed' by anyone including ICANN, and therefore cannot be seized in a lawsuit." 497

Notwithstanding whether or not these countries in question are guilty of these claims, seizing their ccTLDs for these countries is not a suitable action and would be prepared for a global episode. As any attempts to unconnectedly appropriate the ccTLDs by a single country of others would run against to the crucial multi-stakeholder framework of internet governance and would disrupt and interrupt the global DNS. ${ }^{498}$ Despite the fact that ICANN is based in the U.S., it is purely a doorkeeper for cyberspace and should continue to attend that role.

\footnotetext{
${ }^{493}$ Domainnews, In Case over Attempts to Seize Iran's ccTLD, ICANN Tells Court ccTLDs Are Not Property, <www.domainnews.com/icann-cctlds-are-not-property/> accessed 13 May 2016.

${ }^{494}$ ICANN, ICANN Tells U.S. Court That ccTLDs Are Not "Property": Files Motion to Quash in U.S. Legal Action Aimed at Seizing Top-Level Domains, 2014, <https://www.icann.org/resources/press-material/release-2014-07-30en> accessed 13 May 2016.

${ }^{495}$ Ibid.

${ }^{496}$ Ibid.

${ }^{497}$ Ibid.

${ }^{498}$ The multistakeholder governance framework "has three components: it is informed by

a) opened-ended unleashed innovation (infrastructure)

b) decentralized governance institutions (governance) and,

c) open and inclusive processes (human)."

Internet Society, Internet Governance - Why the Multistakeholder Approach Works, 2016, $<$ https://www.internetsociety.org/doc/internet-governance-why-multistakeholder-approach-works> accessed 20 July 2016.
} 


\subsubsection{The Mechanism of the Anticybersquatting Consumer Protection Act (ACPA)}

Notwithstanding, its name "Anti-cybersquatting Consumer Protection Act", the main purpose of issuing the ACPA is to protect the trademark proprietors against cybersquatting acts. In Ford Motor Co. v. GreatDomains.com, Inc. Case, the court held that the ACPA "does not have consumer protection as its central purpose. ${ }^{" 499}$ Fairly, the ACPA was issued primarily to protect trademark proprietors "against extortion by the domain name cybersquatters." $" 500$ To carry on a lawsuit under the ACPA, a trademark lawsuit must be filed, too. The costs of launching a lawsuit differ, but certainly an ACPA proceeding is much more expensive than the UDRP procedure. Further, under the ACPA, the court can rule with award up to $\$ 100,000$ in damages each unlawfully registered domain name, but this relief is not accessible under UDRP. ${ }^{501}$ The ACPA lawsuit is certainly a novel mechanism to protect trademark proprietors against cybersquatters in digital age.

However, the ACPA explicitly entitles the proprietor of a distinctive or well-known trademark to sue the owner of a domain name that is identical or confusingly similar to the holder's mark if the owner of domain name had a "bad faith intent" to profit from that trademark. Section 43 (d) (1) (a) of the ACPA provides as follows: "A person shall be liable in a civil action by the owner of a mark, including a personal name which is protected as a mark under this section, if, without regard to the goods or services of the parties, that person--

(i) has a bad faith intent to profit from that mark, including a personal name which is protected as a mark under this section; and

(ii) registers, traffics in, or uses a domain name that:-

(I) in the case of a mark that is distinctive at the time of registration of the domain name, is identical or confusingly similar to that mark;

(II) in the case of a famous mark that is famous at the time of registration of the domain name, is identical or confusingly similar to or dilutive of that mark." 502

\footnotetext{
${ }^{499}$ Ford Motor Co. v. GreatDomains.com, Inc. 177 F. Supp. 2d 628, 643 (2001).

${ }^{500}$ Ibid.

501 Office of General Counsel of the California State University, Protecting Internet Domain Names, 2004, <https://www.calstate.edu/gc/Docs/Domain_Name_Handbook.doc> accessed 20 July 2016.

502 ACPA, 15 U.S.C. $§ 43$ (d) (1) (a).
} 
In the light of this wording, the holder of trademark must establish that the owner's domain name is identical or confusingly similar to the holder's trademark, and has bad faith intent to profit from that trademark. On the other hand, in cases where the trademark is well-known, the holder of famous trademark must build a litigation base that the owner's domain name is dilutive of his trademark. ${ }^{503}$ On the other hand, the ACPA does not forbid the use of any combination of letters that are similar to trademark. What requires is that the domain name is confusingly similar to that trademark. The court in Virtual Works, Inc. v. Volkswagen of Am., Inc., ${ }^{504}$ held that "the ACPA was not enacted to give companies the right to fence off every possible combination of letters that bears any similarity to a protected mark." 505

In other words, the ACPA mainly forbids the act of registering, trafficking in or using a domain name that is identical or confusingly similar to a mark or dilutive of a famous mark provided that the act should be with bad faith intent to profit. ${ }^{506}$ The elements of this new federal tort are:

(i) the existence of a protected mark (registered or not, including a personal name),

(ii) which, without regard to goods and services a corresponding domain name was registered, trafficked or used,

(iii) with a bad faith intent to profit from that activity. 507

In the following part, the aforementioned elements will be discussed in details respectively:

\subsubsection{1. "Identity or Confusing Similarity" Standard}

The ACPA's cybersquatting concept relays to trademarks, and thus forms two dissimilar standards: one for famous marks, and another standard for distinctive marks. ${ }^{508}$ Protection by the law is activated when the trademark in question is either famous, distinctive, or both at the time the domain name owner registered the domain name, thus providing also a protection for non-well-

\footnotetext{
503 ACPA, 15 U.S.C. $\$ 1125$ (d) (1) (A) (ii) (II).

${ }^{504}$ Virtual Works, Inc. v. Volkswagen of Am., Inc, 238 F. 3d 264, (2001).

505 Ibid.

506 ACPA, 15 U.S.C. $\$ 1125$ (d) (1) (A).

${ }^{507}$ Ibid.

${ }^{508}$ Cyber Harvard, Anti-Cybersquatting Piracy Act (ACPA),

<https://cyber.harvard.edu/property00/domain/legislation.html> accessed 20 July 2016.
} 
known or non-famous marks. It is clear that "famous" or "distinctive" are not defined by the ACPA.

The term "distinctive" is referring to the uniqueness that a trademark enjoys within Lanham Act. ${ }^{509}$ The relative distinctiveness of a trademark determines the degree of protection it can receive. There is not any definition for the term "famous" within the ACPA. The fact that the ACPA's adopted the famousness or goodwill concept as its use in the FTDA.

Generally, the likelihood of confusion standard under trademark infringement claim requires and involves a more examination than the confusingly similarity standard under ACPA claim. ${ }^{510}$

In Northern Light Technology v. Northern Lights Club Case, ${ }^{511}$ the trademark owner wanted a relief on the basis of a claim under the ACPA and trademark infringement claim. The court said that the ACPA's confusingly similar requirement was insufficient to a mere "comparison of the mark and the allegedly offensive domain name". 512 Conversely, on the subject of the trademark infringement claim, the court held that the domain name "northernlights.com" is similar to the trademark "Northern Light". Such similarity "is determined on the basis of the designation's total effect and infringement does not exist, though the marks be identical and the goods very similar, when the evidence indicates no likelihood of Confusion." $" 513$

However, it has been decided that the likelihood of confusion standard employed in trademark infringement cases is different standard and not the same as the identity or confusing similarity standard under the ACPA. In Sporty's Farm, ${ }^{514}$ the court decided that "we note that 'confusingly similar' is a different standard from the 'liklihood of confusion' standard for trademark infringement." ${ }^{515}$ On the other hand, measured misspelling or spelling mistake of a domain name for the aims of leading a consumers from the trademark holder's web pages to the domain name owner or cybersquatter's own web pages is clearly unlawful under the ACPA on condition that it

\footnotetext{
${ }^{509}$ Lanham Act, 15 U.S.C. $§ 1052$.

${ }^{510}$ Badgley, Domain Name Disputes, p 9.

${ }^{511}$ Northern Light Technology v. Northern Lights Club 97 F. Supp. 2d 96, 110 (2000).

512 Ibid.

513 Ibid.

514 Sporty's Farm LLC v. Sportsman's Market, Inc., 202 F.3d 489, (2000).

515 Ibid.
} 
is confusingly similar to the trademark in question. In Shields v. Zuccarini, ${ }^{516}$ the court concluded that "Cybersquatters often register well-known marks to prey on consumer confusion by misusing the domain name to divert customers from the mark owner's site to the cybersquatter's own site, many of which are pornography sites that derive advertising revenue based on the number of visits, or "hits", the site receives." In the same way, the court added "for example, the Committee was informed of a parent whose child mistakenly typed in the domain name for 'dosney.com', expecting to access the family-oriented content of the Walt Disney home page, only to end up starting at a screen of hardcore pornography because a cybersquatter had registered that domain name in anticipation that consumers would make that exact mistake." 517

\subsubsection{The "Bad Faith" Requirement}

Under ACPA the trademark owner shall establish that the domain name owner had a bad faith intent to profit from the holder's mark. The concept of "bad faith" is governed by ACPA 1125 (d) (1) (B), which provides as follows:

"In determining whether a person has a bad faith intent described under subparagraph (A), a court may consider factors such as, but not limited to-

(I) the trademark or other intellectual property rights of the person, if any, in the domain name

(II) the extent to which the domain name consists of the legal name of the person or a name that is otherwise commonly used to identify that person;

(III) the person's prior use, if any, of the domain name in connection with the bona fide offering of any goods or services;

(IV) the person's bona fide noncommercial or fair use of the mark in a site accessible under the domain name;

(V) the person's intent to divert consumers from the mark owner's online location to a site accessible under the domain name that could harm the goodwill represented by the mark, either

\footnotetext{
516 Shields v. Zuccarini, 254 F. 3d 476, (2001).

517 Ibid.
} 
for commercial gain or with the intent to tarnish or disparage the mark, by creating a likelihood of confusion as to the source, sponsorship, affiliation, or endorsement of the site;

(VI) the person's offer to transfer, sell, or otherwise assign the domain name to the mark owner or any third party for financial gain without having used, or having an intent to use, the domain name in the bona fide offering of any goods or services, or the person's prior conduct indicating a pattern of such conduct;

(VII) the person's provision of material and misleading false contact information when applying for the registration of the domain name, the person's intentional failure to maintain accurate contact information, or the person's prior conduct indicating a pattern of such conduct;

(VIII) the person's registration or acquisition of multiple domain names which the person knows are identical or confusingly similar to marks of others that are distinctive at the time of registration of such domain names, or dilutive of famous marks of others that are famous at the time of registration of such domain names, without regard to the goods or services of the parties; and (IX) the extent to which the mark incorporated in the person's domain name registration is or is not distinctive and famous within the meaning of subsection (c)(1) of section 43 [subsec. (c)(1) of this section].

(ii) Bad faith intent described under subparagraph (A) shall not be found in any case in which the court determines that the person believed and had reasonable grounds to believe that the use of the domain name was a fair use or otherwise lawful." ${ }^{518}$

These factors are essentially guidelines and non-exclusive to support the court in determining whether there is an existence of bad faith or not. Equally, in determining, whether there is an existence of bad faith, a court may consider the above non-exclusive factors. Each case will depend upon the circumstances of the case. In other words, some of these factors in a number of cases may be significant while in others may not, and the decision may be based on other factors that are not listed above.

It is clear that ACPA stated very important factor which is "whether the mark is famous or dilutive; or whether the defendant knowingly registered multiple domain name that are identical or

${ }^{518}$ ACPA, 15 U.S.C. $\$ 1125$ (d) (1) (B). 
confusingly similar to distinctive marks or dilute famous marks of others that are famous at the time of registration of such domain names without regard to the goods or services of such persons." 519 This factor looks to protect the innocent registrant by requiring that the defendant in a cybersquatting claim have knowledge that the domain name in question was identical or confusingly similar to the mark of another. It also notes that the court should examine famousness at the time of registration of the domain name in question. ${ }^{520}$ While a trademark receives protection from uses that are identical or confusingly similar to the trademark, famous marks receive protection under a more liberal standard. ${ }^{521}$

It is very important to note that the defendants have liability only if they are domain names registrants or their authorized licensee. For example, in Fare Deals, Ltd v. World Choice Travel.com, Inc. Case, ${ }^{522}$ the plaintiff, as a trademark owner, was a travel services provider under the mark "Fare Deals". However, the plaintiff litigated the first defendant who is the proprietor of the domain name "faredeals.com", and the second defendant was HRN, which provided online hotel-booking services at its own Web site. As a contract with the domain name owner, and HRN's Website was manageable via a hyperlink on the "faredeals.com". The court dismissed the case against HRN, it held that HRN was not the registrant of "faredeals.com" and HRN did not sign a license agreement as a licensee of that registrant. The fact that a hyperlink at the "faredeals.com" website led to HRN's site was not considered sufficient to render HRN responsible under the ACPA. ${ }^{523}$ It could be concluded from this precedent that ACPA was primarily issued to prevent cybersquatters from registering domain names that infringe the mark's holder, which means that other acts that took place via internet shall not be considered as an actionable under the ACPA, such as hyperlinking.

\subsubsection{The Defense in Cybersquatting Claim}

ACPA provides that the bad faith shall not be found "in any case in which the court determines that the person believed and had reasonable grounds to believe that the use of the domain name

\footnotetext{
519 Ibid, $\$ 1125$ (d) (1) (B) (i) (VI).

${ }^{520}$ Ibid, $§ 1125$ (d) (1)(A)(ii)(I).

${ }^{521}$ Ibid.

${ }^{522}$ Fare Deals, Ltd v. World Choice Travel.com, Inc., 180 F. Supp. 2d 678 (2001).

523 Ibid.
} 
was a fair use or otherwise lawful." 524 Thus, if such concept is proven by the ACPA defendant the court shall reject the case.

In Chatam International, Inc. v. Bodum, Inc., ${ }^{525}$ the plaintiff traded "Chabord" liqueur and the defendant traded "Chambord" coffee makers. The defendant, as domain name owner, registered "chambord.com" and used that domain name to sell its products online. The court rejected the plaintiff's claim on the grounds of the "safe harbor"

On the other hand, the court, in E. \& J. Gallo Winery v. Spider Webs Ltd., ${ }^{528}$ rejected the "safe harbor" defense. The defendant registered the domain name "ernestandjuliogallo.com". The court said that the defendant "cannot legitimately contend that it believed or had reasonable grounds to believe that its registration and use of the domain name... was a fair use or otherwise lawful." ${ }^{, 029}$ The court disallowed the "safe harbor" defense on the basis that the defendant did not seek any advice from counsel as to whether it might be engaging in infringement conduct which violate the legal provisions. The court added that the defendant's failure to seek counsel's advice "supports a finding of bad faith." 530

In addition, the US courts stated that if the defendant deeds were even partially or incompletely in bad faith in terms of registration and use of that domain name, the "safe harbor" defense will not be effective. For example, in Victoria's Secret Stores v. Artco Equipment Co. Inc., ${ }^{531}$ the court held that "a defendant who acts even partially in bad faith in registering a domain name... is not entitled to benefit from the ACPA's safe harbor provision." 532 The court added that this policy "prevents the safe harbor from eviscerating the statute." 533 It is very obvious that the US courts had adopted an absolute standard in "safe harbor" cases, ${ }^{534}$ especially when the defendant deeds were even

\footnotetext{
${ }^{524}$ ACPA, 15 U.S.C. $\$ 1125$ (d) (1) (B) (ii).

525 Chatam International, Inc. v. Bodum, Inc., 157 F. Supp 2d 549 (2001).

${ }^{526}$ A safe harbor is a provision of a statute that clarifies that the conduct will not be considered to violate a given rule.

527 Ibid.

${ }^{528}$ E. \& J. Gallo Winery v. Spider Webs Ltd., 129 F. Supp. 2d 1033 (2001).

${ }^{529}$ Ibid.

${ }^{530}$ Ibid.

${ }^{531}$ Victoria's Secret Stores v. Artco Equipment Co., Inc., 194 F. Supp. 2d. 270 (2001).

532 Ibid.

533 Ibid.

${ }^{534}$ ACPA, 15 U.S.C. $\$ 1125$ (d) (1) (B) (ii).
} 
incompletely in bad faith in terms of registration and use of that domain name, the "safe harbor" defense will not be effective.

\subsubsection{Remedies under the ACPA}

US courts are permitted under the ACPA, to issues remedies such as transfer or cancel the domain name, ruling injunctive relief, award damages and attorney fees, which will be examined respectively herein.

Similar to the remedies under the UDRP, the ACPA also enables the courts to cancel the domain name or transfer the domain name to the owner of the trademark. ${ }^{535}$ Section $1125(\mathrm{~d})(1)(\mathrm{c})$ of the ACPA provides that: "in any civil action involving the registration, trafficking, or use of a domain name under this paragraph, a court may order the forfeiture or cancellation of the domain name or the transfer of the domain name to the owner of the mark." 536

In the light of the foregoing, the court is clearly authorized to order the forfeiture or cancellation of the domain name or to transfer the domain name to the owner of the mark. For example, in Coca-Cola Co. v. Purdy, ${ }^{537}$ the defendant was the proprietor for many domain names including; "drinkcoke.org", "mycocacola.com", indicating for a famous trademarks, such as; "Pepsi" and "McDonalds", and he connected those domain names to other web-pages. The plaintiffs, including McDonald's, Coca-Cola, and PepsiCo, were looking for preliminary injunction and an urgent short-term restraining order against the defendant under the ACPA. The court ruled the preliminary injunction and temporary restraining order requests, among other things, that the defendant must transfer each of the disputed domain names to the suitable plaintiff within three days of the court order. $^{538}$

In addition, the court can award actual damages and attorney fees to the trademark proprietor, pursuant to the remedial provision of the Lanham Act. ${ }^{539}$ Also, the trademark proprietor may choose during trial procedure and before the final verdict is issued by the trial court to recover,

\footnotetext{
${ }_{535}^{535}$ ACPA, 15 U.S.C. $\S 1125(\mathrm{~d})(1)(\mathrm{c})$.

${ }^{536}$ Ibid.

${ }^{537}$ Coca-Cola Co. v. Purdy, 194 F. Supp. $2 \mathrm{~d} 704$ (2002).

${ }^{538}$ Ibid.

${ }^{539}$ Lanham Act, 15 U.S.C. § 1117.
} 
instead of actual damages and profits, an award of statutory damages in the amount of not less than $\$ 1000$ and not more than $\$ 100.000$ per domain name under the ACPA. ${ }^{540}$

As Jeffrey Davidson says 'the statutory damages amount is left to the court's discretion presumably, the more odious the cybersquatter's actions, the higher the award." 541 The statutory damages are rendered for actual damages and lost profits. On the other hand, statutory damages are only effective for domain names that were registered after the date of 29 November 1999 which was the date of effect ACPA. ${ }^{542}$ Furthermore, the ACPA also provides for the awarding of attorney's fees and costs, for instances, if the defendant's conduct is “malicious, fraudulent, willful or deliberate in nature." ${ }^{, 54}$ This remedy can be applied retrospectively, and dissimilar with the statutory damages provision of the ACPA.

For example, in United Greeks v. Klein, ${ }^{544}$ the court ruled for statutory damages and attorney fees at the same time. The plaintiff was awarded $\$ 10,000$ statutory damages, about $\$ 2.000$ per domain name, and also the attorney fees were $\$ 5,950$ assessed against the defendant. ${ }^{545}$

In Shields v. Zuccarini, ${ }^{546}$ the plaintiff had domain name "joecartoon.com" and the trademark rights holder in "Joe Cartoon". The defendant registered five domain names that differed slightly from the plaintiff's domain name, for example, "joecarton.com". ${ }^{447}$ The defendant confessed that his goal was to attract Internet users to his Web site by misspelling the plaintiff's domain name. Applying the ACPA, the court held that the defendant must deactivate his Web sites during the pendency of the lawsuit. The court finally awarded $\$ 10,000$ statutory damages per domain name, and $\$ 39,109$ attorney fees. ${ }^{548}$

\footnotetext{
540 Ibid.

${ }^{541}$ Jeffrey Davidson, Posts Tagged 'Anticybersquatting Consumer Protection Act, <https://davidsontm.wordpress.com/tag/anticybersquatting-consumer-protection-act/> accessed 20 July 2016.

${ }^{542}$ United States Patent and Trademark Office (USPTO), Report to Congress: The Anticybersquatting Consumer Protection Act Of 1999, <https://www.uspto.gov/web/offices/dcom/olia/tmcybpiracy/repcongress.pdf> accessed 5 December 2016.

${ }^{543}$ Fernbach, "What is in a name?” A Comparative Look at the ICANN Uniform Domain Name Dispute Resolution Policy and the United States Anti-Cybersquatting Consumer Protection Act, p 2.

Pinehurst, Inc. v. Wick, 256 F. Supp. 2d 424, 433 (2003).

Ethical Treatment of Animals v. Doughney, 263 F.3d 359, 370 (2001).

${ }^{544}$ United Greeks v. Klein, 2000 U.S. Dist. LEXIS 5670, (2000).

${ }^{545}$ Ibid.

546 Shields v. Zuccarini, 254 F. 3d 476, (2001).

547 Ibid.

${ }^{548}$ Ibid.
} 
Finally, in Mattel, Inc. v. Adventure Apparel, ${ }^{549}$ the court ruled that the defendant was liable under the ACPA for using and registering the domain name "barbiesbeachwear.com" and "barbiesclothing.com". ${ }^{550}$ In addition the court had held to cancel those two domain name registrations and awarded $\$ 2,000$ in statutory damages. Further, the court "enjoined the defendant from further violations of the ACPA with respect to trademarks owned by Mattel." ${ }^{551}$

\subsubsection{In Rem Jurisdiction ${ }^{552}$ and the ACPA}

It is clear that ACPA had interested in respect of cybersquatters who live outside and inside of the U.S., and may have provided false registration information for the domain name registrars in order to disappear. 553 "The ACPA is broadly divided into two parts: (i) the trademark section, which imposes liability on a person engaged in the act of cybersquatting by employing a traditional personal jurisdiction analysis, and (ii) the in rem section, which provides jurisdiction over the actual domain name by targeting the situs of the domain name registry (ie, location) and asserting jurisdiction over the domain name's res, or property interest."

Accordingly, the ACPA provides a provision enabling for in rem actions, which are lawsuits against the domain name itself. It would not be exaggerating to say that it is stressful duty for the U.S. courts to hear cases against cybersquatter who, in most cases, live in another country and may have provided false contact information with the domain name registrar. ${ }^{555}$

The ACPA plaintiff would find it useful to recourse to Section 1125 (d) (2) (a) of the ACPA which stipulates as follows:

"(A)The owner of a mark may file an in rem civil action against a domain name in the judicial district in which the domain name registrar, domain name registry, or other domain name authority that registered or assigned the domain name is located if--

\footnotetext{
${ }^{549}$ Mattel, Inc. v. Adventure Apparel, 2001 U.S. Dist. LEXIS 13885, (2001).

${ }^{550}$ Ibid.

551 Ibid.

552 is a Latin phrase means "status" against a person over whom the court does not have in personam jurisdiction.

${ }^{553}$ Fernbach, "What is in a name?" A Comparative Look at the ICANN Uniform Domain Name Dispute Resolution Policy and the United States Anti-Cybersquatting Consumer Protection Act, p 22.

554 Karin Segall and Ellen Dowling, the ACPA's Role in International Domain Name Dispute Resolution, <www.worldtrademarkreview.com/Blog/detail.aspx?g=8315e447-300a-4483-871b-73503abe7bdf> accessed 21 July 2016.

555 ACPA, 15 U.S.C. $\$ 1125$ (d) (2) (a).
} 
(i) the domain name violates any right of the owner of a mark registered in the Patent and Trademark Office, or protected under subsection (a) or (c); and

(ii) the court finds that the owner--

(I) is not able to obtain in personam jurisdiction over a person who would have been a defendant in a civil action under paragraph (1);

or

(II) through due diligence was not able to find a person who would have been a defendant in a civil action under paragraph (1) by-

(aa) sending a notice of the alleged violation and intent to proceed under this paragraph to the registrant of the domain name at the postal and e-mail address provided by the registrant to the registrar; and

(bb) publishing notice of the action as the court may direct promptly after filing the action."556

According to the wording above, the ACPA provides an in rem cause of action which qualifies the ACPA plaintiff (trademark owner) to initiate an in rem civil action against a domain name itself in the judicial district in which the domain name registry, domain name registrar or other domain name authority is located if the ACPA plaintiff met certain factors. ${ }^{557}$ However, to allow such in rem jurisdiction, the court must find that the trademark holder either is unable to get in personam jurisdiction over the domain name holder, or he was unable to find a domain name holder by sending due notification of the dispute to the domain name holder at the postal and e-mail addresses provided by the domain name holder to the registrar, and publishing notification of the lawsuit as the court may promptly direct after filing the action. ${ }^{558}$

In Mission v. Shajmarg.org ${ }^{559}$ the court held that publication was mandatory in the ACPA in rem cases. The court obliged the plaintiff for a publication of notice of the lawsuit within two weeks in India Abroad, India Abroad online, and the Washington Post. ${ }^{560}$

\footnotetext{
556 Ibid.

557 Ibid.

${ }^{558}$ Ibid.

${ }^{559}$ Mission v. Shajmarg.org, 139 F. Supp. 2d 721, 723-724 (2001).

${ }^{560}$ Ibid.
} 
In Lucent Technologies, Inc. v. Lucentsucks.com ${ }^{561}$ the court discharged the plaintiff's in rem ACPA lawsuit against the domain name "lucentsucks.com". The court dismissal of the claim was based on shortages of the ACPA, as the plaintiff was able to search and find the domain name registrant as well as the plaintiff filed the in rem suit only after eight days of sending notice. The court held it was very short for a notice period to fulfil according to the process under the ACPA. ${ }^{562}$

The proprietor of trademark may select between in rem claim and in personam ${ }^{563}$ claim under the ACPA, but not both of them. In Alitalia-Linee Aeree Italiane S.p.A. v. Casinoalitalia.com, ${ }^{564}$ the defendant had website support an online casino. The plaintiff, was an Italian airline, filed a lawsuit against the defendant under the Lanham Act and the ACPA. The court decided that the plaintiff could not instantaneously uphold an in personam ACPA action and an in rem ACPA action. The court confirmed that one of the two ways for the trademark owner to establish in rem jurisdiction was to display that the personal jurisdiction over the defendant domain name is nonexistent.

Additionally, the U.S. courts held that the ACPA applies, as well, on U.S. trademarks and non U.S. trademarks. For example, in Barcelona.com, Inc. v. Excelentisimo Ayuntamiento de Barcelona Case ${ }^{565}$ the defendant "City Council of Barcelona, Spain", had succeeded in an ICANN dispute over "Barcelona.com". ${ }^{566}$ As the plaintiff was not winning in an ICANN dispute, then he quickly filed a lawsuit in federal court, seeking an affirmation that its possession and use of that domain name were not illicit. The defendant "City Council of Barcelona" had also prevailed in front of the court. The court held that the City Council's Spanish trademark were subject to the ACPA's protection. The court remarked that Congress had drawn no distinction between U.S. and foreign marks. ${ }^{567}$

It is very clear that under in rem jurisdiction, the remedies are limited to a court order for forfeiture or cancellation of the domain name, or its transfer to the trademark owner.

\footnotetext{
${ }^{561}$ Lucent Technologies, Inc. v. Lucentsucks.com, 95 F. 2d 528 (2000).

562 Ibid.

563 In personam is a Latin phrase meaning directed toward a particular person.

${ }^{564}$ Alitalia-Linee Aeree Italiane S.p.A. v. Casinoalitalia.com, 128 F. Supp. 2d 340 (2001).

${ }^{565}$ Barcelona.com, Inc. v. Excelentisimo Ayuntamiento de Barcelona, 189 F. Supp. 2d 367 (2002).

566 Ibid.

${ }^{567}$ Ibid.
} 
In other words, in rem action enables trademark holder to file lawsuit against domain name itself, which means that a foreigner registrant of domain name in gTLDs space could find their domain name transferred canceled or even seized by a US court order pursuant to the ACPA's in rem provisions, which are under ICANN's management. ${ }^{568}$

\subsubsection{Registrar's Liability and the ACPA}

As previously mentioned, the registrar of a domain name is the authorized authority for its cancellation, suspending or transferring the same by virtue of its rules that govern the relation between the registrar and the domain name owner. ${ }^{569}$ In this context, the question that should be answered is whether the registrar could be held responsible or liable for its role in registration, cancellation, transferring or suspending its client's domain name under the U.S. legislation?

In Lockheed Martin Corp. v. Network Solutions, Inc. ${ }^{570}$ the plaintiff sued defendant "registrar NSI" in connection with the latter's acting of permitting persons to register domain names that definitely infringe on trademark "Lockheed". The court, refused plaintiff's argument that, NSI was liable for trademark infringement because its domain name registration deeds. The court stated that NSI provided the domain name registration service and did not contribute or support the actual use of the domain name holder. ${ }^{571}$

In Zurakov v. Register .com, ${ }^{572}$ the plaintiff sought compensation for damages against the defendant "Register.com" (registrar). As the reason for asking damages was that Register.com linked the plaintiff's new domain name "laborzionist.org" to a "Coming Soon Page." The plaintiff claimed that "Register.com" did not advise or tell him that such content and ads would arise or appear on his Web site, and sought damages for this breach. The court rejected plaintiff's argument, and dismissed this complaint. The court stated that pursuant to the domain name service contract between the parties, the registrar "Register.com" retained the right to "suspend, cancel, transfer or

\footnotetext{
568 Segall and Dowling, the ACPA's Role in International Domain Name Dispute Resolution, <www.worldtrademarkreview.com/Blog/detail.aspx?g=8315e447-300a-4483-871b-73503abe7bdf> accessed 21 July 2016.

569 ICANN, Non-Lawyers' Guide to the May 2009 Registrar Accreditation Agreement, <https://www.icann.org/resources/pages/non-lawyers-guide-2010-02-15-en> accessed 12 December 2016.

${ }^{570}$ Lockheed Martin Corp. v. Network Solutions, Inc., 197 F.3d 980 (1999).

${ }^{571}$ Ibid.

${ }^{572}$ Zurakov v. Register .com, 600703/01 (2001).
} 
modify [plaintiff's] use of the service at any time, for any reason, in [Register.com] sole discretion." 573

Indeed, the domain name registration agreement between a registrar and the registrant is normally complete with provisos of liability, hold-harmless conditions, and stipulate covenants that the registrant cannot litigate or sue the registrar at all.

For example, the UDRP contains two provisions claiming to isolate the registrar from responsibility or liability. First, paragraph 4 (h) of the UDRP states that "we [the registrar] do not, and will not, participate in the administration or any conduct of any proceeding before an Administrative Panel. In addition, we will not be liable as a result of any decisions rendered by the Administrative Panel." Second the paragraph 6 of the UDRP provides as follows:

"We will not participate in any way in any dispute between you and any party other than us regarding the registration and use of your domain name. You shall not name us as a party or otherwise include us in any such proceeding. In the event that we are named as a party in any such proceeding, we reserve the right to raise any and all defenses deemed appropriate, and to take any other action necessary to defend ourselves." 574

Similarly, the ACPA provides legal protection for domain name registrars in the event of an ACPA action. ${ }^{575}$ It is required for the registrar to deposit with the court documents "sufficient to establish the court's control and authority" ${ }^{576}$ for the domain name registration in question of the dispute, and the registrar may not "transfer, suspend, or otherwise modify the domain name" period of the pendency of the lawsuit, except by court order. The ACPA also provides that "the domain name registrar or registry or other domain name authority shall not be liable for injunctive or monetary relief under this paragraph except in the case of bad faith or reckless disregard, which includes a willful failure to comply with any such court order." 578

\footnotetext{
${ }^{573}$ Ibid.

${ }^{574}$ Paragraph 6 of the UDRP Policy.

${ }^{575}$ ACPA 15 U.S.C. $\$ 1125$ (D) (2) (d) (ii).

${ }^{576}$ Ibid.

577 Ibid.

${ }^{578}$ Ibid.
} 


\subsubsection{National Registration of Domain Names under ccTLD (.us) for the United States}

Historically, on February 15, 1985, us was the first ccTLD in the world. ${ }^{579}$ "Its original administrator was Jon Postel of the Information Sciences Institute (ISI) at the USC. He administered (.us) under a subcontract that the ISI and USC had from SRI International (which held the (.us) and the gTLD contract with the United States Department of Defense) and later Network Solutions (which held the (.us) and the gTLD contract with the National Science Foundation). ${ }^{, 580}$ In October 1998, Postel died. The NSF transferred the control of the .us domain to the National Telecommunications and Information Administration (NTIA) of the United States Department of Commerce. In 2000, these duties were transferred to Network Solutions, which had recently been obtained by Verisign (Internet Company). ${ }^{581}$

In 2001, Neustar was given the contract to manage (.us). In 2007, Neustar's contract was renewed by the NTIA and recently in $2014 .^{582}$

However, Robert Badgley remarks that "Many nations restrict the availability of their countrycode TLD to their own citizens or foreign persons who have a sufficient local presence. (Other nations, of course, have thrown open their ccTLD to the entire world). The United States ccTLD, “.us," may be registered on a first-come, first-served basis. However, a foreign person or entity is subject to having a ".us" domain name taken a ways if a successful challenge is mounted under the us Nexus Dispute Policy (usNDP)." ${ }^{583}$ In order to register a domain name that uses the .us TLD, some additional information known as the Nexus requirements must be provided as a following: "Registrants in the usTLD must be either:

1. A natural person (i) who is a United States citizen, (ii) who is a permanent resident of the USA or any of its possessions or territories, or (iii) whose primary place of domicile is in the USA or any of its possessions [Nexus Category 1],

\footnotetext{
${ }^{579}$ History of Domain names, . US Created, 2002, <www.historyofdomainnames.com/us/> accessed 12 April 2016.

580 Ibid.

${ }^{581}$ Ibid.

582 Ibid.

${ }^{583}$ Badgley, Domain Name Disputes, p 25.
} 
2. A United States entity or organization that is (i) incorporated within one of the fifty (50) U.S. states, the District of Columbia, or any of the United States possessions or territories, or (ii) organized or otherwise constituted under the laws of a state of the USA, the District of Columbia or any of its possessions or territories (including a federal, state, or local government of the United States or a political subdivision thereof, and non-commercial organizations based in the United States) [Nexus Category 2], or

3. A foreign entity or organization that has a bona fide presence in the USA or any of its possessions or territories [Nexus Category 3]."584

In other words, several U.S. Policies ${ }^{585}$ were adopted to manage the disputes of .us ccTLD by Neustar, ${ }^{586}$ however, the following are the main two policies: usTLD Nexus Dispute Policy (usNDP) and usTLD Dispute Resolution Policy (usDRP).

\subsubsection{1. usTLD Nexus Dispute Policy (usNDP)}

usTLD Nexus Dispute Policy (usNDP) applies to disputes concerning a claim that registering a (.us) domain name is in violation of the abovementioned Nexus Requirements. These days, the NAF manages disputes with regard to (.us) domain names on the basis of usNDP. ${ }^{587}$ The usNDP applies particularly to disputes involving a complaint that an .us top-level domain (TLD) name is not registered by a United States entity and is in violation of the Nexus Requirements for (.us) TLDs. ${ }^{588}$ The usNDP may apply to Internationalized Domain Names (IDNs). ${ }^{589}$ The remedies obtainable to a complainant according to any proceeding before the panelist shall be limited with respect to the cancellation of your domain name. ${ }^{590}$

\footnotetext{
${ }^{584}$ Neustar, the usTLD Nexus Requirements Policy, <www.neustar.us/the-ustld-nexus-requirements/> accessed 12 April 2016.

585 Such as usTLD Rapid Suspension Dispute Policy (usRS), which is very similar to the ICANN's URS Policy. Neustar, Policies, < www.neustar.us/policies/> accessed 12 April 2016.

586 Ibid.

587 Bart Besien, Different Ways for a Trademark Owner to Claim Back a Domain Name (gTILD), 2014, <www.newmedia-law.com/news/different-ways-for-a-trademark-owner-to-claim-back-a-domain-name-gtld-/> accessed 25 April 2016.

${ }^{588}$ Neustar, the usTLD Nexus Requirements Policy, <www.neustar.us/the-ustld-nexus-requirements/> accessed 12 April 2016.

589 Ibid.

${ }^{590}$ Paragraph (3) (e) of the usNDP.

Neustar, Policies, < www.neustar.us/policies/> accessed 12 April 2016.
} 
It is important to note that usDRP applies particularly to disputes in respect of a complaint that a (.us) TLD is registered and/or used in bad faith and infringes trademark, thus such complaints it should not be filed under the usNDP; but, should be filed under the usDRP. ${ }^{591}$ As a result, it should be highlighted the role of usDRP in the following section, as it is clearly addressing the trademark cybersquatting under (.us) ccTLDs.

\subsubsection{2. usTLD Dispute Resolution Policy (uSDRP):}

Neustar adopted usTLD Dispute Resolution Policy (usDRP) 592 which applies to disputes concerning a claim that a (.us) domain name is used and/or registered in bad faith and infringes trademark. $^{593}$

On February 21, 2002, the usDRP was approved by the United States Department of Commerce ${ }^{594}$ and it is funded by registry Neustar. ${ }^{595}$ According to the Neustar the dispute providers for usTLD Disputes are:

- National Arbitration Forum [NAF] (approved effective 4 April 2002), ${ }^{596}$

- American Arbitration Association [AAA] (approved effective 21 February 2002). ${ }^{597}$

The fact that the usDRP is very similar to the UDRP which has governed disputes concerning gTLDs, there are two main dissimilarities between the usDRP Uniform Policy and UDRP. First, whereas the UDRP requires the complainant trademark owner to establish both "bad faith" registration and use of the disputed domain name by the respondent, while the usDRP requires a showing of either "bad faith" registration or use.

There are also two main dissimilarities between the UDRP and the usDDRP;

\footnotetext{
${ }^{591}$ Paragraph 4 (b) (i) of the usDRP.

Neustar, usTLD Dispute Resolution Policy, 2014, < http://www.neustar.us/ustld-dispute-resolution-policy/> accessed 12 April 2016.

$592 \mathrm{Ng}$, the Domain Name Registration System: Liberalization, Consumer Protection and Growth, Routledge, p 42.

${ }^{593}$ Neustar, usTLD Dispute Resolution Policy, < http://www.neustar.us/ustld-dispute-resolution-policy/ > accessed 12 April 2016.

${ }^{594}$ Neustar, USDRP Approval Process, < http://www.neustar.us/usdrp-approval-process/ > accessed 14 April 2016.

${ }^{595} \mathrm{Ng}$, the Domain Name Registration System: Liberalization, Consumer Protection and Growth, p 42.

${ }^{596}$ Neustar, Dispute Providers, < www.neustar.us/dispute-providers/> accessed 14 April 2016.

597 Ibid.
} 
- First, whereas the usDRP involves the complainant trademark proprietor to establish either "bad faith" registration or use, ${ }^{598}$ the UDRP requires a showing of both "bad faith" registration and at the same time use of the disputed domain name by the cybersquatter. ${ }^{599}$

- $\quad$ Second, paragraph 4 (c) of UDRP stated three circumstances under which the cybersquatter may have "rights or legitimate interests" 600 in the domain name, while the usDRP increased a fourth circumstance, when the cybersquatter is "the owner beneficiary of a trade or service mark that is identical to the domain name."

Robert Badgely observed, that "this provision does not require that the respondent's trademark rights be U.S. trademark rights. Thus, the foreign trademark rights or state trademark rights should carry the day for the respondent, as long as his mark is identical to his domain name."602

Paragraph (3) of usDRP Uniform Policy stipulated the situations for "Cancellations, Transfers, and Changes" as follows:

"We will cancel, transfer or otherwise make changes to a domain name registration that is subject to this Policy under the following circumstances:

a. Subject to the provisions of Paragraph 8, our receipt of written or appropriate electronic instructions from you or your authorized agent to take such action;

b. Our receipt of an order from a court or arbitral tribunal, in each case of competent jurisdiction in the United States, requiring such action; and/or

c. Our receipt of a decision of an Administrative Panel requiring such action in any administrative proceeding to which you were a party and which was conducted under this Policy." 603

Accordingly, "the remedies available to a Complainant pursuant to any proceeding before an Administrative Panel shall be limited to requiring the cancellation of your domain name or the transfer of your domain name registration to the Complainant." 604

\footnotetext{
${ }^{598}$ Paragraph 4 (b) (i) of the usDRP.

${ }^{599}$ Paragraph 4 (c) of the UDRP.

600 Ibid.

${ }^{601}$ Paragraph 4 (c) (i) of the usDRP.

${ }^{602}$ Badgley, Domain Name Disputes, p 24.

${ }^{603}$ Paragraph 3 of the usDRP.

${ }^{604}$ Ibid, paragraph 4 (h)(i).
} 
It would be interesting to mention that the first arbitral decision under the usDRP was an easy success for the complainant Pepsi Cola. In Pepsico v. Thompson, ${ }^{605}$ the panel ordered to transfer "pepsico.us" to the complainant, it reasoned that "Pepsi" had enjoyed with highly reputation as a result, there was many visitors to the respondent's website. ${ }^{606}$

However, it should be mentioned that the U.S. did not adopt the UDRP Policy ${ }^{607}$ for (.us) ccTLD which is used and/or registered in bad faith and infringes trademark rights, while other countries such Namibia (.nu), Tuvalu (.tv), Samoa (.ws)...etc, that have adopted the UDRP Policy on a voluntary basis. ${ }^{608}$

To conclude, usDRP had been exempted in the registration application from any liability for any administrative proceeding that may be sustained ${ }^{609}$ "except in the case of deliberate wrongdoing, neither the Provider nor a Panelist shall be liable to a Party for any act or omission in connection with any administrative proceeding under the Policy and the Rules."

\footnotetext{
${ }^{605}$ Pepsico v. Thompson, FA114678, (2002).

606 Ibid

${ }^{607}$ UDRP Policy as a domain name dispute resolution method by WIPO Arbitration and Mediation Center.

608 WIPO, Domain Name Dispute Resolution Service for Generic Top-Level Domains, <www.wipo.int/amc/en/domains/gtld/> accessed 12 March 2016.

${ }^{609}$ In the same way usNDP also had been exempted in the registration application from any liability for any administrative proceeding that may be sustained.

Paragraph 3 (c) (x) of the usNDP.

Neustar, Nexus Dispute Policy, < www.neustar.us/nexus-dispute-policy > accessed 17 April 2016.

${ }^{610}$ Paragraph 3 (c) (xiii) of the usDRP.
} 


\subsection{Cybersquatting in the European Union}

The EU Member States have not enacted any ideal statute to deal with domain name disputes yet. The majority of the EU Member States did not legislate norms which regulate immediately cybersquatting activities similarly to the ACPA. The anticybersquatting claims are regulated individually by each member European countries. Thus, European courts essentially "transfer intellectual property, business and other laws designed for real space, to the exigencies of cyberspace". 611

As Sebastian Baum observes on statutory trends in the cyberspace age "legislators hardly reacted to the new regulatory challenge". ${ }^{612}$ For instance, at the time of the first appearance of the domain name disputes, the German courts treated the domain names only such as addresses that cannot have any legal protection. The German court of Mannheim accepted the domain name as identifier in 1996. It held that the domain name should comply with the attitudes of denominations such as trademarks. ${ }^{613}$ This discipline was successively approved by the German Judicial authority. ${ }^{614}$

Each EU Member State has adopted its own legal regime for protecting trademarks and registering trademarks ${ }^{615}$ and should comply with the EU Trademarks Directive. ${ }^{616}$ Noteworthy is that the majority of EU Member states follow a civil law system, such as Austria, France, Germany and

${ }^{611}$ Lyombe Eko, American Exceptionalism, the French Exception, and Digital Media Law, Lexington Books, 2013, p 242.

${ }^{612}$ Sebastian Baum, Domain Name Conflicts in Germany: an Economic Analysis of the Federal High Court's Recent Decisions, 4 EUR. BUS. ORG. L. REV. 137, 2003, p 161.

${ }^{613}$ Landgericht (LG Mannheim), Regional Court of Mannheim, March, 8, 1996, Neue Juristische Wochenschrift [NJW] 2736, 1996.

${ }^{614}$ Michel Béjot and Isabelle Setton, Current Approaches to Domain Name Management in Europe, J. INTERNET L., June 2000, p10.

${ }^{615}$ INTA, International Trademark Rights,

<http://www.inta.org/TrademarkBasics/FactSheets/Pages/InternationalTrademarkRightsFactSheet.aspx > accessed 15 October 2016.

${ }^{616}$ The first Trademark Directive was issued in 1989 and codified in 2008 and then the last codified in 2015. Directive (EU) 2015/2436 of the European Parliament and of the Council of 16 December 2015 to Approximate the Laws of the Member States Relating to Trade Marks [2015] OJ L 336/1. 
Hungary ${ }^{617}$ While UK and Ireland are the only common law countries in EU, thus they depend on custom and judicial precedent rather than laws. ${ }^{618}$

In other words, some European member states have approved immediate anticybersquatting statutes, such as France. It is more typical, however, that EU member states protect trademarks from cybersquatting activities on the bases of anticybersquatting claims under trademarks law, unfair completion law, and civil law, such as; Austria, Hungary, and Germany.

Nevertheless, the EU has also approved Regulation 874/2004 in 2004, ${ }^{619}$ which deals with trademark cybersquatting in (.eu) ccTLDs, for instance; "speculative and abusive" ${ }^{620}$ registrations. The Regulation pursues the tactic of ICANN's UDRP ${ }^{621}$ Policy, ${ }^{622}$ as any disputes regarding (.eu) ccTLDs are subject to the (.eu) Alternative Dispute Resolution Rules (the "ADR Rules"). ${ }^{623}$

This section highlights the methods of protecting trademarks from cybersquatting activities in the $\mathrm{EU}$, and how the trademark owners can affirm their rights in the trademark. This section provides a quick view of the relevant laws in several EU Member States with respect to anticybersquatting claims, as well as presents the registration of domain names under (.eu) domain names and the ADR for cybersquatting in (.eu) ccTLDs as a solution.

\subsubsection{Overview of Anticybersquatting Claims in EU Member States}

Most of the EU Member States do not have any laws which regulate anticybersquatting activities similar to the ACPA. Thus, the European courts, such as, French courts essentially transferred intellectual property laws which designed for real space, to the exigencies of Internet. ${ }^{624}$

\footnotetext{
${ }^{617}$ World Bank Group, Key Features of Common Law or Civil Law Systems, 2006, $<\quad$ https://ppp.worldbank.org/public-private-partnership/legislation-regulation/framework-assessment/legalsystems/common-vs-civil-law\#civil > accessed 16 February 2016.

618 Syam Piyali, What is the Difference Between Common Law and Civil Law? 2014, <https://onlinelaw.wustl.edu/blog/common-law-vs-civil-law/> accessed 17 February 2016.

${ }^{619}$ Commission Regulation (EC) No 874/2004 of 28 April 2004 laying down Public Policy Rules Concerning the Implementation and Functions of The .eu Top Level Domain and the Principles Governing Registration [2004] OJ L $162 / 40$.

${ }^{620}$ Articles are 21 to 23 of Regulation (EC) No 874/2004 of April, 2004.

${ }^{621}$ Taylor, Alternative Dispute Resolution, p 235.

${ }^{622}$ For instance, the wording in article 21 of the eu Regulation is very similar the paragraph 4 (a) of the UDRP.

${ }^{623}$ EURid, (.eu)- Alternative Dispute Resolution, <https://eurid.eu/media/filer_public/a0/69/a0694eb7-5a9c-4ff7a510-a7bae3787c71/adr_rules_en.pdf > accessed 22 February 2016.

${ }^{624}$ Eko, American Exceptionalism, the French Exception, and Digital Media Law, p 242.
} 
The following is a summary of the possible legal instruments by which trademark owner can be protected against cybersquatting activities in several EU jurisdictions:

\subsubsection{Austria}

In Austria, the attractiveness of ICANN's UDRP Policy had increased, as well as the filing of domain name lawsuits had also become high ${ }^{625}$ since the Austrian Supreme Court had affirmed that the UDRP costs may be remunerated as compensations in the Austrian courts judgments. ${ }^{626}$

However, the most acceptable remedies to the trademark owners, as victims of cybersquatting in Austria, were considered by Austrian Trademark Act of $1970^{627}$ as amended and Austrian Unfair Amendment Competition Act of $2007^{628}$ as amended. ${ }^{629}$

\subsection{Anticybersquatting Claims under Austrian Trade Mark Act}

If the domain name is confusingly similar to a registered trademark, then the trademark proprietor could stress the Austrian Trademark Act with respect to effect his rights in the trademark against the cybersquatter (domain name holder).

The Austrian Trademark Act states that the grounds for the lawsuits established on trademark infringement are the use of:

- $\quad$ an identical sign on identical or similar products or services;

- a similar mark on identical or similar products or services; and

\footnotetext{
625 Ibid.

${ }^{626}$ For instance, Delikomat Betriebsverpflegung Gesellschaft m.b.H. v. Alexander Lehner WIPO Case, and Austrian Supreme Court Decision in delikomat.com.

WIPO, Search WIPO Cases and WIPO Panel Decisions/ WIPO Case No. D2001-1447, 2001, <http://www.wipo.int/amc/en/domains/decisions/html/2001/d2001-1447.html > accessed 25 January 2016.

Delikomat.com Case, Austrian Supreme Court dated 16 March 2004, MR 2004, 431.

Federal Chancellery of Austria, Case Law, <http://www.ris.bka.gv.at/defaultEn.aspx > accessed 25 January 2016.

627 Austrian Trade Mark Act of 1970 as amended.

${ }^{628}$ Federal Act amending the 1984 Federal Act against Unfair Competition. Austrian Unfair Amendment Competition Act of 2007 as amended.

${ }^{629}$ WIPO, Austria,$<w w w . w i p o . i n t / w i p o l e x / e n / p r o f i l e . j s p ? c o d e=A T>$ accessed 25 January 2016.
} 
- an identical or similar sign on dissimilar products, where the registered trademark is well known in Austria and the use takes unfair advantage of, or is harmful to, the repute or the distinguishing character of the trademark. ${ }^{630}$

If the cybersquatter (domain name holder) infringes a trademark then the trademark proprietor has the right to claim a cease and desist, a claim for removal, ${ }^{631}$ a claim for the publication of judgement, ${ }^{632}$ a claim for damages, ${ }^{633}$ and a claim for remuneration of the profit. ${ }^{634}$

\subsection{Anticybersquatting Claims under Austrian Unfair Amendment Competition Act}

If a domain name registered in bad faith, as cybersquatters usually do, then the trademark holder may establish his case on section 1 of the Austrian Unfair Amendment Competition Act 2007 as amended, which prohibits business means that are against fair competition and honest morals. ${ }^{635}$ The Austrian Supreme Court judgements have confirmed several ways of protection against illicit domain name registrations which infringe prior rights in the trademark. For instance in the hotspring.at case, ${ }^{636}$ the Austrian court decided that the defendant had registered the domain name to prohibit the plaintiff from using the domain name to distribute his goods in Austria. The court held that conduct constitutes cybersquatting activity that is against fair competition and good morals and thus infringes section 1 of the Austrian Unfair Competition Act. ${ }^{637}$

If the cybersquatter (domain name holder) infringes a trademark then the trademark proprietor has the right to protect his rights in the trademark against an illicit registration of a domain name; order

\footnotetext{
${ }^{630}$ Sections 10 and 51 of the Austrian Trade Mark Act.

${ }^{631}$ Chapter III Civil rights claims in respect of infringements of trade mark rights Section 51-59 of the Austrian Trade Mark Act.

632 Section 55 of the Austrian Trade Mark Act.

${ }^{633}$ Ibid, section 53.

${ }^{634}$ Ibid.

635 Section 1 Austrian Unfair Amendment Competition Act.

636 (hotspring.at) Case, Austrian Supreme Court dated 2005, MR 2005, 141.

${ }^{637}$ Ibid.
} 
to cease and desist; ${ }^{638}$ damages; $; 39$ cancellation of the domain name; ${ }^{640}$ publication of the judgement. ${ }^{641}$

A cease and desist order involves that the plaintiff should illustrate a possibility that the domain name holder may continue the violation for his trademark. ${ }^{642} \mathrm{~A}$ cease and desist order will be assumed essentially if the domain name holder remains to use the domain name in noncompliance of an earlier prohibition by the Austrian court. ${ }^{643}$

In addition, the plaintiff has only the right to demand cancellation of the domain name registration. ${ }^{644}$ It is impossible to request from the court to transfer the domain name to the plaintiff. ${ }^{645}$ Thus, this way can be a disadvantage to the trademark owner, since third parties may possibly, meanwhile, acquire the domain name. For instance, the registry does not provide the trademark owner (plaintiff) any chance to obtain the registration before it is transferred to the general pool of domain names.

Generally, the domain name is returned in the general pool directly after the cancellation. ${ }^{646}$ However, if the plaintiff (trademark owner) does not act in response fast enough to register the domain name after it had been transferred to the general pool, a third party may possibly register the domain name before the plaintiff (trademark owner) ${ }^{647}$ For this reason litigation in Austria can be more unfavorable than using the ICANN's UDRP Policy, since through the latter it is possible to request for a transfer of the domain name ${ }^{648}$ and the plaintiff may also claim for damages. ${ }^{649}$

\footnotetext{
${ }^{638}$ Section 1 (5) and 2 (3) Austrian Unfair Amendment Competition Act.

${ }^{639}$ Ibid, section 1 (1).

${ }^{640}$ Deniz Egon and Partik Gabriela, Protection of Trade Marks Used on the Internet: Austria, < http://www.cmslawnow.com/ /media/lawnow/pdfs/cms\%20publications/sector\%20specific\%20publications/tmc/ip/cmsanticybersq uattingguide.pdf > accessed 25 March 2016.

${ }^{641}$ Section 16 (a) Austrian Unfair Amendment Competition Act.

642 Egon and Gabriela, Protection of Trade Marks Used on the Internet: Austria, < http://www.cmslawnow.com/ /media/lawnow/pdfs/cms\%20publications/sector\%20specific\%20publications/tmc/ip/cmsanticybersq uattingguide.pdf $>$ accessed 25 March 2016.

${ }^{643}$ Ibid.

644 Ibid.

645 Ibid.

646 Ibid.

${ }^{647}$ Ibid

648 Ibid

649 Ibid
} 
As a claim for compensations in the Austrian courts can involve the costs of previous UDRP proceedings. ${ }^{650}$

\subsection{National Registration of Domain Names under ccTLD (.at)}

Historically, in Austria the domain name registration under (.at) ccTLD was delegated to the University of Vienna in $1988 .{ }^{651}$ The University of Vienna also served as the registry for (.at) ccTLDs for the duration of the next 10 years. ${ }^{652}$ The rapid growth of delegation numbers until 1997, refers to the fact that the primarily severe delegation rules were liberalized.

In 1998, (nic.at) was awarded to manage the registration and administration of (.at) ccTLDs. ${ }^{653}$ Currently, (nic.at) works in close collaboration with the University of Vienna, the previous (.at) ccTLD Registry, where a huge part of the technical tools (name server, data bases) is located. ${ }^{654}$ (nic.at) and the Internet Foundation Austria (IPA) represent the interests of the Austrian internet community in different public bodies, ${ }^{655}$ such as ICANN, Council of European National Top Level Domain Registries (CENTR) ${ }^{656}$ and Réseaux IP Européens (RIPE) ${ }^{657}$

It is noteworthy that (nic.at) did not adopt the UDRP Policy as a domain name dispute resolution method by WIPO Arbitration and Mediation Center for (.at) domain name. ${ }^{658}$ If the disputed

\footnotetext{
${ }^{650}$ For instance, Delikomat Betriebsverpflegung Gesellschaft m.b.H. v. Alexander Lehner WIPO Case, and Austrian Supreme Court Decision in delikomat.com.

WIPO, Search WIPO Cases and WIPO Panel Decisions/ WIPO Case No. D2001-1447, 2001, <http://www.wipo.int/amc/en/domains/decisions/html/2001/d2001-1447.html > accessed 25 January 2016.

Delikomat.com Case, Austrian Supreme Court dated 16 March 2004, MR 2004, 431.

Federal Chancellery of Austria, Case Law, <http://www.ris.bka.gv.at/defaultEn.aspx > accessed 25 January 2016.

${ }^{651}$ Nic.at, Domain Statistics, <https://www.nic.at/en/aboutnic/statistics/> accessed 25 April 2016.

652 Ibid.

${ }^{653}$ Ibid.

${ }^{654}$ Nic.at, Duties and Responsibilities of (nic.at), <https://www.nic.at/en/aboutnic/> accessed 25 April 2016.

655 Ibid.

656 The association of European Internet country code top-level domain registries, such as (.de) for Germany or (.si) for Slovenia. The objectives of CENTR are to promote and participate in the development of high standard of Internet Country Code Top-Level Domain Registries (ccTLDs) for the benefit of its members and the Internet. The organization has a European focus.

${ }^{657}$ RIPE is a not-for-profit organization that works to support the RIPE (Réseaux IP Européens) community and the wider Internet community. The RIPE NCC membership consists mainly of Internet service providers, telecommunication organizations and large corporations. It is headquartered in Amsterdam.

RIPE NCC, About RIPE NCC, < https://www.ripe.net/about-us > accessed 25 April 2016.

${ }^{658}$ WIPO, ccTLD Database, <www.wipo.int/amc/en/domains/cctld_db/index.html > accessed 12 March 2016.
} 
domain name cannot be settled between the parties, then legal action could be before the Austrian court as a last resolution. ${ }^{659}$

\subsubsection{Hungary}

In Hungary, since the Hungarian courts have ruled with illicit registration or use of domain names, ${ }^{660}$ there have been a limited number of cybersquatting cases. ${ }^{661}$

However, the most acceptable remedies to the victims of cybersquatting activities in Hungary, were regulated by the following statutes: ${ }^{662}$

1. Act XI of 1997 on the Protection of Trademarks and Geographical Product Signs ${ }^{663}$ ("Act on Trade Marks"). ${ }^{664}$

2. Act LVII of 1996 on the Prohibition of Unfair and Restrictive Market Practices ${ }^{665}$ ("Unfair Market Practices Act"). ${ }^{666}$

3. Act IV of 2012 on the Criminal Code ${ }^{667}$ ("Criminal Code"). ${ }^{668}$

4. Act $\mathrm{V}$ of 2013 on the Civil Code. ${ }^{669}$

${ }^{659}$ Nic.at, Legal Issues, < https://www.nic.at/en/faq/legal-issues/> accessed 25 April 2016.

${ }^{660}$ Nikoletta Szederjessy and Ágnes Sólyom, Protection of Trade Marks Used on the Internet: Hungary, <http://www.cms-lawnow.com/ /media/lawnow/pdfs/cms\%20publications/sector\%20specific\%20publications/tmc /ip/cmsanticybersq uattingguide.pdf $>$ accessed 25 March 2016.

${ }^{661}$ Ibid.

662 Ibid.

${ }^{663}$ Act XI of 1997 on the Protection of Trade Marks and Geographical Product Signs ("Act on Trade Marks").

${ }^{664}$ Hungarian Intellectual Property Office, Act XI of 1997 on the Protection of Trade Marks and Geographical Product Signs, <http://www.sztnh.gov.hu/English/jogforras/Trademark_Act_EN.pdf> accessed 26 April 2016.

${ }^{665}$ Act LVII of 1996 on the Prohibition of Unfair and Restrictive Market Practices ("Unfair Market Practices Act") 2016.

${ }^{666}$ British Institute of International and Comparative Law, Act LVII of 1996 on the Prohibition of Unfair and Restrictive Market Practices, <http://www.biicl.org/files/5900_hungary_-_act_lvii_pura_\%5Beng\%5D.pdf> accessed 26 April 2016.

${ }^{667}$ Act IV of 2012 on the Criminal Code ("Criminal Code").

668 United Nation office on Drugs and Crime, Act 2012 the Criminal Code,www.oit.org/dyn/natlex/natlex4.detail?p_lang=en\&p_isn=96662\&p_classification=01, accessed 10 August 2017.

669 Act V of 2013 on the Civil Code. 


\subsection{Anticybersquatting Claims under Hungarian Act on Trademarks $^{670}$}

In Hungary, the trademark rights have been governed by the Act No. XI of 1997 on the Protection of Trademarks and Geographical Indication. ${ }^{671}$ The trademark owner has an exclusive right regarding the use of his registered trademark. ${ }^{672}$ Pursuant to article 12 of the Act No. XI of 1997 on the Protection of Trademarks and Geographical Indication:

“(1) Trade mark protection shall confer on its holder the exclusive right to use the trade mark.

(2) On the basis of the exclusive right of use, the holder shall be entitled to prevent any person not having his consent from using in the course of trade:

(a) any sign identical with the trade mark in relation to goods or services which are identical with those for which the trade mark is registered;

(b) any sign where, because of its identity with or similarity to the trade mark and the identity or similarity of the goods or services, there exists a likelihood of confusion on the part of the public; (c) any sign which is identical with or similar to the trade mark in relation to goods and services which are not identical with or not similar to those for which the trade mark is registered, provided that the trade mark has a reputation in the country and the use of that sign without due cause would take unfair advantage of, or would be detrimental to, the distinctive character or the repute of the trade mark.

(3) The following, in particular, shall be prohibited under paragraph

(2): (a) affixing the sign to the goods or to the packaging thereof;

\footnotetext{
${ }^{670}$ It is also a high potential to rely on the unlawfulness of domain name registration taking into consideration the responsibilities to act and exercise rights in good faith, as prescribed in section 4 of the Civil Code. However, the Civil Code only contains the requirement to exercise rights in good faith in general, and the claimant must specify particular facts and circumstances in any statement of claim. The provisions of the Civil Code concerning a person's inherent rights and the protection of a person's good reputation (and also companies' goodwill) may be applied in certain cases of trade mark infringement.

Szederjessy and Sólyom, Protection of Trade Marks Used on the Internet: Hungary, <http://www.cms-lawnow.com/ /media/lawnow/pdfs/cms\%20publications/sector\%20specific\%20publications/tmc /ip/cmsanticybersq uattingguide.pdf > accessed 25 March 2016.

671 Hungarian Intellectual Property Office, Trademarks and Domain Names, <www.hipo.gov.hu/en/trademarks/trademarks-and-domain-names> accessed 25 March 2016. ${ }^{672}$ Ibid.
} 
(b) putting on the market or offering for sale the goods under that sign or stocking them for such purposes;

(c) offering or supplying services under that sign;

(d) importing or exporting the goods under the sign;

(e) using the sign in business correspondence and in advertising."

Accordingly, the trademark owner has the right to file a claim in the Hungarian court against any infringer (including cybersquatter) who uses in his commercial activity a sign identical to or similar with his trademark without proper license. ${ }^{674}$ Primarily, if the trademark is used in electronic commerce without the license of the owner of the trademark. ${ }^{675}$

The Hungarian trademark also has civil protection under civil law. ${ }^{676}$ The owner of the trademark may claim from the cybersquatter, among others, to cease the infringement of the trademark, ${ }^{677}$ to surrender the enrichment obtained by infringement and to pay damages pursuant to the rules of civil law liability. ${ }^{678}$ During the proceedings of the trademark infringement legal action, the Hungarian court may also order provisional measures. ${ }^{679}$

In Royal Canin SAS v. Mr. Árpád Fekete ${ }^{680}$ the Metropolitan Court of Appeal of Hungary issued a decision in respect of the reseller to use a trademark with regard to reselling the products covered by that trademark. ${ }^{681}$ The defendant "Árpád Fekete" registered the domain name <royalcaninbolt.hu> on March 9, 2009. ${ }^{682}$ The term "bolt” in Hungarian language means "shop". Thus the defendant distributed foodstuffs for animals on the web-shop under his domain name

\footnotetext{
${ }^{673}$ Article 12 of the Act No. XI of 1997 on the Protection of Trademarks and Geographical Indication.

674 Hungarian Intellectual Property Office, Trademarks and Domain Names, <www.hipo.gov.hu/en/trademarks/trademarks-and-domain-names> accessed 25 March 2016.

675 Ibid.

676 Ibid.

${ }^{677}$ Ibid.

${ }^{678}$ Ibid.

${ }^{679}$ Ibid.

${ }^{680}$ Royal Canin SAS v. Mr. Árpád Fekete Case, (2012) Judgment No. 8.Pf.20.336/2012/4.

${ }^{681}$ Ibid.

682 Ibid.
} 
<royalcaninbolt.hu>, using the (ROYAL CANIN BOLT) and a logo that was confusingly similar to the trademark (ROYAL CANIN), registered by the plaintiff "Royal Canin SAS". 683

The plaintiff filed a trademark infringement lawsuit to the Hungarian Metropolitan Court. The defendant did not file any answer or response. The Court held that Mr Fekete prohibited from using the domain name, using "Royal Canin" as a trade name, as well as using the company logo on his website as his deeds infringed the prior rights of the trademark owner. ${ }^{684}$ However, the defendant did not comply and filed an appeal against the decision in front of the Metropolitan Court of Appeal of Hungary. In his appeal he stated that he has been licensed to use the domain name because he was selling (ROYAL CANIN) products, which is in the interest and favor of the trademark proprietor. ${ }^{685}$

The European Court of Justice raised a question; that under which circumstances resellers may use a trademark without a license from the trademark proprietor. ${ }^{686}$

\subsection{Anticybersquatting Claims under Hungarian Unfair Market Practices Act}

In Hungary, it is also possible to rely on the Act LVII of 1996 on the Prohibition of Unfair and Restrictive Market Practices (Unfair Market Practices Act), in respect of the illegal domain name registration or use. Section 2 of the Hungarian Unfair Market Practices Act provides "it is prohibited to conduct economic activities in an unfair manner, in particular, in a manner violating or jeopardizing the lawful interests of competitors and consumers, or in a way which is in conflict with the requirements of business integrity." 687

Section 2 of the Hungarian Unfair Market Practices Act is considered to be a general clause, which affirms a general principle that the prevention of infringement is a fundamental rule of commercial

\footnotetext{
683 Ibid.

${ }^{684}$ International Association for the Protection of Intellectual Property, Correct Use of Marks by Resellers - The "Royal Canin Bolt" Case, <www.aippi.hu/hu/hirek/70-correct-use-of-marks-by-resellers-the-royal-canin-boltcase.html> accessed 26 March 2016.Ibid.

${ }^{685}$ Ibid.

686 Ibid.

${ }^{687}$ Section 2 of the Hungarian Unfair Market Practices.
} 
activity. This general clause prevents all types of unfair behavior in commercial and business activity without determining what will be considered exactly "unfair" conduct. ${ }^{688}$

This provision is used in those circumstances when the relevant unfair competition behavior is not regulated by any other clause of the Unfair Market Practices Act, but where the conduct of business is questionable.

Also, section 6 of the same Act provides that "without the express prior consent of the competitor, goods or services (hereinafter referred to collectively as "goods") may not be produced, placed on the market or advertised with such typical external appearance, packaging or marking (including the indication of origin) by which the competitor or its goods are normally recognized; furthermore, any such name, marking or indication of goods may not be used by which the competitor or its goods are normally recognized." 689

The Act also states that products or services that appear ${ }^{690}$ to be confusingly similar to a products or services of the competitor, may not be produced, traded or advertised without the prior permission of the competitor. This provision becomes extremely significant when products are not prohibited by prior permission of the competitor under the trademark protection law. ${ }^{691}$

These provisions of the Act are prohibiting the imitation, can also protect the competitors regarding trademarks which had previously entered to the market and had also become famous against competitors entering the market later. However, this provision can only be relied on if the plaintiff has used his trademark in Hungary and can be considered to be a competitor in respect of a defendant's business activities. ${ }^{692}$

\footnotetext{
${ }^{688}$ Ibid.

${ }^{689}$ Section 6 of the Hungarian Unfair Market Practices Act.

${ }^{690}$ For instance, outside appearance, packaging, marking, name etc.

${ }^{691}$ Szederjessy and Sólyom, Protection of Trade Marks Used on the Internet: Hungary, $<$ http://www.cms-lawnow.com/ /media/lawnow/pdfs/cms\%20publications/sector\%20specific\%20publications/tmc /ip/cmsanticybersq uattingguide.pdf > accessed 25 March 2016.

${ }^{692}$ Ibid.
} 


\subsection{Anticybersquatting Crime under Hungarian Criminal Code}

In addition, the Hungarian trademark has criminal protection, ${ }^{693}$ section 329 (D) of the Hungarian Criminal Code, states that:

“(1) Any person who infringes the industrial property right of the rightful holder afforded by law, international agreement promulgated by an act of Parliament, or under European Union legislation: a) by imitating or copying the subject matter of protection;

b) by the marketing of goods produced by imitating or copying the subject matter of protection, or by way of obtaining or keeping such goods for the purpose of distribution; thereby causing financial loss, is guilty of a misdemeanour punishable by imprisonment not exceeding two years. (2) The penalty shall be imprisonment between one to five years for a felony if the infringement of industrial property rights is committed on a commercial scale.

(3) If the infringement of industrial property rights:

a) results in substantial financial loss, the penalty shall be imprisonment between one to five years; b) results in particularly considerable financial loss, the penalty shall be imprisonment between two to eight years; c) results in particularly substantial financial loss, the penalty shall be imprisonment between five to ten years.

(4) For the purposes of this Section:

a) industrial property rights shall cover: aa) patents, ab) plant variety rights, ac) supplementary protection certificates, ad) trademarks, ae) geographical indications, af) designs rights, ag) utility models,ah) topographies;

b) 'goods' shall mean any goods of a fungible nature that are capable of being delivered, including services." 694

In the light of this wording, any person who infringes the rights of the trademark owner by imitating or attainment the trademark and causes pecuniary loss may possibly be sentenced for up to two years in jail, ${ }^{695}$ to public work or to a fine. On the other hand, the sentence can even be an

\footnotetext{
${ }^{693}$ Hungarian Intellectual Property Office, Trademarks and Domain Names, <www.hipo.gov.hu/en/trademarks/trademarks-and-domain-names> accessed 25 March 2016. ${ }^{694}$ Section 329 (D) of the Hungarian Criminal Code.

695 Hungarian Intellectual Property Office, Trademarks and Domain Names, <www.hipo.gov.hu/en/trademarks/trademarks-and-domain-names> accessed 25 March 2016.
} 
imprisonment between one to five years for a felony if the infringement of industrial property rights is committed on a commercial scale. ${ }^{696}$

According to the Hungarian courts the registration of a name identical or similar to a trademark as a domain name can be considered infringement of a trademark, depending on the actual use of the domain name (business related or not) on the Internet and the particular facts of the case. ${ }^{697}$

\subsection{National Registration of Domain Names under ccTLD (.hu)}

In Hungary, the Council of Internet Service Providers (CISP) is a national registry adopting rules of domain name registration under the (.hu) ccTLD. ${ }^{698}$ CISP is a non-governmental organization and has a policy which manages the procedure of domain names registration under the (.hu) ccTLD. ${ }^{699}$

According to the CISP's Policy, an ad hoc Court of Arbitration and a legal advisory board supports CISP to prohibit unlawful and abusive domain name registration attempts. ${ }^{700}$

The following individuals may apply to register a domain name directly under (.hu) ccTLD:

“- any Hungarian citizen or any natural person having a residence permit in Hungary,

- any legal person or organization without legal personality having its seat in Hungary,

- in the case of the registration of a trademark registered by the Hungarian Intellectual Property Office as domain name, the owner of the trademark, irrespective of his nationality." 701

\footnotetext{
696 Ibid.

${ }^{697}$ Ibid.

${ }^{698}$ Kathryn Rosenblum, Intellectual Property Law in the European Community: A Country-by-country Review, World Trade Executive, Inc., 2004, p 202-203.

${ }^{699}$ Ibid

${ }^{700}$ Ibid.

701 Hungarian Intellectual Property Office, Trademarks and Domain Names, <www.hipo.gov.hu/en/trademarks/trademarks-and-domain-names> accessed 25 March 2016.
} 
Proprietors of trademarks registered by the Hungarian Intellectual Property Office can register domain names under (.hu) ccTLDs even if they do not reside in Hungary or do not have Hungarian nationality. ${ }^{702}$

Similar to ICANN's pre- and post-delegation dispute resolution procedures, the CISP's Rules of Delegation and Registration of Internet Domain Names in the Public Domain ('Rules') ${ }^{703}$ also states the pre- and post-delegation dispute resolution procedures. ${ }^{704}$ Rule 9 of CISP's Rules stipulates the settlement of legal disputes prior to delegation, ${ }^{705}$ while rule 10 of CISP's Rules states the settlement of legal disputes after the delegation. ${ }^{706}$

Actually, the CISP does not serve or negotiate directly with applicants. ${ }^{707}$ As stated by the CISP's Rules, that the (.hu) domain names must be registered by registrars in Hungary. The registrar announces the application for registration of the (.hu) domain name publicly on the webserver, by confirming the date of the application. Before accepting the domain name, objections may be made to the delegation of the (.hu) domain name until the end of the two weeks from the confirmed date of the delegation of the domain name. If no one objects against the registration, the registrar registers the domain name. However, if any individual submits objection then the application is not fulfilled until reaching the resolution in respect of disputed domain name.

If the proprietor of the trademark asks the registrar to register a trademark registered by the Hungarian Intellectual Property Office as a domain name, the aforesaid two-week announcement period are not obligatory. ${ }^{708}$

As noted above, the registration of a name identical to a trademark as a domain name might infringe the trademark, based on the actual use of the domain name in commerce via

\footnotetext{
702 Ibid.

${ }^{703}$ Rules of Delegation and Registration of Internet Domain Names in the Public Domain ('Rules'). Official (.hu) Domain Name Registry, Registration Rules And Procedures, <www.domain.hu/domain/English/szabalyzat/szabalyzat.html> accessed 26 March 2016.

704 Ibid.

705 Ibid.

706 Ibid.

707 Hungarian Intellectual Property Office, Trademarks and Domain Names, <www.hipo.gov.hu/en/trademarks/trademarks-and-domain-names> accessed 25 March 2016.

708 Ibid.
} 
cyberspace. ${ }^{709}$ This is also maintained by the general decision $7 / 2000$ (V.31.) of CISP, ${ }^{710}$ where the Council stated that "an application for a domain name can be an infringement of a trademark if the application is made with the intention of using the domain in the course of business." 711

In short, the CISP's Rules for domain name registration obliges applicants to act with maximum caution in choosing the domain name and not to violate a trademark holder's rights. Therefore, whether the domain name registration is associated with the commerce or not should always be considered in the circumstances. ${ }^{712}$

\subsubsection{France}

As observed by Lyombe Eko, since France does not have any law which regulates anticybersquatting activities similar to the ACPA, the French Courts, essentially "transfer intellectual property, business and other laws designed for real space, to the exigencies of cyberspace". 713

However, any illegal use of a domain name that associates with a trademark may give rise to an unfair competition claim or a trademark infringement claim in France. ${ }^{714}$

Under French law, cybersquatting activities might be governed under a number of legal statutes. ${ }^{715}$ The most acceptable remedies to the trademark owners, as victims of cybersquatting, under French law, are regulated by French Intellectual Property Code No 92-597 of 1992 as amended, ${ }^{716}$ French Civil Code No.2004-164 as amended ${ }^{717}$ and French Postal and Electronic Communication Code No. 2007-162 of 2007 as amended. ${ }^{718}$

\footnotetext{
709 Ibid.

710 Ibid.

711 Ibid.

712 Ibid.

${ }^{713}$ Eko, American Exceptionalism, the French Exception, and Digital Media Law, p 242.

714 Anne Villedieu, Protection of Trade Marks Used on the Internet: France, <http://www.cms-lawnow.com/ /media/lawnow/pdfs/cms\%20publications/sector\%20specific\%20publications/tmc /ip/cmsanticybersq uattingguide.pdf > accessed 25 March 2016.

${ }^{715}$ Eko, American Exceptionalism, the French Exception, and Digital Media Law, p 242.

${ }^{716}$ French Intellectual Property Code No 92-597 of 1992 as amended.

${ }^{717}$ French Civil Code No.2004-164 as amended up to 2004.

${ }^{718}$ French Postal and Electronic Communication Code No. 2007-162 of 2007 as amended up to with Code No.2014329 of 2014.
} 


\subsection{Anticybersquatting Claims under French Intellectual Property Code}

French Trademark Law was codified basically by Law No $91-7$ of $1991,{ }^{719}$ which was also repealed by issuing the French Intellectual Property Code No $92-597$ of $1992^{720}$ as amended. ${ }^{721}$

The last legislation founds the Intellectual Property Code, which covers all types of intellectual property rights in France. The French Intellectual Property Code canceled the previous intellectual property laws relating to industrial property, as well as artistic and literary property. ${ }^{722}$ The French Intellectual Property Code covers subject matters involving copyright and related rights (neighboring rights), geographical indications, industrial designs, intellectual property regulatory body, layout designs of integrated circuits, patents (inventions), plant variety protection, and trademarks. ${ }^{723}$

The law governed substantive trademark aspects under articles L711-1 to L716-16. ${ }^{724}$ The regulatory issues are governed under articles R712-1 to R718-4. ${ }^{725}$

Any illegal use of a domain name that associates with a trademark may give rise to a trademark infringement claim in France. ${ }^{726}$

The French Intellectual Property Code entitles trademark owners to prevent any unlawful or unlicensed use of their trademarks, including via cyberspace as a domain name, where there is a likelihood of confusion between the trademark and the domain name.

Articles L713-2, L713-3 and L713-5 of the French Intellectual Property Code states the acts which shall be prohibited, without license of the trademark owner as following:

\footnotetext{
${ }^{719}$ French Trademark Law No 91-7 of 1991.

${ }^{720}$ French Intellectual Property Code No 92-597 of 1992 as amended.

${ }^{721}$ Article 5 of French Intellectual Property Code No. 92-597 of July 1, 1992, as last amended by Laws Nos. 94-361 of May 10, 1994, and 95-4 of January 3, 1995.

722 Ibid.

723 WIPO, France: Law No. 92-597 of 1 July, 1992, on the Intellectual Property Code, <www.wipo.int/wipolex/en/details.jsp?id=12766> accessed 25 April 2016.

${ }^{724}$ Articles L711-1 to L716-16 of the French Intellectual Property Code.

${ }^{725}$ Articles R712-1 to R718-4 of the French Intellectual Property Code.

${ }^{726}$ Villedieu, Protection of Trade Marks Used on the Internet: France, <http://www.cms-lawnow.com/ /media/lawnow/pdfs/cms\%20publications/sector\%20specific\%20publications/tmc /ip/cmsanticybersq uattingguide.pdf > accessed 25 March 2016.
} 
Article L713-2 of the French Intellectual Property Code provides that:

"The following shall be prohibited, unless authorized by the owner:

a) The reproduction, use or affixing of a mark, even with the addition of words such as: "formula, manner, system, imitation, type, method," or the use of a reproduced mark for goods or services that are identical to those designated in the registration;

b) The suppression or modification of a duly affixed mark." 727

Article L713-3 of the French Intellectual Property Code provides that:

"The following shall be prohibited, unless authorized by the owner, if there is a likelihood of confusion in the mind of the public:

a) The reproduction, use or affixing of a mark or use of a reproduced mark for goods or services that are similar to those designated in the registration;

b) The imitation of a mark and the use of an imitated mark for goods or services that are identical or similar to those designated in the registration." 728

Article L713-5 of the French Intellectual Property Code provides ${ }^{729}$ that:

"Any person who uses a mark enjoying repute for goods or services that are not similar to those designated in the registration shall be liable under civil law if such use is likely to cause a prejudice to the owner of the mark or if such use constitutes unjustified exploitation of the mark. The foregoing paragraph shall apply to the use of a mark that is well known within the meaning of Article 6bis of the Paris Convention for the Protection of Industrial Property referred to above."

${ }^{727}$ Article L713-2 of the French Intellectual Property Code.

${ }^{728}$ Ibid, article L713-3.

${ }^{729}$ According to article L.711-4 of the French Intellectual Property Code, a sign cannot be registered as a trademark if it violates earlier rights, including:

- A registered trademark covering an identical sign and identical goods and services.

- A registered trademark covering a similar sign and identical or similar goods and services, creating a likelihood of confusion in the public's mind.

- A well-known registered trademark: for all products and services.

- A prior unregistered well-known trademark with identical signs and/or identical/similar goods and services.

- A prior company name, domain name, if the registration of the trade mark is likely to create confusion for the public.

${ }^{730}$ Article L713-5 of the French Intellectual Property Code. 
In other words, the following acts shall be prohibited, unless licensed by the owner of trademark:

- the reproduction, use or affixing of a trademark, with the addition of words such as: 'formula, manner, system, imitation, type, method' or the use of a reproduced trademark for products or services identical to those designated in the registration; 731

- the reproduction, use or affixing of a trademark for products or services similar to those designated in the registration if such use would create a possibility of public confusion; ${ }^{732}$

- the use of a sign identical or similar to a famous trademark, regarding products or services dissimilar to those designated in the registration, if such use could be harmful to the owner of the famous trademark or constitutes an unfair use of such trademark. ${ }^{733}$ Infringement famous trademark action should be brought by the owner of the trademark for asking civil remedies under civil law if the trademark unregistered. ${ }^{734}$

Accordingly, when a trademark cybersquatting activity arises, the French court should make a discrimination based on whether the trademark is a "reputable" "famous" trademark; or the trademark it is not famous ("ordinary" trademark). In all cases the famous and ordinary trademark should be registered to attain a protection under the French Intellectual Property Code. ${ }^{735}$

1. If the trademark "has a reputation", 736 article L. 713-5 of the French Intellectual Property Code shall apply. The use of a sign identical or similar to a trademark "having a reputation", even in respect of products or services dissimilar to those designated in the registration, if such use could be harmful to the owner of trademark "having a reputation", or creates an unfair use of such a trademark, can be found in the unlicensed user (cybersquatting) being found liable for

\footnotetext{
${ }^{731}$ Ibid, article L713-2 of the French Intellectual Property Code.

${ }^{732}$ Ibid, article L713-3.

${ }^{733}$ Ibid, article L713-5.

${ }^{734}$ Ibid.

${ }^{735}$ Dissimilar to the U.S. Lanham Act, which stated that the trademark rights may exist on trademarks that are not registered, while under French trademark system, trademarks which are registered, only acquired the trademark protection.

${ }^{736}$ French trademark law distinguishes between trademarks "having reputation" and "well-known trademarks" protected by article 6 bis of Paris Union convention. The main difference between them is that trademarks "having reputation" are registered and well known trademarks are normally not registered.

Rosenblum, Intellectual Property Law in the European Community: A Country-by-country Review, p 151.
} 
infringement on the grounds of civil liability. ${ }^{737}$ In the Vichy Case $^{738}$ it was held that the registration of the (vichy.com) domain name was on unlawful utilization as it was caused a detriment for the reputation of the L'Oréal as well-known trademark. The court reasoned that the defendant's acts caused a detriment of appearance for L'Oréal and also lost opportunities to commercialize L'Oréal products via the Internet because the consumers would not reach the website of Vichy under the (vichy.com) domain name. ${ }^{739}$

2. If trademark is an "ordinary" trademark, under articles L713-2 and L713-3 of the French Intellectual Property Code, the plaintiff's claim can only be winning if the proprietor of the trademark is able to prove that, the domain name is identical or similar to his trademark, and the public could be confused as to the origin of the services or products offered on the website. ${ }^{740}$ In Saint-Tropez ${ }^{741}$ Case, the claimant was the "Saint Tropez" town, which was holder for both the domain name (saint-tropez.fr), and also trademark rights. The defendant registered domain name (saint-tropez.com) and activated a website under domain name (sainttropez.com) which was offering services identical to those of the claimant. The French court decided that the deeds of defendant were considered a trademark infringement. ${ }^{742}$

Many French firms have tried to use the international class 38 (telecommunication) in their trademark's registration with the purpose of avoiding to state and demonstrate that the goods and services presented on a website were either identical or similar to the goods and services in their registered trademark.

\footnotetext{
${ }^{737}$ However, a well-known mark within the meaning of Article 6bis of the Paris Convention may be protected under civil law, even if it has not been registered in France, if:

- $\quad$ an unauthorised use of the mark by a third party is likely to cause damage to the mark owner; or

- $\quad$ such use constitutes an unjustified exploitation of the mark.

${ }^{738}$ L'Oreal, Parfums Guy Laroche, the Polo Lauren. Company Co., Cacharely Ralph Lauren, v. PLD Enterprises, the Court of First Instance of Nanterre "the tribunal de grande instance de nanterre" cf. TGI Paris, 3e ch., 2e sect., 27 March 1998. Raphael Picot d Aligny d Assignies, the Law of New Technologies, <https://www.legalis.net/> accessed 26 May 2016.

${ }^{739}$ Torsten Bettinger, and Allegra Waddell, Domain Name Law and Practice, Oxford University Press, 2005, p 292. ${ }^{740}$ Ibid.

${ }^{741}$ Saint-Trope, v. Eurovirtuel, the Court of First Instance of Nanterre "the tribunal de grande instance de nanterre" Draguignan, 1st civil chamber, 21, August, 1997.

${ }^{742}$ Ibid.
} 
The French Supreme Court held in Sté Soficar vs. Sté le Tourisme ${ }^{743}$ case that a domain name cannot violate or infringe an earlier trademark (Locatour) by imitation or, reproduction registration under class 38 being worthless, to select communication services, except if the goods and services presented via website are either identical or similar to its prior registered trademark and are likely to mislead or cause confusion in the mind public consuming. ${ }^{744}$

The remedies available under French Intellectual Property Code includes, prevention of further infringement $;{ }^{745}$ indemnification of damages; ${ }^{746}$ publication of the judgment in the newspaper; $;{ }^{74}$ and, where applicable, criminal sanctions. ${ }^{748}$

It is vital to note that France Courts have the jurisdiction regarding trademark infringement claim, even if the domain name has been registered out of the France country. Hence the website may be accessed in France, then as a general rule, the infringement is located in France. ${ }^{749}$

\subsection{Anticybersquatting Claims under French Civil Code}

In the French Legal system, "as long as the behavior of the infringer does not immediately infringe or violate the sign itself the owner will have to sue the infringer for unfair competition." 750 Thus, another useful remedy to the trademark owners, as victims of cybersquatting, is unfair competition claim. ${ }^{751}$

\footnotetext{
${ }^{743}$ Sté Soficar vs. Sté le Tourisme Moderne Compagnie Parisienne du Tourisme, the Court of First Instance of Nanterre "the tribunal de grande instance de nanterre", No. G 04-10.143, No. 1672, 13 December, 2005.

${ }^{744}$ Ibid.

${ }^{745}$ Articles L716-7 and L716- 9 of the French Intellectual Property Code.

${ }^{746}$ Damages allowed by French Civil Courts are compensators damages, as is set forth by the article 1382 of French Civil Code. They are usually not high in practice and do not always compensate the prejudice suffered, nor deter the infringement. There is no such thing as punitive damages under French Law. Reimbursement of part of the legal fees can be obtained by the winning party from the losing party, under Article 700 of French Civil Code procedure Rosenblum, Intellectual Property Law in the European Community: A Country-by-country Review, p 152-153.

${ }^{747}$ Article L716-13 of the French Intellectual Property Code.

${ }^{748}$ Article L716-1 of the French Intellectual Property Code provides that: "Infringement of the rights of the owner of a mark shall constitute an offense incurring the civil law liability of the offender. Violation of the prohibitions laid down in Articles L713-2, L713-3 and L. 713-4 shall constitute an infringement of the rights in a mark." Articles L716-1, L716-9, L716-10, L716-11-1, L716-11-2, and L716-14 of the French Intellectual Property Code. ${ }^{749}$ Dennis Campbell, the Internet [2009] - II: Laws and Regulatory Regimes, Yorkhill Law Publishing, 2009, p11.

${ }^{750}$ Rosenblum, Intellectual Property Law in the European Community: A Country-by-country Review, p156.

${ }^{751}$ Ibid.
} 
In France, under unfair competition law, a civil wrong which renders its creator responsible and liable if any harm or tort occurs. ${ }^{752}$ In other words, the unfair competition claim comprises in performance when the behavior of the offender (cybersquatter) has infringed and violated the freedom of business, thus such as a claim is based on article 1382 of the French Civil Code No.2004-164 as amended up to $2004 .{ }^{753}$ As competition between the actors of marketplace has not to be done in a disloyal behavior scorns and violates commerce freedom but has to be done in respect of the principle of loyalty and fair use. ${ }^{754}$

Article 1382 of the French Civil Code provides that "any act of man, which causes damages to another, shall oblige the person by whose fault it occurred to repair it". 755

In order to prevail, the plaintiff must meet with the three requirements of article 1382 of the French Civil Code. The defendant (cybersquatter) may be found liable under civil law if ${ }^{756}$

(i) the offender committed an actual fault (tort),

(ii) the victim has suffered a damage (loss),

(iii) a direct link can be established between the damage (loss), and the fault (tort)

In YouTube Case, the court held that there was no confusion as to the origin of the videos posted by cyberspace users and the services provided by YouTube. The court added that such use did not affect the purpose of indicating to consumers the origin of the products or services. The court decided that there was no trademark infringement. ${ }^{757}$

Indeed, it is important that the trademark owner is able to file infringement trademark claim and unfair competition action cumulatively. However, filing infringement trademark claim does not forbid the unfair use of one's protected trademark, such unlawful use can also be punished on the grounds of unfair competition claim. If the infringer is not a competitor of the trademark owner, a sanction may be ordered on the grounds of trademark cybersquatting. It can be considered as

\footnotetext{
${ }^{752}$ An unfair competition claim is based on tort law. Ibid.

${ }^{753}$ French Civil Code No.2004-164 as amended up to 2004.

${ }^{754}$ Rosenblum, Intellectual Property Law in the European Community: A Country-by-country Review, p156.

${ }^{755}$ Article 1382 of the French Civil Code.

756 British Institute of International and Comparative Law, Introduction to French Tort Law, <http://www.biicl.org/files/730_introduction_to_french_tort_law.pdf> accessed 26 May 2016.

${ }^{757}$ As a result, all claims against YouTube were refused. TF1 and others $v$. YouTube Case, the Court of First Instance of Nanterre "the tribunal de grande instance de nanterre", 3rd Chamber-1st Section, No. 10/11205, 29 May 2012.
} 
'fraud' on the grounds of civil liability. The fact that various French companies struggled against trademark infringement. However, the adoption of the loi Doubin of December 311989 the general direction of competition consumption and fraud repression (DGCCRF) ${ }^{758}$ can interfere on all the French country among importers producers wholesalers and in every market place selling products with infringed trademark. ${ }^{759}$

\subsection{National Registration of Domain Names under ccTLD (.fr)}

In 1997, the Association for French Network Information Centre (AFNIC) had been established in Saint-Quentin en Yvelines, France. ${ }^{760}$ AFNIC is a non-governmental organization and has a policy which manages the procedure of domain names registration under the (.fr) ccTLD and (.re) (Reunion Island). ${ }^{761}$

Currently, AFNIC is governed by the provisions of the Law of 1 July 1901, and serves as a provider of registry services and technical solutions such as ventures for new gTLDs, including .paris and .bzh. ${ }^{762}$

Currently, AFNIC has improved in line with its Consultative Committee and in line with the Council of European National Top- level Domain Registries (CENTR) which is an entity that entitles exchanges between top-level domain managers and reacts to the cyberspace need of domain name registries to be operated by the exchange of information, a set of "Registration rules for (.fr) domain names". ${ }^{763}$

\footnotetext{
758 In 1990, the French General Direction for Consumption, Competition and Fraud Repression (DGCCRF) tries to make an inventory of the uses and to make them official by a publication (after having consulted the professionals and the departmental committee of consumption) at the departmental administrative acts bulletin.

European Communities, Calendar and Temperature Effects in the Analysis of Textile and Leather Consumption Series in France, 2006 <www.uni-mannheim.de/edz/pdf/eurostat/06/KS-DT-06-022-EN.pdf> accessed 26 May 2016.

759 The French government has released two guidance documents on food-contact legislation. The first document, published by the French enforcement authority Directorate General for Competition, Consumer Affairs and Repression of Fraud (DGCCRF), provides clarification on the enforcement of France's ban on bisphenol A (BPA), Law No. 2010-729, as amended by law No. 2012-1442 of December 24, 2012. Legifrance, Suspending the Manufacture, Import, Export and Placing on the Market of Any Food-based Packaging Containing Bisphenol, $<$ https://www.legifrance.gouv.fr/affichTexte.do?cidTexte=JORFTEXT000026830015> accessed 27 May 2016.

${ }^{760}$ AFNIC, About AFNIC, <https://www.afnic.fr/en/about-afnic/ > accessed 27 May 2016.

${ }^{761}$ Ibid.

${ }^{762}$ Ibid.

${ }^{763}$ Arturo Flores, to Each Country, Its Own Law and Domain: The Legal Structures of ccTLD's in Comparative Perspective, ProQuest LLC, 2008, p 104.
} 
The domain names managed by AFNIC are attributed in the public interest ${ }^{764}$ thus AFNIC has adopted a set of rules for the allocation and management of domain names registered under the (.fr) TLD (the 'Charter') targeted at ensuring, especially, applicants' obedience with intellectual property rights. ${ }^{765}$

Pursuant to rule 5 of the charter "any individual residing and any legal entity having its headquarters or principal place of business as specified below may apply to register or renew a domain name in each of the top-level domains:

- within the territory of one of the member states of the EU;

- within the territory of the following countries: Iceland, Liechtenstein, Norway, and Switzerland."766

In case of an anonymous WHOIS result, the French registry made available for the public the data of domain names under ccTLD (.fr) to communicate with the domain name's administrative contact. $^{767}$

In addition, AFNIC has no legal association with the holder of domain name or applicant for registration a domain name as well as it cannot be held liable for the relations between Internet service provider and its consumers. ${ }^{768}$ Neither ISPs nor the AFNIC make any search to conclude the existence of prior claims to domain names.

The Charter states that a domain name should not infringe third-party rights, specifically IP rights. The applicant for the registration domain name should bear sole liability for checking the requested domain name's is not conflicted or disputed with third parties' rights such as trademark right. ${ }^{769}$

\footnotetext{
764 Ibid.

765 AFNIC, Charters, <https://www.afnic.fr/en/about-afnic/ > accessed 27 May 2016.

766 AFNIC, Naming Policy for the French Network Information Centre,

< https://www.afnic.fr/medias/documents/Cadre_legal/Afnic_Naming_Policy_12122016_VEN.pdf > accessed 28 May 2016.

767 AFNIC, About AFNIC, <https://www.afnic.fr/en/about-afnic/ > accessed 27 May 2016.

${ }^{768}$ Flores, to Each Country, Its Own Law and Domain: The Legal Structures of ccTLD's in Comparative Perspective, p 104.

${ }^{769}$ Article 2.4 - (paragraph 26) of Naming Policy for the French Network Information Centre. AFNIC, Naming Policy for the French Network Information Centre, <https://www.afnic.fr/medias/documents/Cadre_legal/Afnic_Naming_Policy_12122016_VEN.pdf > accessed 28 May 2016.
} 
In 2007, France also enacted the first French Postal and Electronic Communication Code No. 2007-162 of 2007 as amended. ${ }^{770}$ Pursuant to the article L. $45-2$ of the French Postal and Electronic Communication Code, a domain name must not:

- disrupt public policy and morality and must not infringe rights recognized by the French Constitution or by French law; or

- infringe intellectual property rights, unless the registrant gives a reasons that he or she has a lawful interest and is acting in good faith; or

- be similar or identical to the name of the French Republic, or to the name of a regional collectivity, which are the country subdivisions in France, or a group thereof, unless the registrant gives a reasons to justify that he or she has a lawful interest and is acting in good faith. 771

When registering a domain name in (.fr) or (.re), the registrant shall subscribe to the Charter. The registrant of the domain name undertakes to comply with an extrajudicial $\mathrm{ADR}^{772}$ in case of any dispute in future between the registrant and a third party in respect of the registration of domain name. ${ }^{73}$ Accordingly, the registrant of a domain name (as defendant) cannot avoid since the registrant of undertakes to comply with these procedures under the AFNIC registration regulations.

Recently, the WIPO and the AFNIC, declared the launch of a new ADR procedure to settle domain name disputes under the (.fr) ccTLD. This ADR procedure, which is available on 4 July 2016, is also called as "PARL EXPERT". 774

The PARL EXPERT is managed by WIPO. ${ }^{775}$ It is also an alternate to the existing Syreli procedure, which is additional ADR procedure already offered for (.fr) domain names, but

\footnotetext{
${ }^{770}$ French Postal and Electronic Communication Code No. 2007-162 of 2007 as amended up to with Code No.2014329 of 2014.

${ }^{771}$ Article L. 45-2 of the French Postal and Electronic Communication Code.

${ }^{772}$ AFNIC, ADR Trends : AFNIC Out-of-court Dispute Resolution Procedures, <https://www.afnic.fr/medias/documents/RESOUDRE_UN_LITIGE/brochuresjuridiques/ADR-Trends-Afnic.pdf> accessed 28 May 2016.

${ }^{773}$ Flores, to Each Country, Its Own Law and Domain: The Legal Structures of ccTLD's in Comparative Perspective, p $105-106$.

${ }^{774}$ David Taylor, France: New ADR Procedure for .FR Domain Names, 2016, <www.lexology.com/library/detail.aspx?g=d4bc252e-02f2-4ec1-b022-11fc0b03e8a0> accessed 28 May 2016. ${ }^{775}$ Ibid.
} 
administered by AFNIC instead of WIPO. ${ }^{776}$ Both types of French ADR procedures now applies French Postal and Electronic Communication Code. ${ }^{777}$

During ADR procedures, AFNIC must suspense operations on the disputed domain name. The complainant should pay the fees and charges of the procedure and should request either to cancel or delete the domain name or to transfer of the disputed domain name to complainant. ${ }^{778}$ Lastly, starting such a procedure in France should not prevent either party from turning to the competent court at any time. ${ }^{779}$

\subsubsection{Germany}

Germany has not enacted any specific legislations to cover Anticybersquatting claims. As Lamber Pechan remarks that besides trademark, and competition law, "the general provision of civil are used to fill gaps in protection, particularly the general prohibition against intentional damage contrary to public policy under section 826 of the German Civil Code". 780

However, any unlawful use or registration of a domain name that associates with a trademark in Germany may give rise to an unfair competition claim, a trademark infringement claim, and civil claim. $^{781}$

Under German law, cybersquatting activities are governed under a number of legal statutes. ${ }^{782}$ The most acceptable remedies to the trademark owners, as victims of cybersquatting, under German norms, were included in the German Act on the Protection of Trade Marks and other Signs of

\footnotetext{
${ }^{776}$ Ibid.

${ }^{777}$ Ibid.

${ }^{778}$ Ibid.

${ }^{779}$ Ibid.

${ }^{780}$ Lamber Pechan, Domain Grabbing in Germany; Limitations of Trade Mark Protection and How to Overcome Them, Journal of Intellectual Property Law \& Practice, Vol. 7, No. 3, 2012, p167.

${ }^{781}$ Ibid.

${ }^{782}$ Ibid.
} 
$1996^{783}$ as amended and German Act Against Unfair Competition of 2010 as amended ${ }^{784}$ and German Civil Code of $1896^{785}$ as amended. ${ }^{786}$

\subsection{Anticybersquatting Claim under German Trademark Law}

At the time of the first appearance of the domain name, the German courts treated the domain names only such as addresses that cannot have any legal protection, when the court of Mannheim accepted the domain name as identifier in 1996, it held that the domain name should comply with the attitudes of denominations such as trademarks, ${ }^{787}$ thus this discipline was successively approved by the German court practice. ${ }^{788}$

In general, the registration or use of a domain name can be considered an infringement of trademark rights under German Act on the Protection of Trademarks and other Signs of 1996 as amended. ${ }^{789}$ Similar to the US trademark legal system, German Act on the Protection of Trade Marks and other Signs of 1996 as amended protects unregistered and registered trademark owners. The unregistered trademark owner should approve that the sign "has acquired prominence in trade circles by their use, or are well known within the meaning of article 6 of the Paris Convention". ${ }^{790}$

\footnotetext{
${ }^{783}$ Act on the Protection of Trade Marks and other Symbols of 25 October 1994 (Federal Law Gazette [BGB1.]) Part I p. 3082, as last amended by Art. 3 of the Act of 19 October 2013, Federal Law Gazette (Bundesgesetzblatt)".

Sections 119 to 125 entered into force with effect from 20 March 1996 in accordance with the published on 24 April 1996, Federal Law Gazette Part I p. 682. The Act was adopted by the Federal Parliament with the approval of the Federal Council as Article 1 of the Act (423-5-1) of 25 November 1994, Federal Law Gazette Part I p. 3082. It entered into force with effect from 1 January 1995 in accordance with Art. 50 para. 3 of this Act pursuant to paras. 1 and 2. Geman Act on the Protection of Trade Marks and other Signs of 1996, as amended. (Published on 24 April 1996, Federal Law Gazette Part I p. 682).

${ }^{784}$ German Act Against Unfair Competition of 2010 (published on 3 March 2010 (Federal Law Gazette [BGB1.]) Part I p. 254).

${ }^{785}$ German Civil Code of 1896 of as amended (published on 18 August 1896 (RGBI. P. 195).

${ }^{786}$ German Civil Code in the version promulgated on 2 January 2002 (Federal Law Gazette [Bundesgesetzblatt] I page 42, 2909; 2003 I page 738), last amended by Article 4 para. 5 of the Act of 1 October 2013 (Federal Law Gazette I page 3719).

${ }_{787}$ Landgericht [LG Mannheim] [Regional Court of Mannheim] Neue Juristische Wochenschrift [NJW] 2736, 8 March 1996.

${ }^{788}$ Béjot and Setton, Current Approaches to Domain Name Management in Europe, p 8-10.

${ }^{789}$ Pechan, Domain Grabbing in Germany; Limitations of Trade Mark Protection and How to Overcome them, p167.

${ }^{790}$ Bernd Stegmaier, German and European Trademark Law, Trademark Law at Millennium's Turn: Part Six: Trademarks in the International Arena: Comparative Law, Journal of Contemporary Legal Issues Volume 12, 2002, p 433.
} 
According to section 14 (2) of German Act on the Protection of Trade Marks and other Signs, the following are the grounds of a trademark infringement claim:

"1. using a sign which is identical to the trade mark for goods or services which are identical to those for which it enjoys protection,

2. using a sign if the likelihood of confusion exists for the public because of the identity or similarity of the sign to the trade mark and the identity or similarity of the goods or services covered by the trade mark and the sign, including the likelihood of association with the trade mark, or

3. using a sign identical with or similar to the trade mark for goods or services which are not similar to those for which the trade mark enjoys protection if the trade mark is a trade mark which has a reputation in this country and the use of the sign without due cause takes unfair advantage of, or is detrimental to, the distinctive character or the repute of the trade mark which has a reputation.",791

As section 14 (2) of German Act on the Protection of Trademarks and other Signs provide that "A third party shall be prohibited, without the consent of the proprietor of the trade mark in the course of trade"792 Thus, similar to the majority of EU Member States, the main point to consider the cybersquatting claim under German Trademark Law that the act should be "in the course of trade" such as offering products under the sign, to put them on the market, or to stock them for the abovementioned purposes, or to offer or provide services under the sign. ${ }^{793}$

A remarkable judgement regarding cybersquatting claim was delivered in the eBay-Anwalt ${ }^{794}$ Case the plaintiff was eBay Inc. The defendant was a solicitor who registered a collection of similar domain names, such as (anwalteBay.de), (anwalt-eBay.de) and many others. The defendant used these domain names to advertise his legal services via cyberspace. The German court decided that

\footnotetext{
${ }^{791}$ Section 14 (2) of German Act on the Protection of Trade Marks and other Signs.

792 Ibid.

793 Ibid, section 14 (3).

${ }^{794}$ Landgericht [LG Hamburg] [Regional Court of Hamburg] June 17, 2008, Multimedia and Recht 143 (Ls.), 2009.
} 
such uses and registrations infringed eBay's reputation as famous trademark on the grounds of section 14 (2) of German Act on the Protection of Trade Marks and other Signs. ${ }^{795}$

The remedies available under the Act include prevention of further infringement; ${ }^{796}$ and indemnification of damages. ${ }^{797}$

The remedies available under the Act regarding anticybersquating claims include; injunctions on use of the domain name. ${ }^{798}$ Conversely, it is clear that the trademark owner does not have any right to cancel or transfer of a domain name in Germany under the Act. ${ }^{799}$ Nonetheless, this remedy might be available under German Unfair Competition Law. ${ }^{800}$

\subsection{Anticybersquatting Claim under German Unfair Competition Law}

Similar to French legal system, the unfair competition claim is considered to be an alternative way to trademark infringement claims in the context of the cybersquatting activity. ${ }^{801}$ It is really a secondary claim against cybersquatting activity, which arises when German Trademark Law is not effective. Unfair competition claim also seems to be the only substitute remedy in context of cybersquatting under the circumstances where the trademark infringement claim did not success and also it did not convince the German court in respect of cybersquatting activity. ${ }^{802}$

Torsten Bettinger observed that it is constantly approved that any individual who registers a domain name to prohibit competitor registering his commercial designation or trademark as a domain name or any individual who registers a domain name identical with trademark in order to

\footnotetext{
795 Veronika Popelenskaya, Overlapping between Trademarks and Domain Names: Law Cases in Germany and Russia, Comparative Analysis on the Example of "eBayAnwalt" Case in Germany and "odnoklassniki.km.ru" Case in Russia, Master thesis, Munich Intellectual Property Law Center (MIPLC), 2009, p 21.

${ }^{796}$ Sections 18, 146, and 147 of the German Act on the Protection of Trade Marks and other Signs.

${ }^{797}$ Section 14 paragraph (6) of the German Act on the Protection of Trade Marks and other Signs states "Any person who undertakes such infringing action intentionally or negligently shall be liable for compensation to the proprietor of the trade mark for damage suffered therefrom."

${ }^{798}$ Pechan, Domain Grabbing in Germany; Limitations of Trade Mark Protection and How to Overcome them, p 169.

${ }^{799}$ Ibid, p167.

${ }^{800}$ Ibid, p173.

${ }^{801}$ Bettinger, and Waddell, Domain Name Law and Practice, p 525.

${ }^{801}$ Ibid.

802 Bettinger Torsten, Trademark Law in Cyberspace: The Battle for Domain Names, 28 Int'l. Rev. Indus. Prop. \& Copyright L, 508, 1997, p 534.
} 
hold it and then selling it again for the trademark owner, such as these transferring, selling acts are contrary to honest practices under the German Unfair Competition Act section $1 .{ }^{803}$

Thus, the remedies under unfair competition claim might arise on the following grounds:

1. Sections 823 (1) or 826 of the German Civil Code for illegitimate interference in the course of trade for the trademark or intended unlawful damage for the trademark respectively.

Section 823 paragraph (1) of the German Civil Code provides that:

“(1) A person who, intentionally or negligently, unlawfully injures the life, body, health, freedom, property or another right of another person is liable to make compensation to the other party for the damage arising from this." 804

Section 826 of the German Civil Code provides that "Intentional damage contrary to public policy a person who, in a manner contrary to public policy, intentionally inflicts damage on another person is liable to the other person to make compensation for the damage." 805

2. In addition, this claim may also fall on the ground of section 1 of German Act Against Unfair Competition $^{806}$ as an act is considered as dishonest behaviors. ${ }^{807}$

Section 1 of the German Act Against Unfair Competition provides that "this Act shall serve the purpose of protecting competitors, consumers and other market participants against unfair commercial practices. At the same time, it shall protect the interests of the public in undistorted competition." 808

A remarkable decision regarding cybersquatting claim was delivered in the (Rechtsanwaelte.de) Case, ${ }^{809}$ where the violation of section 1 of the German Act Against Unfair Competition was claimed. The German court held that the defendant had not used the advantage of the domain name in an inappropriate way since it was not targeting to drive competitors out of the market. ${ }^{810}$

\footnotetext{
${ }^{803}$ Bettinger, and Waddell, Domain Name Law and Practice, p 321.

${ }^{804}$ Section 823 paragraph (1) of the German Civil Code.

${ }^{805}$ Ibid, section 826.

${ }^{806}$ Section 1 of German Act Against Unfair Competition.

${ }^{807}$ Remedies under anticybersquatting claim might also involve sections 3, and 4 (10) of German Act Against Unfair Competition.

${ }^{808}$ Section 1 of the German Act Against Unfair Competition.

${ }^{809}$ Landgericht [LG München I] [Regional Court of Munich I] Nov. 11, 2000, Neue Juristische Wochenschrift [NJW] $2100,2001$.

${ }^{810}$ Ibid.
} 
Generally, the plaintiff under unfair competition claim entitles to cessation and abatement of the detrimental conduct ${ }^{811}$ and indemnification of damages. ${ }^{812}$

To sum up, the trademark owner does not have any right to cancel or transfer of a domain name in Germany under German Act on the Protection of Trade Marks and other Signs,${ }^{813}$ however, this remedy is available based on a claim under German Unfair Competition Law. ${ }^{814}$

\subsection{National Registration of Domain Names under ccTLD (.de)}

Historically, the ccTLD (.de) for the Federal Republic of Germany had been launched before 30 years. ${ }^{815}$ The country code (.de) was delegated by IANA on 5 November $1986 .{ }^{816}$ The birth of DENIC the (the Network Information Centre responsible for ccTLD (.de)) was in 1996, as an association of 37 German ISPs agreed to cooperate for the purpose of administering the German domain names. In July 1997, DENIC established its head office in Frankfurt am Main. ${ }^{817}$

There are more than 16 million registered domain names under ccTLD (.de) for the Federal Republic of Germany, it is currently the most popular ccTLD in the world. ${ }^{818}$ This is mainly due to the fact that any individual can apply to register (.de) domain name. Domain name applicants can directly submit their application to DENIC or through a DENIC member. ${ }^{819}$ Generally speaking, DENIC registration shall be approved if the application is successfully achieved. ${ }^{820}$

Pursuant to the "DENIC Domain Terms and Conditions" DENIC has not adopted ADR to settle domain name disputes. ${ }^{821}$ In other words, German did not adopt the UDRP Policy for (.de) domain names ${ }^{822}$ which are used and/or registered in abusive bad faith and violate trademark rights. It has chosen to resolve its domain name disputes exclusively by the judicial authority. Compared with

\footnotetext{
${ }^{811}$ Section 8 of the German Act Against Unfair Competition.

812 Ibid, section 9.

${ }^{813}$ Pechan, Domain Grabbing in Germany; Limitations of Trade Mark Protection and How to Overcome them, p167.

${ }^{814}$ Ibid, p173.

${ }^{815}$ DENIC, de Domains, <https://www.denic.de/en/domains/de-domains/> accessed 25 July 2016.

816 Ibid.

817 Ibid.

${ }^{818}$ Ibid.

819 DENIC, DENIC Domain Terms and Conditions, < https://www.denic.de/en/domain-terms-and-conditions/> accessed 25 July 2016.

${ }^{820}$ Ibid.

${ }^{821}$ Ibid.

${ }^{822}$ WIPO, ccTLD Database, <www.wipo.int/amc/en/domains/cctld_db/index.html > accessed 12 March 2016.
} 
the total number of registered domain names under (.de) ccTLD, the figure of disputes is enormously low, "possibly little more than one domain name in a thousand is affected by some sort of dispute or disagreement." 823

According to the DENIC Domain Terms and Conditions "the Domain Holder agrees not to hold DENIC liable in any way for claims filed by third parties and has the duty to compensate DENIC for any harm and costs that it may suffer through third parties taking action against it on the grounds that the registration of the domain on behalf of the Domain Holder and/or its use by the Domain Holder infringe their rights. In the same way, the Domain Holder also has the duty to compensate DENIC or DENIC employees for any harm and costs they may incur through criminal prosecutions on account of the registration and/or the use of the domain." ${ }^{824}$

In case of an anonymous WHOIS result, the DENIC registry allows for the use of its data to obtain an information about the domain name holder to communicate with the domain name's administrative contact. ${ }^{825}$

\subsubsection{United Kingdom}

Similar to the US, the UK is a common law country, thus its law based on judicial precedent rather than laws. ${ }^{826}$ The United Kingdom has not also enacted any law concerning cybersquatting activities, however, the law regulating the protection of UK registered trademarks, including, cybersquatting activities, is contained in the UK Trademarks Act of 1994 as amended. ${ }^{827}$

The UK Trademark Law is dissimilar to the US Lanham Act, as the UK Trademark Act does not clearly provide legal protection for unregistered trademarks. ${ }^{828}$ Conversely, if a trademark has been used in the course of trade or business but is unregistered, then it is possible to forbid use by an

\footnotetext{
${ }^{823}$ DENIC, Legal Information, < https://www.denic.de/en/know-how/legal-issues/ > accessed 25 July 2016.

824 DENIC, DENIC Domain Terms and Conditions, < https://www.denic.de/en/domain-terms-and-conditions/> accessed 25 July 2016.

${ }^{825}$ DENIC, Service, < https://www.denic.de/en/service/whois-service/> accessed 26 July 2016.

${ }^{826}$ Piyali, What is the Difference Between Common Law and Civil Law?, <https://onlinelaw.wustl.edu/blog/commonlaw-vs-civil-law/> accessed 17 February 2016.

${ }^{827}$ UK Trade Marks Act 1994 as amended.

${ }^{828}$ Brazell Lorna, Intellectual Property Law Handbook, 1st ed. Law Society Publishing, 2008, p 55.
} 
infringer "third party" by filing a claim under the claim of "passing off", on the other hand, the success in this claim is more difficult than a trademark infringement claim. ${ }^{829}$

However, the UK does not note a tort of unlawful use or registration of a domain name that associates with a trademark or cybersquatting activity, two most important grounds of claim have formed from the jurisprudence, specifically legislative trademark infringement and the common law tort of passing off.

Under English law, cybersquatting activities are governed in a common law through the English court's decisions, which usually apply UK Trademarks Act 1994 as amended and the common law tort of passing off. For instance, the first English court decision on cybersquatting was the Harrods ${ }^{830}$ case, concerning the famous trademark "Harrods". The English court settled the claim on the ground of trademark infringement and passing off.

\subsection{Anticybersquatting Claim under UK Trade Marks Act}

Under the English trademark system, for many years the court were tried primarily to apply principles of equity, to lawsuits brought before it as most of the plaintiffs, who were a trademarks owners, wanted relief and injunction, to oblige the trademark infringer to cease passing off or diluting the trademark reputation. ${ }^{831}$

However, a reorganized tactic was required and commercial interests stressed for a structure of registering trademarks. Accordingly, the UK Trademarks Registration Act was enacted in $1875 .{ }^{832}$ This statute became the originator to the subsequent acts, for instance; the UK Trademark Act of $1934^{833}$ and UK Trademark Act of 1994. ${ }^{834}$

However, cybersquatting activities are governed in a common law perspective through the English court's decisions, which usually apply UK Trademarks Act 1994 as amended. Thus, under UK

\footnotetext{
${ }^{829}$ In passing off the proprietor of trademark should prove that the trade mark has acquired a reputation and such reputation has suffered damage. Ibid.

${ }^{830}$ Harrods Ltd. v. UK Network Services Ltd., [1996] EWHC (Ch), [1997] 4 E.I.P.R. D106.

${ }^{831}$ William Cornish, and David Llewelyn, Intellectual Property: Patents, Copyright, Trade Marks and Allied Rights, Sweet \& Maxwell, 2007, p 607.

${ }^{832}$ Ibid, p 608.

${ }^{833}$ UK Trade Mark Act of 1934.

${ }^{834}$ UK Trade Mark Act of 1994.
} 
trademark law, trademark owners may give rise to a trademark infringement claim to fight against the cybersquatting.

The following are the most important grounds to establish a trademark infringement claim. According to article 10 (1) (2) of UK Trade Mark Act:

"(1)A person infringes a registered trademark if he uses in the course of trade a sign which is identical with the trademark in relation to goods or services which are identical with those for which it is registered.

(2)A person infringes a registered trademark if he uses in the course of trade a sign where because-

(a)the sign is identical with the trademark and is used in relation to goods or services similar to those for which the trademark is registered, or

(b) the sign is similar to the trademark and is used in relation to goods or services identical with or similar to those for which the trademark is registered,

there exists a likelihood of confusion on the part of the public, which includes the likelihood of association with the trademark." 835

In the light of the foregoing, the vital part of the trademark infringement claim that a trademark shall be used in the course of trade or business. ${ }^{836}$ The UK Trade Mark Act provides a nonexclusive list of examples of use in the course of trade or business such as; offers products for sale, puts them on the market under the sign, or offers or supplies services under the sign; or exports or imports products under the sign. ${ }^{837}$

In addition, pursuant to article 10 (2) of the UK Trademark Law, if the infringers "cybersquatters" use domain names that are identical or similar to trademarks, likelihood of confusion shall be proven to affirm an infringement. Thus, when products or services are put on sale on a website, likelihood of confusion is possible. ${ }^{838}$

\footnotetext{
${ }^{835}$ Article 10 (1) (2) of UK Trade Mark Act of 1994.

${ }^{836}$ Lorna, Intellectual Property Law Handbook, p 68.

${ }^{837}$ Article 10 (4) of the UK Trade Mark Act of 1994.

${ }^{838}$ Bettinger, and Waddell, Domain Name Law and Practice, p 853.
} 
In a British Telecommunications Plc v One in a Million Ltd ${ }^{839}$ Case the defendant had registered a great variety of domain names in "UK-TLD" and "gTLD" such as "marksspencer.com" and "marksspencer.co.uk". However, the court recognized that there was no prevailing authority or control for the cyberspace thus it suffered to hold how to issue a decision in the case due to the complications in dealing with cybersquatting activity within the trademark law background. The argument was that the defendant had registered a number of domain names but had not activated or even used the domain names in the course of trade or business relating to products or services. ${ }^{840}$

The court finally steered a "passing off" trademark infringement ground under article10 (3), ${ }^{841}$ and stated "the appellants seek to sell the domain names which are confusingly similar to registered trademarks. The domain names indicate origin. That is the purpose for while they were registered. Further they will be used in relation to the services provided by the registrant who trades in domain names." ${ }^{442}$ The court also added: "There is only one possible reason why anyone who was not part of the Marks \& Spencer Plc group should wish to use such a domain address, and that is to pass himself off as part of that group or his products of as theirs." 843

Consequently, cybersquatting actions could be resolved on classic trademark infringement claims or even the common law tort of passing off such as the "One-in-a-Million" case. However, a wide range of remedies are available in trademark infringement and passing off claims, including: an injunction to cease the unauthorized use of the trademark, declarations and damages or an account of profits. ${ }^{844}$ In addition, a court can also order the defendant to transfer a disputed domain name registration to the plaintiff, ${ }^{845}$ and/or issue an order for the cancelation on oath of any documents

\footnotetext{
${ }^{839}$ British Telecommunications Plc. v. One in a Million Ltd., [1998] EWCA (Civ) 1272, [1999] 1 W.L.R. 903, 926.

${ }^{840}$ This view of the court, is not absolutely clear. The question arise which is: does the registration of a domain name establish aground of "course of trade" under UK Trademark Act? However, the answer for this question is that the English court decisions were contradictions. In several English court decisions, the courts stated that infringement does not essentially involve use as a trademark. Other courts take the opposite opinion.

British Sugar Plc. v. James Robertson \& Sons Ltd., [1996] EWHC (Ch), [1996] R.P.C. 281, 291. The same was held by Aldous L.J. in Arsenal Football Club Plc. v. Reed, [2003] EWCA (Civ) 696, [33]. Regina v. Johnstone, [2003] UKHL 28, [2003] 1 W.L.R. 1736, [13].

${ }^{841}$ Article 10 (1) (2) of UK Trade Mark Act states that infringement of a trade mark occurs when a third party uses, in the course of trade, a sign which is identical with or similar to that trade mark where the trade mark has a reputation in the UK and the use of the sign, being without due cause, takes unfair advantage of, or is detrimental to, the distinctive character or the repute of the trade mark.

${ }^{842}$ British Telecommunications Plc. v. One in a Million Ltd., [1999] F S R 265.

${ }^{843}$ Ibid.

844 Anna Carboni, and Jane Cornwell, Defeating Trade Mark Infringement on the Internet and Beating the Cybersquatters, <http://www.austlii.edu.au/au/journals/ANZCompuLawJl/2001/22.pdf> accessed 25 July 2016.

${ }^{845}$ Ibid.
} 
or even the setting up and the content of a website. ${ }^{846}$ Further, the registration authorities comply with all binding court orders regarding non-use of disputed domain names and/or their transfer. ${ }^{847}$

\subsection{National Registration of Domain Names under ccTLD (.uk)}

During the 1980s the first use of the (.uk) TLD was managed by a number of volunteers called the Naming Committee. ${ }^{848}$ In 1996, this was changed to the UK NOMINET, a private non-profit company limited by guarantee. ${ }^{849}$ Nowadays, NOMINET manages over 8.6 million domain names, as the fourth-largest cyberspace registry in the world. ${ }^{850}$

However, polices and rules of the registration of (.uk) TLD had been adopted by the NOMINET's Policy Advisory Board. ${ }^{851}$ These include rules and procedures governing NOMINET's Dispute Resolution Service (DRS). ${ }^{852}$

In the UK, proceedings to settle conflicts between (.uk) domain name and a trademark may be initiated by using the NOMINET's Dispute Resolution Service. ${ }^{853}$ According to the rules and procedures governing NOMINET's DRS, the complainant must demonstrate that there has been an abusive registration, ${ }^{854}$ which is similar to the bad faith requirement of the UDRP policy.

Section 1 of the rules and procedures governing NOMINET's DRS provides:

"Abusive Registration means a Domain Name which either:

i. was registered or otherwise acquired in a manner which, at the time when the registration or acquisition took place, took unfair advantage of or was unfairly detrimental to the Complainant's Rights; or

\footnotetext{
846 Ibid.

${ }^{847}$ Ibid.

${ }^{848}$ Alan Davidson, Social Media \& Electronic Commerce Law, Cambridge University Press, 2015 , p 452.

${ }^{849}$ Ibid.

${ }^{850}$ NOMINET, NOMINET, < http://www.nominet.uk/> accessed 25 July 2016.

${ }^{851}$ Davidson, Social Media \& Electronic Commerce Law, p 452.

${ }^{852}$ NOMINET, Policies And Rules, <www.nominet.uk/resources/policy/policies-rules/\#drspolicy> accessed 28 July 2016.

${ }^{853}$ Ibid.

${ }^{854}$ Section 2 of the NOMINET's Dispute Resolution Service.

NOMINET, Dispute Resolution Service Policy, <http://nominet-prod.s3.amazonaws.com/wpcontent/uploads/2016/08/Final-proposed-DRS-Policy.pdf> accessed 28 July 2016.
} 
ii. is being or has been used in a manner which has taken unfair advantage of or has been unfairly detrimental to the Complainant's Rights." ${ }^{855}$

In addition, pursuant to section 2.9 of the rules and procedures governing NOMINET's DRS "neither NOMINET nor our directors, officers, employees or servants nor any Expert shall be liable to a Party for anything done or omitted in connection with any proceedings under the DRS unless the act or omission is shown to have been in bad faith.." 856

DRS, similar to UDRP, has the advantage of being quicker and cheaper than filing a trademark infringement or passing off claims through the English courts. In addition, similar to the UDRP, the most important disadvantage of DRS is that the only remedy accessible under it is the cancellation or transfer of the unlawful domain name. Injunctions are not covered by the DRS. ${ }^{857}$

The NOMINET registry allows to use its data to obtain an information about who is the domain name holder to communicate with the domain name's administrative contact in case any dispute arise. $^{858}$

\subsubsection{Registration of Domain Names under ccTLD (.eu)}

In 1999, the European Council had discussed an exclusive TLD for European Union. ${ }^{859}$ "The roots of .EU go back to as early as 1998. In 2000, the European Commission published Working Paper COM (2000) 153 on the creation of a new EU Internet top-level domain setting out the case for its creation. This formed part of the European Commission's eEurope initiative where an indicator of European identity for suppliers of services and information on the Internet was perceived as a valuable stimulus to electronic commerce and to the European transition to the information society." $\$ 60$

\footnotetext{
${ }^{855}$ Section 1 of the NOMINET's Dispute Resolution Service.

${ }^{856}$ Ibid, section 2.9 .

${ }^{857}$ Ibid, section 4.

${ }^{858}$ NOMINET, WHOIS, < http://www.nominet.uk/whois/> accessed 28 July 2016.

${ }^{859}$ EURid, EURid's Timeline, <https://eurid.eu/en/about-us/eu-timeline/> accessed 28 July 2016.

${ }^{860}$ Taylor, Alternative Dispute Resolution, p 231.
} 
In 2002, (.eu) TLD has been launched with the adoption of the Regulation No 733/2002 European Parliament and Council ${ }^{861}$ which addressed with the execution of the new Community TLD ${ }^{862}$ In May, 2003, the non-profit European Registry for Internet Domains (EURid) has been appointed by the European Commission as the registry to run the (.eu) TLD. ${ }^{863}$

Currently, EURid does not serve (.eu) domain name registrations immediately to the registrants, though, EURid's accredited registrars register (.eu) domain names for their customers (registrants). ${ }^{864}$ Domain name based on (.eu) TLD can be registered by any entity or organization established with a place of business within the Community, or by any natural person who is a resident of the European Community. ${ }^{865}$ (.eu) TLDs are registered under the "first come first served" principle. ${ }^{866}$

However, the European Commission adopted public policy rules for eu TLDs by enacting Regulation (EC) No 874/2004 of April, 2004, ${ }^{867}$ in order to deal with speculative and abusive domain name registrations and protection of trademarks as well as other rights. ${ }^{868}$

The Regulation states that any disputes relating to (.eu) domain names are related to the provider of which shall be nominated by the registry. ${ }^{869}$ In 2005, the Czech Arbitration Court was chosen as the ADR provider for all disputes regarding (.EU $)^{870}$ the procedure was stated in the Regulation (EC) No 874/2004 and improved in the Rules of the Czech Arbitration Court. ${ }^{871}$

\footnotetext{
${ }^{861}$ Council Regulation (EC) 733/2002 of 22 April 2002 on the Implementation of the (.eu) Top Level Domain [2002] OJ L113/1.

${ }^{862}$ EURid, EURid's Timeline, <https://eurid.eu/en/about-us/eu-timeline/> accessed 28 July 2016.

${ }^{863}$ Ibid.

${ }^{864}$ EURid, the (.eu) Registry EURid Annual Report 2012, <https://eurid.eu/media/filer_public/cb/c0/cbc0c0dd-83324361-8567-45d7fec7552a/annual_2012.pdf> accessed 29 July 2016.

${ }^{865}$ Article 4(2) (b) of Regulation (EC) No 733/2002.

${ }^{866}$ Article 2 of the Council Regulation (EC) 733/2002.

${ }^{867}$ Council Regulation (EC) 874/2004 of 28 April 2004 laying down Public Policy Rules Concerning the Implementation and Functions of the (.eu) Top Level Domain and the Principles Governing Registration, [2004] OJ L162/40.

${ }^{868}$ Articles are 21 to 23 of Regulation (EC) No 874/2004.

${ }^{869}$ Ibid, article 23.

${ }^{870}$ Taylor, Alternative Dispute Resolution, p 232.

871 EURid, (.eu) - Alternative Dispute Resolution, <https://eurid.eu/media/filer_public/a0/69/a0694eb7-5a9c-4ff7a510-a7bae3787c71/adr_rules_en.pdf > accessed 22 February 2016.
} 
Actually, cybersquatting is stated in the Regulation as an "abusive registrations". 872 The protection of the distinguishing signs in the context of cybersquatting activity include, "inter alia, registered national and community trademarks, geographical indications or designations of origin, and, in as far as they are protected under national law in the Member State where they are held: unregistered trademarks, trade names, business identifiers, company names, family names, and distinctive titles of protected literary and artistic works." 873 On the other hand, the (.eu) ADR Rules of the Czech Arbitration Court is similar to the UDRP. ${ }^{874}$ The .EU ADR Rules also permit any party to challenge the appointment of a panelist. ${ }^{875}$

"The language of the ADR proceeding will be the language of the Registration Agreement. In addition, upon written request of a party, a panel may decide in its sole discretion that the language of the ADR proceeding will be different to that of the Registration Agreement. Decisions are published both in the original language and in an unofficial English translation provided by the provider." $\$ 876$

In general, starting such an ADR procedure should not prevent either party from claiming to the competent court at any time. ${ }^{877}$

However, the remedies available under the .EU ADR Rules are either cancellation or transfer of the disputed domain name. ${ }^{878}$ In case of an anonymous WHOIS result, the EURid registry states the possibility to use its data line to communicate with the domain name's administrative contact. $^{879}$

\footnotetext{
${ }^{872}$ Articles 21 to 22 of Regulation (EC) No 874/2004 of April, 2004.

${ }^{873}$ Ibid, article 10 (1).

874 Taylor, Alternative Dispute Resolution, p 235.

${ }^{875}$ Dissimilar to UDRP. Taylor, Alternative Dispute Resolution, p 237.

${ }^{876}$ Ibid, p 237-238.

${ }^{877}$ Article 12 (a) of the .eu Alternative Dispute Resolution Rules.

${ }^{878}$ Ibid.

${ }^{879}$ EURid, WHOIS Search, <https://eurid.eu/en/register-a-eu-domain/> accessed 3 August 2016.
} 


\section{Chapter 4}

\section{Anticybersquatting Legal System from the Middle Eastern Countries, Jordan as a Case Study}

\subsection{Overview}

Broadly speaking, there has been limited research on comprehensive study of anti-cybersquatting acts in the Middle East area, as a result of varying geographically descriptions of Middle East area within different academic circles.

Indeed, despite having varying geographical descriptions of Middle East area within different academic circles, ${ }^{880}$ Jordan is located in heart of the Middle East area ${ }^{881}$ under all different academic circles. This thesis selected Jordan as an example from the Middle East for a several reasons.

Jordan is classified as a middle-income country compared to the other Middle Eastern countries by World Bank. ${ }^{882}$ Jordan is a state without oil resources in contrast to the neighboring Middle Eastern countries such as Iraq and Saudi Arabia, which makes it similar to many other Middle Eastern countries. The Hashemite Kingdom of Jordan is a good case study of a Middle Eastern country that is using its narrow resources to make necessary changes for economic and social development.

According to statistics of Jordanian Ministry of Information and Communication Technology, it could be noted that Internet penetration rate has grown rapidly up to $83 \%$ in $2015 .{ }^{883}$ Such growth of the Internet services penetration shall be accompanied by laws and regulations that govern such use. In order to keep pace with the growth of information technology require that the Jordanian

\footnotetext{
${ }^{880}$ Brown, Middle East, Mid East, Near East, North Africa, <http://peprimer.com/middle-east.html> accessed 28 April, 2016.

881 Jordan is located in the heart of the Middle East, northwest of Saudi Arabia, south of Syria, southwest of Iraq, and east of Israel and the Occupied West Bank.

The Embassy of the Hashemite Kingdom of Jordan-Washington, D.C., Quick Facts, 2016, <http://www.jordanembassyus.org/page/quick-facts> accessed 28 April, 2016.

882 The World Bank, World Bank Country and Lending Groups, 2016, <https://datahelpdesk.worldbank.org/knowledgebase/articles/906519-world-bank-country-and-lending-groups> accessed 29 April, 2016.

883 Jordanian Ministry of Information and Communication Technology, Investment in Information and Communication Technology sector, <moict.gov.jo/content/page-164> accessed 30 April, 2016.
} 
legislator issues new legislation, or amends the existing laws, which aim to regulate the transactions via the cyberspace.

Certainly, the cybersquatting activities in Jordan implicate indirectly issues of trademark law, unfair competition law, and other legal principles. Nevertheless, the lack of qualified local law deals directly with cybersquatting activities, has left the remedies for the domain name disputes in an ambiguous situation.

However, this section focuses specifically on cybersquatting of .jo ccTLD of Jordan which are reserved with the National Information Technology Center (NITC) ${ }^{884}$ In addition to the domain names, ccTLD or gTLD, that might be found identical or confusingly similar to a trademark under the laws of Jordan.

Accordingly, this section discusses the roots and developments of the legal framework of cyberspace in Jordan and then inspects whether it is possible to apply the Unfair Competition Law and Trademarks Law of Jordan to cybersquatting acts. The last section of this chapter analyses the capacity of the NITC and its role in curbing cybersquatting activities.

\subsection{Roots and Developments of the Legal Framework of Cyberspace in Jordan}

Jordan perceives the significance of investment, and trade electronically and its commercial future via cyberspace thus has made upon major legislative reforms to create a more attractive and trusted E-environment for businesses via cyberspace. In this regard, the Jordanian legislator has amended the Law of Evidence ${ }^{885}$ to provide an evidential weight to digital documents, such as email and fax. $^{886}$

In April 2002, the first Electronic Transactions interim Law No. 85 for the year 2001 was enacted, this Law was cancelled by issuing Law No. 15 for the year 2015. ${ }^{887}$ As of May 15, 2015, the

\footnotetext{
${ }^{884}$ NITC, About Us, < https://www.dns.jo/about_us.aspx > accessed 1 May 2016.

885 The Law of Evidences was amended in the year 2005, by virtue of the Law Amending the Law of Evidences No.16 for the year 2005. This Law was published in the Official Gazette issue No. 4709 dated 1/6/2005, p 2188.

${ }^{886}$ Article 13 of the Jordanian Law of Evidences No. 30 for the year 1952 as amended.

${ }^{887}$ As the first Law was interim and the last Law entered into full force and effect in Jordan after ratifying by the Jordanian Parliament.
} 
Electronic Transactions Law No. 15 for the year 2015 entered into full force in Jordan. This is considered as a brave step to launch the electronic government project and electronic commerce. It involves various articles covering all legal aspects in the cyberspace.

Primarily, the law objects the creation an electronic legal framework and electronic transactions principles to make simpler conduct the E-transactions, E-contracts, and to remove the obstacles in front of the E-commerce. Jordanian Electronic Transactions Law addresses several issues such as definitions; E-transactions, records and E-signature requirements; in addition to the conditions related to the certificates, authentication, and the acceptance of the E-transaction.

The Law No. 15 for the year 2015 opened the door for E-services and E-payments, such as E-filing for trademark, and tradenames applications, in order to get in easy way an electronic authenticated certifications for trademarks and tradenames by the Directorate of Industrial Property. ${ }^{888}$

On the 16th of October 2010, the Information Systems Crimes Law No.30 for the year $2010^{889}$ came into force in Jordan. Essentially, the law objects to maintain the Jordanian legal mechanism for fighting cyber-crimes. The Law No. 30 for the year 2010 addresses the nature and scope of cyber-crime's terminology. There are several activities that have been criminalized via cyberspace, theses specifically are unlicensed access to information system, ${ }^{890}$ manipulating with information systems through destroying, deleting or copying it, ${ }^{891}$ impersonation, ${ }^{892}$ disturbing the information system by jamming or disarray, ${ }^{893}$ or objection of information by unlawful or unauthorized electronic eavesdropping, ${ }^{894}$ unlicensed or unauthorized obtaining information about credit cards and financial or banking transactions. ${ }^{895}$ In addition, the law prevents the sexual exploitation of

The Jordanian Electronic Transactions interim Law No. 85 of 2001 was published in the Official Gazette issue No.4524 dated 31/12/2001, p 6010, and was cancelled by issuing the Laws: No. 15 for the year 2015 published in the Official Gazette issue No.5341 dated 17/5/2015, p 5292.

${ }^{888}$ Ministry of Industry, Trade and Supply, E-services, <http://www.mit.gov.jo/Pages/viewpage.aspx?pageID=307.> accessed 18 October 2015.

${ }^{889}$ Information Systems Crimes Law No.30 for the year 2010 was published in the Official Gazette issue No.5056 dated 16/9/2010, p 5334.

Raed Faqir, Saleh Sharari and Salameh Salameh A., Cyber Crimes and Technical Issues under the Jordanian Information System Crimes Law, Journal of Politics and Law: Canadian Center of Science and Education; Vol. 7, No. 2; 2014, p 100 .

${ }^{890}$ Article 3 (a) of the Jordanian Information Systems Crimes Law No. 30 for the year 2010.

${ }^{891}$ Ibid, article 3 (b).

${ }^{892}$ Ibid.

${ }^{893}$ Ibid, article 4.

${ }^{894}$ Ibid, article 5.

${ }^{895}$ Ibid, article 6 (a). 
children, ${ }^{896}$ and actions of online prostitution, ${ }^{897}$ supporting or facilitation of terrorist acts, promotion of terrorist doctrines, ${ }^{898}$ and illicitly accessing to information concerning national security or relationships with; foreign countries or public safety and national economy. ${ }^{899}$

It would be interesting to mention that article 2 of the Information Systems Crimes Law, defines the cyberspace as a following: "Internet: A link between more than one information system to acquire and exchange the data and information." ${ }^{900}$ Further, the same article also defines the website as "A place where information on the Internet is available through a specific address (domain name)"

Unfortunately, neither the Electronic Transactions Law nor the Information Systems Crimes Law addressed or covered the domain names disputes, such as the cybersquatting activities. Despite the fact that many authors say any cyber law should adopt a provisions covering the domain names disputes.

Actually, it can be obvious that the current Information Systems Crimes Law does not even stipulate any provision that deals with the infringements of intellectual property right, via cyberspace.

It should be mentioned that the Jordanian legislator should consider the infringements intellectual property rights and domain names disputes via cyberspace as a crime as any cyber law should adopt such as these provisions in question.

Indeed, there is no doubt that the current activities of cybersquatting in Jordan, is still fresh and not commonly widespread as in the U.S. or EU. For this reason the Jordanian laws did not yet cover so far the activities of cybersquatting directly. It can be observed that none of the domain names disputes addressed by such laws or even applied before the Jordanian courts, though it is expected to be the case in the near future. On the other hand, the absence of an eligible local law has left the remedies and injunction for the domain name disputes in an ambiguous situation,

\footnotetext{
${ }^{896}$ Ibid, article 8 (a).

${ }^{897}$ Ibid, article 8 (d).

${ }^{898}$ Ibid, article 10.

${ }^{899}$ Ibid, article 11.

${ }^{900}$ Ibid, article 2.

901 Ibid.
} 
particularly with the remarkable increase for the registration of trademarks and domain names in Jordan.

\subsection{The Mechanism of Cybersquatting Claim}

Certainly, the cybersquatting activities in Jordan implicate indirectly issues of trademark law, unfair competition law, and other legal fields of law. As prior mentioned, the nonexistence of a qualified local law deals directly with cybersquatting activities, has left the remedies for the domain name disputes in an ambiguous situation.

However, this section inspects whether it is possible to apply the Unfair Competition Law and/or Jordanian Trademarks Law to cybersquatting claims.

\subsubsection{The Mechanism of Cybersquatting Claim under the Jordanian Trademark Law}

As Adam Waxer remarks that "a domain name that includes or implements a famous trademark conveys all the goodwill and intangible value that is epitomized in the trademark. Indeed trademark law helps assure a producer that it (and not an imitating competitor) will reap the financial, reputation rewards associated with a desirable product."902

Those cybersquatters who registered domain names conflicting with trademarks usually had a goal to make use of the reputation or goodwill of that identical trademark, or to negotiate with the owner of the identical trademark to buy the domain name in an expensive price. For these reasons the trademark law was the first option to come to mind when dealing with domain names that are identical with or similar to trademarks. Thus "trademark lawyers, would like to resolve the conflict by directly using trademark law or indirectly through the application of its principles."903

\footnotetext{
902 Adam Waxer, the Domain Name Fiasco: The Legal Battle between the Current Domain Name Registration System and Traditional Trademark Law, <http://www.yumpu.com/en/document/view/6524427/the-domain-name-fiasco-thelegal-hofstra-university> accessed 18 October 2015.

${ }^{903}$ Spyros Maniatis, Trademark Law and Domain names- Back to Basics, European Intellectual Property Law Review, volume 24, Issue, 2002, p 401.
} 


\subsubsection{Infringement Claim under Trademarks Law}

The Jordanian Trademark Law No. 33 of 1952 as amended, defines trademark as "any visible sign used or to be used by any person to distinguish his goods, products or services of others. " ${ }^{904}$ Article 7 of the law sets also forth several conditions for the trademark, such as distinctiveness. ${ }^{905} \mathrm{~A}$ trademark should be able to distinguish products and services of its owner from those of others. By comparing between applying these conditions on trademarks and the domain names, it could be concluded that a domain name is also visually perceptible, and in some circumstances it is used to distinguish goods and services of one trader from those of another. Thus, in some circumstances domain names shall be treated as trademarks.

Accordingly, the trademark owner shall be entitled to file a lawsuit based on traditional infringement of the Jordanian Trademark Law No. 33 of 1952 as amended.

Generally speaking, protection of registered trademarks in Jordan, is either civil or criminal. While unregistered trademarks do not qualify for civil or criminal protection under Jordanian Trademark Law, however, in the context of cybersquatting activities, the owner of a registered trademark in Jordan has an option to file either a civil claim or a criminal one or both at the same claim.

\subsubsection{Civil Remedies under the Trademarks Law}

The Jordanian Trademarks Law does not give the owner of a trademark the right to obtain compensations for the damages caused to him unless his trademark was registered. ${ }^{906}$

Article 34 of the Jordanian Trademark Law states that "No person shall have the right to file a lawsuit to claim damages for any infringement upon a trademark not registered in the Kingdom...,907

According to article 39 of Jordanian Trademark Law No. 33 of 1952 as amended, which states that "the proprietor of a trademark registered at the time of filing the lawsuit..." 908

\footnotetext{
${ }^{904}$ Article 2 of the Jordanian Trademark Law No. 33 of 1952 as amended.

${ }^{905}$ Ibid, article 7.

${ }^{906}$ Ibid, article 33.

${ }^{907}$ Ibid, article 34.

${ }^{908}$ Ibid, article 39.
} 
In addition, article 26 of the Jordanian Trademark Law states that "If the trademark is famous but not registered, then its owner may demand from the competent court to prevent third parties from using it on identical goods or services..."

However, in the context of cybersquatting activities, the owner of the registered trademark, which has been infringed, shall have the right to bring a civil lawsuit against any person, such as domain name registrant (cybersquatter), who had activities for instance, committing, causing or facilitating that infringement. ${ }^{910}$

Thus, it can be noticed that the civil protection is the tortuous liability, which is one of the sources of obligation stipulated in the Jordanian Civil Law, No. 43 of 1976, that obliges the compensation for any tortuous act, where article 256 of the Jordanian Civil Law, provides: "Every injurious act shall render the person who commits it liable for damages even if he is a non-discerning person." 911 Thus, the injurious act, which might be caused by any cybersquatting activity, shall render the cybersquatter (registrant of domain name) liable for damages even if he is a non-discerning person.

In order to file a civil lawsuit the claimant should prove first that there is an injurious act that caused damage to the trademark owner by any cybersquatting activities, such as, registering a domain name in the name of trademark or very similar to it.

Second, a person who initiates a civil law suit against a trademark's infringer, such as cybersquatter, has to prove that he is the owner of the infringed trademark. This condition is an application of the "legitimate interest rule" established in article 3 of the Law for Civil Procedures. ${ }^{912}$ When filing a civil lawsuit the burden of proof falls upon the plaintiff who alleges the infringement. ${ }^{913}$ The plaintiff has to prove that:

- He is the legitimate proprietor of the trademark in question;

- The trademark is registered in Jordan for the propose demanding damages; and

- There has been an infringement to his trademark and he suffered loss due to that infringement.

\footnotetext{
${ }^{909}$ Ibid, article 26.

${ }^{910}$ Ibid, article 37.

${ }^{911}$ Article 256 of the Jordanian Civil Law, No. 43 of 1976 as amended.

912 Article 3 of the Jordanian Civil Procedures Law No. 24 of 1988 as amended.

${ }^{913}$ Article 77 of the Jordanian Civil Law, No. 43 of 1976 as amended.
} 
After succeeding in proving these elements, the competent court will estimate the sum of compensation according to actual damages and loss of potential profit. ${ }^{914}$ The trademark owner might also request the cease of the violation by requesting the court to issue a decision for cancellation of the domain name registration as well as claiming compensation for the actual damage sustained and the lost profit but he does not have any possibility to get a civil remedies in a way that enables him to own the infringing material, which is a domain name, as the domain name registrant (cybersquatter) paid the price of the domain name registration while the trademark owner did not pay the price of domain name registration, which is subject to the cybersquatting activities, as a result, no way to obtain it by a court judgment. On the other hand, the Jordanian Trademarks Law also gives the right to the trademark owner for applying to provisional measures. Such provisional measures include: ${ }^{915}$

\section{Cease the infringement.}

2. Place a provisional attachment on the product subject of infringement wherever found.

3. Preserve the evidence related to the infringement.

In addition, the following remedies are stipulated in the Trademarks Law: ${ }^{916}$

1. Confiscation of the goods, packaging, rolling materials, advertisement, portraits, seals and other tools and materials primarily used for printing the trademark on goods, or used for committing the infringement, or resulted in the infringement.

2. Destruction of the goods, packaging, rolling materials, advertisement, portraits, seals, and other tools and materials primarily used for printing the trademark on goods, or used for committing the infringement, or resulted in the infringement, or its use for non-commercial purposes.

The court shall also decide to compensate to the winning litigant, the party whom in favor the judgement was issued, for the fees and expenses arising from filing the lawsuit and its procedures. Besides these sorts of fees and expenses, the court shall also decide on compensation of attorneys' fees. $^{917}$

\footnotetext{
${ }^{914}$ Ibid, articles 256, 257, 259, 263, 266, 267, 268 and 269.

915 Article 38 of the Jordanian Trademarks Law No. 33 of 1952 as amended.

916 Ibid.

${ }^{917}$ Articles 161 and 167 of the Jordanian Civil Procedures Law No. 24 of 1988 as amended.
} 


\subsubsection{Criminal Sanctions under the Trademarks Law}

Article 37 of the Jordanian Trademarks Law provides the following:

"1.Whoever committed with the intention to cheat any of the following deeds shall be penalized by an imprisonment term of no less than three months and no more than one year, or a fine of no less than 100 Jordanian Dinars and of no more than 6000 Jordanian Dinars or by those two penalties:

A. Whoever counterfeited a trademark registered under this law, imitated it in any other way that misleads the public, or affixed a counterfeit or imitation mark on the same goods for which the trademark has been registered.

B. Whoever illegally used a trademark owned by another on the same class of goods or services for which that trademark is registered.

C. Whoever sold or possessed for the purpose of selling or offered for sale goods bearing a trademark whose use is regarded as an offense under paragraphs (A) and (B) of this Article if he was cognizant of that beforehand.

2. Notwithstanding what is mentioned in paragraph 1 of this Article, whoever sells, or offers for sale, or possesses for the purpose of selling goods bearing a trademark whose use is regarded as a contravention under the items (A) and (B) of paragraph 1 shall be penalized by a fine of no less than 50 Jordanian Dinars and no more than 500 Jordanian Dinars.

3. The provisions of paragraph 1 of this Article shall apply to whoever started to commit any of those acts provided for in this Article or aided or abetted another to commit it." 918

In the light of the foregoing, it is clear that to initiate criminal liability for cybersquatting activities, the main condition, is that the trademark must be a registered to gain criminal protection.

By comparing between applying these conditions on infringement of trademarks on the domain names disputes cases, it could be concluded that the main obstacle to apply trademark law is the

${ }^{918}$ Article 37 of the Jordanian Trademarks Law No. 33 of 1952 as amended. 
trademark should be registered. According to this pre-requisite, if a trademark owner did not register the trademarks in Jordan, he shall not be granted criminal protection under the infringement lawsuit of Trademarks Law. As a result, they shall not be entitled to file a criminal claim under the provision in the Jordanian Trademarks Law.

To sum up, neither civil remedies nor criminal sanctions could be taken in a way that enables the plaintiff (trademark owner) to own the infringing material, which is a domain name. Further, there is no civil or criminal protection for unregistered trademark. Thus, even if the said barriers were overcome, and the application of the traditional Trademark Law provisions of infringement claim was possible to the cybersquatting activities, the decision for a civil remedy or criminal sanction would not be enough effective.

It can be noted that the Jordanian Trademark Law No. 33 of 1952 as amended in its current situation is not capable of dealing with the cybersquatting activities.

\subsubsection{The Mechanism of Cybersquatting Claim under the Unfair Competition and Trade Secrets Law}

As the Jordanian Trademark Law does not settle the issue of the cybersquatting and does not provide clear protection for the unregistered trademark that is registered as a domain name. Thus, the trademark owner has to find the applicable law and shall go to the court in order to stop cybersquatter from using his trademark in the course of DNS.

Generally speaking, the Jordanian Unfair Competition and Trade Secrets Law No. 15 of 2000 as amended, has founded a criteria for the Unfair Competition activities, based on Jordan's reforms under the umbrella of TRIPs Agreement to combine the provisions of article 10bis of Paris Convention for the Protection of Industrial Property. ${ }^{919}$

The trend established by the Jordanian Unfair Competition Law relays on providing a wide definition of activities against unfair competition. It provides that any act contrary to honest

\footnotetext{
${ }^{919}$ Articles 1 (2), 2 (1), 8 (2), 16 (1), 22 (2), 39, and 40 of the Trade Related Aspects of Intellectual Property Rights (TRIPs Agreement). Article 10bis of Paris Convention for the Protection of Industrial Property.
} 
practices in industry and trade will be considered and encountered as an act of unfair competition, and as such, the right holder has to be protected against such kind of practices.

Article 2 (a) of Jordanian Unfair Competition Law includes a non-exhaustive list, the followings are considered as examples for unfair competition activities in Jordan:

"Any competition contradictory to the honest practices in the commercial and industrial activities shall be deemed one of the unfair competition acts and particularly the following:

1. The activities that may nature cause confusion with entity, products or commercial or industrial activities of one of competitors.

2. Untrue assumptions in practicing trade, whereby causing deprivation of trust from one of the competitors' entity, products or industrial or commercial activities.

3. The data or assumptions, which use in commerce, may mislead public in respect to the product nature, methods of manufacturing, properties, amounts, and availability for use.

4. Any practice that reduce the product reputation, cause confusion in respect to the product general shape or presentation, or mislead the public on declaring the product price or the method of counting thereof." ${ }^{\prime 20}$

It is remarkable that one of the most vital results and advantages of the Jordanian Unfair Competition Law is the protection of non-registered trademark under Article 2(b) of the Jordanian Unfair Competition Law. Whether a trademark is registered or not, such trademark is protected against unfair competition if such use of the trademark would mislead the public. Similarly, paragraph (c) of the same article provides the same meaning to service mark. ${ }^{921}$

\subsubsection{Infringement Claim under the Unfair Competition Law}

Indeed, any person with interest may claim for compensation for any damages caused by unfair competition. For instances, the owner of the trademark can file a civil lawsuit, in the context of cybersquatting activities, against anyone who registers a domain name that is identical or very similar to his trademark, if the claimant can prove that the registration of that domain name is an

\footnotetext{
${ }^{920}$ Article 2 (a) of Jordanian Unfair Competition and Trade Secrets Law No.15 of 2000 as amended.

${ }^{921}$ Ibid, article 2 (c).
} 
act of unfair competition and that the registration of that domain name may deceive the public and cause confusion to them which may lead to believe that there is connection between that domain name and trademark. This conduct should be considered as unfair use of the fame and the reputation of the trademark.

The Unfair Competition Law is actually the best method to compensate the owner of a registered and non-registered trademark for any damages which was caused to him by cybersquatter. On the other hand, in order to success his claim, the trademark owner shall prove that the cybersquatter's deed by registering a domain name is an act of unfair competition.

A person who initiates a civil law suit against a trademark's infringer, such as cybersquatter, under Unfair Competition Law, has to prove that he is the owner of the infringed trademark by registering a trademark or even a non-registering trademark ${ }^{922}$ in Jordan. This condition is an application of the "legitimate interest rule" established in article 3 of the Law for Civil Procedures. ${ }^{923}$ When filing a civil lawsuit the burden of proof falls upon the plaintiff alleging infringement. ${ }^{924}$ The plaintiff has to prove that:

- $\quad$ he is the legitimate proprietor of the trademark in question;

- the cybersquatting activities deceive the public and cause confusion for them which may lead to believe that there is connection between domain name and trademark, thus this conduct should be considered as unfair use of the fame and the reputation of the trademark; and

- there has been an infringement to his trademark and he suffered loss due to that infringement.

\subsubsection{Civil Remedies under the Unfair Competition Law}

Similar to the civil remedies under the trademark law, after succeeding in proving the listed elements, the competent court will estimate the sum of compensation according to actual damages and loss of potential profit. ${ }^{925}$ In other words, the trademark owner can ask to stop the violation by

\footnotetext{
922 The owners of unregistered trademarks in Jordan can prove that they have the rights of unregistered trademarks, for instances, stating that they registered these trademarks in the countries other than Jordan.

${ }_{923}$ Article 3 of the Jordanian Civil Procedures Law, No. 24 of 1988 as amended.

924 Article 77 of the Jordanian Civil Law No. 43 of 1976 as amended.

925 Ibid, articles 256, 257, 259, 263, 266, 267, 268 and 269.
} 
asking the court to issue a decision for cancellation of the domain name registration as well as claiming compensation for the actual damage sustained and the lost profit but he does not have any possibility to get a civil remedies in a way that enables him to own the infringing material, which is a domain name, as the registrant of the domain name (cybersquatter) paid the price of the domain name registration a the trademark owner did not pay the price of domain name registration which is subject to the cybersquatting activities, as a result, no way to obtain it by a court judgment.

On the other hand, the Jordanian Unfair Competition Law also gives the right to the trademark owner for applying to provisional measures. Such provisional measures include: ${ }^{926}$

1. Cease the infringement.

2. Place a provisional attachment on the product subject of infringement wherever found.

3. Preserve the evidence related to the infringement.

In addition, the following remedies are stipulated in the Jordanian Unfair Competition Law: ${ }^{927}$

1. Confiscation of the goods, packaging, rolling materials, advertisement, portraits, seals and other tools and materials primarily used for printing the trademark on goods, or used for committing the infringement, or resulted in the infringement.

2. Destruction of the goods, packaging, rolling materials, advertisement, portraits, seals, and other tools and materials primarily used for printing the trademark on goods, or used for committing the infringement, or resulted in the infringement, or its use for non-commercial purposes.

Similar to the claim under Trademark Law, the court shall also decide to compensate the winning party, litigant in favor of whom the judgement was issued, for the fees and expenses arising from filing the lawsuit under Jordanian Unfair Competition Law and its procedures. Besides these sorts of fees and expenses, the court shall decide on compensation of attorneys' fees. ${ }^{928}$

It is noteworthy that the Unfair Competition and Trade Secrets Law No.15 of 2000 as amended did not cover the criminal sanctions, thus the trademark owner have only the right to file a civil

\footnotetext{
${ }_{926}$ Article (3) of Jordanian Unfair Competition and Trade Secrets Law No.15 of 2000 as amended.

927 Ibid.

${ }^{928}$ Articles 161 and 167 of the Jordanian Civil Procedures Law, No. 24 of 1988 as amended.
} 
lawsuit, under Unfair Competition and Trade Secrets Law No.15 of 2000 as amended, against the cybercquatter.

\subsubsection{Jordanian Jurisdiction over Cybersquatting Claims}

In Jordan, the Constitution ${ }^{929}$ divides the courts into three main kinds of courts: regular, ${ }^{930}$ religious $^{931}$ and special ${ }^{932}$ courts. $^{933}$

The civil, criminal and administration jurisdiction is exercised under the title of "Regular Courts" as a following:

- the civil and criminal Magistrates' court ${ }^{934}$ and the courts of First Instance, ${ }^{935}$

- the civil and criminal court of Appeal, ${ }^{936}$

- the civil and criminal court of Cassation (Supreme Court). ${ }^{937}$

- Administrative court. ${ }^{938}$

Under Jordanian judicial system, the model of "Specific Jurisdiction" does not existed, for instance "the same judge may examine a bankruptcy case (which is considered a commercial dispute) and at the same time look into a labor case (which is not a commercial dispute). However, in practice, courts tend to direct cases of a certain nature, such as investment cases, general commercial cases, intellectual property cases, Bank cases or companies' cases to certain judges or committee of judges who happen to have more experience in such disputed matters."939

\footnotetext{
${ }^{929}$ Jordanian Constitution of 1952 as amended, was published in the Official Gazette issue No.1093 dated 8/1/1952, p 3.

${ }_{930}$ Articles 102 and 103 of the Jordanian Constitution of 1952 as amended.

931 Religious courts were divided into Shari'a courts for Muslims and Tribunals of other Religious Communities. Article 104 of the Jordanian Constitution of 1952 as amended.

932 There are several Special courts in Jordan, each court regulated with its Law such as, Special Labor court , Jordanian Labour Law No 8 of 1996 as amended.

933 Article 99 of the Jordanian Constitution of 1952 as amended.

934 Article 3, a of the Jordanian Regular Courts Formation Law No.17 of 2001 as amended, was published in the Official Gazette issue No. 4480 dated 18/3/2001, p 1308.

935 Ibid, article 4.

936 Ibid, article 6.

${ }^{937}$ Ibid, article 9.

938 Article 100 of the Jordanian Constitution of 1952 as amended.

939 Tariq Hammouri, Dima Khleifat, and Qais Mahafzah, Arbitration and Mediation in the Southern Mediterranean Countries: Jordan, Kluwer Law International, Wolters Kluwer - Netherlands, Volume 2, Number 1, 2007, p7.
} 
However, the jurisdiction of the Jordanian courts in domain names disputes requires to stress on provisions of the Jordanian Civil Procedures Law that deal with the jurisdiction over foreigners.

As prior noted, it is quite often the case that cybersquatters try to register domain names identical or similar to a famous trademark that attained its reputation in territory other than their place of residence. Thus, it would not be exaggerating to emphasize on jurisdiction of the Jordanian courts over foreigners in civil cases.

Foremost, if a domain name registrant has a domicile or residence in Jordan, the civil courts of Jordan shall have the jurisdiction over the disputed domain name. Article 27 (1) of the Jordanian Civil Procedures Law provides "the Regular Courts in the Hashemite Kingdom of Jordan shall practice the right of judiciary with all people in relation with all the civil and penal articles."

On the other hand, if the cybersquatter does not have a domicile or residence in Jordan but resides out of Jordan, that Jordanian civil courts, inter alia, shall have the jurisdiction over the disputed domain name. Article 28 of the Jordanian Civil Procedures Law states that the Jordanian civil courts are authorized to hear cases filed against foreigners who do not have a domicile or residence in Jordan in any of the following situations:

a- if having a selected location in Jordan;

b- if the case related to a property in Jordan or to a commitment resulting from, executed, has to be executed;

c- if one of the defendants has a residence place in Jordan. ${ }^{941}$

In addition, Jordanian courts shall also have jurisdiction in law suits filed against foreigners, if the defendant accepts, whether explicitly or impliedly, the competence of the court. ${ }^{942}$

Article 27 (2) of the Jordanian Civil Procedures Law provides that "the Jordanian Courts will adjudicate the case even if not within the scope of its competence if the litigant party explicitly and implicitly accepts the jurisdiction of such courts. ${ }^{.943}$

\footnotetext{
${ }^{940}$ Article 27 (1) of the Jordanian Civil Procedures Law, No. 24 of 1988 as amended.

${ }^{941}$ Article 28 of the Jordanian Civil Procedures Law No. 24 of 1988 as amended.

${ }^{942}$ Ibid, article 27 (2).

${ }^{943}$ Ibid.
} 
By applying these provision on cybersquatting activities, it is undisputed that the above provisions shall be sufficient in such disputes.

In addition, as prior noted, that ICANN obliges its accredited registrars, under the umbrella of RAA, to enter into contracts with domain name registrants that involve the registrant of gTLDs, has to agree that "the court of competent jurisdiction is in general is either the location of Registrar's principal office or the registrant's address as shown in WHOIS database."944

It is vital to note that these are non-exclusive selections, as there is also the provision regarding "other potentially applicable jurisdictions". 945 As observed by Francis Medeiros that "it has a symbolic value, as a third party who is not bound by a contract that he has not signed is not subject to these jurisdiction agreements." 946

Actually, if the registered domain name in gTLDs conflicts with a famous trademark, then the trademark owner can easily ascertain the court of competent jurisdiction by searching in WHOIS data, for the location of the registrar or the cybersquatter's domicile location (registrant's domicile), in order to file a lawsuit against the cybersquatter.

In this context, the question that should be answered how the ICANN's jurisdiction is addressed under the Jordanian Private International Law principles.

For answering this question reference shall be made to article 27 of the Jordanian Civil Procedures Law. For instance, if the trademark owner found in WHOIS data that cybersqautter resides in Jordan or the registry is located in Jordan, then the Jordanian courts shall have jurisdiction in lawsuits filed against cybersquatter, as the defendant, whether he is foreigner or Jordanian cybersquatter, accepted explicitly the jurisdiction of the court under his contract with the registrant previously. On the other hand, ICANN jurisdiction is coexistent with Jordanian Civil Procedures Law. Article 27 (1) of the Jordanian Civil Procedures Law states that the Jordanian courts shall have the right of judiciary in all the civil cases with all people, ${ }^{947}$ among of them might be

\footnotetext{
${ }^{944}$ Olwan, the Case of Suck Domain Names and Cyber-smearing Examination of Suck Cases with the WIPO Arbitration and Mediation Center, <docshare01.docshare.tips/files/390/3901550.pdf > accessed 20 September 2016. ${ }^{945}$ Medeiros, Is 'com' International? The .com gTLD: an Analysis of Its Global Nature through the Prism of Jurisdiction, p 278.

946 Ibid.

${ }^{947}$ Ibid, article 27 (1).
} 
Jordanian cybersquatters. Furthermore, article 27 (2) of the Jordanian Civil Procedures Law confirms that the Jordanian courts shall have the right to adjudicate the case if the foreigner litigant party explicitly accepted the jurisdiction of such courts. ${ }^{948}$ Thus even in case that the cybersquatter is foreigner, and if he will assume and defence that the Jordanian court does not have the right to adjudicate on his case, then the court shall decide that it has the full jurisdiction, as the cybersquatter contract with registrar beside article 27 (2) Jordanian Civil Procedures Law, authorizes the Jordanian court to adjudicate the case without any doubt.

However, the RAA and the contract between ICANN's accredited registrars and registrant, do not apply or cover for ccTLDs registrations as accreditation of registrars for ccTLDs is a subject of choice for the ccTLD registry operators. ${ }^{949}$ Accordingly, each ccTLD registry is subject to the legal jurisdiction in which the registry manager is based. Thus, within that jurisdiction the ultimate authority is a court. ${ }^{950}$ This is mean that the cybersquatter under ".jo" ccTLD registry in Jordan is undoubtedly subject to the legal jurisdiction of the Jordanian courts.

Lastly, after succeeding in proving the jurisdiction of Jordanian courts, it is very important to note that the competency of the civil court would be determined according to the amount of money pleaded in the bill of action. Accordingly, if the amount of money pleaded is above seven thousand Jordanian Dinner, the jurisdiction would be given to the Court of First Instance but if the amount of money pleaded is less than seven thousand Jordanian Dinner then the jurisdiction would be given to the Magistrate Court (Peace Court). ${ }^{951}$

It should also be noted, as prior stated, that no mention regarding "choice of law" or "applicable laws" was made concerning gTLDs under ICANN's RAA or even the contractual relationship between the registrant and registrar. ${ }^{952}$ The contractual relationship between the registrant and

\footnotetext{
948 Ibid, article 27 (2).

949 ICANN, Non-Lawyers' Guide to the May 2009 Registrar Accreditation Agreement, <https://www.icann.org/resources/pages/non-lawyers-guide-2010-02-15-en> accessed 12 December 2016.

950 Arx, and Hagan, Sovereign Domains: A Declaration of Independence of ccTLDs from Foreign Control, <http://scholarship.richmond.edu/jolt/vol9/iss1/6> accessed 12 December 2016.

951 Article 3 of the Jordanian Magistrate Courts No. 15 of 1952 as amended.

The Jordanian Magistrate Courts No. 15 of 1952 as amended, was published in the Official Gazette issue No.1102 dated 16/3/1952, p 135 .

952 Medeiros, Is 'com' International? The .com gTLD: an Analysis of Its Global Nature through the Prism of Jurisdiction, p 276.
} 
registrar is silent regarding which law shall govern gTLDs disputes, ${ }^{953}$ while in the ccTLD delegation there is a clear acknowledgement that the laws of national jurisdictions should form the administration of this type of ccTLD space. ${ }^{954}$

Briefly, the elimination of a jurisdiction clause does not help to determine which jurisdiction would be the most suitable for hearing disputes involving international domain names. ${ }^{955}$

\subsection{The National Information Technology Centre (NITC)}

National Information Centre (NIC) was established in Jordan according to the National Information Regulation No. 50 of $1992 .{ }^{956}$ NIC is authorized "deployment of information technology resources in government organization". ${ }^{957}$ In 1995, NIC was the first to launch the Internet service in Jordan and become, in 1996, the first ISP for the public sector. ${ }^{958}$

In 2003, the National Information Regulation was cancelled by issuing Deployment of Information Technology Resources in Government Organization Law No. 81 for 2003. ${ }^{959}$ According to this law the name of "National Information Centre" became "National Information Technology Center (NITC)." 960

According to article 8 (a) (3) of law No. 81 of 2003, NITC is considered the registry and registrar for domain names under (.jo) ccTLD. ${ }^{961}$ Broadly speaking, after a comprehensive registration and

\footnotetext{
${ }^{953}$ The gTLD provision is silent regarding such matters. As a result, the Jordanian Private International Law principles should apply. Ibid.

954 Thus it is interesting to note that under IANA contract "the contractor shall also take into account the relevant national frameworks and applicable laws of the jurisdiction that the TLD registry serves." Ibid.

955 Ibid.

${ }^{956}$ National Information Regulation No. 50 of 1992, was published in the Official Gazette issue No. 3864 dated 16/11/1192, p 2380.

${ }_{957}$ NITC, About Us, < https://www.dns.jo/about_us.aspx > accessed 1 May 2016.

958 The Official Site of the Jordanian E-Government, National Information Technology Center, <http://www.jordan.gov.jo/> accessed 29 December 2016.

959 Deployment of Information Technology Resources in Government Organization Law No. 81 of 2003 , was published in the Official Gazette issue No. 4606 dated 16/6/2003, p 3352.

${ }^{960}$ Articles 2 and 21 of the Deployment of Information Technology Resources in Government Organization Law No. 81 of 2003.

961 Article 8 (a) (3) of the Deployment of Information Technology Resources in Government Organization Law No. 81 of 2003.
} 
delegation process, ICANN granted the use of the top level (.jo) for NITC, as a result, it has become an authorized manager for (.jo) ccTLD to start registering Jordanian domain names. ${ }^{962}$

As prerequisite for registration a domain name in Jordan, the NITC requires the applicant for registering a domain name to present official documents which approve the identity of the domain name's owner. ${ }^{963}$

NITC, as an independent governmental body, thus it is managed by a Board of Directors. ${ }^{964}$ Currently, the Board of Directors put out the plans and general policies of NITC. ${ }^{965}$ Currently, one of these polices is the aim to have a transparent policy in registering national domain names under the (.jo) TLD in order to provide a fair treatment for all domain name registrants. ${ }^{966}$

The NITC has accepted the registration policy under which the online registration application will be approved. ${ }^{967}$ Generally speaking, in order to register a Jordanian domain name, this policy is considered as a contract between the domain name registrant and NITC as a registrar.

The registration policy provided some circumstances under which prevents the registration of a name as a domain name as well as such these circumstances are considered as precautionary and preventive protection to avoid the conflict between trademarks and domain names. The following are two main circumstances, as stated in the registration policy, which prevent the registration of a name as a domain name:

“- the chosen domain name does not relate to the name of the registrant or one of the registrants' registered trademarks.

-the domain name is in conflict with one of the well-known registered trademarks." 968

\footnotetext{
962 NITC, About Us, < https://www.dns.jo/about_us.aspx > accessed 1 May 2016.

${ }^{963}$ NITC, Required Documents, <https://www.dns.jo/paper.aspx > accessed 8 August 2016.

964 The Minister of Information and Communication Technology is the chair of Board of Directors. Article (10) (a) of the Deployment of Information Technology Resources in Government Organization Law No. 81 of 2003. 965 Ibid.

${ }^{966}$ NITC, About Us, < https://www.dns.jo/about_us.aspx > accessed 1 May 2016.

${ }^{967}$ NITC, Registration Policy, <https://www.dns.jo/Registration_policy.aspx> accessed 8 August 2016.

968 Ibid.
} 
However, the NITC did not specify any certain legislation provision or even dispute resolution policy that clearly demonstrates how to resolve the domain name disputes in the situation where someone registers others' famous trademark as (jo) domain name. ${ }^{969}$

In other words, neither NITC nor any other Jordanian official entity have put out rules for solving the domain names disputes in ccTLD space under (.jo). The center even exempts itself in the registration policy from any liability for any damage that may be sustained. ${ }^{970}$ As prior noted, such an exemption in reality means that the domain name disputes in Jordan are subject to the traditional Jordanian judicial system. Thus, the trademark owner who has a legitimate right on the trademark, has to file a lawsuit in the local court to stop cybersquatter from using his trademark in the course of DNS.

It is noteworthy that if the litigation is filed against the cybersquatter, NITC attains the right to deactivate, or delete the cybersquatter's domain name under certain conditions. ${ }^{971}$

In this regard, the following question could be raised: which court shall have the right to cancel the registration of the domain name?

Under article 5 (a/7) of the Administrative Judicial Law No. (27) for the year 2014, ${ }^{972}$ which states that it is within the jurisdiction of the Administrative Court to accept a contestation of a final administrative decision issued by any official or governmental entity. ${ }^{973}$ Accordingly, since the entity that authorized the registration of the domain names in Jordan is a public official entity, it's final administrative decisions in that matter (such as, accepting the domain name to be registered) are subject to contest by cancellation in front of the Administrative Courts.

Despite the fact that the trademark owner does not have any possibility to get remedies in a way that entitles him to transfer the registration of the disputed domain name to be on his behalf, as the registrant (cybersquatter) paid the price of the domain name registration while the trademark owner did not pay the price of domain name registration, thus this is leading to the logical result which is

\footnotetext{
${ }^{969}$ However, the NITC reserves the right to revoke or delete the name as it sees necessary. Ibid.

${ }^{970}$ NITC will abide by all court orders without being names as party to a lawsuit. Ibid.

${ }^{971}$ Ibid.

972 Administrative Judicial Law No. 27 of 2014, was published in the Official Gazette issue No.5297 dated 17/8/2014, p 4866.

${ }^{973}$ Article (5) (a/7) of the Administrative Judicial Law No. 27 of 2014.
} 
that no way to transfer the registration of the domain name to be under the name of the trademark owner by issuing even an administrative judgment. Further, the court does not have any power to transfer the disputed domain name, as its power is only limited to cancel the administrative decision according to the Administrative Judicial Law No. 27 for the year 2014.

To conclude, it should be mentioned that the Jordan did not adopt the UDRP Policy to settle the (.jo) domain names disputes by WIPO Arbitration and Mediation Center. ${ }^{974}$ Furthermore, the Jordanian registry provides Whois data to communicate with the domain name's administrator or holder.

${ }^{974}$ WIPO, ccTLD Database, <www.wipo.int/amc/en/domains/cctld_db/index.html > accessed 12 March 2016. 


\section{Conclusion}

Since the late 1990s, electronic commerce was one of the most significance method to do business via cyberspace. ${ }^{975}$ To launch this new method of commerce, the first phase is to develop a website, where the trader shall advertise the products or services. As seen throughout the thesis, there is no online website without registering a domain name thus the trader shall also register domain name for this aim in old style "gTLD", such as (.com) and/or "new gTLD" such as (.apple) or "ccTLD" such as; (.hu).

It is common sense and exercise for these traders to use their famous trademarks in the domain names therefore the Internet consumers shall find them easily via the cyberspace. In some circumstances, such traders are shocked that their trademark or famous trademarks they want to register as domain names had been already registered by persons, competitive companies or noncompetitive companies. When infringers register or use domain names of a trademark, especially famous undertakings names, with the purpose to resell. This activity is called "cybersquatting". Cybersquatters have been described as "individuals who attempt to profit from the Internet by reserving and later reselling or licensing domain names back to the companies that spent millions of dollars developing the goodwill of the trademark." 976

As previously mentioned, since the end of the last century, law reviews and court recorders were crowded with debates about how the statute should arrange the Cybersquatting phenomenon and domain names disputes, specifically in terms of their correlation with trademark law. ${ }^{977}$ In addition, it was hard to determine or find the details about the owner of the abusive domain name (cybersquatter), who is the cybersquater? In order to file a case before the competent courts in the right jurisdiction or to apply the private law. Thus, countries have been moved towards evolving a comprehensive domain name dispute resolution mechanisms to address the disputed domain name, in the context of cybersquatting phenomenon, before the national courts and/or out-court dispute resolution.

\footnotetext{
${ }^{975}$ Lipton, Beyond Cybersquatting: Taking Domain Name Disputes Past Trademark Policy, p 1361.

976 Chalikian, Cybersquatting, p 106.

${ }^{977}$ Lipton, Beyond Cybersquatting, p 1362.
} 
The author found that the trademark owners can directly adjudicate the cybersquatter out-court dispute resolution mechanism such as ICANN's UDRP or they can easily determine the court of competent jurisdiction by searching in WHOIS data, (https://whois.icann.org/en), ${ }^{978}$ which provides publicity online accurate details for each registration in gTLDs or new gTLDs, including the information for the location of the registrar or the cybersquatter's domicile location (registrant's domicile), in order to file a lawsuit against the cybersquatters. ${ }^{979}$

Thus, this thesis resulted that domain name dispute resolution mechanisms to address the disputed domain name, in the context of cybersquatting phenomenon, could be before the national courts and/or out-court dispute resolution as following:

- National courts. The courts have addressed the problem of cybersquatting by applying traditional trademark infringement legislations to claims brought by the trademark owner. ${ }^{980}$ Filing anticybersquatting claim under traditional trademark law before the national courts has become much more sophisticated, when the cybersquatters register and/or use trademarked names on the cyberspace without any indication to the products or services. As the trademark legislation provides the legal protection of trademarks with reference to the products and services in the course of trade, but it does not provide any protection against such unauthorized use. ${ }^{981}$ In addition, in some countries the trademarks do not attain any legal protection under trademark legislations without registration. Accordingly, there is a various approaches applied by the countries. Some countries enacted special domain name legislations, such as France and United State. ${ }^{982}$ While some other countries provide the legal protection against cybersquatting phenomenon based on traditional trademark infringement and unfair competition legislations such, Hungary, Austria, Germany and Jordan.

- Out-court dispute resolution mechanism. The out-court dispute resolution mechanism well addressed the problem of cybersquatting such as, ICANN's UDRP as a model for trademark

\footnotetext{
978 while WHOIS service for ccTLDs, it may be accessed the via the concerned registrar's website.

979 Medeiros, Is 'com' International? The .com gTLD: an Analysis of Its Global Nature through the Prism of Jurisdiction, p 278.

${ }^{980}$ Chalikian, Cybersquatting, p 106.

981 The Cybersquatting phenomenon also generates a tension when it comes to private international law and specifically to jurisdiction and applicable law

982 American Anti-cybersquatting Consumer Protection Act (ACPA) of 1999, and the French Postal and Electronic Communication Code of 2007.
} 
cybersquatting disputes settlement. ${ }^{983}$ According to the (UDRP); the trademark owner must prove that the domain name registered is identical or confusingly similar to a trademark in which the trademark owner has rights, the registrant has no rights or legitimate interests in respect of domain name registered, and the domain name has been registered and is being used in bad faith. ${ }^{944}$ The ICANN's UDRP applies to settle the domain name disputes wither in old style gTLDs, new style gTLDs ${ }^{985}$ and some ccTLDs. ${ }^{986}$ Regarding to the ccTLDs system, some countries have evolved their own ADR mechanism that are unrelated to the UDRP such as the USA adopted usDRP. ${ }^{987}$ While some other did not adopt any ADR mechanism such as Austria then legal action could be filed before Austrian court as a last resolution. ${ }^{988}$ Under European Union, the EU Regulation 874/2004 of 28 April 2004, ${ }^{989}$ which deals only trademark cybersquatting in (.eu) ccTLDs. Similar to the ICANN's UDRP Policy, ${ }^{990}$ the Regulation pursues the tactic of ICANN's UDRP Policy, ${ }^{991}$ as any disputes regarding (.eu) ccTLDs are subject to the (.eu) “ADR Rules”).992

The author also found that the new gTLD program has released unforeseen and sophisticated a legal troubles. It allowed for the registration of trademarks under TLDs, which created another arena for trademark Cybersquatting, requiring trademark owners to monitor applications for new TLDs to ensure that their rights are not infringed. Thus, ICANN sets up newly advanced out-court dispute resolution mechanisms to assist trademark owners in preventing third parties from registering their trademarks under a new gTLD. The new protection mechanisms are now available to the trademark owners in the pre-delegation phase "Pre-delegation Dispute Resolution" by

\footnotetext{
${ }^{983}$ Tunkel, and York, E-commerce: A Guide to the Law of Electronic Business, p 186.

${ }^{984}$ Paragraph 4 (a) of the UDRP Policy.

${ }^{985}$ WIPO, Domain Name Dispute Resolution Service for country code top level domains (ccTLDs), <http://www.wipo.int/amc/en/domains/gtld/udrp/> accessed 11 March 2016.

${ }^{986}$ While in the context of trademark cybersquatting in ccTLDs, some ccTLD registry operators have completely adopted the UDRP such Namibia (.nu), Tuvalu (.tv), Samoa (.ws). ICANN, Non-Lawyers' Guide to the May 2009 Registrar Accreditation Agreement, <https://www.icann.org/resources/pages/non-lawyers-guide-2010-02-15-en> accessed 12 December 2016.

${ }^{987} \mathrm{Ng}$, the Domain Name Registration System: Liberalization, Consumer Protection and Growth, Routledge, p 42.

${ }_{988}^{98}$ Nic.at, Legal Issues, < https://www.nic.at/en/faq/legal-issues/> accessed 25 April 2016.

989 Commission Regulation (EC) No 874/2004 of 28 April 2004 laying down Public Policy Rules Concerning the Implementation and Functions of The .eu Top Level Domain and the Principles Governing Registration [2004] OJ L $162 / 40$.

${ }^{990}$ Taylor, Alternative Dispute Resolution, p 235.

${ }^{991}$ For instance, the wording in article 21 of the eu Regulation is very similar the paragraph 4 (a) of the UDRP.

${ }^{992}$ EURid, (.eu)- Alternative Dispute Resolution, <https://eurid.eu/media/filer_public/a0/69/a0694eb7-5a9c-4ff7a510-a7bae3787c71/adr_rules_en.pdf > accessed 22 February 2016.
} 
DRSPs, as a new way for settlement the disputes in new gTLD space, whereas other mechanisms apply after the delegation of the gTLD "Post-delegation Dispute Resolution", ${ }^{993}$ which is called the Trademark Post-delegation Dispute Resolution Procedure (Trademark PDDRP). In fact, the ICANN's new gTLDs Program has shown pros and cons. On one hand, it has created another cadre for trademark disputes, requiring trademark proprietors to monitor and observe the abusive new gTLD to ensure that their rights are not infringed. On the other hand, some authors argue that the new gTLD process is, complex, expensive and time consuming, and might be considered nothing more than an unwanted problem by some trademark holders. ${ }^{994}$

The author also found that the Jordanian legislator had constructed a well-based mechanism that aims to control registration and use of trademarks. The online source identifier shall be regulated as well via the cyberspace, particularly, in the light of the notable evolution of Internet usage in Jordan, and in the light of the advanced position that Jordan has acquired as a civilized country in dealing with legal aspects of technological matters by enacting the Electronic Transactions Law No. 15 for the year 2015 and Information Systems Crimes Law No.30 for the year 2010.

To sum up, a harmonization of the legislation governing domain names disputes is needed on the global stage. It needs more efforts to obligate all the countries to admit a uniform anticybersquatting legal system such as:

- Determine what is confusingly similar between domain name and trademark, either before the national courts and/or out-court dispute resolution, as there is no any international agreement or convention rules the anticybersquatting legal system.

- National Judges shall be trained on resolving domain names disputes, and how to deal with such disputes. This could be achieved by periodically attending international workshops and seminars to become familiar with combining the law and the technology to provide the maximum protection of trademarks via cyberspace under the umbrella of ICANN.

Finally, despite the fact that ICANN is based in the U.S., it is purely a doorkeeper for cyberspace and should continue to attend that role. It could be said that the flexible law reviews and court

\footnotetext{
993 Allen and Overy, the new gTLDs: What do trademark owners need to know? , <www.allenovery.com/SiteCollectionDocuments/The\%20new\%20gtlds.pdf > accessed 13 December 2016.

994 Roberts, An Overview of the New gTLD Programme, <https://valideus.com/sites/default/files/documents/newgTLD-white-paper-final.pdf $>$ accessed 11 December 2016.
} 
recorders which regulate the anticybersquatting legal system has reached the limits of its variations, as a result the norms which rule the domain names, especially anticybersquatting legal system, should be regulated commonly and amended in future periodically under global stage in order to adapt to new technological advances on international stage. While there is no commonly agreed detailed agreement governing domain names disputes, trademark owner might take advantage of dispute resolution mechanisms wither before the national court and/or out-court dispute resolution such as ICANN's UDRP. 


\section{Bibliography}

\section{Book:}

- Armstrong J, Rhys-Jones M, and Dresner D, Managing Risk: Technology and Communications: Managing Risk Series, Taylor \& Francis, 2004.

- $\quad$ Badgley R, Domain Name Disputes, Aspen Publishers Online, 2002.

- Battersby G, and Grimes C, Trademark \& Copyright Disputes: Litigation Forms and Analysis, Aspen Publishers Online, 2003.

- Campbell D, the Internet [2009] - II: Laws and Regulatory Regimes, Yorkhill Law Publishing, 2009.

- Chissick M and Kelman A, Electronic Commerce: law and practice, third edition, London, Sweet \& Maxwell, 2002.

- Cornish W, and David Llewelyn, Intellectual Property: Patents, Copyright, Trade Marks and Allied Rights, Sweet \& Maxwell, 2007.

- Christopher H, and L Chung, the Protection of Well-known Marks in Asia, Max Planck Series on Asian Intellectual Property Law, 2000.

- Eko L, American Exceptionalism, the French Exception, and Digital Media Law, Lexington Books, 2013.

- Flores A, to Each Country, Its Own Law and Domain: The Legal Structures of ccTLD's in Comparative Perspective, ProQuest LLC, 2008.

- Komaitis K, the Current State of Domain Name Regulation: Domain Names as Second Class Citizens in a Mark-Dominated World, Routledge, 2010.

- $\quad$ Lars D, Law and Internet, Oxford, Hart publishing, 1997.

- $\quad$ Lorna B, Intellectual Property Law Handbook, 1st ed. Law Society Publishing, 2008.

- $\mathrm{Ng} \mathrm{J}$, the Domain Name Registration System: Liberalization, Consumer Protection and Growth, Routledge, 2012.

- Overbeck W, and Belmas G, Major Principles of Media Law, Cengage Learning, 2011.

- Rockman H, Intellectual Property Law for Engineers and Scientists, John Wiley \& Sons, 2004.

- $\quad$ Rustad M, Global Internet Law, West Academic, 2013.

- Schwabach A, Internet and the Law: Technology, Society, and Compromises, ABC-CLIO, California/USA, 2014. 
- Smith G, Internet Law and Regulation, third edition, London, Sweet \& Maxwell, 2002.

- $\quad$ Tunkel D, and York S, E-commerce: A Guide to the Law of Electronic Business, second edition, Butterworths, 2000.

\section{Articles:}

- $\quad$ Anaracki M, On Domain names and Trademarks, Vol. 15 Issue 12, Journal of Internet Law, 2012.

- Azmi I, Domain Names and Cyberspace: the Application of Old Norms to New Problems, International Journal of Law and Information Technology, Vol.8, no.2, 2000.

- $\quad$ Baum S, Domain Name Conflicts in Germany: an Economic Analysis of the Federal High Court's Recent Decisions, 4 EUR. BUS. ORG. L. REV. 137, 2003.

- $\quad$ Béjot M, and Setton I, Current Approaches to Domain Name Management in Europe, J. INTERNET L., June 2000.

- $\quad$ Brian Holland, Tempest in a Teapot or Tidal Wave? CyberSquatting Remedies Run Amok, Journal of Technology Law and Policy Vol. 10, 2005.

- $\quad$ Chalikian A, Cybersquatting, Journal of Legal Advocacy and Practice San Fernando Valley College of Law, Vol.3, 2001.

- $\quad$ Davidson A, Social Media \& Electronic Commerce Law, Cambridge University Press, 2015.

- $\quad$ Efroni Z, the Anticybersquatting Consumer Protection Act and the Uniform Dispute Resolution Policy: New Opportunities for International Forum Shopping? , Columbia Journal of Law \& the Arts, Vol. 26, 2003.

- $\quad$ Faqir R, Sharari S and Salameh A., Cyber Crimes and Technical Issues under the Jordanian Information System Crimes Law, Journal of Politics and Law: Canadian Center of Science and Education; Vol. 7, No. 2; 2014.

- $\quad$ Haigh D, Brand Valuation - Understanding, Exploiting and Communicating Brand Values, London, Financial Times Retail \& Consumer Publishing, 1998.

- $\quad$ Hammouri T, Khleifat D, and Mahafzah Q, Arbitration and Mediation in the Southern Mediterranean Countries: Jordan, Kluwer Law International, Wolters Kluwer Netherlands, Volume 2, Number 1, 2007. 
- Hestermeyer $\mathrm{H}$, the Invalidity of ICANN's UDRP under National Law, Intellectual Property Revew, 2002.

- $\quad$ Lipton J, Beyond Cybersquatting: Taking Domain Name Disputes Past Trademark Policy, Wake Forest Law Review, V. 40, 2005.

- $\quad$ Maniatis S, Trademark Law and Domain names-Back to Basics, European Intellectual Property Law Review, volume 24, Issue, 2002.

- Medeiros F, Is '.com' International? The com gTLD: an Analysis of Its Global Nature Through the Prism of Jurisdiction, International Journal of Law and Information Technology, Vol. 21, No. 3, 2013.

- $\quad$ Pechan L, Domain Grabbing in Germany; Limitations of Trade Mark Protection and How to Overcome Them, Journal of Intellectual Property Law \& Practice, Vol. 7, No. 3,2012

- $\quad$ Stegmaier B, German and European Trademark Law, Trademark Law at Millennium's Turn: Part Six: Trademarks in the International Arena: Comparative Law, Journal of Contemporary Legal Issues Volume 12, 2002.

- Taylor D, Alternative Dispute Resolution: It's Application to Protect Intellectual Property Rights under .EU: The First Pan-Regional Top Level Domain Tribune, International Business Law Journal (Revue De Droit Des Affaires) No. 1, 2007.

- Vezzani S, ICANN's New Generic Top-Level Domain Names Dispute Resolution Procedure Viewed Against the Protection of the Public Interest of the Internet Community: Litigation Regarding Health-Related Strings, the Law \& Practice of International Courts and Tribunals: A Practitioners' Journal, Volume 13, Issue 3, 2014.

\section{Report:}

- The Secretariat of the WIPO, Multilingual Domain Names: Joint ITU/WIPO Symposium, Geneva, 2001.

- USA Congressional Record, Proceedings and Debates of the 106th Congress, First Session, V. 145, Pt. 21, 1999.

\section{Thesis:}

- Fernbach T, "What is in a name?” A Comparative Look at the ICANN Uniform Domain Name Dispute Resolution Policy and the United States Anti-Cybersquatting Consumer Protection Act, Munich Intellectual Property Law Center (MIPLC) Master thesis, 2011. 
- Korman T, the Relationship between Domain Names and Trademarks, LL.M. thesis, Legal Studies Department, Central European University, 2013.

- Popelenskaya V, Overlapping between Trademarks and Domain Names: Law Cases in Germany and Russia, Comparative Analysis on the Example of "eBayAnwalt" Case in Germany and "odnoklassniki.km.ru” Case in Russia, Master thesis, Munich Intellectual Property Law Center (MIPLC), 2009.

- Torsten B, Trademark Law in Cyberspace: The Battle for Domain Names, 28 Int'1. Rev. Indus. Prop. \& Copyright L, 508, 1997.

- Ventsislav P, the Prevention of Cybersquatting in Europe: Diverging Approaches and Prospects for Harmonization, Munich Intellectual Property Law Center (MIPLC) Master thesis, 2012.

\section{Statutory Instruments:}

- American Anti-cybersquatting Consumer Protection Act (ACPA) of 1999

- American Trade Mark Act (Lanham Act) of 1946, as amended.

- Austrian Trade Mark Act of 1970 as amended.

- Austrian Unfair Amendment Competition Act of 2007 as amended.

- Commission Regulation (EC) No 874/2004 of 28 April 2004 Laying down Public Policy Rules Concerning the Implementation and Functions of The .eu Top Level Domain and the Principles Governing Registration [2004] OJ L 162/40.

- Council Regulation (EC) 733/2002 of 22 April 2002 on the Implementation of the (.eu) Top Level Domain [2002] OJ L113/1.

- Council Regulation (EC) 874/2004 of 28 April 2004 laying down Public Policy Rules Concerning the Implementation and Functions of the (.eu) Top Level Domain and the Principles Governing Registration, [2004] OJ L162/40.

- Directive (EU) 2015/2436 of the European Parliament and of the Council of 16 December 2015 to Approximate the Laws of the Member States Relating to Trade Marks [2015] OJ L 336/1.

- Directive (EU) 2015/2436 of the European Parliament and of the Council of 16 December 2015 to Approximate the Laws of the Member States Relating to Trade Marks [2015] OJ L 336/1. 
- French Civil Code No.2004-164 as amended.

- French Intellectual Property Code No 92-597 of 1992 as amended.

- French Postal and Electronic Communication Code No. 2007-162 of 2007 as amended.

- French Postal and Electronic Communication Code of 2007.

- German Act against Unfair Competition of 2010 as amended

- German Act on the Protection of Trade Marks and other Signs of 1996 as amended

- German Civil Code of 1896 as amended

- Hungarian Act IV of 2012 on the Criminal Code ("Criminal Code").

- Hungarian Act LVII of 1996 on the Prohibition of Unfair and Restrictive Market Practices ("Unfair Market Practices Act").

- Hungarian Act V of 2013 on the Civil Code.

- Hungarian Act XI of 1997 on the Protection of Trade Marks and Geographical Product Signs.

- Jordanian Administrative Judicial Law No. 27 of 2014.

- Jordanian Civil Law, No. 43 of 1976 as amended.

- Jordanian Civil Procedures Law No. 24 of 1988 as amended.

- Jordanian Constitution of 1952 as amended

- Jordanian Deployment of Information Technology Resources in Government Organization Law No. 81 of 2003 as amended.

- Jordanian Electronic Transactions interim Law No. 85 of 2001.

- Jordanian Electronic Transactions Law No. 15 for the year 2015.

- Jordanian Evidences Law No. 30 for the year 1952 as amended.

- Jordanian Information Systems Crimes Law No.30 for the year 2010.

- Jordanian Labor Law No 8 of 1996 as amended.

- Jordanian Magistrate Courts No. 15 of 1952 as amended

- Jordanian National Information Regulation No. 50 of 1992.

- Jordanian Regular Courts Formation Law No.17 of 2001 as amended.

- Jordanian Trademarks Law No. 33 of 1952 as amended.

- Jordanian Unfair Competition and Trade Secrets Law No.15 of 2000 as amended

- Paris Convention for the protection of Industrial Property rights (1883).

- The Trade-Related aspects of Intellectual Property rights (TRIPs Agreement) (1993). 


\section{Court Judgement:}

American Cases

- Alitalia-Linee Aeree Italiane S.p.A. v. Casinoalitalia.com, 128 F. Supp. 2d 340 (2001).

- Barcelona.com, Inc. v. Excelentisimo Ayuntamiento de Barcelona, 189 F. Supp. 2d 367 (2002).

- Chatam International, Inc. v. Bodum, Inc., 157 F. Supp 2d 549 (2001).

- Coca-Cola Co. v. Purdy, 194 F. Supp. 2d 704 (2002).

- E. \& J. Gallo Winery v. Spider Webs Ltd., 129 F. Supp. 2d 1033 (2001).

- Ethical Treatment of Animals v. Doughney, 263 F.3d 359, 370 (2001).

- Fare Deals, Ltd v. World Choice Travel.com, Inc., 180 F. Supp. 2d 678 (2001).

- Ford Motor Co. v. GreatDomains.com, Inc. 177 F. Supp. 2d 628, 643 (2001).

- Lockheed Martin Corp. v. Network Solutions, Inc., 197 F.3d 980 (1999).

- Lucent Technologies, Inc. v. Lucentsucks.com, 95 F. 2d 528 (2000).

- Mattel, Inc. v. Adventure Apparel, 2001 U.S. Dist. LEXIS 13885, (2001).

- Mission v. Shajmarg.org, 139 F. Supp. 2d 721, 723-724 (2001).

- Nabisco Inc. v. PF Brands Inc., 191 F.3d 208, 216 (2d Cir. 1999).

- North America, Inc v. Porsche.net, 302 F. 3d 240 (2002).

- Northern Light Technology v. Northern Lights Club, 97 F. Supp. 2d 96, 110 (2000).

- Pepsico v. Thompson, FA114678, (2002).

- Pinehurst, Inc. v. Wick, 256 F. Supp. 2d 424, 433 (2003).

- Shields v. Zuccarini, 254 F. 3d 476, (2001).

- Sporty's Farm LLC v. Sportsman's Market, Inc., 202 F.3d 489, (2000).

- $\quad$ United Greeks v. Klein, 2000 U.S. Dist. LEXIS 5670, (2000).

- Victoria's Secret Stores v. Artco Equipment Co., Inc., 194 F. Supp. 2d. 270 (2001).

- Virtual Works, Inc. v. Volkswagen of Am., Inc, 238 F. 3d 264, (2001).

- Weber-Stephen Prods. Co. v. Armitage Hardware \& Bldg. Supply, 54 U.S.P.Q.2d1766 (2000)

- Zurakov v. Register.com, 600703/01 (2001).

Austrian Cases

(Hotspring.at) Case, Austrian Supreme Court dated 2005, MR 2005, 141. 
- $\quad$ Delikomat.com Case, Austrian Supreme Court dated 16 March 2004, MR 2004, 431.

French Cases

- Saint-Trope, v. Eurovirtuel, the Court of First Instance of Nanterre "the tribunal de grande instance de nanterre” Draguignan, 1st civil chamber, 21, August, 1997.

- Sté Soficar vs. Sté le Tourisme Moderne Compagnie Parisienne du Tourisme, the Court of First Instance of Nanterre "the tribunal de grande instance de nanterre", No. G 04-10.143, No. 1672, 13 December, 2005.

- TF1 and others v. YouTube Case, the Court of First Instance of Nanterre "the tribunal de grande instance de nanterre”, 3rd Chamber-1st Section, No. 10/11205, 29 May 2012.

\section{German Cases}

- Landgericht (LG Mannheim), Regional Court of Mannheim, March, 8, 1996, Neue Juristische Wochenschrift [NJW] 2736, 1996.

- Landgericht [LG Hamburg] [Regional Court of Hamburg] June 17, 2008, Multimedia and Recht 143 (Ls.), 2009.

\section{Hungarian Case}

- Royal Canin SAS v. Mr. Árpád Fekete Case, (2012) Judgment No. 8.Pf.20.336/2012/4.

\section{UK Cases}

- Aldous L.J. in Arsenal Football Club Plc. v. Reed, [2003] EWCA (Civ) 696, [33].

- British Sugar Plc. v. James Robertson \& Sons Ltd., [1996] EWHC (Ch), [1996] R.P.C. $281,291$.

- British Telecommunications Plc. v. One in a Million Ltd., [1998] EWCA (Civ) 1272, [1999] 1 W.L.R. 903, 926.

- Harrods Ltd. v. UK Network Services Ltd., [1996] EWHC (Ch), [1997] 4 E.I.P.R. D106.

- Regina v. Johnstone, [2003] UKHL 28, [2003] 1 W.L.R. 1736, [13]. 


\section{World Wide Web/ Internet Materials:}

- A CMS IP Group Publication, Protection of Trade Marks: Online Use and Anticybersquatting, A European Perspective, 2007<docplayer.net/10942010-Protectionof-trade-marks-online-use-and-anticybersquatting.html> accessed 20 September 2015.

- $\quad$ AFNIC, About AFNIC, <https://www.afnic.fr/en/about-afnic/ > accessed 27 May 2016.

- AFNIC, ADR Trends: AFNIC Out-of-court Dispute Resolution Procedures, <https://www.afnic.fr/medias/documents/RESOUDRE_UN_LITIGE/brochuresjuridiques /ADR-Trends-Afnic.pdf> accessed 28 May 2016.

- $\quad$ AFNIC, Charters, <https://www.afnic.fr/en/about-afnic/ > accessed 27 May 2016.

- AFNIC, Naming Policy for the French Network Information Centre, <https://www.afnic.fr/medias/documents/Cadre_legal/Afnic_Naming_Policy_12122016_ VEN.pdf > accessed 28 May 2016.

- Alasdair T, How to register a UK trade mark without a lawyer, 2011, <http://www.seqlegal.com/blog/how-register-uk-trade-mark-without-lawyer> Accessed 17 October 2015.

- Allen and Overy, the new gTLDs: What do trademark owners need to know? , 2012 <www.allenovery.com/SiteCollectionDocuments/The\%20new\%20gtlds.pdf > accessed 13 December 2016.

- Arx K, and Hagan G, Sovereign Domains: A Declaration of Independence of ccTLDs from Foreign Control, 2002, <http://scholarship.richmond.edu/jolt/vol9/iss1/6> accessed 12 December 2016.

- Beal V, IP Address - Internet Protocol (IP) Address, <http://www.webopedia.com/TERM/I/IP_address.html> accessed 26 November 2016.

- Bennett

A, Cybersquatting, 2015 , <http://campus.murraystate.edu/academic/faculty/wlyle/540/2015/ BennettPaper.docx> accessed 20 September 2015.

- Besien B, Different Ways for a Trademark Owner to Claim Back a Domain Name (gTILD), 2014, <www.newmedia-law.com/news/different-ways-for-a-trademark-owner-to-claimback-a-domain-name-gtld-/> accessed 25 April 2016. 
- British Institute of International and Comparative Law, Act LVII of 1996 on the Prohibition of Unfair and Restrictive Market Practices, <http://www.biicl.org/files/5900_hungary_-_act_lvii_pura_\%5Beng\%5D.pdf> accessed 26 April 2016.

- British Institute of International and Comparative Law, Introduction to French Tort Law, <http://www.biicl.org/files/730_introduction_to_french_tort_law.pdf> accessed 26 May 2016.

- Brown J, Middle East, Mid East, Near East, North Africa, <http://peprimer.com/middleeast.html> accessed 28 April, 2016.

- California Licensed Real Estate Brokerage, Worldwide Domain Name Registration and Renewal, <http://www.domainsnext.com/topleveldomains.htm> accessed 2 December 2016.

- Carboni A, and Cornwell J, Defeating Trade Mark Infringement on the Internet and Beating the Cybersquatters <http://www.austlii.edu.au/au/journals/ANZCompuLawJ1/2001/22. pdf> accessed 25 July 2016.

- Caruana C, the Legal Nature of Domain Names, <www.elsa.org.mt/wpcontent/uploads/2015/02/5.-Caruana-Claudio-The-Legal-Nature-of-Domain-Names.pdf > accessed 11 December 2016.

- ccNSO, About, <https://ccnso.icann.org/about> accessed 9 December 2016.

- Cyber Harvard, Anti-Cybersquatting Piracy Act (ACPA), <https://cyber.harvard.edu/property00/domain/legislation.html> accessed 20 July 2016.

- Cyber Harvard, Domain Name Case Law, <https://cyber.harvard.edu/property00/domain/CaseLaw.html> accessed 29 January 2016.

- Dand E, Challenging Delegated Top-level Domains: ICANN's Trademark Post Delegation Dispute Resolution Procedure, 2014, <www.lexology.com/library/detail.aspx?g=9e339387-e627-4d19-a8a5-5dddd79732c4> accessed 25 September 2015.

- Davidson J, Here's How Many Internet Users There Are, 2015, <http://time.com/money/3896219/internet-users-worldwide/> accessed 26 November 2016. 
- Davidson J, Posts Tagged 'Anticybersquatting Consumer Protection Act, $<$ https://davidsontm.wordpress.com/tag/anticybersquatting-consumer-protection-act/> accessed 20 July 2016.

- DENIC, .de Domains, <https://www.denic.de/en/domains/de-domains/> accessed 25 July 2016.

- DENIC, DENIC Domain Terms and Conditions, < https://www.denic.de/en/domainterms-and-conditions/> accessed 25 July 2016.

- DENIC, Legal Information, < https://www.denic.de/en/know-how/legal-issues/ > accessed 25 July 2016.

- DENIC, Service, < https://www.denic.de/en/service/whois-service/> accessed 26 July 2016.

- Dictionary.com, Cybersquatting, < www.dictionary.com/browse/cybersquatting?s=t > accessed 16 December 2016.

- Digital Production Group, Domain Name Information, < www.dpgnc.com/informationabout-domains.html> accessed 4 December 2016.

- Domain Name Business, What is a Top-Level Domain? <http://domainbiz.org/topdomain.asp > accessed 28 November 2016.

- Domainnews, In Case over Attempts to Seize Iran's ccTLD, ICANN Tells Court ccTLDs Are Not Property, <www.domainnews.com/icann-cctlds-are-not-property/> accessed 13 May 2016.

- Egon D, and Gabriela P, Protection of Trade Marks Used on the Internet: Austria, $<$ http://www.cmslawnow.com/ /media/lawnow/pdfs/cms\%20publications/sector\%20spec ific\%20publications/tmc/ip/cmsanticybersquattingguide.pdf > accessed 25 March 2016.

- Egon Deniz and Gabriela Partik, Protection of Trade Marks Used on the Internet: Austria, $<$ http://www.cmslawnow.com/ /media/lawnow/pdfs/cms\%20publications/sector\%20spec ific\%20publications/tmc/ip/cmsanticybersquattingguide.pdf > accessed 25 March 2016.

- EURid, (.eu) - Alternative Dispute Resolution, <https://eurid.eu/media/filer_public/a0/69/a0694eb7-5a9c-4ff7-a510a7bae3787c71/adr_rules_en.pdf> accessed 22 February 2016. 
- EURid, (.eu)- Alternative Dispute Resolution, <https://eurid.eu/media/filer_public/a0/69/a0694eb7-5a9c-4ff7-a510

a7bae3787c71/adr_rules_en.pdf> accessed 22 February 2016.

- EURid, EURid's Timeline, <https://eurid.eu/en/about-us/eu-timeline/> accessed 28 July 2016.

- EURid, the (.eu) Registry EURid Annual Report 2012, $<$ https://eurid.eu/media/filer_public/cb/c0/cbc0c0dd-8332-4361-856745d7fec7552a/annual_2012.pdf> accessed 29 July 2016.

- EURid, WHOIS Search, <https://eurid.eu/en/register-a-eu-domain/> accessed 3 August 2016.

- European Communities, Calendar and Temperature Effects in the Analysis of Textile and Leather Consumption Series in France, 2006 <www.unimannheim.de/edz/pdf/eurostat/06/KS-DT-06-022-EN.pdf> accessed 26 May 2016.

- Federal Chancellery of Austria, Case Law, <http://www.ris.bka.gv.at/defaultEn.aspx > accessed 25 January 2016.

- Ghosh S, Domain Name Disputes and Evaluation of The ICANN's Uniform Domain Name $\begin{array}{llll}\text { Dispute } & \text { Resolution } & \text { Policy, } & \text { September }\end{array}$ <www.niscair.res.in/ScienceCommunication/ResearchJournals/rejour/jipr/Fulltextsearch/ 2004/September\%202004/JIPR-vol\%209-September\%202004-pp\%20424-439.htm> accessed 12 March 2016.

- GNSO, About the (GNSO), 2014, < https://gnso.icann.org/en/about > accessed 9 December 2016.

- Govtrack, U.S. Anti-Cybersquatting Consumer Protection Act 1999, <https://www.govtrack.us/congress/bills/106/s1255/text> accessed 30 December 2016.

- History of Domain names, .US Created, 2002, <www.historyofdomainnames.com/us/> accessed 12 April 2016.

- Hungarian Intellectual Property Office, Act XI of 1997 on the Protection of Trade Marks and Geographical Product Signs, <http://www.sztnh.gov.hu/English/jogforras/Trademark_Act_EN.pdf> accessed 26 April 2016. 
- Hungarian Intellectual Property Office, Trademarks and Domain Names, <www.hipo.gov.hu/en/trademarks/trademarks-and-domain-names> accessed 25 March 2016.

- $\quad$ IANA, IANA, < http://www.iana.org/> accessed 4 December 2016.

- $\quad$ IANA, Number Resources, < https://www.iana.org/numbers > accessed 3 December 2016.

- ICANN, About the Program, <https://newgtlds.icann.org/en/about/program > accessed 10 December 2016.

- ICANN, About WHOIS, <https://whois.icann.org/en/about-whois>, accessed 10 September, 2015.

- ICANN, Applicant Guidebook, 2011, <http://www.icann.org/en/topics/new-gtlds/rfpclean-30may11-en.pdf> accessed 11 December 2016.

- ICANN, Basics of WHOIS, <https://whois.icann.org/en/basics-whois >, accessed 10 September, 2015.

- ICANN, Consensus Policies, <https://www.icann.org/resources/pages/registrars/ consensus-policies-en > accessed 11 December 2016.

- ICANN, Domain Name Registration Process, <https://whois.icann.org/en/domain-nameregistration-process > accessed 10 December 2016.

- ICANN, Glossary, <https://www.icann.org/resources/pages/glossary-2014-02-03-en > accessed 2 December 2016.

- ICANN, Glossary of Who is Terms, <https://whois.icann.org/en/glossary-whois-terms > accessed 27 November 2016.

- ICANN, gTLD Applicant Guidebook, <https://newgtlds.icann.org/en/applicants/agb/guidebook-full-04jun12-en.pdf>, accessed 10 July, 2016.

- ICANN, ICANN and the International Organization for Standardization (ISO), <https://www.icann.org/resources/pages/icann-iso-3166-2012-05-09-en > accessed 29 November 2016.

- ICANN, ICANN Appoints MFSD as First European Uniform Rapid Suspension System Provider, <https://www.icann.org/news/announcement-2-2015-12-16-en>, accessed 10 July, 2016. 
- ICANN, ICANN Tells U.S. Court That ccTLDs Are Not "Property": Files Motion to Quash in U.S. Legal Action Aimed at Seizing Top-Level Domains, 2014, <https://www.icann.org/resources/press-material/release-2014-07-30-en> accessed 13 May 2016.

- ICANN, List of Approved Dispute Resolution Service Providers, <http://www.icann.org/udrp/approved-providers.htm > accessed 16 December 2016.

- ICANN, List of Approved Dispute Resolution Service Providers, <https://newgtlds.icann.org/en/ > accessed 16 December 2016.

- ICANN, New gTLD Dispute Resolution Procedure, 2012, $<$ https://newgtlds.icann.org/en/applicants/agb/dispute-resolution-procedure-04jun12en.pdf>, accessed 15 July, 2016.

- ICANN, Non-Lawyers' Guide to the May 2009 Registrar Accreditation Agreement, <https://www.icann.org/resources/pages/non-lawyers-guide-2010-02-15-en> accessed 12 December 2016.

- ICANN, Post-Delegation Dispute Resolution Procedures (PDDRP), 2012, <https://newgtlds.icann.org/en/program-status/pddrp>, accessed 27 July, 2016.

- ICANN, Program History, 2012, <https://newgtlds.icann.org/en/about/program >, accessed 15 July, 2016.

- ICANN, Registrant Rights and Responsibilities Under the 2009 Registrar Accreditation Agreement, < https://www.icann.org/resources/pages/responsibilities-2014-03-14-en> accessed 12 December 2016.

- ICANN, Registry Listing, <https://www.icann.org/resources/pages/listing-2012-02-25en> accessed 10 September, 2015.

- ICANN, Trademark Clearinghouse (TMCH), <https://newgtlds.icann.org/en/about/ trademark-clearinghouse >, accessed 28 July 2016.

- ICANN, Trademark Clearinghouse, 2012, <https://newgtlds.icann.org/en/applicants /agb/trademark-clearinghouse-11jan12-en.pdf>, accessed 16 July 2016.

- ICANN, Trademark Post-delegation Dispute Resolution Procedure (Trademark PDDRP), 2012, 〈https://newgtlds.icann.org/en/applicants/agb/pddrp-04jun12-en.pdf>, accessed 15 July, 2016. 
- ICANN, Understanding Post-Delegation Dispute Resolution Procedures, <https://newgtlds.icann.org/en/program-status/pddrp > accessed 13 December 2016.

- ICANN, Uniform Domain Name Dispute Resolution Policy, <https://www.icann.org/resources/pages/help/dndr/udrp-en > accessed 12 December 2016.

- ICANN, Uniform Domain Name Dispute Resolution Policy, August 26, 1999, <https://www.icann.org/resources/pages/policy-2012-02-25-en > accessed 12 December 2016.

- ICANN, Uniform Domain-Name Dispute-Resolution Policy, 1999, <http://www.icann.org/udrp/udrp-policy-24oct99.htm >, accessed 19 September, 2015.

- ICANN, Uniform Rapid Suspension System (URS) Rules, <https://newgtlds.icann.org/en/applicants/urs/rules-04mar13-en.pdf >, accessed 10 July, 2016.

- ICANN, Uniform Rapid Suspension System (URS), <https://newgtlds.icann.org/en/applicants/urs>, accessed 27 July 2016.

- ICANN, Uniform Rapid Suspension <https://newgtlds.icann.org/en/applicants/urs/procedure-01mar13-en.pdf >, accessed 1 July, 2016.

- ICANN, Who Registered That? < https://whois.icann.org/en >, accessed 10 September, 2015

- INTA, International Trademark Rights, <http://www.inta.org/TrademarkBasics/FactSheets/Pages/InternationalTrademarkRightsF actSheet.aspx> accessed 15 October 2016.

- International Association for the Protection of Intellectual Property, Correct Use of Marks by Resellers - The "Royal Canin Bolt" Case, <www.aippi.hu/hu/hirek/70-correct-use-ofmarks-by-resellers-the-royal-canin-bolt-case.html> accessed 26 March 2016.

- International Telecommunication Union, Administering the Root: Delegations and Redelegations - $\quad$ Every Country is Unique, 2003, <https://archive.icann.org/en/cctlds/administering-the-root-25feb03.pdf > accessed 7 December 2016.

- Internet Society Organization, DNS Transition to the Private Sector, <http://www.internetsociety.org/dns > accessed 26 November 2016. 
- Internet Society, Internet Governance - Why the Multistakeholder Approach Works, 2016, <https://www.internetsociety.org/doc/internet-governance-why-multistakeholderapproach-works> accessed 20 July 2016.

- Isenberg D, When to File a URS Complaint Instead of or in Addition to a UDRP Complaint, 2015 <http://www.gigalaw.com/2015/07/06/when-to-file-a-urs-complaint-instead-of-orin-addition-to-a-udrp-complaint/>, accessed 10 August, 2016.

- Iwase H, Shinbo T and Hara S, Japan: Legal Framework, <www.worldtrademarkreview.com/Intelligence/Yearbook/2016/Country-chapters/Japan> accessed 1 January 2017.

- Buche J, Cybersquatting - What it is and How to Stop it, 2014 <www.pacificpatentlawyers.com/cybersquatting-what-it-is-and-how-to-stop it/\#sdfootnote10sym>, accessed 10 September, 2015.

- Kadam V, Analytical Study of Domain Name System, its Disputes and Legal Issues, 2013 <www.bvimsr.com/documents/publication/NCIT2013/23.pdf > accessed 16 December 2016.

- Karjiker S, the New gTLDs and the Resolution of Trade Mark Disputes, <blogs.sun.ac.za/iplaw/files/2016/04/The-new-gTLDs-and-the-resolution-of-trade-markdisputes.pdf > accessed 10 December 2016.

- Katz M, Rosston G, and Sullivan T, an Economic Framework for the Analysis of the Expansion of Generic Top-Level Domain Names, 2010, $<$ https://archive.icann.org/en/topics/new-gtlds/economic-analysis-of-new-gtlds-16jun10en.pdf $>$ accessed 3 December 2016.

- Kaufman J and Imai K, Ready to object? Protecting your Trademark in the New gTLD Regime, 2012, <http://www.worldtrademarkreview.com/Magazine/Issue/38/Features /Ready-to-object-Protecting-your-trademark-in-the-new-gTLD-regime>， accessed 10 July, 2016.

- Kruger L, Internet Domain Names: Background and Policy Issues, 2015, <https://fas.org/sgp/crs/misc/97-868.pdf > accessed 4 December 2016.

- Legifrance, Suspending the Manufacture, Import, Export And Placing on the Market of Any Food-based Packaging Containing Bisphenol, 
<https://www.legifrance.gouv.fr/affichTexte.do?cidTexte=JORFTEXT000026830015> accessed 27 May 2016.

- Levine G, Failing to Renew Registration: Difficulty of Recapturing Lapsed Domain Names, 2012, <https://www.iplegalcorner.com/failing-to-renew-registration-difficulty-ofrecapturing-lapsed-domain names/> accessed 25 January 2016.

- Levine G, Right of Trademark Owner to Recapture Domain Name after Inadvertent Lapse of Registration, 2008 <https://www.lexisnexis.com/legalnewsroom/intellectualproperty/b/copyright-trademark-law-blog/archive/2008/06/09/right-of-trademark-ownerto-recapture-domain-name-after-inadvertent-lapse-ofregistration.aspx?Redirected=true\#sthash.GAzR78Ry.dpuf> accessed 25 January 2016.

- Lipton J, What's in a Domain Name? , 1999, <https://www2.warwick.ac.uk/fac/soc/law/elj/jilt/1999_2/lipton/> accessed 11 May 2016.

- Little T, ICANN Eyes 2020 as Realistic Timeframe for Next Round of New gTLDs, 2016, <www.worldtrademarkreview.com/blog/detail.aspx?g=530DC4AD-6BD7-4969-8A41EC538340C852> accessed 25 September 2016.

- McKnight G, North American Regional At-Large Organization (NARALO) Tribal

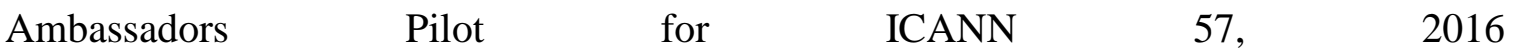
<https://community.icann.org/display/NARALO/NARALO+Tribal+Ambassadors+Pilot+ for+ICANN+57> accessed 9 December 2016.

- Merriam-webster, Definition of Squat, <https://www.merriamwebster.com/dictionary/squat> accessed 15 December 2016.

- Michaelson P, Emergency Arbitration: Fast, Effective and Economical (March 18, 2016), Just Resolutions, American Bar Association Dispute Resolution Section, 2016, <https://ssrn.com/abstract=2762715> accessed 13 December 2016.

- Ministry of Industry, Trade and Supply, E-services, <http://www.mit.gov.jo/Pages/viewpage.aspx?pageID=307.> accessed 18 October 2015.

- Namestats, gTLD Stats, Metrics and Analysis, < http://www.inc.com/peter-roesler/willnew-top-level-domains-matter-in-2015.html > accessed 1st. of December 2016.

- National Arbitration Forum, Facebook Inc. v. Radoslav, Claim No. FA1308001515825, Sep. 27, 2013, <http://www.adrforum.com/domaindecisions/1515825D.htm>, accessed 23 July, 2016. 
- $\quad$ Neustar, Dispute Providers, <www.neustar.us/dispute-providers/> accessed 14 April 2016.

- Neustar, Nexus Dispute Policy, <www.neustar.us/nexus-dispute-policy > accessed 17 April 2016.

- $\quad$ Neustar, Policies, < www.neustar.us/policies/> accessed 12 April 2016.

- Neustar, the usTLD Nexus Requirements Policy, <www.neustar.us/the-ustld-nexusrequirements/> accessed 12 April 2016.

- Neustar, USDRP Approval Process, <http://www.neustar.us/usdrp-approval-process/ > accessed 14 April 2016.

- Neustar, usTLD Dispute Resolution Policy, 2014, <http://www.neustar.us/ustld-disputeresolution-policy/> accessed 12 April 2016.

- Nic.at, Domain Statistics, <https://www.nic.at/en/aboutnic/statistics/> accessed 25 April 2016.

- Nic.at, Duties and Responsibilities of (nic.at), <https://www.nic.at/en/aboutnic/> accessed 25 April 2016.

- $\quad$ Nic.at, Legal Issues, <https://www.nic.at/en/faq/legal-issues/> accessed 25 April 2016.

- $\quad$ NITC, About Us, <https://www.dns.jo/about_us.aspx > accessed 1 May 2016.

- NITC, Registration Policy, <https://www.dns.jo/Registration_policy.aspx> accessed 8 August 2016.

- $\quad$ NITC, Required Documents, <https://www.dns.jo/paper.aspx> accessed 8 August 2016.

- NOMINET, Dispute Resolution Service Policy, <http://nominetprod.s3.amazonaws.com/wp-content/uploads/2016/08/Final-proposed-DRS-Policy.pdf> accessed 28 July 2016.

- $\quad$ NOMINET, NOMINET, <http://www.nominet.uk/> accessed 25 July 2016.

- Nominet, Policies and Rules, <http://www.nominet.uk/resources/policy/policiesrules/\#drspolicy> accessed 27 September 2016.

- $\quad$ NOMINET, WHOIS, <http://www.nominet.uk/whois/> accessed 28 July 2016.

- Office of General Counsel of the California State University, Protecting Internet Domain Names, 2004， <https://www.calstate.edu/gc/Docs/Domain_Name_Handbook.doc> accessed 20 July 2016.

- Official (.hu) Domain Name Registry, Registration Rules and Procedures, <www.domain.hu/domain/English/szabalyzat/szabalyzat.html> accessed 26 March 2016. 
- Olwan R, the Case of Suck Domain Names and Cyber-smearing Examination of Suck Cases with the WIPO Arbitration and Mediation Center, <docshare01.docshare.tips/files/390/3901550.pdf > accessed 20 September 2016.

- Organization for Economic Co-operation and Development, Evolution in the Management of Country Code Top-Level Domain Names (ccTLDs), 2006, <https://www.oecd.org/sti/ieconomy/37730629.pdf> accessed 8 December 2016.

- Oxford Living Dictionaries, Cyber, < https://en.oxforddictionaries.com/definition/cyber> accessed 15 December 2016.

- Piyali S, What is the Difference between Common Law and Civil Law? 2014, $<$ https://onlinelaw.wustl.edu/blog/common-law-vs-civil-law/> accessed 17 February 2016.

- Purkayastha P, and Rishab B, U.S. Control of the Internet Problems Facing the Movement to International Governance, <monthlyreview.org/2014/07/01/u-s-control-of-the-internet/> accessed 6 December 2016.

- Quackit, Second-Level Domain Names, <www.quackit.com/domain-names/secondlevel_domain_names.cfm > accessed 10 December 2016.

- Queensland, What Are the Differences between Trademarks, Business Names, Company Names and Domain Names, Australia, 2015, $<$ https://www.business.qld.gov.au/business/support-tools-grants/tools/intellectualproperty-info-kit/browse/names/differences> Accessed 15 November, 2015.

- Raja A, ICANN's New Generic Top-Level Domain Program and Appication Results, 2012, < www.ipbrief.net/wp-content/uploads/2013/02/IPB_Raja.pdf >, accessed 15 July, 2016.

- RIPE NCC, About RIPE NCC, < https://www.ripe.net/about-us > accessed 25 April 2016.

- Roesler P, Will New Top Level Domains Matter in 2015? Will New URL Endings Change Web Design and Marketing in 2015? , 2015, <http://www.inc.com/peter-roesler/will-newtop-level-domains-matter-in-2015.html > accessed 10 December 2016.

- Roberts A, an Overview of the New gTLD Programme, 2011, <https://valideus.com/sites/default/files/documents/new-gTLD-white-paper-final.pdf > accessed 11 December 2016. 
- Stewardship of ICANN, IANA Functions Transitions to Global Internet Community as Contract with U.S. Government Ends, 2016 <https://www.icann.org/news/announcement2016-10-01-en > accessed 5 December 2016.

- Strato, Particular terms of contract for the Registration, <http://www.stratohosting.co.uk/_assets_uk/pdf/terms_and_conditions/particular_terms.pdf>, accessed 10 July, 2016.

- Syam P, What is the Difference between Common Law and Civil Law? 2014, $<$ https://onlinelaw.wustl.edu/blog/common-law-vs-civil-law/> accessed 17 February 2016.

- Szederjessy N and Sólyom Á, Protection of Trade Marks Used on the Internet: Hungary, $<$ http://www.cmslawnow.com/ /media/lawnow/pdfs/cms\%20publications/sector\%20spec ific\%20publications/tmc /ip/cmsanticybersq uattingguide.pdf > accessed 25 March 2016.

- Talal Abu-Ghazaleh Organization, Laws and Cybersquatting, 2003, <www.agip.com/news.aspx?id=71\&lang=en> accessed 1 January 2016.

- Taylor D, France: New ADR Procedure for .FR Domain Names, 2016, <www.lexology.com/library/detail.aspx?g=d4bc252e-02f2-4ec1-b022-11fc0b03e8a0> accessed 28 May 2016.

- The Embassy of the Hashemite Kingdom of Jordan-Washington, D.C., Quick Facts, 2016, <http://www.jordanembassyus.org/page/quick-facts> accessed 28 April, 2016.

- The Official Site of the Jordanian E-Government, National Information Technology Center, <http://www.jordan.gov.jo/> accessed 29 December 2016.

- The World Bank, World Bank Country and Lending Groups, 2016, <https://datahelpdesk.worldbank.org/knowledgebase/articles/906519-world-bankcountry-and-lending-groups> accessed 29 April, 2016.

- TMCH, Reasons to Record your Marks in the Trademark Clearinghouse, $<$ http://trademark-clearinghouse.com/content/reasons-record-your-marks-trademarkclearinghouse >, accessed 9 July, 2016.

- TMCH, Trademark Agent, <http://trademark-clearinghouse.com/content/trademarkagent>, accessed 9 July, 2016.

- TMCH, Trademark Claims Services, <http://trademarkclearinghouse.com/content/trademark-claims-services >, accessed 9 July, 2016. 
- United Nation office on Drugs and Crime, Act 2012 the Criminal Code,www.oit.org/dyn/natlex/natlex4.detail?p_lang=en\&p_isn=96662\&p_classification= 01 , accessed 10 August 2017.

- U.S. Congress Office of Technology Assessment, Making Government Work: Electronic Delivery of Federal Services, Washington, 1993, <https://www.princeton.edu/ ota/disk1/1993/9333/9333.PDF> accessed 26 November 2016.

- U.S. Department of Commerce, Management of Internet Names and Addresses, <https://www.icann.org/resources/unthemed-pages/white-paper-2012-02-25-en> accessed 4 December 2016.

- United States Patent and Trademark Office (USPTO), Report to Congress: The Anticybersquatting Consumer Protection Act Of 1999, <https://www.uspto.gov/web/offices/dcom/olia/tmcybpiracy/repcongress.pdf> accessed 5 December 2016.

- Villedieu A, Protection of Trade Marks Used on the Internet: France, <http://www.cmslawnow.com/ /media/lawnow/pdfs/cms\%20publications/sector\%20spec ific\%20publications/tmc /ip/cmsanticybersq uattingguide.pdf > accessed 25 March 2016.

- Waxer A, the Domain Name Fiasco: The Legal Battle between the Current Domain Name Registration System and Traditional Trademark Law, <http://www.yumpu.com/en/document/view/6524427/the-domain-name-fiasco-the-legalhofstra-university> accessed 18 October 2015.

- WIPO, Austria, < www.wipo.int/wipolex/en/profile.jsp?code=AT> accessed 25 January 2016.

- WIPO, ccTLD Database, <http://www.wipo.int/amc/en/domains/cctld_db/index.html > accessed 29 November 2016.

- WIPO, DirecTV Group Inc. v. Dish DBS Corporation, Case No. LRO2013-0005, 2013 <https://newgtlds.icann.org/sites/default/files/drsp/25sep13/determination-1-1-200743424-en.pdf > accessed 25 September 2015.

- WIPO, Domain Name Dispute Resolution Service for country code top level domains (ccTLDs), <http://www.wipo.int/amc/en/domains/gtld/udrp/> accessed 11 March 2016. 
- WIPO, Domain Name Dispute Resolution Service for Generic Top-Level Domains, <www.wipo.int/amc/en/domains/gtld/> accessed 12 March 2016.

- WIPO, France: Law No. 92-597 of 1 July, 1992, on the Intellectual Property Code, <www.wipo.int/wipolex/en/details.jsp?id=12766> accessed 25 April 2016.

- WIPO, Joint Recommendation Concerning Provisions on the Protection of Well-known Marks, 1999,<http://www.wipo.int/edocs/pubdocs/en/marks/833/pub833.pdf> accessed 15 April 2016.

- WIPO, Merck \& Co, Inc. v. Merck KGaA, Case No. LRO2013-0069, 2013, <http://www.wipo.int/export/sites/www/amc/en/domains/lro/docs/lro2013-0069.pdf> accessed 25 September 2015.

- WIPO, Search WIPO Cases and WIPO Panel Decisions/ WIPO Case D2003-0596, 2003 <http://www.wipo.int/amc/en/domains/decisions/html/2003/d2003-0596.html> accessed 20 September 2015.

- WIPO, Search WIPO Cases and WIPO Panel Decisions/ WIPO Case D2000-1151, 2000, <http://www.wipo.int/amc/en/domains/decisions/html/2000/d2000-1151.html> accessed 25 January 2016.

- WIPO, Search WIPO Cases and WIPO Panel Decisions/ WIPO Case D2001-0587, 2001, <http://www.wipo.int/amc/en/domains/decisions/html/2001/d2001-0587.html> accessed 28 January 2016.

- WIPO, Search WIPO Cases and WIPO Panel Decisions/ WIPO Case D2001-1195, 2001 <http://www.wipo.int/amc/en/domains/decisions/html/2001/d2001-1195.html> accessed 20 September 2015.

- WIPO, Search WIPO Cases and WIPO Panel Decisions/ WIPO Case D2003-0066, 2003 <http://www.wipo.int/amc/en/domains/decisions/html/2003/d2003-0066.html> accessed 20 September 2015.

- $\quad$ WIPO, Search WIPO Cases and WIPO Panel Decisions/ WIPO Case D2006-0588, 2006, <http://www.wipo.int/amc/en/domains/decisions/html/2006/d2006-0588.html> accessed 25 September 2015.

- WIPO, Search WIPO Cases and WIPO Panel Decisions/ WIPO Case D2016-1975, 2016, <http://www.wipo.int/amc/en/domains/decisions/text/2016/d2016-1975.html> accessed 28 December 2016. 
- WIPO, Search WIPO Cases and WIPO Panel Decisions/ WIPO Case No. D2000-0138, 2000, <http://www.wipo.int/amc/en/domains/decisions/html/2000/d2000-0138.html> accessed 20 September 2015.

- WIPO, Search WIPO Cases and WIPO Panel Decisions/ WIPO Case No. D2000-1106, 2015, <http://www.wipo.int/amc/en/domains/decisions/html/2000/d2000-1106.html / >, accessed 19 September, 2015.

- WIPO, Search WIPO Cases and WIPO Panel Decisions/ WIPO Case No. D2000-1467, 2015, <http://www.wipo.int/amc/en/domains/decisions/html/2000/d2000-1467.html>, accessed 20 September, 2015.

- WIPO, Search WIPO Cases and WIPO Panel Decisions/ WIPO Case No. D2001-1447, $2001<$ http://www.wipo.int/amc/en/domains/decisions/html/2001/d2001-1447.html > accessed 25 January 2016.

- WIPO, Search WIPO Cases and WIPO Panel Decisions/ WIPO Case No. D2003-0004, $2003<$ <ttp://www.wipo.int/amc/en/domains/decisions/html/2003/d2003-0004.html> accessed 20 September 2015.

- WIPO, Search WIPO Cases and WIPO Panel Decisions/ WIPO Case No. D2003-0066, 2015, <http://www.wipo.int/amc/en/domains/decisions/html/2003/d2003-0066.html / >, accessed 18 September, 2015.

- WIPO, Second WIPO Internet Domain Name Process: the Recognition of Rights and the Use of Names in the Internet Domain Name System, <www.wipo.int/amc/en/processes/process2/report/html/report.html >, accessed 10 September, 2015.

- WIPO, Standing Committee on the Law of Trademarks, Industrial Designs and Geographical Indications, 2016, <http://www.wipo.int/edocs/mdocs/sct/en/sct_16/sct_16_9.pdf> accessed 24 November 2015.

- WIPO, the Management of Internet Names and Addresses: Intellectual Property Issues, Final Report of the WIPO Internet Domain Name Process, 1999 <http://www.wipo.int/amc/en/processes/process1/report/finalreport.html > accessed 5 December 2016. 
- WIPO, the Management of Internet Names and Addresses: Intellectual Property Issues, Interim Report of the WIPO Internet Domain Name Process, 1998, <http://www.wipo.int/amc/en/processes/process1/rfc/3/interim2_ch1.html> accessed 26 November 2016.

- WIPO, Trademark Post-Delegation Dispute Resolution Procedure Q\&A, <www.wipo.int/amc/en/domains/tmpddrp/guide/> accessed 25 September 2016.

- WIPO, what is a trademark? $2015<\mathrm{http}: / / \mathrm{www}$.wipo.int/trademarks/en/> accessed15 October 2015.

- WIPO, WIPO Arbitration and Mediation Center: End Report on Legal Rights Objection Procedure, 2013, <www.wipo.int/export/sites/www/amc/en/docs//roreport.pdf > accessed 12 March 2016.

- WIPO, WIPO Guide to the Uniform Domain Name Dispute Resolution Policy (UDRP), <www.wipo.int/amc/en/domains/guide/> accessed 12 March 2016.

- World Bank Group, Key Features of Common Law or Civil Law Systems, 2006, <https://ppp.worldbank.org/public-private-partnership/legislation regulation/frameworkassessment/legal-systems/common-vs-civil-law\#civil > accessed 16 February 2016. 